\title{
Técnicas de reconfigurabilidade dos FPGAs da família APEX 20K - Altera
}

\author{
Marco Antônio Teixeira
}

Orientador: Prof. Dr. Eduardo Marques

Dissertação apresentada ao Instituto de Ciências Matemáticas e de Computação - ICMC-USP, como parte dos requisitos para obtenção do título de Mestre em Ciências de Computação e Matemática Computacional.

USP - São Carlos

Julho de 2002 
Este trabalho é dedicado aos meus pais,

Adevair Teixeira e Tereza Francelin

Teixeira, e ao meu irmão Marcio Teixira. 


\section{Agradecimentos}

Aos meus pais Adevair e Tereza, pela dedicação e incentivo em todos esses anos.

Ao meu orientador e amigo Prof. Dr. Eduardo Marques, por toda dedicação, atenção e orientação, não só acadêmica mas também pessoal e profissional.

A todos os companheiros do LCR, pelos momentos de estudo e diversão compartilhados.

Ao grande amigo Sergio Roberto Viccari, pelo incentivo ao meu ingresso neste programa de mestrado. 


\section{Su mário}

Lista de figuras

Lista de tabelas

Resumo

"Abstract"

1 Introdução 1

2 Dispositivos Lógicos Programáveis .............................. 5

2.1 O Projeto de Circuitos Digitais ............................................................... 5

2.2 A Evolução dos Dispositivos Lógicos Programáveis ................................... 6

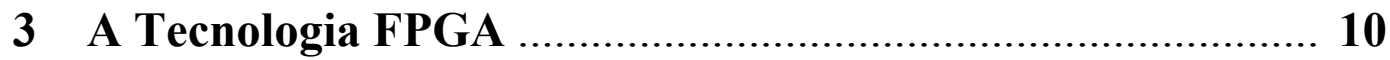

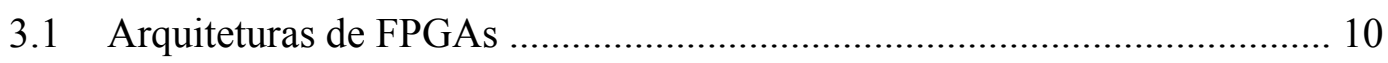

3.2 Tecnologias de programação ................................................................... 12

3.2.1 A tecnologia de Programação SRAM …................................................. 13

3.2.2 A tecnologia Antifuse ................................................................... 14

3.2.3 A tecnologia de Gate Flutuante ........................................................ 14

3.3 Arquitetura dos Blocos Lógicos ........................................................... 16

3.3.1 Blocos de Granulosidade Fina ............................................................... 16

3.3.2 Blocos de Granulosidade Grossa …..................................................... 16

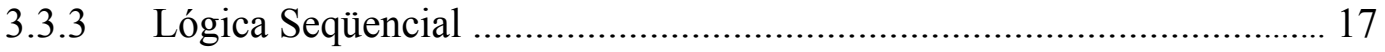

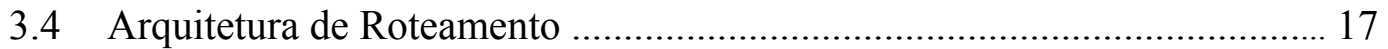

4 A Família de Dispositivos APEX ${ }^{\mathrm{TM}}$ 20K ……….................. 20

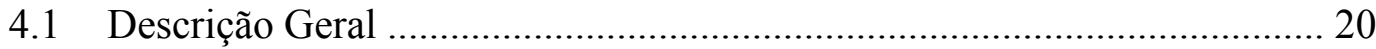

4.2 A Arquitetura MultiCore ${ }^{\mathrm{TM}}$ dos FPGAs APEX 20K ….......................... 21 
4.3 Configurando os Dispositivos APEX 20K .......................................... 23

4.3.1 Dispositivo de Configuração ………...................................................... 24

4.3.2 Configuração Serial Passiva (PS) com Cabo de Download ................... 26

4.3.3 Configuração Serial Passiva (PS) com Microprocessador ..................... 28

4.3.4 Configuração Paralela Síncrona Passiva (PPS) .................................... 29

4.3.5 Configuração Paralela Assíncrona Passiva (PPA) ................................ 31

4.3.6 Configuração e Programação JTAG ...................................................... 33

4.3.7 Configuração e Programação JTAG para Múltiplos Dispositivos ........ 35

5 Dispositivos de Configuração ……………............................ 37

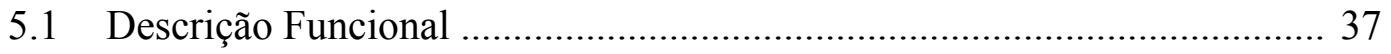

5.2 Dispositivos de Configuração EPC1 e EPC2 ……...................................... 39

5.3 Dispositivos de Configuração EPC16 ..................................................... 40

5.3.1 A Unidade de Controle do EPC16 ....................................................... 41

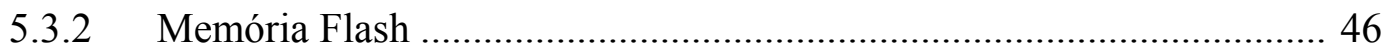

6 O Kit de Desenvolvimento Excalibur .................................. 48

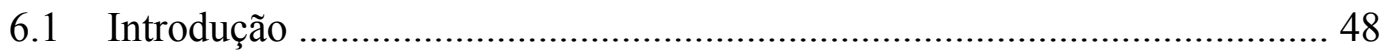

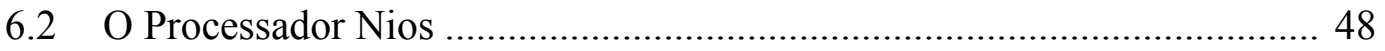

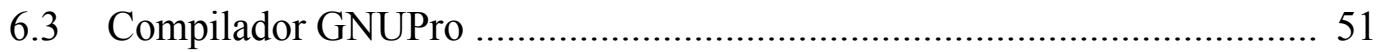

6.4 A Ferramenta de Desenvolvimento Quartus ........................................... 52

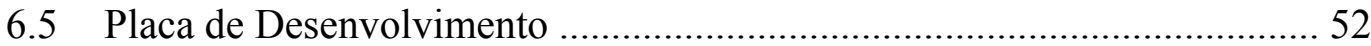

7 Considerações de Projeto …................................................... 54

7.1 Caracterização da Linha de Pesquisa ..................................................... 54

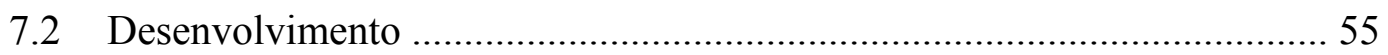

7.2.1 O Esquema de Configuração do Kit de Desenvolvimento Excalibur ... 56

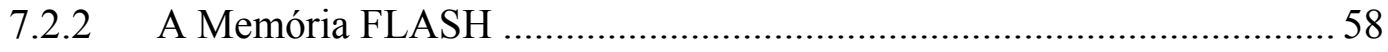

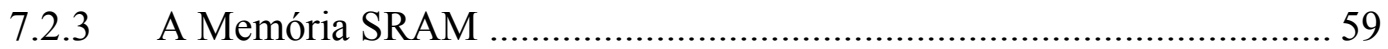

7.3 O Controlador de Configuração do Kit de Desenvolvimento Excalibur .... 59

7.3.1 Bloco Funcional de Seleção do Arquivo de Configuração .................... 61 
7.3.2 Bloco Funcional de Detecção de Erro e Reinicialização de Configuração 62

7.3.3 Bloco Funcional de Divisão de Clock .....................................................6 64

7.3.4 Bloco Funcional de Controle do Sinal "nCONF IG" .............................. 64

7.3.5 Bloco Funcional de Espera por "nSTATUS" ....................................... 65

7.3.6 Bloco Funcional Gerador de Endereços .............................................. 66

7.3.7 Bloco Funcional de Espera por "CONF_DONE" .................................. 67

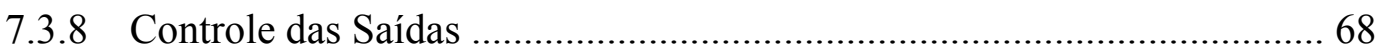

7.4 O Driver do Controlador de Configuração ................................................ 68

7.4.1 O Projeto do Driver do Controlador de Configuração ............................. 68

7.4.2 A Inserção do Processador Nios ............................................................... 69

\section{Detalhes de Implementação do Controlador de}

Configuração

8.1 O Hardware do Novo Controlador de Configuração

8.1.1 A Interface Entre o Driver e o Hardware do Controlador de Configuração

8.1.2 A Interface Entre o Controlador de Configuração e a

Plataforma Reconfigurável 78

8.1.3 A Interface Entre o Controlador de Configuração e o Dispositivo de Armazenamento de Dados 79

8.2 O Driver do Novo Controlador de Configuração ..................................... 80

8.2.1 A Parametrização do Processador Nios $^{\mathrm{TM}}$........................................... 81

8.2.2 Definição do Conjunto de Periféricos ................................................... 81

8.2.3 O Projeto do Driver do Novo Controlador ........................................... 86

9 Validação e Resultados

9.1 Adoção do Método de Validação ............................................................... 92

9.2 O Projeto de Emulação dos FPGAs da Família APEX ............................... 94

9.2.1 O Algoritmo CRC e sua Inserção ao Hardware de Emulação .............. 95

9.2.2 A Geração do Sinal "CONF_DONE" ................................................... 99 
9.2.3 A Geração do Sinal "nSTAtUS" ........................................................ 100

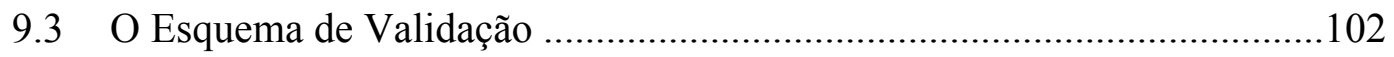

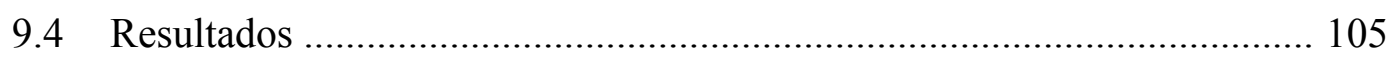

9.4.1 Validação do Hardware de Emulação dos FPGAs APEX ................. 107

9.4.2 Validação do Controlador de Configuração ....................................... 110

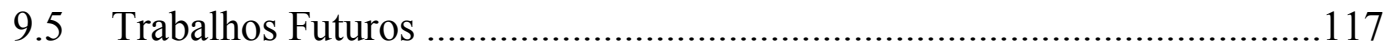

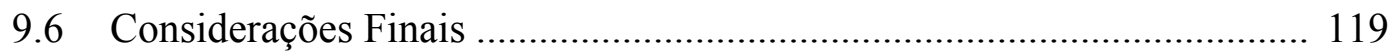

Anexo I .......................................................... 120

Referências Bibliográficas ...................................... 125 


\section{Lista de Figuras}

Fig. 2.1 - Esquema simplificado de um PLA …............................................... 7

Fig. 2.2 - Esquema simplificado de um PAL...................................................... 8

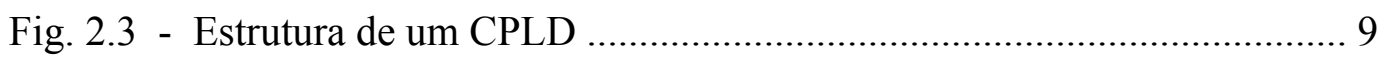

Fig. 3.1 - Estrutura básica de um FPGA …..................................................... 11

Fig. 3.2 - Circuito para um LUT com duas entradas ....................................... 12

Fig. 3.3 - Tecnologia de Programação SRAM ..................................................... 13

Fig. 3.4 - Comutador Programável baseado em EPROM ............................... 15

Fig. 3.5 - Arquitetura Geral de Roteamento de um FPGA ............................... 18

Fig. 4.1 - Níveis de integração da Família APEX ${ }^{\mathrm{TM}}$......................................... 20

Fig. 4.2 - Melhoria de Desempenho com o Emprego do Cobre ....................... 21

Fig. 4.3 - Arquitetura MultiCore ${ }^{\mathrm{TM}}$................................................................ 22

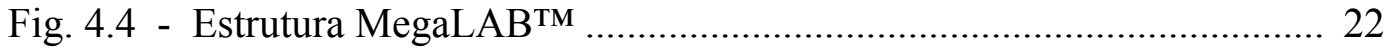

Fig. 4.5 - Esquema para Dispositivo de Configuração ....................................... 24

Fig. 4.6 - Ciclo de Configuração para o APEX 20K …..................................... 25

Fig. 4.7 - Esquema para Configuração com Múltiplos Dispositivos ................ 25

Fig. 4.8 - Esquema de Configuração PS com um Cabo de Download ............... 27

Fig. 4.9 - Configuração de Múltiplos Dispositivos com Cabos de Download ... 27

Fig. 4.10 - Circuito de Configuração com Microprocessador ............................ 28

Fig. 4.11 - Configuração de Múltiplos Dispositivos com

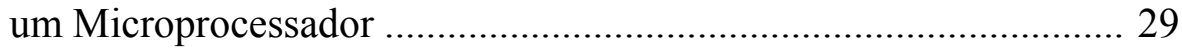

Fig. 4.12 - Circuito para Configuração PPS ...................................................... 30

Fig. 4.13 - Configuração PPS para Múltiplos Dispositivos ............................. 30

Fig. 4.14 - Circuito para Configuração PPA ..................................................... 31

Fig. 4.15 - Configuração PPA para Múltiplos Dispositivos .............................. 32

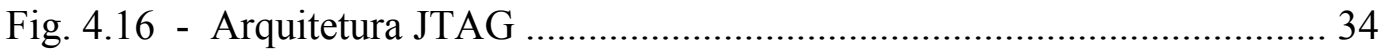

Fig. 4.17 - Circuito para Configuração JTAG ………......................................... 35

Fig. 4.18 - Configuração JTAG para Múltiplos Dispositivos ............................ 35

Fig. 4.19 - Configuração JTAG com um Microprocessador ............................ 36 
Fig. 5.1 - Diagrama de Blocos dos Dispositivos de Configuração EPC1 e EPC2

Fig. 5.2 - FPGA APEX 20K Configurado com EPC1 ou EPC2 …................... 40

Fig. 5.3 - Diagrama de Blocos do Dispositivo de Configuração EPC16

Fig. 5.4 - Diagrama de Blocos da Unidade de Controle do Dispositivo EPC16 42

Fig. 5.5 - A Unidade de Divisão de Clock .................................................... 44

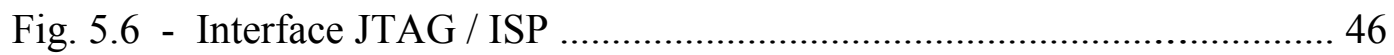

Fig. 6.1 - Diagrama de Blocos do Processador Embutido Nios ........................ 49

Fig. 6.2 - Comunicação entre o Processador Nios e seus Periféricos ................ 50

Fig. 6.3 - Flexibilidade e Escalabilidade dos Processadores Embutidos Nios ... 51

Fig. 6.4 - Placa de Desenvolvimento Excalibur .............................................. 53

Fig. 7.1 - Esquema de Configuração para o Projeto ARMOSH ....................... 55

Fig. 7.2 - Conexões do Controlador de Configuração aos Componentes da Placa de Desenvolvimento Excalibur

Fig. 7.3 - Diagrama de Blocos do Controlador de Configuração do Kit de Desenvolvimento Excalibur 60

Fig. 7.4 - Lógica do Bloco de Seleção do Arquivo de Configuração 61

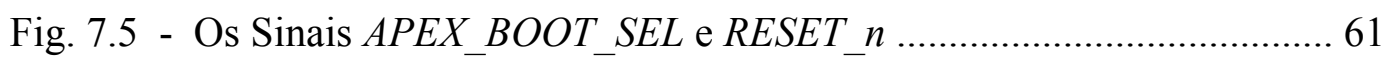

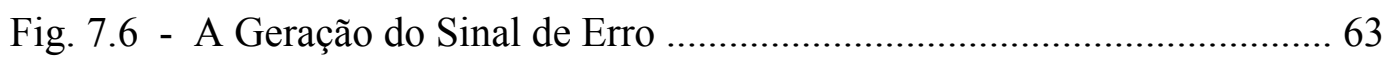

Fig. 7.7 - O Flip-Flop "Counter_Wrapped" ............................. 63

Fig. 7.8 - O Sinal de Reinicialização do Sistema ................................................ 63

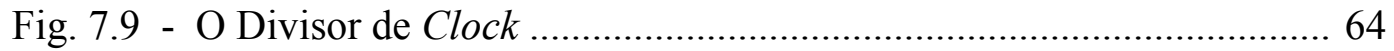

Fig. 7.10 - A Geração do Sinal "nCONFIG" ......................................................... 65

Fig. 7.11 - Implementação do Estado de Espera por "nSTATUS" ................... 65

Fig. 7.12 - A Lógica do Bloco Gerador de Endereços ...................................... 66

Fig. 7.13 - A Lógica do Bloco de Espera por "CONF_DONE" ....................... 67

Fig. 7.14 - O Processador Nios no Esquema de Configuração ........................... 70

Fig. 7.15 - O Hardware do Projeto ARMOSH ............................................... 70 
Fig. 8.1 - Controle da Seleção de Arquivos de Configuração ........................... 74

Fig. 8.2 - Multiplexação e Demultiplexação dos Sinais .................................... 75

Fig. 8.3 - O Sinal de Reinicialização do Novo Sistema ................................... 76

Fig. 8.4 - A Transmissão dos Sinais de Sucesso e de Fracasso na

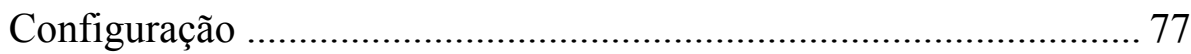

Fig. 8.5 - Um Canal de Configuração …………................................................ 78

Fig. 8.6 - Canais de Configuração para a Plataforma reconfigurável ............... 79

Fig. 8.7 - O Hardware Dedicado e suas Interfaces ........................................... 80

Fig. 8.8 - O Processador Nios e o Conjunto de Periféricos Utilizado ................ 82

Fig. 8.9 - Estrutura de Dados dos Periféricos PIO ........................................... 85

Fig. 8.10 - Fluxograma do Trecho Inicial do Programa C .............................. 87

Fig. 8.11 - Código das Funções "Seleção do Dispositivo"

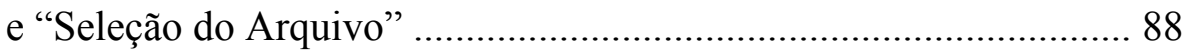

Fig. 8.12 - Código da Função "Pulso" ............................................................. 89

Fig. 8.13 - O Envio das Informações ao Hardware Dedicado .......................... 90

Fig. 8.14 - O Tratamento dos Sinais de Sucesso e Fracasso do Processo

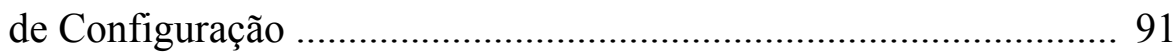

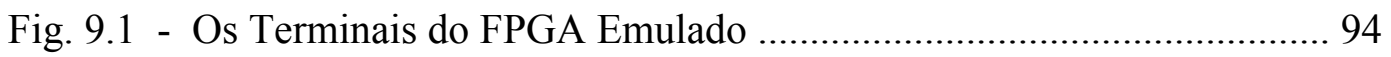

Fig. 9.2 - O Hardware para o CRC Utilizado .................................................... 96

Fig. 9.3 - O CRC Inserido ao Sistema …......................................................... 97

Fig. 9.4 - A Geração dos Sinais "LOAD" e "ENA_ERAME_ERROR" ................. 98

Fig. 9.5 - A Geração do Sinal "FRAME_ERROR_n" ........................................ 99

Fig. 9.6 - A Geração do Sinal "CONF_DONE" .............................................. 100

Fig. 9.7 - A Geração do Sinal "nSTATUS" ......................................................... 101

Fig. 9.8 - O Controlador de Configuração Interligado aos FPGAs Emulados

Fig. 9.9 - O Esquema Final de Validação

Fig. 9.10 - Diagrama de Tempo para os Sinais Envolvidos na Configuração PPS dos FPGAs APEX ........................................... 106

Fig. 9.11 - Parâmetro ${ }_{\text {CF2CD }}$ do Hardware de Emulação .............................. 108

Fig. 9.12 - Parâmetro tCF2ST0 do Hardware de Emulação ........................... 109

Fig. 9.13 - Parâmetro t ${ }_{\mathrm{CF} 2 \mathrm{ST} 1}$ do Hardware de Emulação ........................... 109 
Fig. 9.14 - Parâmetro tDSU do Controlador de Configuração ......................... 112

Fig. 9.15 - Parâmetro t ${ }_{\mathrm{DH}}$ do Controlador de Configuração .......................... 113

Fig. 9.16 - Parâmetro tsT2CK Originalmente Obtido pelo

Controlador de Configuração ....................................................... 114

Fig. 9.17 - Obtenção do Atraso no Sinal "nSTATUS" .................................... 115

Fig. 9.18 - Parâmetro tST2CK após Alterações no Hardware Dedicado do Controlador de Configuração .................................................. 115

Fig. 9.19 - Parâmetro t ${ }_{\mathrm{CF}} 2 \mathrm{CK}$ do Controlador de Configuração ................... 116 


\section{Lista de Tabelas}

Tabela 3.1 - Sumário das Tecnologias de Programação

Tabela 4.1 - Esquemas de Configuração

Tabela 5.1 - Características dos Dispositivos de Configuração da Altera

Tabela 5.2 - Dispositivos de Configuração Disponíveis para a Família APEX 20K 38

Tabela 5.3 - Tamanho dos Arquivos de Configuração dos Dispositivos APEX 20K 38

Tabela 5.4 - Freqüências do Oscilador Interno 43

Tabela 6.1 - Componentes da Placa de Desenvolvimento Excalibur..... 53

Tabela 7.1 - Conteúdos Alocados à Memória FLASH 58

Tabela 8.1 - Parâmetros Ajustáveis para o Periférico UART 83

Tabela 8.2 - Parâmetros Ajustáveis para o Periférico PIO ................................ 84

Tabela 8.3 - As Variáveis do Software ......................................................... 86

Tabela 9.1 - Conteúdo dos Módulos de Memória e seus efeitos sobre o Hardware de Emulação 103

Tabela 9.2 - Parâmetros de Temporização para Dispositivos APEX 20K no Modo PPS 106

Tabela 9.3 - Parâmetros Relativos ao Hardware de Emulação 107

Tabela 9.4 - Parâmetros Relativos ao Controlador de Configuração 110

Tabela 9.5 - Comparativo entre as famílias de FPGAs mais recentes (Altera) 


\title{
Lista de Abreviaturas
}

\author{
AHDL - Altera Hardware Description Language \\ ASIC - Application Specific Integrated Circuit \\ CAM - Content Addressable Memory \\ CCM - Custom Computing Machine \\ CPLD - Complex Programmable Logic Device \\ CRC - Cyclic Redundancy Check \\ EDA - Electronic Design Automation \\ EPLD - Erasable Programmable Logic Device \\ ESB - Embedded System Block \\ FPGA - Field-Programmable Gate Array \\ HDL - Hardware Description Language \\ ISP - In-System Programmability \\ JTAG - Joint Test Action Group \\ LAB - Logic Array Block \\ LABIC - Laboratório de inteligência Computacional \\ LCR - Laboratório de Computação Reconfigurável \\ LUT - Look-Up Table \\ MPGA - Mask-Programmable Gate Array \\ PAL - Programmable Array Logic \\ PBM - Peripheral Bus Module \\ PIO - Parallel Input/Output \\ PLA - Programmable Logic Array \\ PLD - Programmable Logic Device \\ POR - Power-On-Reset \\ PPA - Passive Parallel Asynchronous \\ PPS - Passive Parallel Synchronous \\ SOPC - System-on-a-Programmable-Chip \\ SPLD - Simple Programmable Logic Device \\ UART - Universal Asynchronous Receiver/Transmitter \\ VLSI - Very Large Scale Integration
}




\section{Resumo}

Os dispositivos lógicos programáveis pertencentes à família APEX 20K, são configurados no momento da inicialização do sistema com dados armazenados em dispositivos especificamente desenvolvidos para esse fim. Esta família de FPGAs possui uma interface otimizada, permitindo também que microprocessadores os configure de maneira serial ou paralela, síncrona ou assíncronamente. Depois de configurados, estes FPGAs podem ser reconfigurados em tempo real com novos dados de configuração. A reconfiguração em tempo real conduz a inovadoras aplicações de computação reconfigurável.

Os dispositivos de configuração disponíveis comercialmente, limitam-se a configurar os FPGAs apenas no momento da inicialização do sistema e sempre com o mesmo arquivo de configuração. Este trabalho apresenta a implementação de um controlador de configuração capaz de gerenciar a configuração e reconfiguração de múltiplos FPGAs, a partir de vários arquivos distintos de configuração.

Todo o projeto é desenvolvido, testado e validado através da ferramenta EDA Quartus $^{\mathrm{TM}}$ II, que propicia um ambiente de desenvolvimento integrado de projeto, compilação e síntese lógica, simulação e análise de tempo. 


\section{"Abstract"}

The APEX 20K programmable logic devices family, are configured at system power-up with data stored in a specific serial configuration device. This family of FPGAs contain an optimized interface that permits microprocessors to configure APEX $20 \mathrm{~K}$ devices serially or in parallel, and synchronously or asynchronously. After configured, it can be reconfigured in-circuit by resetting the device and loading new data. Real-time changes lead to innovative reconfigurable computing applications.

The commercial available configuration devices limit to configure the APEX $20 \mathrm{~K}$ devices only on the system power-up and always with the same configuration data file. This work shows a configuration controller implementation that can manage the configuration and reconfiguration of several FPGAs from multiple configuration files.

The entire project is developed, tested and validated through the EDA tool Quartus $^{\mathrm{TM}}$ II, that provide a integrated package with HDL and schematic design entry, compilation and logic synthesis, full simulation and worst-case timing analysis 


\section{Capítulo 1 \\ Introdução}

Para a industria eletrônica, é vital que novos produtos cheguem ao mercado consumidor no menor espaço de tempo possível. Desta forma, a redução do tempo de desenvolvimento de novos projetos tornou-se um fator de grande importância para os fabricantes de dispositivos eletrônicos. Além de prejuízos de mercado, um longo tempo de desenvolvimento implica também na elevação dos custos de projeto [1].

A evolução das metodologias de projeto de hardware, apoiadas em poderosas ferramentas EDA que aceleram o ciclo de desenvolvimento, e especialmente o surgimento de dispositivos reconfiguráveis como os FPGAs (Field-Programmable Gate Arrays), abriram novas possibilidades.

Hoje, é possível desenvolver rapidamente um projeto de sistema digital empregando-se novas metodologias como linguagens de descrição de hardware (HDL), ferramentas de síntese lógica e simulação [2]. Utilizando-se os circuitos reconfiguráveis pode-se implementar em campo, sem necessidade de processos de fabricação de chips, um protótipo ou a versão final do projeto desenvolvido.

A implementação de máquinas computacionais dedicadas e reconfiguráveis, denominadas CCMs (Custom Computing Machines) [3] [4], constitui-se também numa área promissora para aplicação de FPGAs. A implementação destas máquinas envolve o uso das partes programáveis para executar algoritmos, ao invés de compilá-los para a execução numa CPU.

A utilização de FPGAs para realizar computação conduz ao caminho de uma nova classe geral de organização de computadores chamada Arquiteturas de Computação Reconfigurável [5]. Essa classe de arquitetura é importante porque permite que a capacidade computacional da máquina seja altamente customizada para atender às necessidades instantâneas de uma aplicação, enquanto também permite que a capacidade computacional seja reutilizada ao longo do tempo. 
Como será apresentado nas próximas seções, trata-se de uma tecnologia emergente e promissora, apontada como um novo paradigma na computação por pesquisadores mais entusiastas, que oferece, além dos benefícios claros de ganhos de desempenho, um enorme potencial para desenvolver novas aplicações com características revolucionárias como sistemas evolutivos, de aprendizado e de autoreplicação, características presentes em sistemas biológicos [6].

A tecnologia FPGA tem evoluído em direção a mais altos índices de desempenho, elevados níveis de densidade e menores custos de fabricação. Esse fato tende a se acentuar nos próximos anos, tornando cada vez menor a distância entre as FPGAs e os chips diretamente implementados no silício. Isto tem possibilitado o emprego desta tecnologia na implementação de arquiteturas cada vez mais complexas. Além desses avanços, os fabricantes de FPGA têm introduzido, no decorrer dos anos, cada vez mais recursos de reconfigurabilidade em tais dispositivos.

Reconfigurabilidade é a capacidade que alguns FPGAs possuem, de serem configurados e reconfigurados várias vezes. Alguns FPGAs podem ser reconfigurados parcialmente, ou seja, setores do dispositivo são reconfigurados enquanto outros mantêm sua configuração.

Sistemas dinamicamente reconfiguráveis foram recentemente implementados pelos fabricantes de FPGA. O termo "dinamicamente reconfigurável", representa a possibilidade de se alterar, total ou parcialmente, a funcionalidade de um sistema. A disponibilidade de tais componentes tem alterado o processo de desenvolvimento de sistemas digitais. Agora, torna-se possível programar novos circuitos de hardware em um circuito integrado digital enquanto outros circuitos, no mesmo componente, continuam a funcionar sem qualquer degradação no desempenho dos circuitos estáticos. Estes novos sistemas digitais proporcionam muitas oportunidades mas também apresentam novos desafios.

Neste trabalho de mestrado, pretende-se explorar as técnicas de reconfigurabilidade dos FPGAs da família APEX 20K- Altera, visando a definição e o desenvolvimento de um hardware dedicado, bem como a construção de drivers necessários para a reconfiguração destes FPGAs.

Os resultados obtidos com este trabalho serão aplicados ao Projeto ARMOSH (Aprendizado de Robôs Móveis via Software e Hardware - processo FAPESP n. ${ }^{\circ}$. 
2000/02959-3), que vem sendo desenvolvido pelo Laboratório de Computação Reconfigurável - LCR do ICMC-USP, em conjunto com o LABIC (Laboratório de Inteligência Computacional) e com a CMU (Carnegie Mellon University - USA), que visa implementar algoritmos de robótica em software e hardware reconfigurável [7] [8].

Esta monografia é subdividida de acordo com o seguinte roteiro:

- Capítulo 2 - Apresenta uma breve discussão a respeito da evolução dos circuitos digitais e sua implementação nos circuitos integrados. Introduz-se o conceito da tecnologia PLD (Programmable Logic Devices) e sua evolução até os CPLDs (Complex CPLDs).

- Capítulo 3 - Trata do advento da tecnologia FPGA. A estrutura básica destes dispositivos é apresentada, assim como suas tecnologias de programação.

- Capítulo 4 - Especificamente voltado à família de dispositivos $\mathrm{APEX}^{\mathrm{TM}}$ 20K, este capítulo inicia-se com um apanhado geral das características destes FPGAs. Em seguida, o processo de configuração destes dispositivos é apresentado e por fim, são detalhados todos os esquemas de configuração pertinentes.

- Capítulo 5 - Neste capítulo, são apresentados os dispositivos de configuração disponíveis comercialmente e voltados à utilização com os FPGAs APEX 20K. Suas principais características são discutidas e o modelo mais complexo é detalhado.

- Capítulo 6 - Essencial para a conclusão deste trabalho, o kit de desenvolvimento Excalibur ${ }^{\mathrm{TM}}$ e seus componentes são neste capítulo apresentados.

- Capítulo 7 - A motivação e os objetivos do trabalho são neste capítulo apresentados. O capítulo contém as bases do projeto desenvolvido e um esboço do arranjo final a ser construído.

- Capítulo 8 - Apresentação de todo o desenvolvimento do projeto do controlador de configuração e do driver de comunicação com o sistema operacional.

- Capítulo 9 - Destinado à apresentação dos testes realizados com o controlador de configuração projetado, este capítulo contém ainda detalhes do projeto do hardware de emulação dos dispositivos APEX 20K bem como os motivos que 
levaram à necessidade deste desenvolvimento. Ao final, encontram-se alguns comentários finais e propostas para trabalhos futuros. 


\section{Capítulo 2}

\section{Dispositivos Lógicos Programáveis}

\subsection{O Projeto de Circuitos Digitais}

A tecnologia dos circuitos digitais tem se desenvolvido rapidamente nas últimas décadas. Os avanços constantes têm transformado de forma radical todo o processo de projeto de hardware.

Os componentes dos circuitos digitais evoluíram de transistores individuais para circuitos integrados VLSI (very large scale integration). A utilização de ferramentas EDA (eletronic design automation) tem simplificado e acelerado todo o ciclo de projeto. Atualmente, não é mais necessário desenhar portas lógicas individuais e planejar todas suas interconexões. As linguagens de descrição de hardware (HDLs) estão hoje consolidadas no meio acadêmico e industrial como forma padrão na elaboração de projetos. Existem também, ferramentas de síntese lógica automática, disponíveis para mapear circuitos em diversas tecnologias [9].

Todas essas mudanças na tecnologia exigem uma prototipação cada vez mais rápida, pois o ciclo de vida dos produtos modernos está tornando-se cada vez mais curto em relação ao tempo necessário para o projeto e desenvolvimento dos mesmos.

As implementações de circuitos podem ser agrupadas em diversas categorias [10]:

- CI's customizados ou ASICs (application specific integrated circuits): São aqueles que necessitam de um processo de fabricação especial, que requer máscaras específicas para cada projeto. Outras características desse tipo de implementação são o tempo de desenvolvimento longo e os custos extremamente altos. Em aplicações que requerem um grande volume de produção, o alto custo do projeto e dos testes é amortizado.

- MPGAs (mask-programmable gate arrays) : Nesse tipo de implementação, o processo de fabricação é agilizado pelo uso de máscaras 
genéricas de módulos pré-projetados, mas ainda necessita de máscaras específicas para a interconexão dos módulos. O projeto é normalmente facilitado por uma biblioteca de células, proporcionando um tempo de desenvolvimento mais curto e custos mais baixos em relação aos CI's customizados.

- Standard Cells : Essa tecnologia se assemelha muito a das MPGAs, o projeto também é facilitado pelo uso de módulos pré-projetados. Os módulos (standard cells) são geralmente salvos em bancos de dados. Os projetistas selecionam as células desejadas (nesses bancos de dados) para realizar seus projetos. Em comparação aos CI's customizados, os circuitos implementados em standard cells são menos eficientes em tamanho e desempenho, entretanto, seu custo de desenvolvimento é mais baixo.

- PLDs (programmable logic devices): Essa tecnologia possui como principal característica a capacidade de programação (configuração) pelo usuário, eliminando o processo de fabricação e facilitando assim as mudanças de projetos. Em comparação com outras tecnologias, os PLDs apresentam um ciclo de projeto muito curto e custos muito baixos.

O mercado de PLDs encontra-se em plena expansão, de forma que atualmente existem diversos fabricantes e modelos de dispositivos desse tipo. Uma das principais tarefas do projetista hoje é pesquisar e selecionar, dentre as opções disponíveis no mercado, qual a que melhor atende às suas necessidades.

\subsection{A Evolução dos Dispositivos Lógicos Programáveis}

A memória PROM (programmable read-only memory), foi o primeiro tipo de chip programável pelo usuário, que podia implementar circuitos lógicos. As linhas de endereço eram utilizadas como entradas do circuito lógico, e as linhas de dados como saídas desses circuitos. As funções lógicas, entretanto, raramente requerem mais que alguns termos produto, e uma PROM contêm um decodificador completo para seus endereços de entradas. As PROMs, portanto, se mostram como uma arquitetura 
ineficiente para o projeto e realização de circuitos lógicos, e são muito raramente utilizadas para esse fim [11].

Os PLAs (programmables logic arrays) foram os primeiros dispositivos criados especificamente para a implementação de circuitos lógicos. Introduzidos pela Philips no início dos anos 70, estes dispositivos consistem de dois níveis de portas lógicas: um plano de portas wired-AND seguido por um plano de portas wired-OR, ambos programáveis. Um PLA é estruturado de tal forma que cada saída do plano AND pode corresponder a qualquer termo produto das entradas. Da mesma forma, cada saída do plano OR pode ser configurada para produzir a soma lógica de quaisquer saídas do plano AND. A Figura 2.1 mostra um esquema simplificado de um PLA.

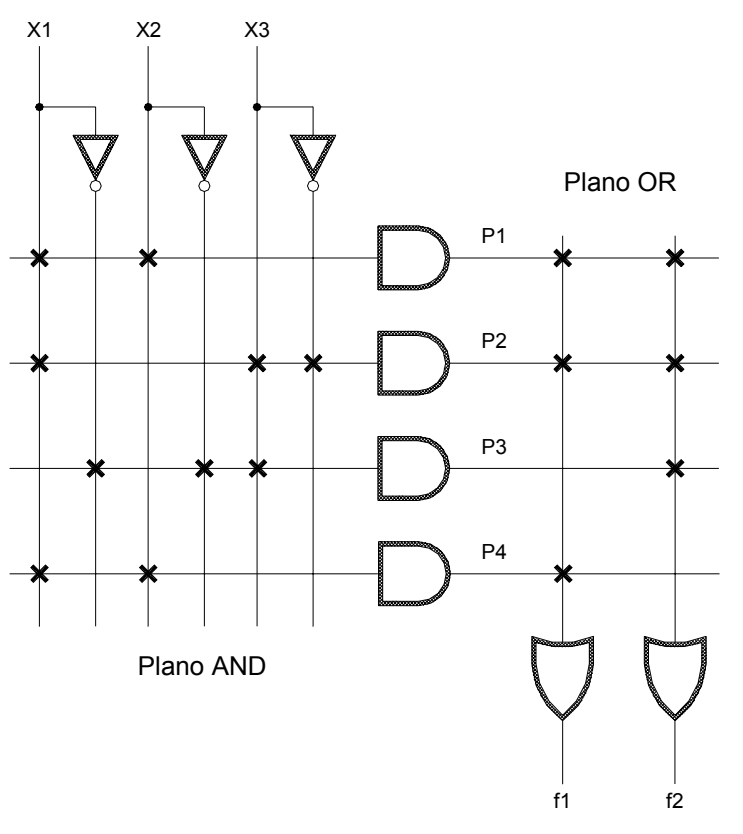

Figura 2.1 - Esquema simplificado de um PLA.

Devido a essa estrutura, os PLAs são adequados para as implementações de funções lógicas na forma de soma de produtos, e eles se apresentam muito versáteis pois, tanto os termos AND como os termos OR podem ter muitas entradas. Porém, essa tecnologia também apresenta alguns problemas como alto custo de fabricação e baixo desempenho em termos de velocidade. Essas desvantagens existem devido aos dois níveis de lógica configurável. Os planos lógicos programáveis são difíceis de serem fabricados e introduzem atrasos significativos de propagação dos sinais elétricos. A tecnologia PAL (programmable array logic) foi então desenvolvida para superar essas deficiências. Os PALs possuem um único nível de programação, um custo mais baixo e 
um melhor desempenho. Nos dispositivos PALs, apenas o plano AND é configurável. A Figura 2.2 apresenta um esquema simplificado de um PAL.

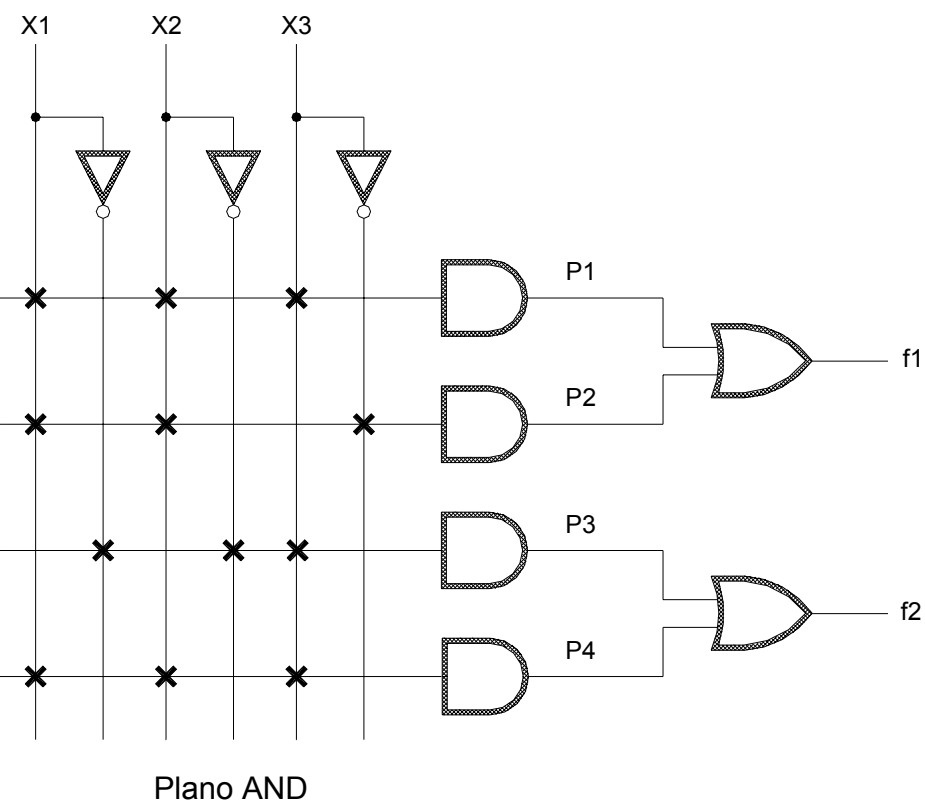

Figura 2.2 - Esquema simplificado de um PAL.

Todos estes PLDs (PALs, PALs e similares) são agrupados em uma única categoria denominada SPLDs (Simple PLDs), cujas principais características são o baixo custo e o alto desempenho. A dificuldade em aumentar a capacidade da arquitetura PLD é que a estrutura de planos lógicos programáveis aumenta muito rapidamente com o aumento do número de entradas. Uma maneira viável de produzir dispositivos com maior capacidade seria então, integrar múltiplos SPLDs em um único chip, e prover interconexões programáveis para conectar os diversos PLDs. A Figura 2.3 apresenta esta estrutura.

Atualmente existem muitos produtos comerciais utilizando-se deste esquema básico. São os chamados CPLDs (Complex PLDs). Os CPLDs provêem capacidade lógica de centenas de dispositivos SPLDs típicos [12]. 


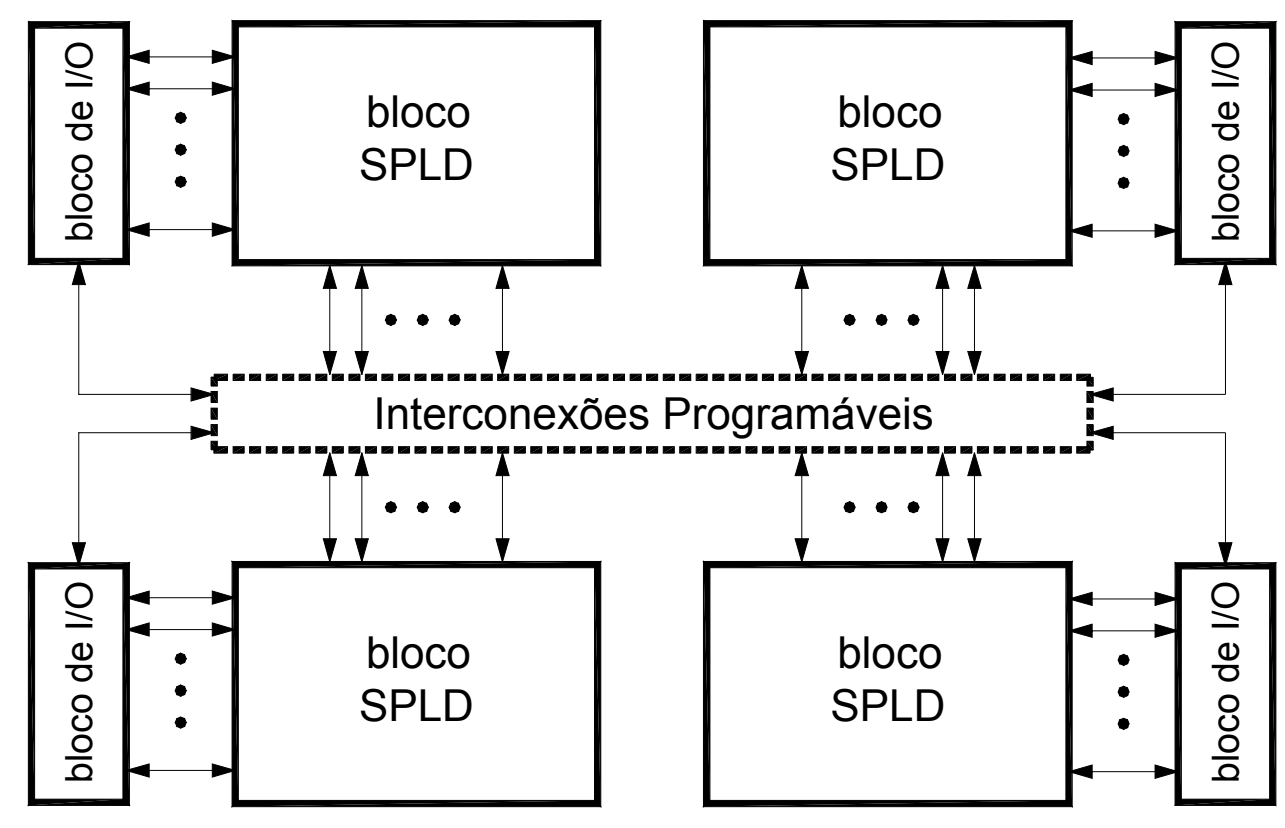

Figura 2.3 - Estrutura de um CPLD

Os CPLDs foram introduzidos pela Altera Corp., inicialmente com sua família de chips chamada Classic EPLDs (Erasable PLDs), e em seguida com três séries adicionais, chamadas MAX5000, MAX7000 e MAX9000. Devido ao rápido crescimento do mercado para grandes PLDs, outros fabricantes desenvolveram dispositivos na categoria CPLD e há atualmente muitas opções disponíveis. Os CPLDs propiciam capacidade lógica de até 50 dispositivos SPLDs típicos, mas é difícil estender essa arquitetura para densidades maiores. Para se construir PLDs com capacidade lógica muito alta, uma abordagem diferente deve ser adotada.

Cada tipo de PLD apresenta vantagens que os tornam mais adequados para algumas aplicações do que outros. Um projetista hoje depara com a difícil tarefa de pesquisar os diferentes tipos de chips, entender qual sua melhor utilização, escolher um fabricante específico, aprender a utilizar as ferramentas EDA, para só então começar a projetar o hardware. 


\section{Capítulo 3}

\section{A Tecnologia FPGA}

\subsection{Arquiteturas de FPGAs}

Os dispositivos descritos anteriormente (ASICs, SPLDs, e CPLDs), permitem a implementação de uma grande variedade de circuitos lógicos. Entretanto, com exceção dos CPLDs, estes componentes possuem pequena capacidade lógica e são viáveis apenas para aplicações relativamente pequenas. Até mesmo para os CPLDs, apenas circuitos moderadamente grandes podem ser acomodados em um único chip [12] [13].

Para se implementar circuitos lógicos maiores, é conveniente utilizar-se de um tipo diferente de chip que possui capacidade lógica maior. Introduzido pela empresa Xilinx Inc. no ano de 1985 [10], o Field-Programmable Gate Array (FPGA) é um dispositivo lógico programável que suporta a implementação de circuitos lógicos relativamente grandes.

Os FPGAs não possuem planos de portas OR ou AND. Em vez disso, estes componentes consistem de um grande arranjo de células configuráveis (ou blocos lógicos) que podem ser utilizadas para a implementação de funções lógicas. A estrutura de um FPGA é ilustrada na Figura 3.1. Um FPGA possui três tipos principais de recursos: blocos lógicos, blocos de entrada e saída (I/O), e chaves de interconexão. Os blocos lógicos formam um arranjo bi-dimensional, e as chaves de interconexão são organizadas como canais de roteamento horizontal e vertical entre as linhas e colunas de blocos lógicos. Estes canais de roteamento possuem chaves programáveis que permitem conectar os blocos lógicos de maneira conveniente, em função das necessidades de cada projeto. 


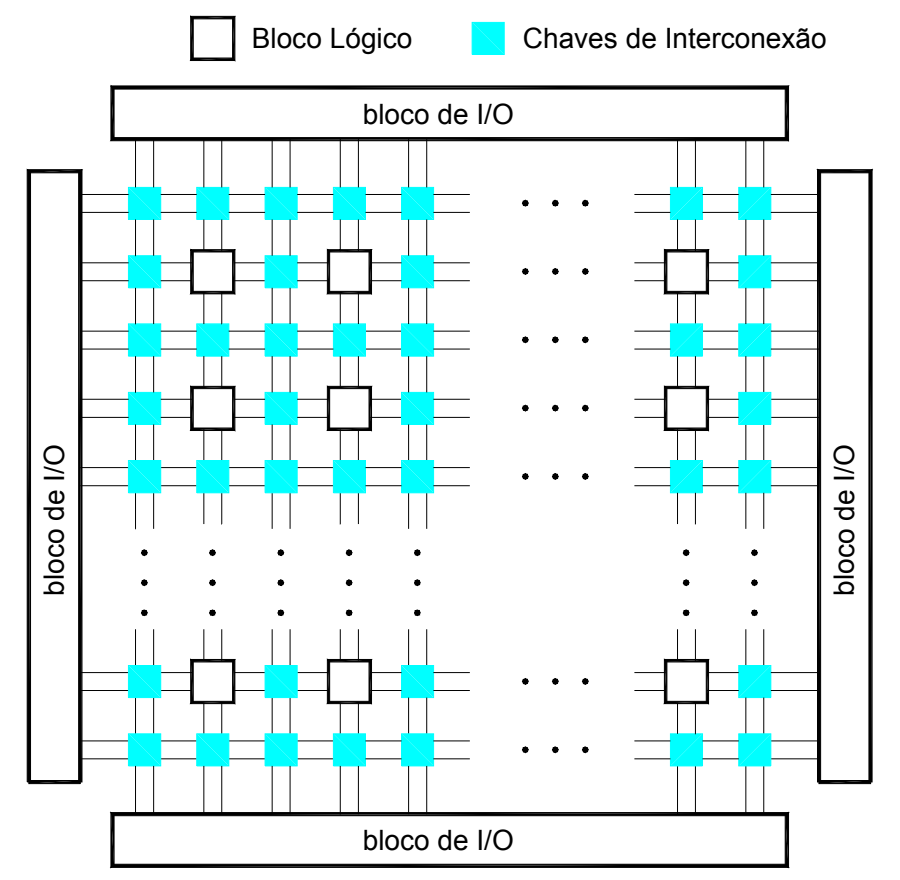

Figura 3.1 - Estrutura básica de um FPGA

Os FPGAs têm sido responsáveis pelas principais mudanças no modo em que os circuitos digitais são projetados.

Os fabricantes destes dispositivos utilizam-se de diferentes tipos de blocos lógicos. O mais comumente utilizado é o lookup table (LUT). Este tipo de bloco lógico contém células de armazenamento que são utilizadas para implementar pequenas funções lógicas. Cada célula é capaz de reter um único valor lógico, 0 ou 1. LUTs de vários tamanhos podem ser criados. A Figura 3.2 mostra a estrutura de um LUT com duas entradas, $x 1$ e $x 2$, e uma saída $f$. As variáveis de entrada x1 e x2 são usadas como chaves seletoras para os três multiplexadores $2 \times 1$ que em conjunto, selecionam uma das quatro células de armazenamento como saída do LUT. Nos FPGAs disponíveis comercialmente, os LUTs possuem geralmente quatro ou cinco entradas, o que exige 16 e 32 células de armazenamento respectivamente. 


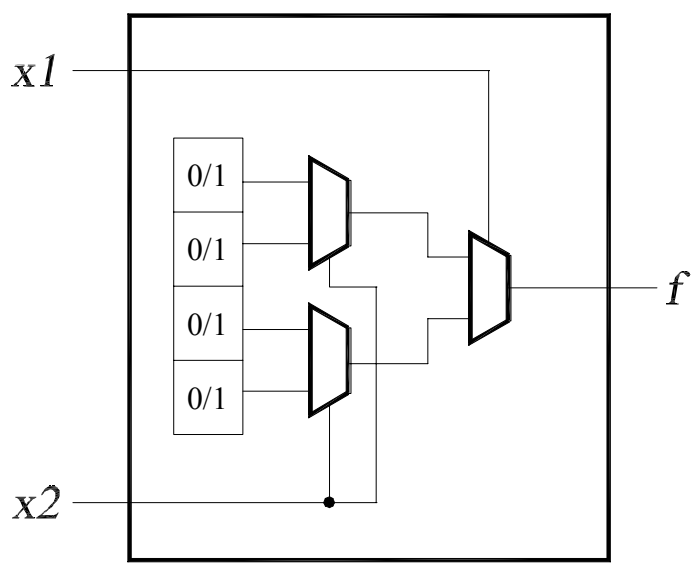

Figura 3.2 - Circuito para um LUT com duas entradas.

Quando um circuito lógico é implementado em um FPGA, os blocos lógicos são programados para realizar as funções necessárias, e os canais de roteamento são estruturados de forma a realizar as interconexões necessárias entre os blocos lógicos. As células de armazenamento dos LUTs de um FPGA são voláteis, o que implica na perda do conteúdo armazenado no caso de falta de alimentação elétrica. Desta forma, o FPGA deve ser programado toda vez que for energizado. Geralmente um pequeno chip de memória PROM é incluído nas placas de circuito impresso que contêm FPGAs. As células de armazenamento são automaticamente carregadas a partir das PROMs toda vez que uma tensão elétrica é aplicada a estes chips.

\subsection{Tecnologias de Programação}

Algumas propriedades dos comutadores dos FPGAs, tais como tamanho, resistência, capacitância e tecnologia de fabricação, afetam principalmente o desempenho e definem características como volatilidade e capacidade de reprogramação. $\mathrm{Na}$ escolha de um dispositivo reconfigurável, estes fatores devem ser avaliados. 
Basicamente existem três tipos de tecnologia de programação:

- SRAM (Static Random Acess Memory), onde o comutador é um transistor de passagem controlado pelo estado de um bit de SRAM.

- Antifuse é originalmente um circuito aberto que quando programado, forma um caminho de baixa resistência.

- Gate Flutuante, onde o comutador é um transistor com gate flutuante.

\subsubsection{A tecnologia de Programação SRAM}

A tecnologia de programação SRAM, ilustrada na Figura 3.3, usa uma célula de RAM estática para controlar transistores de passagem ou multiplexadores. Comercialmente, essa tecnologia é utilizada pela Xilinx, Altera e AT\&T.

Devido à volatilidade destas memórias, os FPGAs que se utilizam dessa tecnologia precisam de uma memória externa do tipo PROM, EPROM, EEPROM ou disco magnético. Essa tecnologia ocupa muito espaço no chip, mas apresenta grandes vantagens: é rapidamente reprogramável e requer apenas a tecnologia padrão de circuitos integrados para a sua fabricação [9].

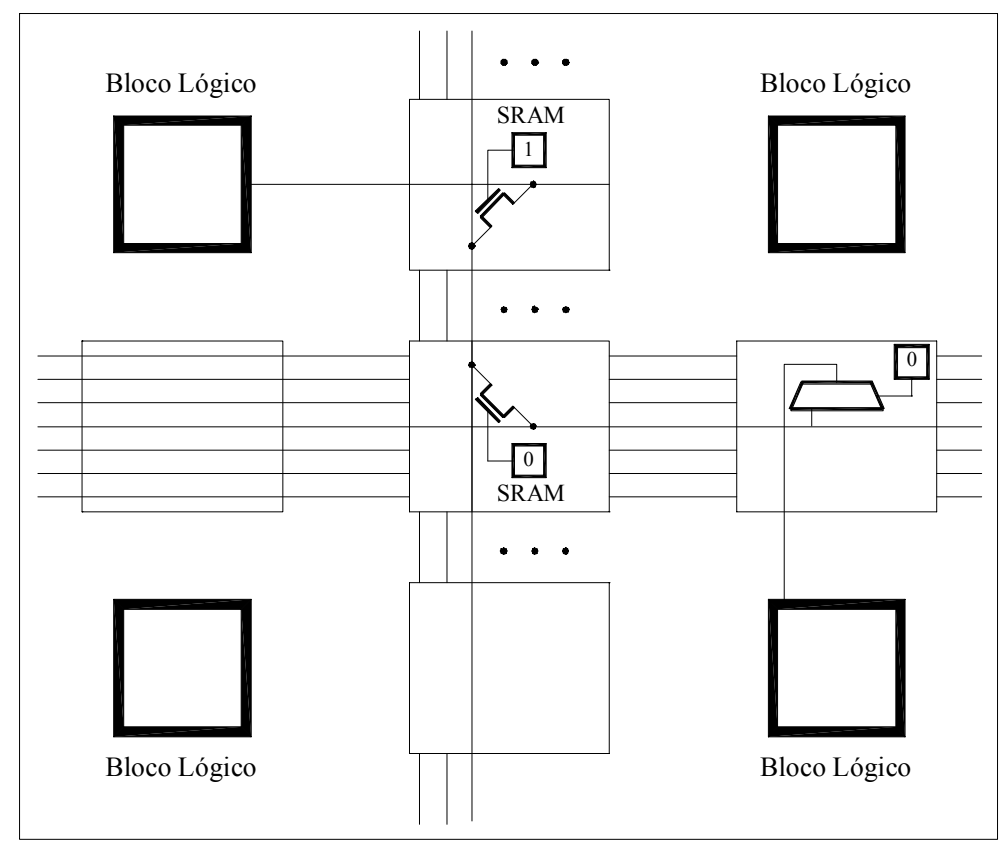

Figura 3.3 - Tecnologia de Programação SRAM 


\subsubsection{A tecnologia Antifuse}

Usado pela Actel, Quicklogic e recentemente pela Xilinx, o antifuse é um dispositivo de dois terminais que no estado não programado apresenta um alta impedância entre seus terminais [14]. Aplicando-se uma tensão entre 11 e 20 volts o antifuse "queima", criando conexão de baixa impedância. Entre as vantagens do antifuse são o tamanho reduzido, baixa capacitância quando não programado e baixa resistência quando programado. Porém, o antifuse não permite reprogramação. Além disso, para programá-los é necessária a presença de transistores com larga área a fim de suportar as correntes de programação $(\sim 5 \mathrm{~mA})$. Finalmente, é necessário gastar um espaço extra para conseguir a isolação dos circuitos de programação, pois os mesmos trabalham com tensão de até $20 \mathrm{~V}$.

\subsubsection{A tecnologia de Gate Flutuante}

Nessa tecnologia, os comutadores programáveis são baseados em transistores com gate flutuante iguais aos usados nas memórias EPROM (Erasable PROM) e EEPROM (Electrical Erasable PROM). Comercialmente, a EPROM é usada pela Altera e a EEPROM pela AMD e Lattice. A Figura 3.4 ilustra um comutador programável do tipo EPROM.

O transistor MOS (Metal-Oxide Semiconductor) especial é construído com dois gates. O gate flutuante armazena carga elétrica que é injetada através da aplicação de uma tensão alta entre o gate 1 e o source do transistor. Essa carga faz com que o threshold do transistor seja aumentado, impedindo a condução do mesmo. Ao expor o componente aos raios ultravioleta (UV), essa carga desaparece e o transistor volta a funcionar normalmente. $\mathrm{Na}$ prática, o transistor do tipo EPROM não é usado diretamente como comutador, mas sim fazendo pull-down. Desta maneira torna-se possível a construção de lógicas do tipo wired-AND, e conseqüentemente a realização de roteamento e lógica. 


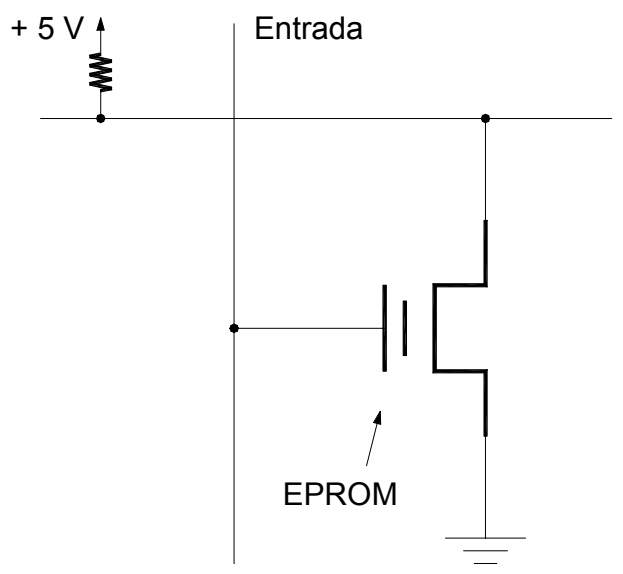

Figura 3.4 - Comutador Programável baseado em EPROM.

A maior vantagem da tecnologia EPROM é sua capacidade de reprogramação e a retenção dos dados. Além disso, com a EEPROM é possível programar e reter as informações com o chip já instalado na placa, característica denominada ISP (In-System Programmability).

Como desvantagens, a tecnologia EPROM exige três processos adicionais, além do processo normal de fabricação. Além disso, a resistência dos comutadores ligados não atinge valores baixos e o consumo total é maior devido aos resistores de pull-down. Quanto a EEPROM, apesar de oferecer a reprogramação no sistema (ISP), cada célula ocupa o dobro de espaço de uma célula EPROM.

A Tabela 3.1 resume as características mais importantes das tecnologias de programação apresentadas.

Tabela 3.1 - Sumário das Tecnologias de Programação

\begin{tabular}{|l|c|c|c|}
\hline Nome & Reprogramação & Volatilidade & Tecnologia \\
\hline EPROM & sim, fora do circuito & não & UVCMOS \\
\hline EEPROM & sim, no circuito & não & EECMOS \\
\hline SRAM & sim, no circuito & sim & CMOS \\
\hline Antifuse & não & não & CMOS + \\
\hline
\end{tabular}




\subsection{Arquitetura dos Blocos Lógicos}

Os blocos lógicos dos FPGAs variam muito de tamanho e capacidade de implementação lógica. Os blocos lógicos dos FPGAS comerciais são baseados em um ou mais dos seguintes componentes:

- $\quad$ Pares de transistores;

- $\quad$ Portas básicas do tipo NAND ou XOR de duas entradas;

- $\quad$ Look-up tables (LUTs);

- $\quad$ Estruturas AND-OR de múltiplas entradas.

Algumas categorias de FPGAs foram criadas afim de classificá-los quanto ao bloco lógico que empregam. Estas categorias foram denominadas de granulosidade fina e de granulosidade grossa, sendo a primeira a designante para blocos simples e pequenos e a segunda para os blocos mais complexos e maiores [15].

\subsubsection{Blocos de Granulosidade Fina}

Um exemplo para um bloco de granulosidade fina é um bloco contendo alguns transistores interconectáveis ou portas lógicas básicas. A principal vantagem no uso deste tipo de bloco lógico é que estes são quase sempre totalmente utilizados. A desvantagem reside no fato de serem em um número muito grande devido à baixa capacidade lógica individual de cada bloco, requerendo desta forma, uma grande quantidade de trilhas de conexão e comutadores programáveis. Um roteamento desse tipo de FPGA se torna lento e ocupa grande área do chip.

\subsubsection{Blocos de Granulosidade Grossa}

Estes são geralmente baseados em multiplexadores e/ou look-up tables (LUTs). Estes blocos lógicos têm a vantagem de fornecer um alto grau de funcionalidade com um número relativamente pequeno de transistores. No entanto, eles possuem muitas 
entradas necessitando de muitos comutadores, o que sobrecarrega o roteamento. Logo, a tecnologia antifuse é mais adequada para a fabricação desse tipo de FPGA, devido ao tamanho reduzido dos comutadores antifuse.

Uma look-up table (LUT), conforme discutido no item 3.1, é uma pequena memória de um bit de largura, onde suas linhas de endereço funcionam como entradas do bloco lógico e sua saída fornece o valor da função lógica. A tabela verdade para uma função de $\mathrm{K}$ entradas é armazenada em uma SRAM de $2^{k}$ x 1 bits. A vantagem das LUTs é que apresentam um alto grau de funcionalidade - uma LUT de K entradas pode implementar qualquer função de $\mathrm{K}$ entradas e existem $2^{2^{k}}$ funções. A desvantagem é que são excessivamente grandes para mais que cinco entradas. Apesar do número de funções que podem ser implementadas aumentar muito rapidamente com o número de entradas, essas funções adicionais não são geralmente utilizadas em projetos lógicos e são difíceis de serem manipuladas por uma ferramenta de síntese lógica.

\subsubsection{Lógica Seqüencial}

A maioria dos blocos lógicos apresenta alguma forma de lógica seqüencial. Geralmente utilizam flip-flops tipo D que podem ser conectados (via programação) às saídas dos blocos combinacionais. Em alguns dispositivos, a lógica seqüencial não está explicitamente presente, e deve ser formada utilizando-se o roteamento programável e os blocos puramente combinacionais.

\subsection{Arquitetura de Roteamento}

A arquitetura de roteamento de um FPGA é a maneira pela qual os comutadores programáveis e segmentos de trilha são posicionados para permitir a interconexão entre as células lógicas [15]. As arquiteturas de roteamento podem ser descritas a partir do modelo geral apresentado na Figura 3.5. São necessários alguns conceitos para um melhor entendimento desse modelo: 
- Pinos: são entradas e saídas dos blocos lógicos.

- Conexão: ligação elétrica de um par de pinos de blocos lógicos.

- Rede: é um conjunto de pinos de blocos lógicos que estão conectados.

- Comutador de roteamento (switch): utilizado para conectar dois segmentos de trilha.

- Segmento de trilha: segmento não interrompido por comutadores programáveis.

- Trilha: seqüência de um ou mais segmentos de trilha em uma direção.

- Canal de roteamento: área entre duas linhas ou colunas de blocos lógicos. Um canal contém um grupo de trilhas paralelas.

O modelo contém duas estruturas básicas. A primeira é o bloco de conexão que aparece em todas as arquiteturas. O bloco de conexão permite a conectividade das entradas e saídas de um bloco lógico com os segmentos de trilhas nos canais. A Segunda estrutura é o bloco de comutação que permite a conexão entre os segmentos de trilhas horizontais e verticais. Em algumas arquiteturas, o bloco de comutação e o bloco de conexão são distintos, em outras estão combinados numa mesma estrutura. Nem todas as arquiteturas seguem esse modelo. Existem arquiteturas que apresentam uma estrutura hierárquica e outras que possuem somente canais horizontais.

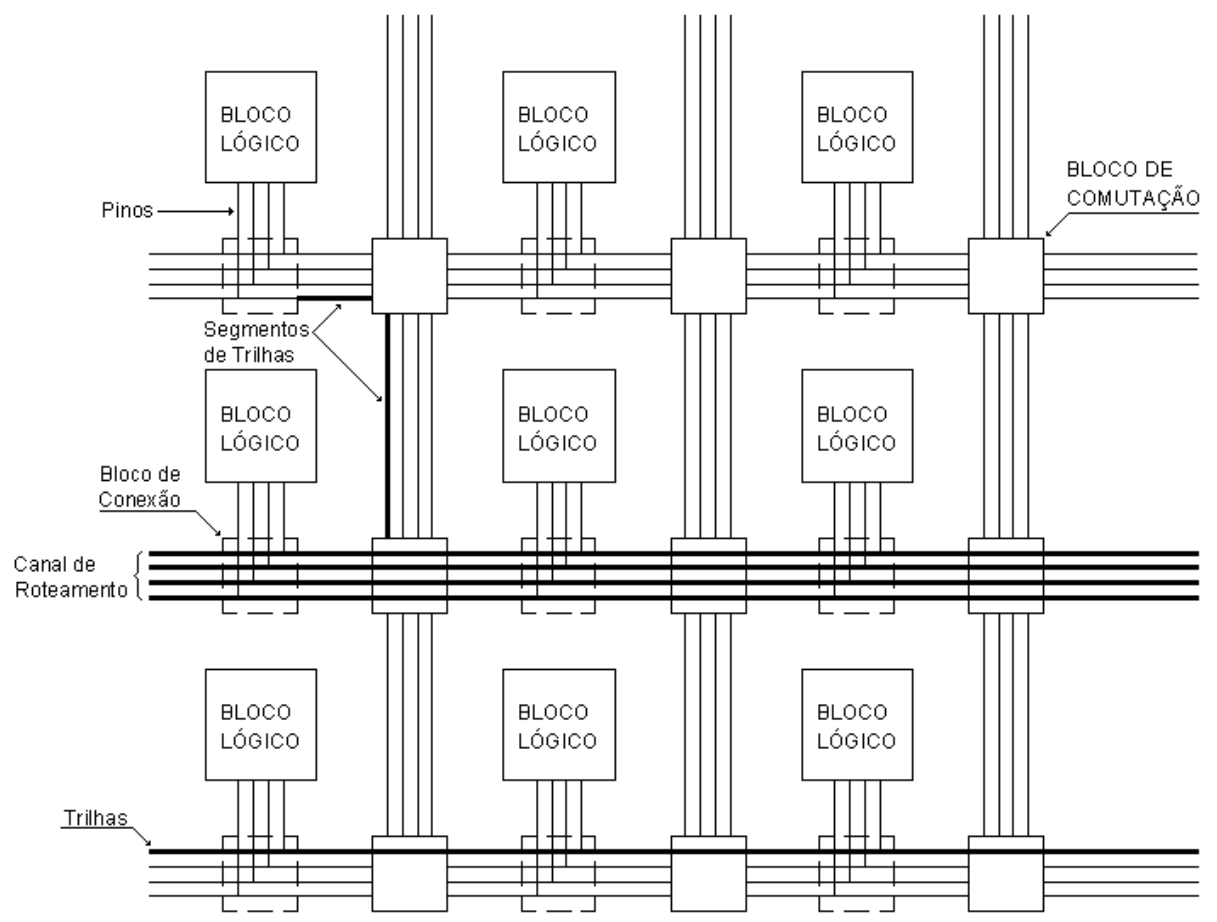

Figura 3.5 - Arquitetura Geral de Roteamento de um FPGA. 
Uma importante questão a ser considerada é se a arquitetura de roteamento permite que se alcance um roteamento completo e, ao mesmo tempo, uma alta densidade lógica. Sabe-se que usando um grande número de comutadores programáveis torna-se fácil alcançar um roteamento completo, mas esses comutadores consomem área, que é desejável minimizar. Algumas pesquisas estabelecem uma relação entre a flexibilidade da arquitetura de roteamento, a capacidade de roteamento e uso eficiente da área [15]. 


\section{Capítulo 4}

\section{A Família de Dispositivos APEX ${ }^{\mathrm{TM}}$ 20K}

\subsection{Descrição Geral}

A família de dispositivos APEX $^{\mathrm{TM}}$ da Altera ${ }^{\circledR}$ possibilita uma completa integração de sistemas em um único chip. Através da arquitetura MultiCore ${ }^{\mathrm{TM}}$, esta família de dispositivos acentua o desempenho dos PLDs que a antecederam, possibilitando flexibilidade de projeto e eficiência para aplicações SOPC (System-on- $a$ programmable-chip) de alto desempenho [16].

Com densidades variando entre 30.000 e 1,5 milhões de portas lógicas e melhoria de desempenho com o emprego de interconexões de cobre, estes dispositivos tornam-se compatíveis com arquiteturas PCI de 64 bits e 66MHz. O nível de integração dos chips da família APEX varia de $0.22 \mu \mathrm{m}$ a $0.15 \mu \mathrm{m}$, conforme Figura 4.1.

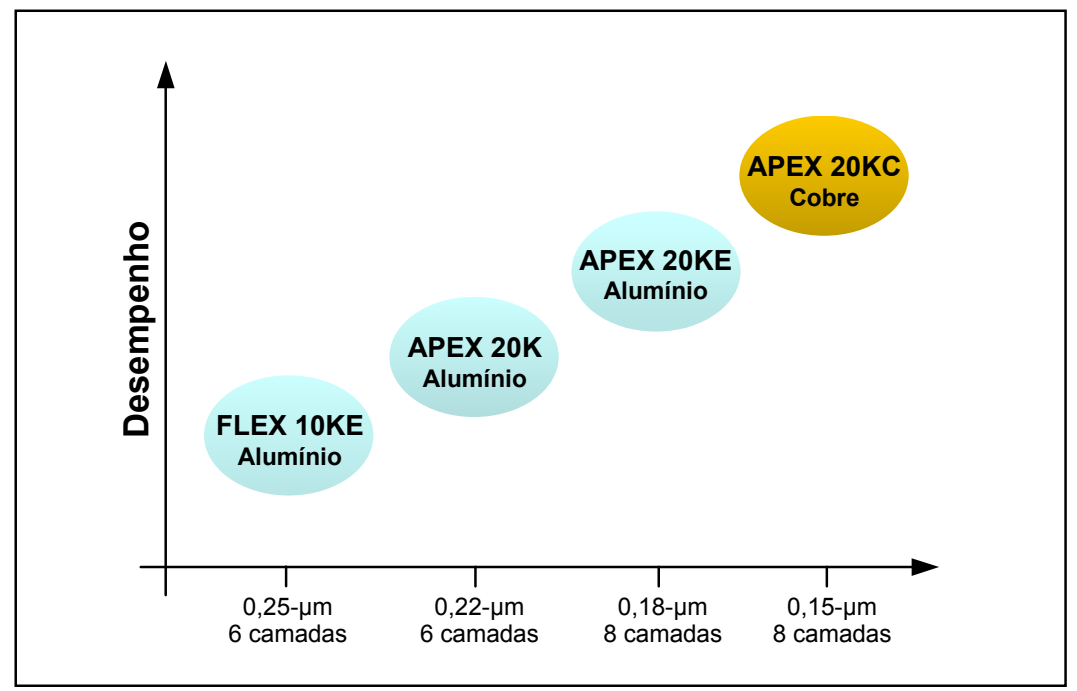

Figura 4.1 - Níveis de integração da Família APEX ${ }^{\mathrm{TM}}$ 
No FPGA APEX 20KC, o alumínio, tradicionalmente utilizado nas camadas que compõem a estrutura de roteamento, foi substituído pelo cobre. Com o emprego desta nova tecnologia, obtêm-se tempos de atraso menores (Figura 4.2), menor dissipação de calor, e uma melhor utilização do espaço físico ocupado pelo componente.

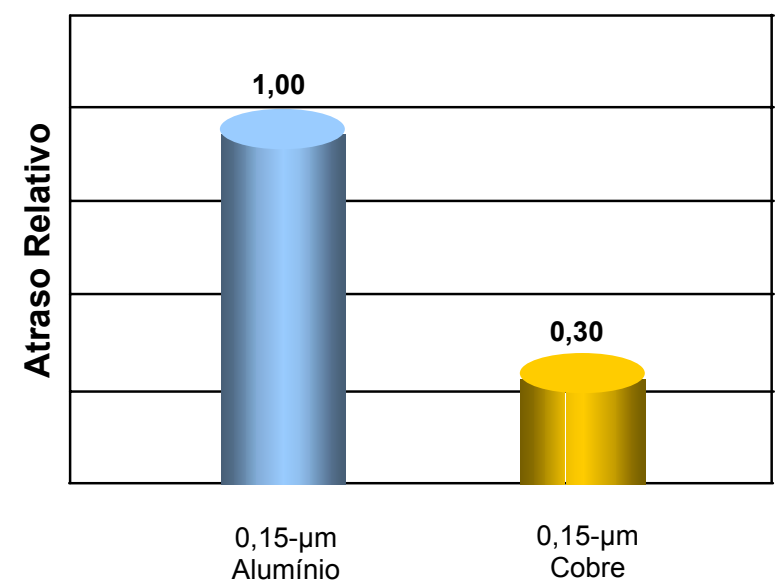

Figura 4.2 - Melhoria de Desempenho com o Emprego do Cobre.

\subsection{A Arquitetura MultiCore ${ }^{\mathrm{TM}}$ dos FPGAs APEX 20K}

A arquitetura MultiCore contém dois tipos de estruturas de PLDs: as look-uptable (LUT) presentes nas famílias FLEX 10K e FLEX 6000, e os blocos de memória embutidos (ESBs - Embedded Sistem Blocks), presentes na família FLEX 10KE [16]. Estas duas estruturas são combinadas em uma única arquitetura, eliminando a necessidade de múltiplos dispositivos e consequentemente, simplificando a implementação de sistemas complexos. A Figura 4.3 mostra este arranjo.

Os ESBs constituem-se no principal elemento da arquitetura MultiCore. Os 2.048 bits programáveis de cada ESB podem ser configurados como dual-port RAM, ROM, ou como memória de conteúdo endereçável (CAM). 


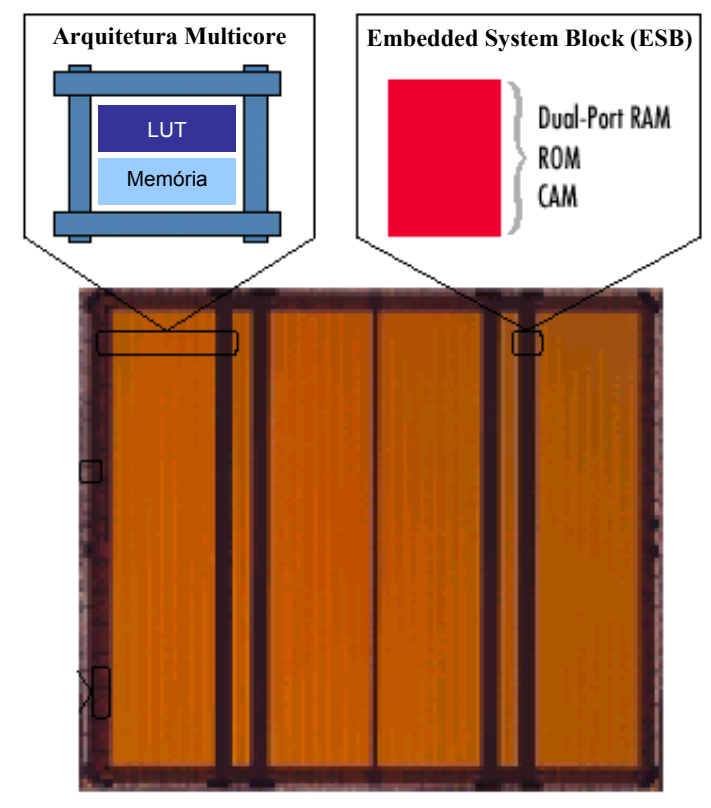

Figura 4.3 - Arquitetura MultiCore ${ }^{\mathrm{TM}}$.

Além destas características, a arquitetura MultiCore introduz ainda um novo nível de hierarquia chamado de estrutura MegaLAB ${ }^{\mathrm{TM}}$ (Figura 4.4). Esta estrutura contém 16 conjuntos de blocos lógicos (LABs - Logic Array Blocks), e um bloco de memória embutido (ESB - Embedded System Block). Conjuntos de LABs e ESBs são interligados por uma estrutura de conexão MegaLAB, utilizando-se para isto de poucos recursos de roteamento disponíveis no componente. Em adição, troca de sinais entre LABs adjacentes são realizadas através de um barramento de conexão local, aliviando assim a utilização das conexões MegaLAB.

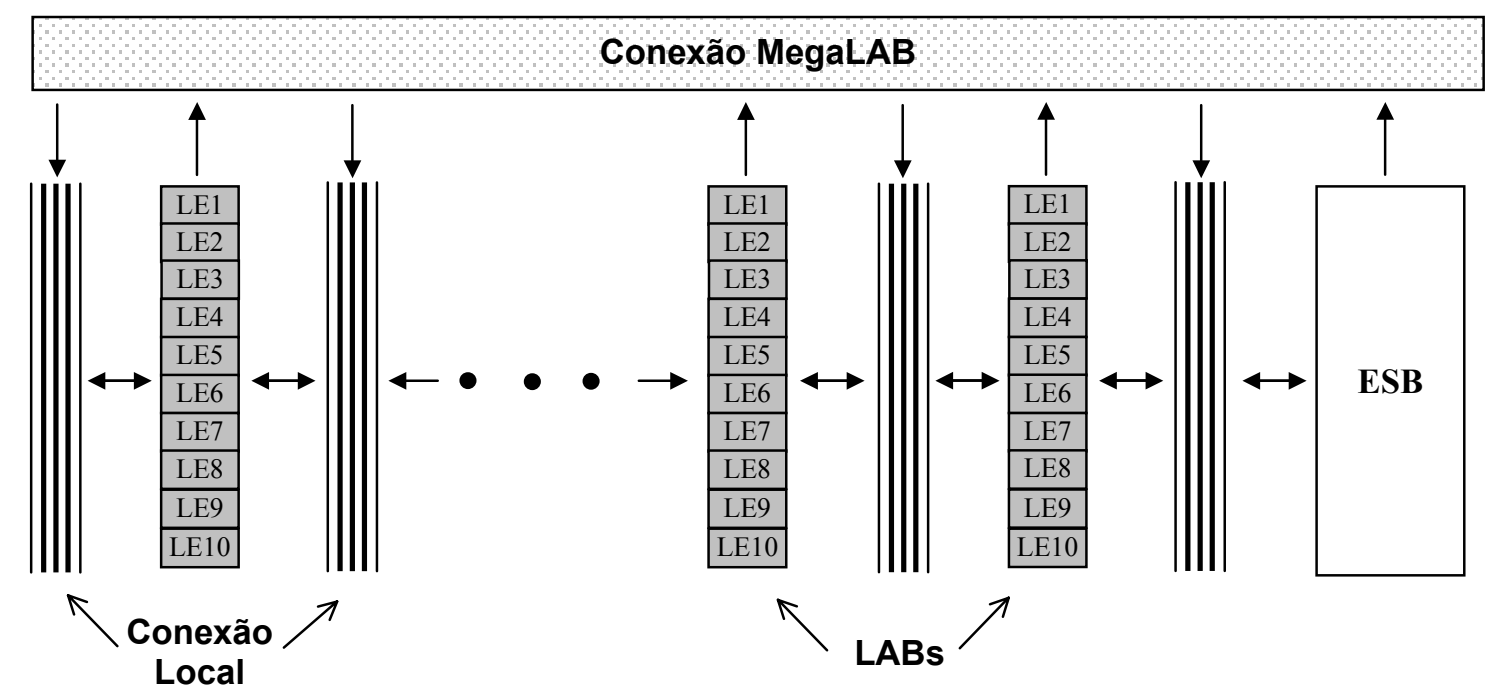

Figura 4.4 - Estrutura MegaLAB ${ }^{\mathrm{TM}}$. 
Para o roteamento de sinais entre as estruturas MegaLAB e entre estas e os pinos de I/O, utiliza-se de uma estrutura denominada FastTrack® - uma série canais em forma de linhas e colunas contínuas dispostas ao longo de toda área útil do dispositivo.

\subsection{Configurando os Dispositivos APEX 20K}

A arquitetura APEX utiliza elementos de configuração SRAM. Devido à sua inerente volatilidade, estes elementos precisam ser carregados com os dados de configuração toda vez que o dispositivo for inicializado. O processo de se carregar fisicamente os elementos SRAM com seus dados é chamado de configuração.

A família APEX 20K suporta vários esquemas de configuração, os quais são ideais para uma variedade de sistemas [17]. Cada esquema de configuração utiliza-se de microprocessadores ou de dispositivos de configuração. A Tabela 4.1 ilustra os cinco esquemas de configuração disponíveis para os FPGAs APEX 20K.

\section{Tabela 4.1 - Esquemas de Configuração}

\begin{tabular}{|l|l|}
\hline \multicolumn{1}{|c|}{$\begin{array}{c}\text { Esque m a de } \\
\text { Configura çã o }\end{array}$} & \multicolumn{1}{c|}{ Uso Típico } \\
\hline Dispositivo de Configuração & Configuração com os dispositivos EPC16, EPC2, EPC1, ou EPC1441. \\
\hline Serial Passivo (PS) & $\begin{array}{l}\text { Configuração com interface microprocessada serial síncrona e cabo } \\
\text { de comunicação MasterBlaster, cabo parlelo de download } \\
\text { ByteBlasterMV, ou cabo serial de download BltBlaster } .\end{array}$ \\
\hline $\begin{array}{l}\text { Paralelo Passivo } \\
\text { Sincrono (PPS) }\end{array}$ & Configuração com interface microprocessada paralela síncrona. \\
\hline $\begin{array}{l}\text { Paralelo Passivo } \\
\text { Assíncrono (PPA) }\end{array}$ & Configuração com interface microprocessada paralela assíncrona. \\
\hline JTAG & Configuração através do padrão IEEE - 1149.1. \\
\hline
\end{tabular}

Nas seções seguintes, serão descritos detalhadamente os cinco esquemas de configuração indicados na Tabela 4.1. 


\subsubsection{Dispositivo de Configuração}

O esquema com Dispositivo de Configuração usa um componente serial que fornece os dados de configuração para o FPGA APEX 20K (Figura 4.5).

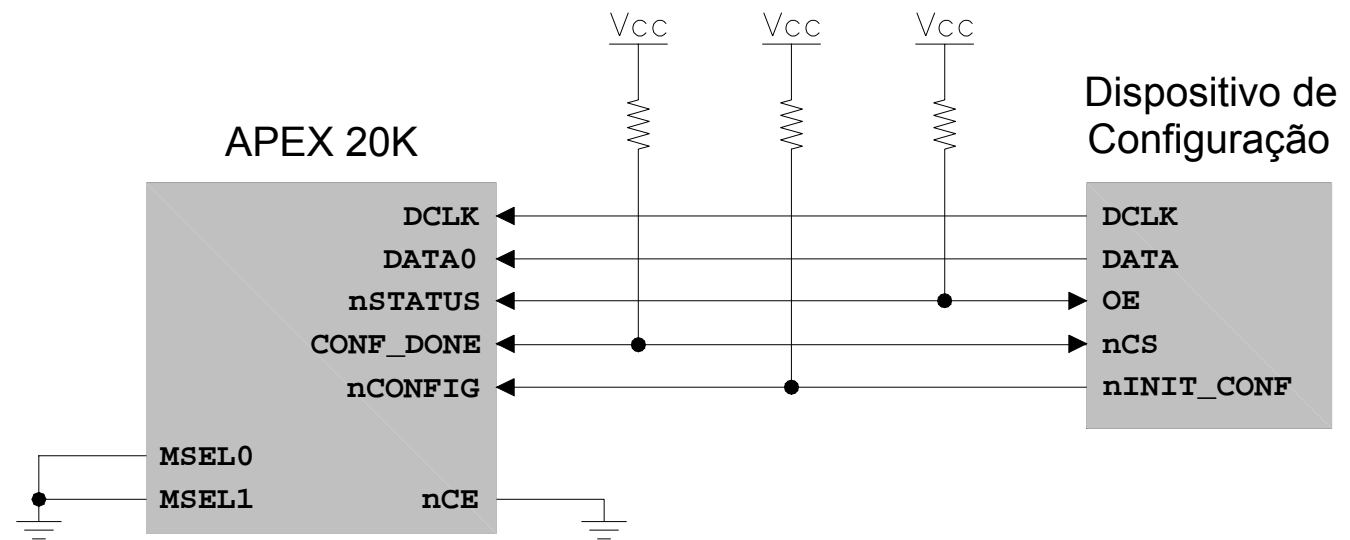

Figura 4.5 - Esquema para Dispositivo de Configuração.

Antes de ter início a configuração, o dispositivo de configuração impõem um atraso de 200ms (máximo) para que haja a estabilização da fonte de alimentação do circuito; durante este período, o dispositivo de configuração leva o pino OE para o nível lógico baixo. A este atraso dá-se o nome de POR (power-on-reset). O POR atrasa a configuração, pois o pino OE está conectado ao pino nSTATUS do dispositivo alvo. Quando os dois dispositivos completam o POR, o pino nSTATUS é liberado e é então levado ao nível lógico alto através do resistor pull-up. Quando esta transição acontece, o dispositivo de configuração envia de maneira serial os dados de configuração nele armazenados, usando para isto um oscilador interno.

Obtendo-se sucesso na configuração, o pino CONF_DONE é liberado pelo dispositivo alvo e é levado ao nível alto pelo resistor pull-up. Terminada a inicialização, o dispositivo de configuração entra no modo usuário. A Figura 4.6 mostra o ciclo de configuração para o arranjo em questão. 


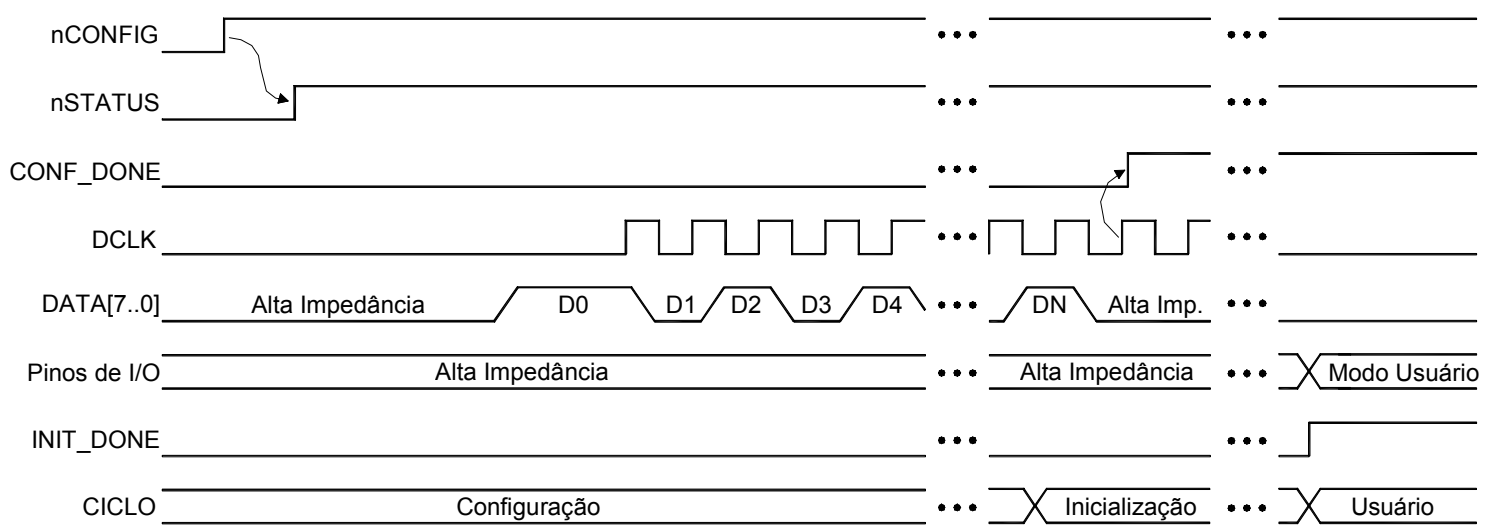

Figura 4.6 - Ciclo de Configuração para o APEX 20K.

Quando CONF_DONE não assume nível lógico alto após a configuração, o dispositivo de configuração reconhece que o dispositivo alvo não foi configurado com sucesso. Neste caso, o dispositivo de configuração leva OE para o nível baixo por alguns micro-segundos, tornando baixo o nível do pino nSTATUS do dispositivo alvo. Assim que nSTATUS volta ao nível alto, o dispositivo de configuração reconfigura o dispositivo alvo.

A Figura 4.7 mostra o esquema para configuração de múltiplos FPGAs APEX $20 \mathrm{~K}$ com dois dispositivos de configuração. Este circuito é similar ao circuito utilizado na configuração de um único FPGA, exceto que aqui os dispositivos estão dispostos em cascata para a múltipla configuração.

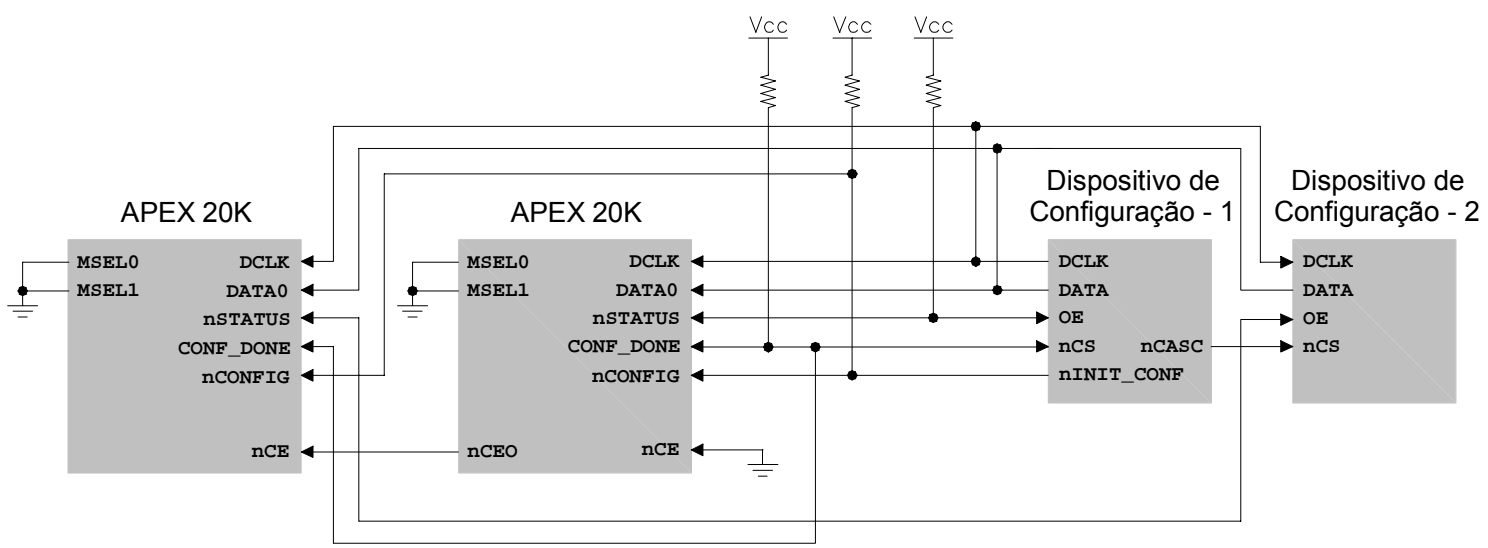

Figura 4.7 - Esquema para Configuração com Múltiplos Dispositivos. 
Depois que o primeiro dispositivo alvo tiver completado sua configuração durante a configuração de múltiplos dispositivos, seu pino $\mathrm{nCEO}$ ativa o pino $\mathrm{nCE}$ do segundo dispositivo, habilitado-o a iniciar sua configuração.

Em adição, todos os pinos nSTATUS estão sob o mesmo potencial; desta forma, se algum dispositivo (incluindo o dispositivo de configuração) detectar um erro, o processo de configuração é encerrado para toda cadeia envolvida. Além disso, se o primeiro dispositivo de configuração não receber a transição do pino CONF_DONE indo do nível baixo para alto no final da configuração, ele reinicia a cadeia levando o pino OE para o nível baixo por alguns micro-segundos. Este evento leva nSTATUS de todos os dispositivos alvo para o nível baixo, fazendo com que estes detectem um estado de erro. Esta situação permanece inalterada até que nCONF IG receba nível lógico baixo.

Quando o primeiro dispositivo de configuração termina o envio de seus dados, ele torna baixo o nível de $\mathrm{nCASC}$, levando consigo o pino nCS do dispositivo de configuração subsequente. Em função do primeiro dispositivo de configuração requerer menos que um ciclo de clock para ativar o dispositivo de configuração subsequente, o envio dos dados não é interrompido.

\subsubsection{Configuração Serial Passiva (PS) com Cabo de Download}

Neste esquema de configuração, um host inteligente transfere dados a partir de um dispositivo de armazenamento para o FPGA via cabo MasterBlaster, ByteBlasterMV ou BitBlaster. Para iniciar a configuração neste esquema, o cabo de download gera uma transição baixo-alto no pino nCONFIG do dispositivo alvo. O host então coloca os dados de configuração serialmente no pino DATAO do dispositivo. O processo continua até que o nível de CONF_DONE torna-se alto. A Figura 4.8 ilustra este esquema de configuração.

Múltiplos APEX 20K podem ser também programados através de programação via host. Para isto, os pinos $\mathrm{nCEO}$ de cada dispositivo alvo devem ser conectados aos pinos $\mathrm{nCE}$ dos dispositivos subsequentes (ver Figura 4.9). Todos os outros pinos de configuração são conectados a cada dispositivo dentro da cadeia. Devido ao fato de os 
pinos CONF_DONE estarem conectados entre si, todos os dispositivos da cadeia inicializam e entram no modo usuário ao mesmo tempo. Além disso, com os pinos nSTATUS interconectados, toda a cadeia interrompe o processo de configuração se algum dispositivo detecta um erro.

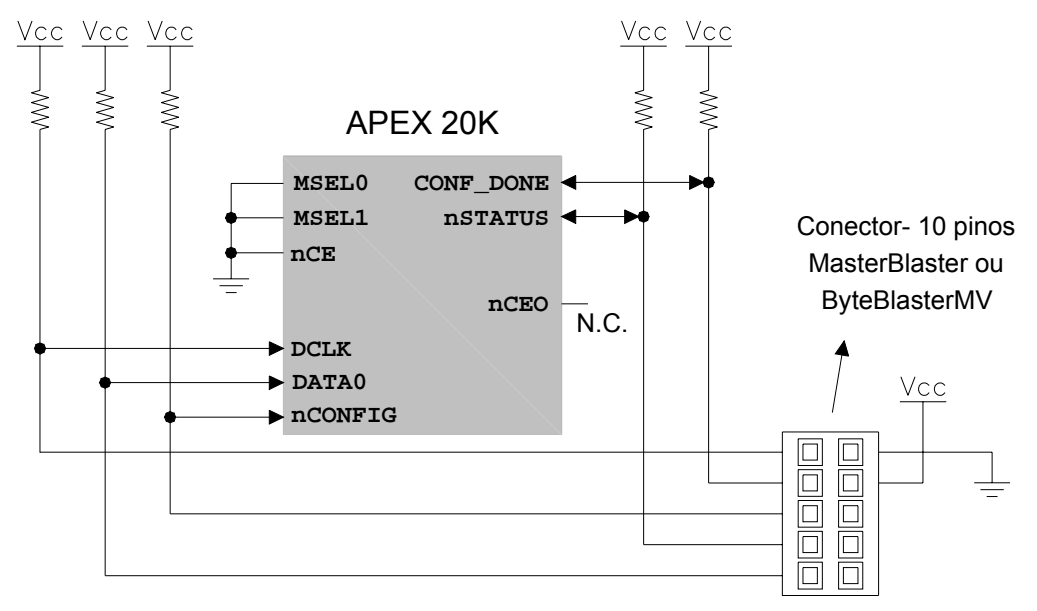

Figura 4.8 - Esquema de Configuração PS com um Cabo de Download.

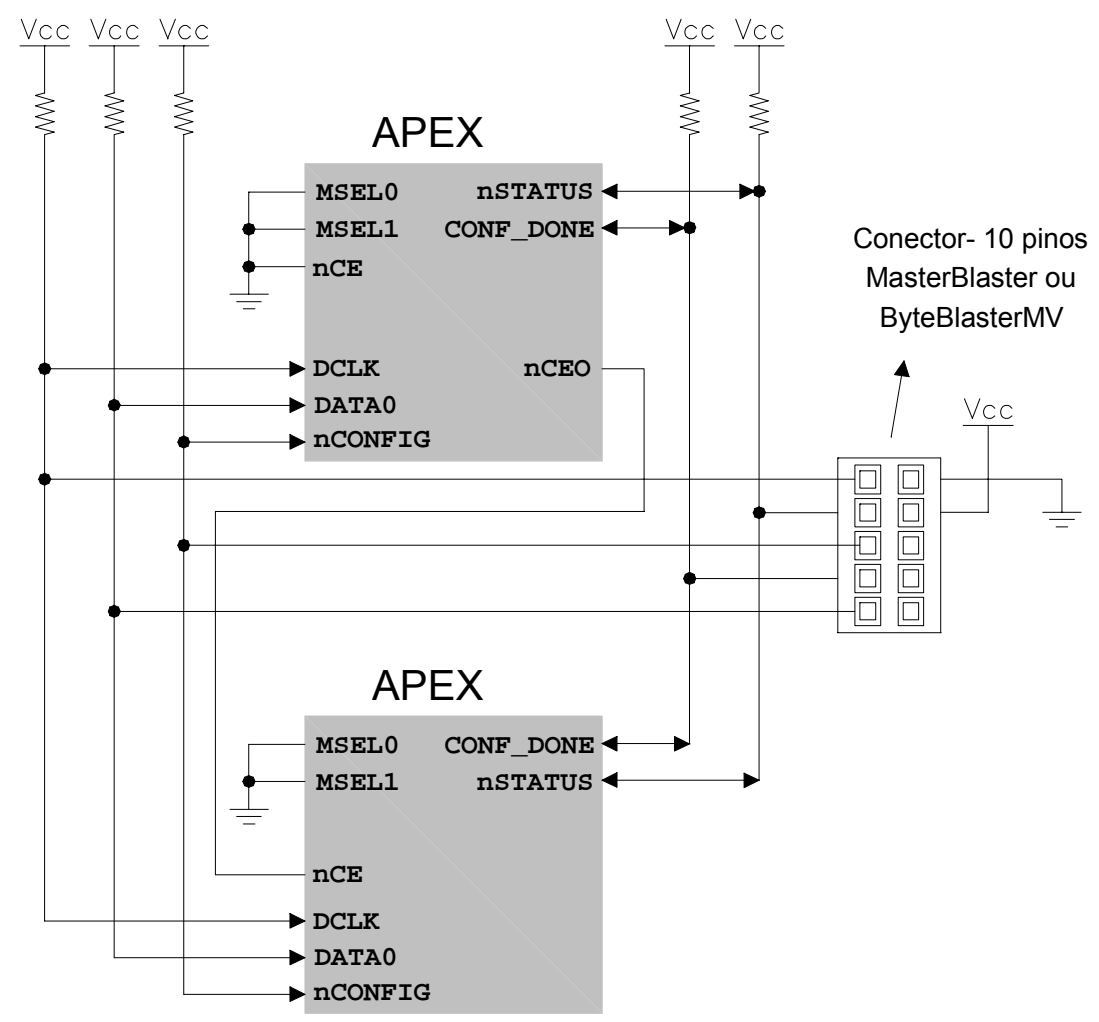

Figura 4.9 - Configuração de Múltiplos Dispositivos com Cabos de Download. 


\subsubsection{Configuração Serial Passiva (PS) com Microprocessador}

Neste esquema de configuração, um microprocessador transfere dados a partir de um dispositivo de armazenamento para o FPGA, via programação em hardware. Para iniciar a configuração neste esquema, o microprocessador deve gerar uma transição baixo-alto no pino nCONFIG do dispositivo alvo. O microprocessador então coloca os dados de configuração serialmente no pino DATAO do dispositivo alvo. O processo continua até que o nível de CONF_DONE torna-se alto.

Se o FPGA detecta um erro durante a configuração, ele torna baixo o nível do pino nSTATUS, alertando o microprocessador. Este então, leva nCONFIG para o nível baixo, reiniciando o processo de configuração.

O microprocessador pode ainda monitorar o pino CONF_DONE para se assegurar do sucesso da configuração. Se o microprocessador envia todos os dados e inicia o clock de inicialização, mas CONF_DONE não assume nível alto, o microprocessador deve reconfigurar o dispositivo alvo. A Figura 4.10 apresenta o circuito para configuração PS com um microprocessador.

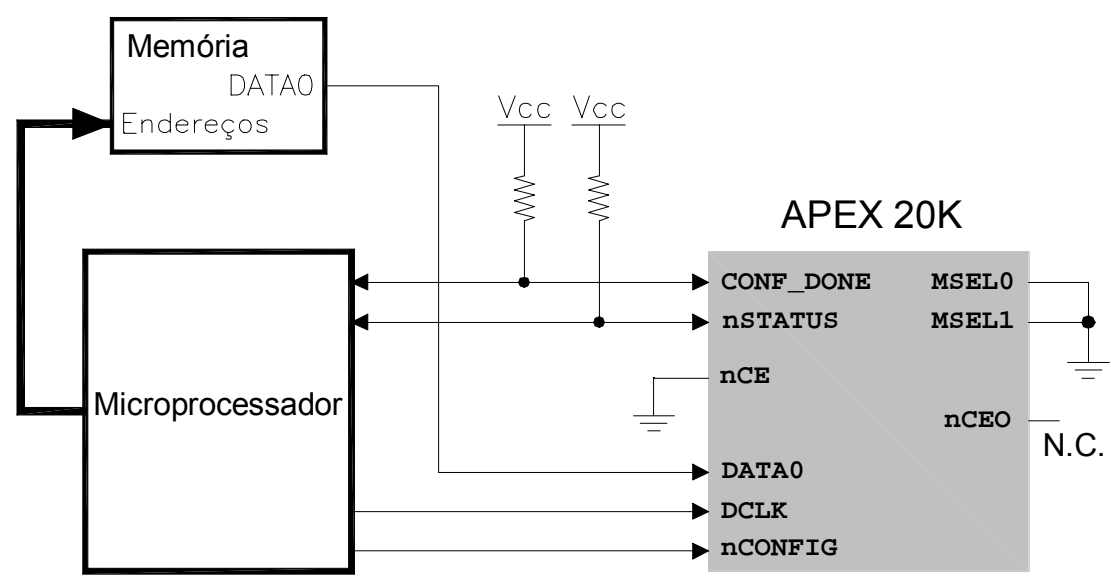

Figura 4.10 - Circuito de Configuração com Microprocessador.

Para a configuração de múltiplos dispositivos através deste esquema de configuração, o pino nCEO do primeiro dispositivo alvo deve ser conectado ao pino $\mathrm{nCE}$ do dispositivo subsequente. $\mathrm{O}$ segundo dispositivo na cadeia inicia sua configuração em um ciclo de clock. Entretanto, o destino dos dados de transferência é 
transparente ao microprocessador. A Figura 4.11 apresenta este esquema de configuração para múltiplos dispositivos.

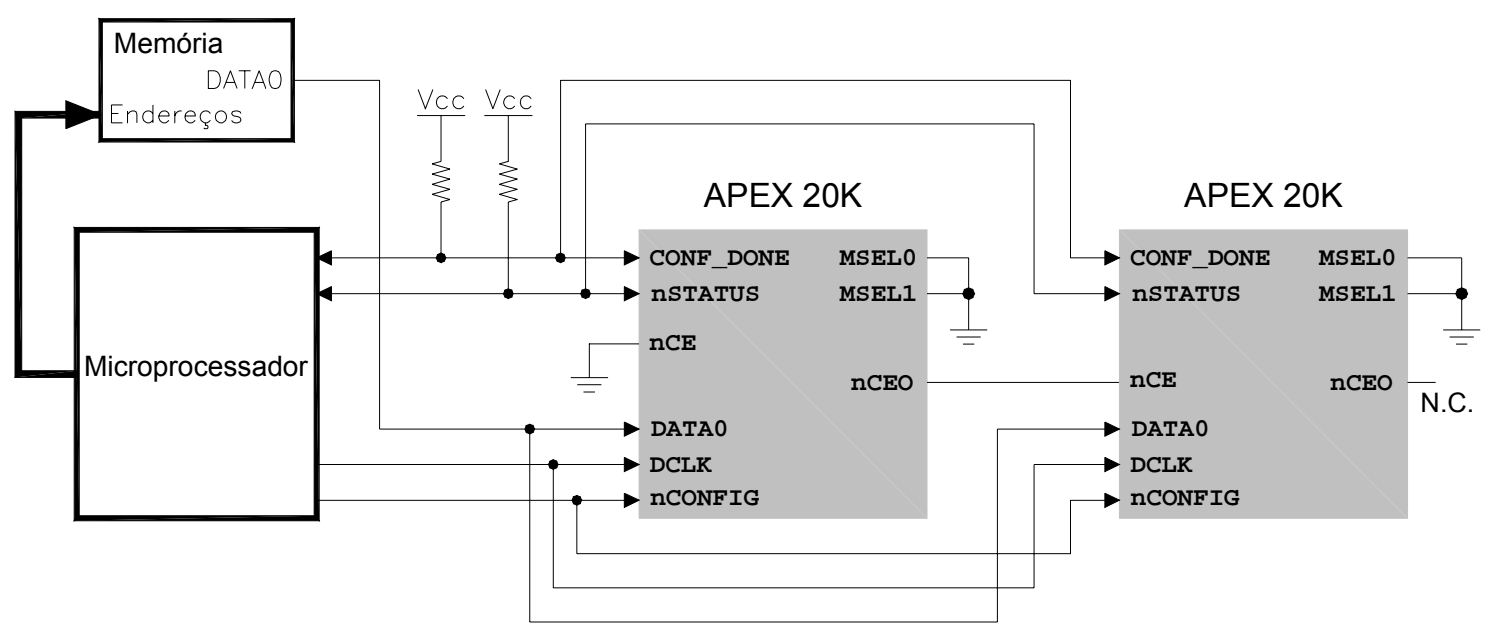

Figura 4.11 - Configuração de Múltiplos Dispositivos com um Microprocessador.

\subsubsection{Configuração Paralela Síncrona Passiva (PPS)}

No esquema de configuração PPS, um host inteligente comanda o dispositivo alvo. O host envia os dados para o dispositivo alvo de maneira paralela. O FPGA recebe estes dados nos pinos DATA [7..0], e depois os serializa internamente.

Para dar início à configuração, nCONF IG recebe uma transição baixo-alto e o host coloca palavras de configuração de 8 bits na entrada de dados do dispositivo alvo. O host comanda a temporização do FPGA; novos dados podem ser apresentados pelo host e aceitos pelo dispositivo alvo a cada ciclo de oito clocks. Um pino de status (RDYnBSY) no FPGA indica quando os dados estão sendo serializados e quando este está pronto para receber o novo byte de dados. Se algum erro ocorrer durante a configuração, nSTATUS é levado ao nível lógico baixo. O host detecta este sinal e inicia a reconfiguração ou envia um sinal de erro.

Se configurado com sucesso, o dispositivo alvo libera CONF_DONE que assume nível lógico alto através do resistor pull-up, indicando o término da configuração. A Figura 4.12 ilustra o esquema em questão. 


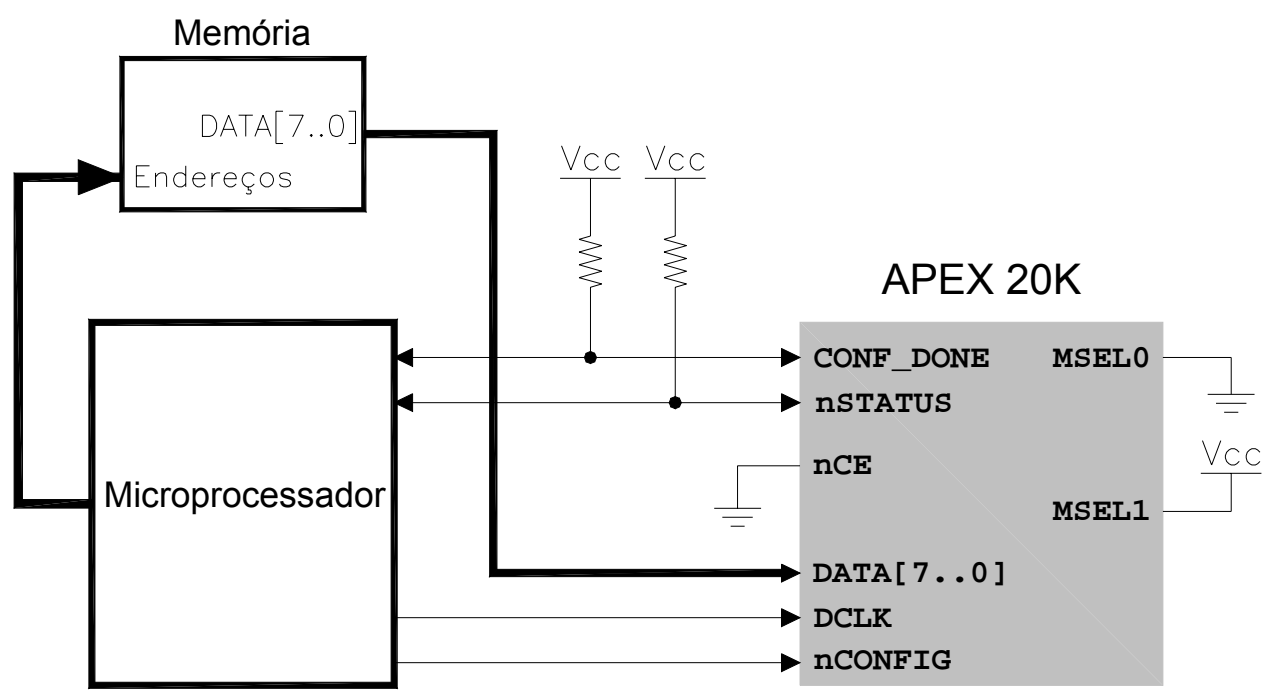

Figura 4.12 - Circuito para Configuração PPS.

Múltiplos dispositivos APEX 20K podem ser configurados utilizando-se do modo PPS. Uma vez configurado o primeiro dispositivo, torna-se baixo o nível lógico do pino $\mathrm{nCEO}$, levando consigo o nível do pino $\mathrm{nCE}$ do segundo dispositivo. Os pinos CONE_DONE são interligados, fazendo com que todos os dispositivos na cadeia inicializem e entrem no modo usuário ao mesmo tempo. A Figura 4.13 mostra este método de configuração.

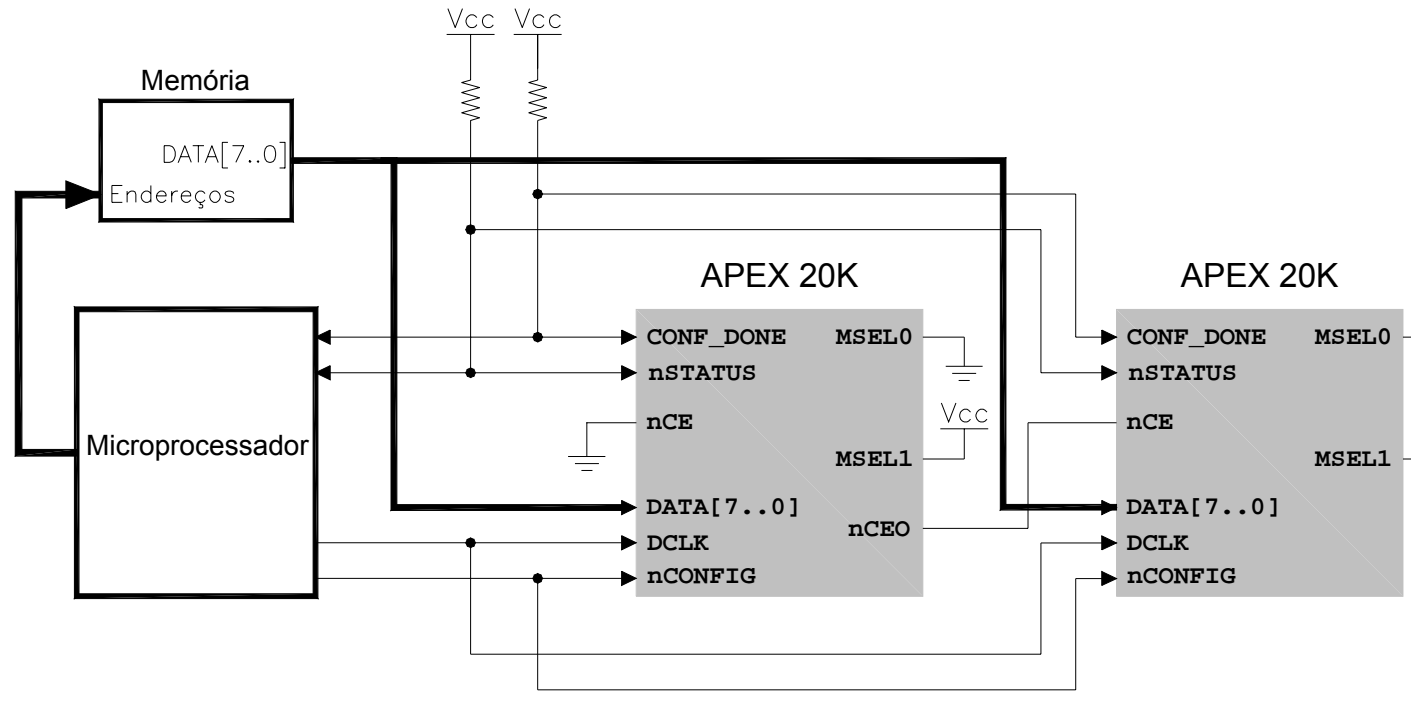

Figura 4.13 - Configuração PPS para Múltiplos Dispositivos. 


\subsubsection{Configuração Paralela Assíncrona Passiva (PPA)}

No esquema PPA, um microprocessador envia dados ao dispositivo APEX 20K via um cabo de download. Para começar a configuração, o microprocessador torna alto o nível de nCONFIG. Em seguida, uma palavra de configuração de 8-bits é colocada nas entradas de dados do dispositivo alvo e o pino nWS é levado ao nível lógico baixo pelo microprocessador. O FPGA então retém o byte de configuração levando para nível lógico baixo o pino RDYnBSY, indicando que está processando o byte recebido. $\mathrm{O}$ microprocessador pode então executar outras funções enquanto o dispositivo APEX $20 \mathrm{~K}$ processa o byte de configuração.

Em seguida, nSTATUS e CONF_DONE são checados. Se estes estiverem com nível lógico alto, o microprocessador envia o próximo byte. Se o nível de nSTATUS estiver baixo, um erro de configuração pode ter ocorrido e o FPGA deve ser reconfigurado. Quando CONF_DONE tiver nível alto, a configuração estará completa.

Um decodificador de endereços opcional pode controlar os pinos nCS e CS do dispositivo alvo. Este decodificador permite ao microprocessador selecionar o dispositivo alvo através do acesso de um endereço particular, simplificando o processo de configuração. A Figura 4.14 mostra o esquema de configuração PPA.

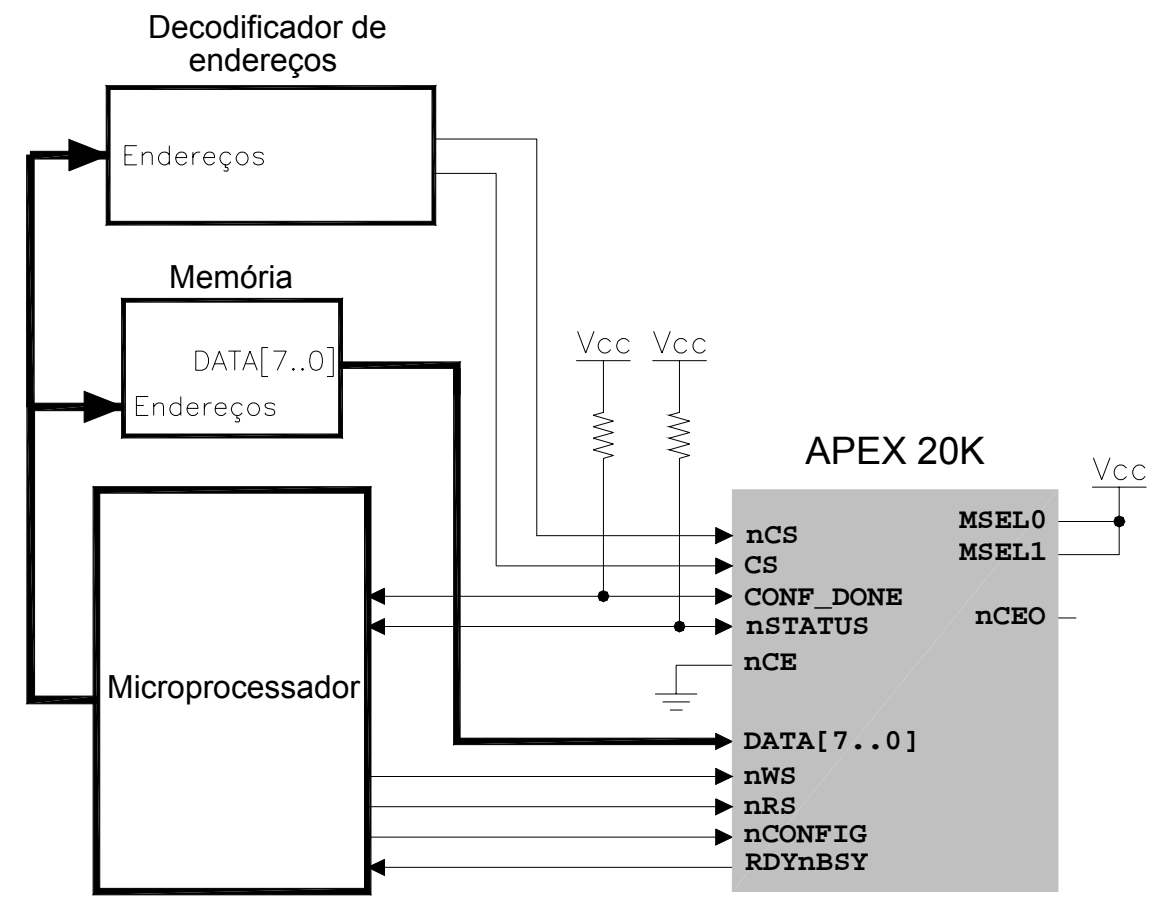

Figura 4.14 - Circuito para Configuração PPA. 
O dispositivo alvo leva para baixo o nível de nSTATUS se ocorrer algum erro durante a configuração, alertando assim o microprocessador. Este então pode tornar nCONF IG baixo, reiniciando o processo de configuração.

O modo de configuração PPA pode também ser usado para configuração de múltiplos dispositivos. O arranjo para este modo de configuração é similar ao usado indicado na Figura 4.14, exceto que os FPGAs são dispostos em cascata. Depois de configurado o primeiro dispositivo, este indica o evento através do pino $\mathrm{nCEO}$, ativando o pino $\mathrm{nCE}$ do segundo dispositivo, causando o início de sua configuração. O destino dos dados é transparente ao microprocessador. Os pinos CONF_DONE de todos os dispositivos são interconectados, por isto todos eles inicializam e entram no modo usuário ao mesmo tempo. A Figura 4.15 apresenta o esquema.

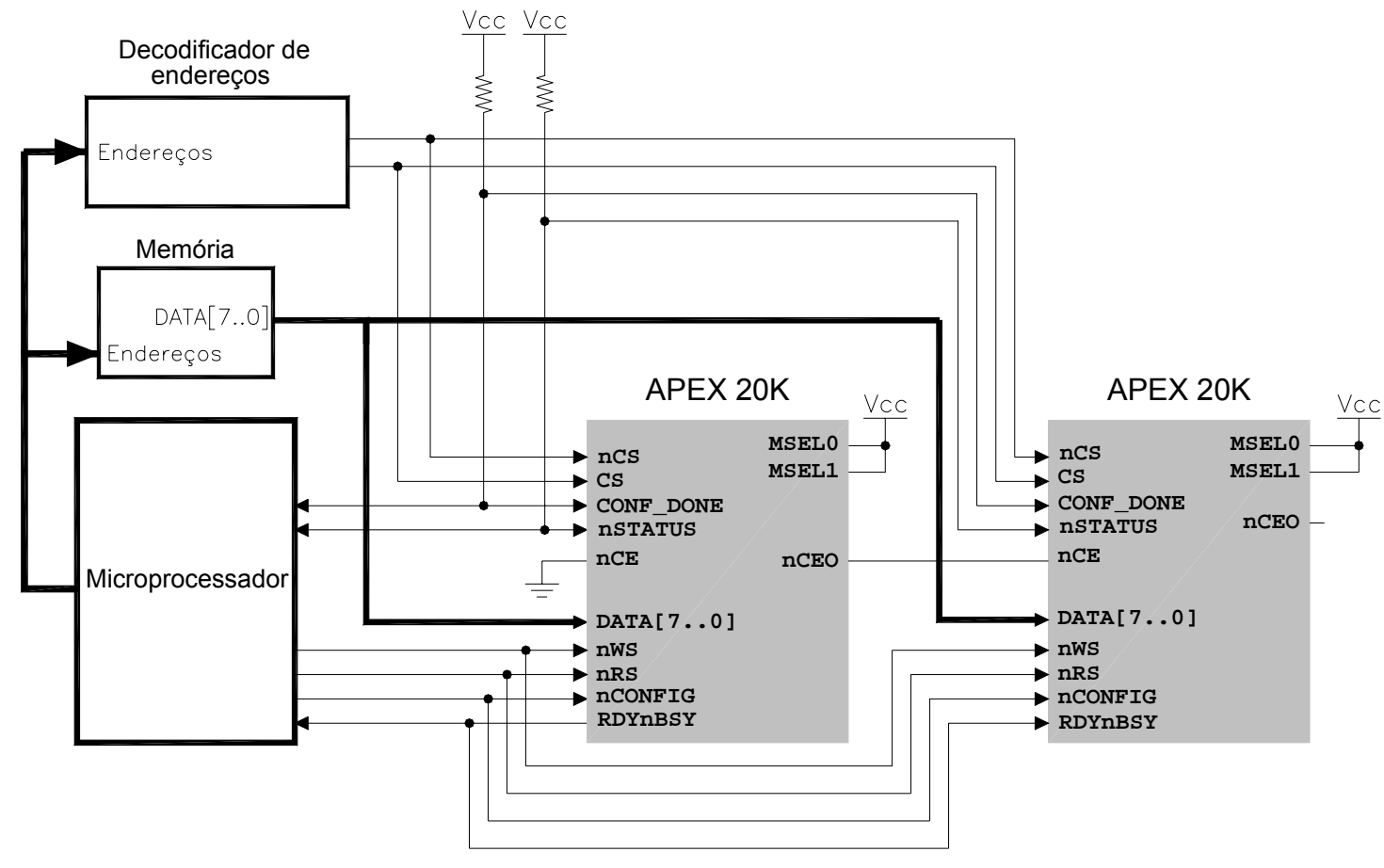

Figura 4.15 - Configuração PPA para Múltiplos Dispositivos. 


\subsubsection{Configuração e Programação JTAG}

O padrão IEEE 1149.1 - Test Access Port and Boundary-Scan, comumente chamado de JTAG (Joint Test Action Group), é um método popular de testes. Este padrão provê maneiras de se assegurar a integridade de componentes individuais e as interconexões entre estes ao nível de placa de circuito impresso. Com o aumento da densidade de componentes nestas placas, e métodos mais sofisticados de montagem, este método de testes tem se tornado largamente utilizado pelas companhias de engenharia eletrônica [22] [23].

O JTAG propôs uma arquitetura básica para testes (Boundary-scan test), a ser incorporada a nível de CI's. Dispositivos contendo esta arquitetura podem enviar dados através de seus pinos de $\mathrm{I} / \mathrm{O}$, de forma a testar suas conexões. $\mathrm{O}$ padrão JTAG pode também ser usado para testar o funcionamento de dispositivos específicos contidos em uma placa. A arquitetura Boundary-scan permite que dispositivos com ela equipados possuam um conjunto de instruções que serão utilizadas na configuração e verificação da sua funcionalidade.

Um esquema da lógica de testes definida pelo padrão IEEE Std 1149.1 pode ser visualizado na Figura 4.16.

Este esquema pode ser dividido em quatro blocos principais:

- $\quad$ Controlador TAP.

Gera sinais de clock e controle, necessários para os outros blocos.

- $\quad$ Registrador de Instruções.

É um registrador de deslocamento, carregado serialmente com as instruções a serem executadas.

- $\quad$ Registradores de Dados.

Estímulos e resultados de operações são serialmente carregados nestes registradores.

- $\quad$ Porta de Acesso aos Testes JTAG (TAP).

Através de seus pinos TMS (Modo de Seleção de teste), TCK (Clock do Teste), TDI (Entrada de Dados de Teste) e TDO (Saída de Dados de 
Teste), o TAP controla os outros blocos do sistema e funciona como porta de entrada e saída para instruções e dados.

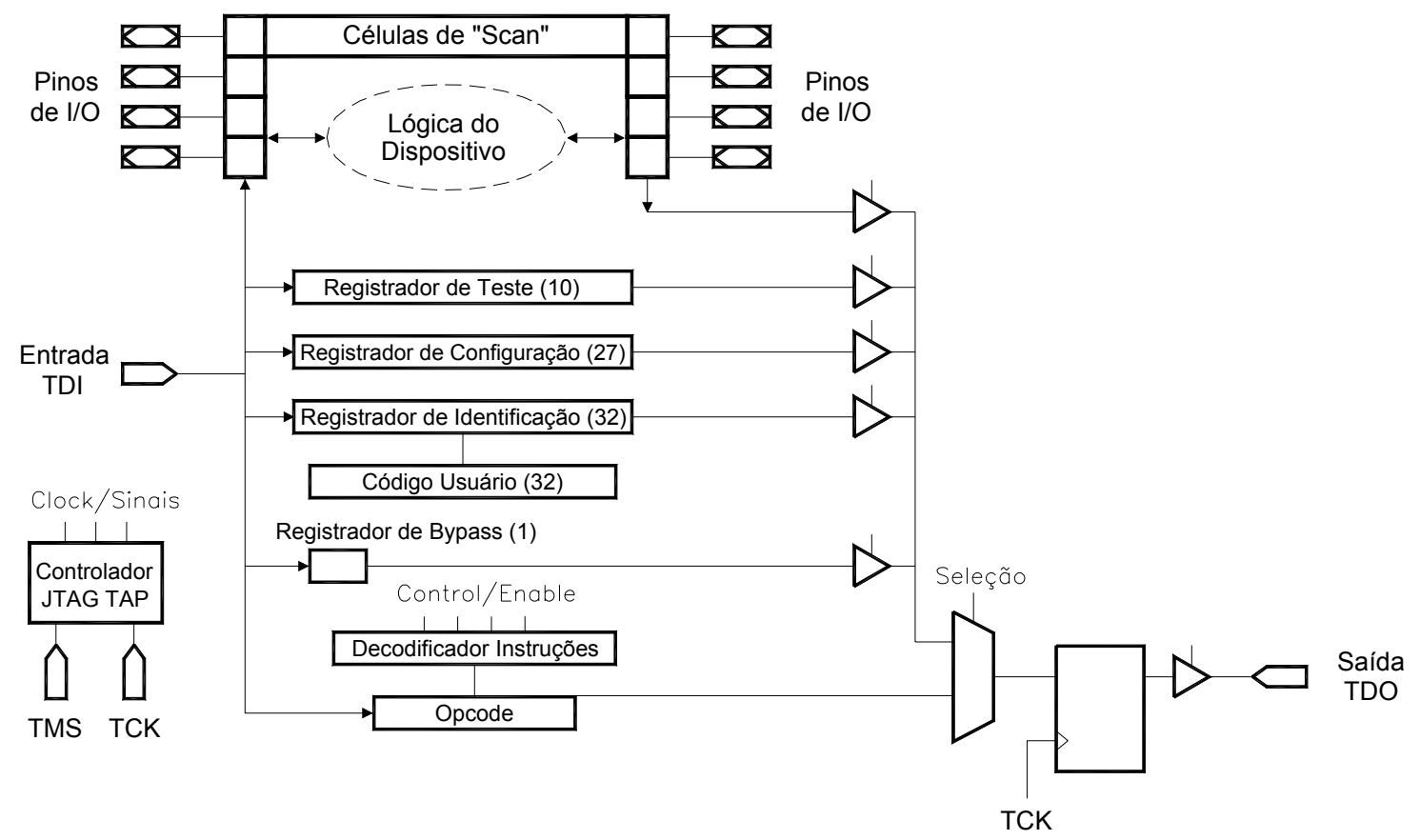

Figura 4.16 - Arquitetura JTAG.

Para configurar um dispositivo no modo JTAG, o software de programação, através do pino TMS, coloca todos os dispositivos no modo BYPASS. Neste modo de operação, os dispositivos passam os dados de programação do pino TDI para o pino TDO através de um registrador de bypass, sem serem afetados internamente. Este esquema habilita o software de programação a programar ou verificar o dispositivo alvo. Os dados de configuração levados para o dispositivo aparecem no pino TDO um ciclo de clock mais tarde. A Figura 4.17 ilustra este modo de programação.

Durante a configuração JTAG, os dados são enviados ao dispositivo através de cabos MasterBlaster, ByteBlasterMV ou BitBlaster. 


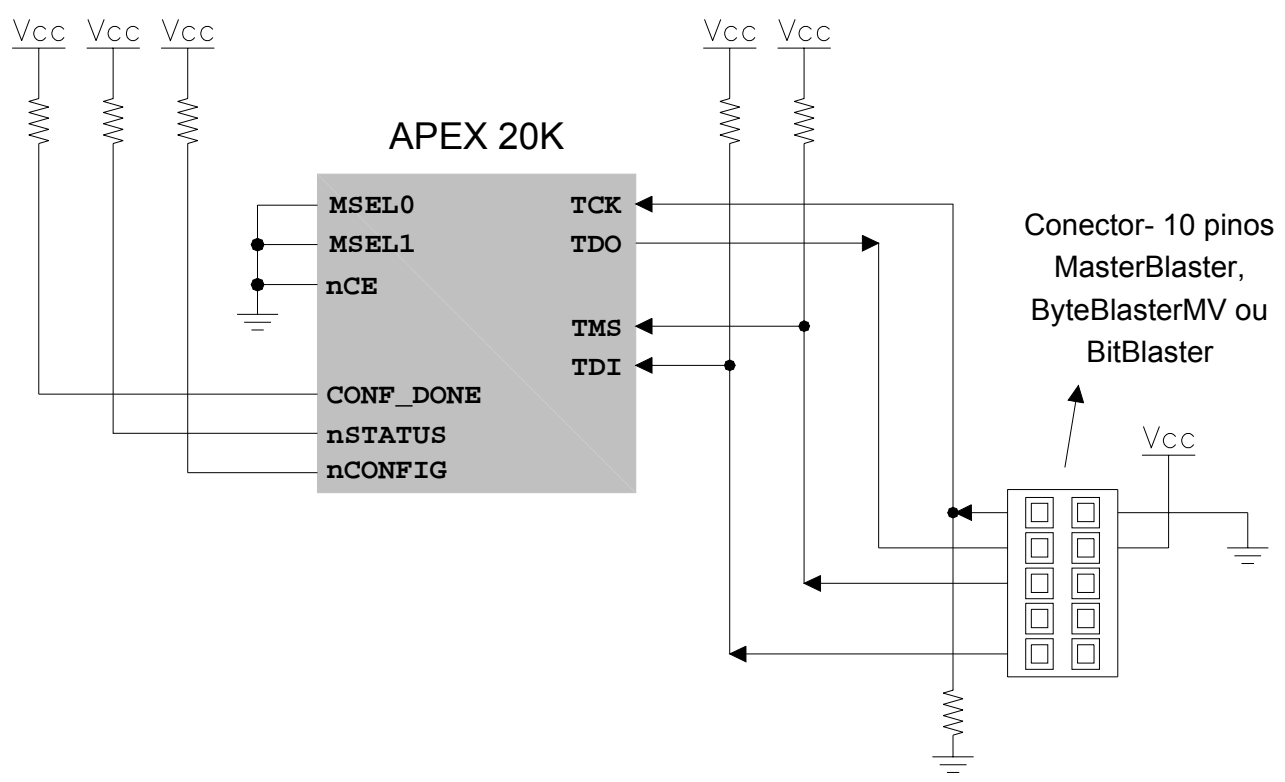

Figura 4.17 - Circuito para Configuração JTAG.

\subsubsection{Configuração e Programação JTAG para Múltiplos Dispositivos}

Para a programação de múltiplos dispositivos através de configuração e programação JTAG, um conector JTAG compatível é usado para a ligação entre os vários dispositivos alvo. O número de componentes numa cadeia JTAG é limitado apenas pela capacidade do cabo de download. No entanto, a Altera recomenda que se mais de cinco dispositivos forem conectados, os sinais para os pinos TCK, TDI, e TMS devem passar por buffers. A Figura 4.18 apresenta a configuração JTAG para múltiplos dispositivos.

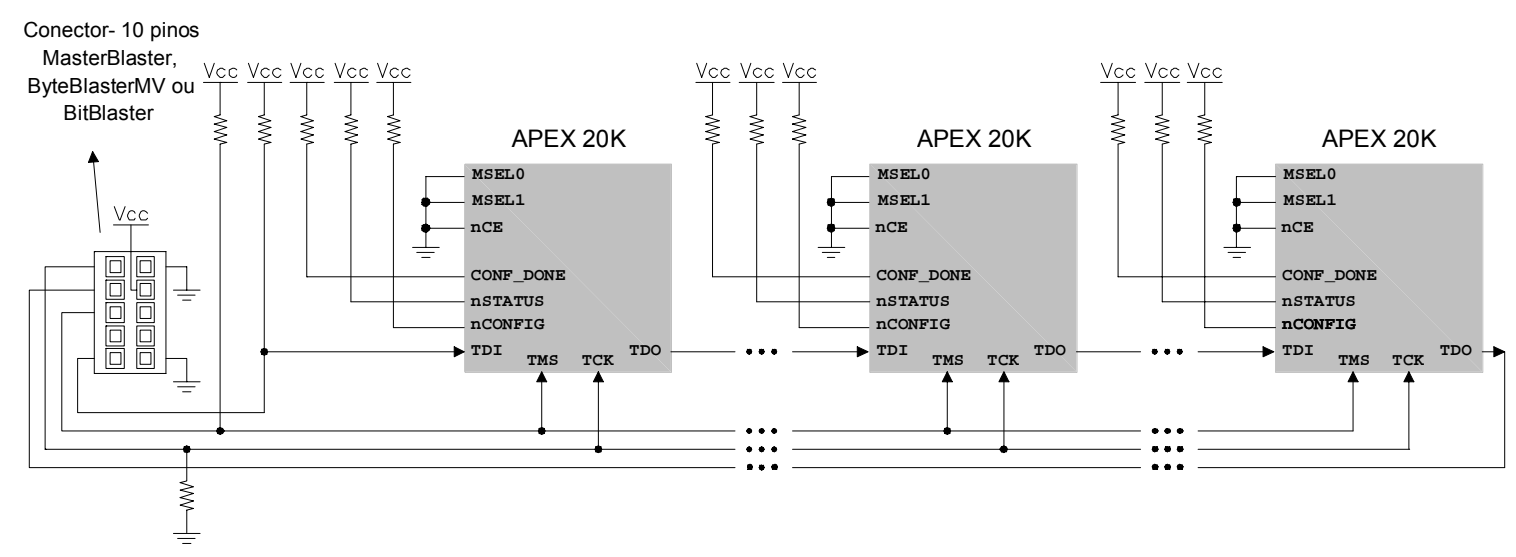

Figura 4.18 - Configuração JTAG para Múltiplos Dispositivos. 
O estado do pino CONF_DONE é testado pelo software de programação de forma a se determinar o sucesso do processo de configuração.

Configurações JTAG e não-JTAG não devem ser aplicadas simultaneamente. A Figura 4.19 ilustra a configuração JTAG de um APEX 20K com um microprocessador.

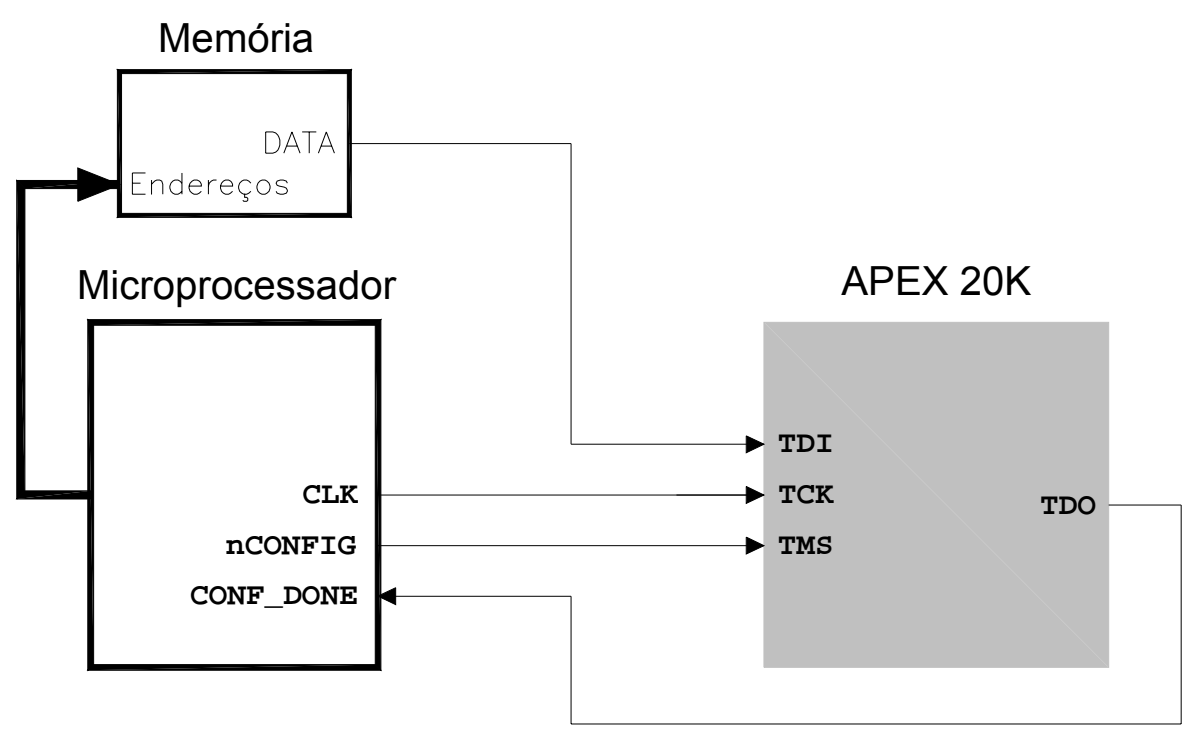

Figura 4.19 - Configuração JTAG com um Microprocessador. 


\section{Capítulo 5}

\section{Dispositivos de Configuração}

\subsection{Descrição Funcional}

Nos FPGAs baseados na tecnologia de programação SRAM, os dados de configuração devem ser recarregados toda vez que o dispositivo for inicializado ou quando novos dados de configuração forem necessários. Os dispositivos de configuração constituem-se na maneira mais fácil de se configurar os PLDs baseados nesta tecnologia. A tabela 5.1 apresenta características de alguns dispositivos de configuração da Altera.

Tabela 5.1 - Características dos Dispositivos de Configuração da Altera.

\begin{tabular}{|l|l|}
\hline \multicolumn{1}{|c|}{ Característica } & \multicolumn{1}{|c|}{ Be nefíc io } \\
\hline Alta Densidade & $\begin{array}{l}\text { Oferece a melhor solução para configuração de dispositivos baseados } \\
\text { na tecnologia de programação SRAM. }\end{array}$ \\
\hline $\begin{array}{l}\text { Programabilidade } \\
\text { In-System (ISP) }\end{array}$ & $\begin{array}{l}\text { Os dispositivos EPC2 e EPC16 podem ser programados in-system } \\
\text { através do JTAG. }\end{array}$ \\
\hline $\begin{array}{l}\text { Tempo de } \\
\text { Configuração }\end{array}$ & Capacidade de transmissão de 320 megabits por segundo (Mbps). \\
\hline $\begin{array}{l}\text { Programação } \\
\text { Paralela }\end{array}$ & $\begin{array}{l}\text { Programação serial de oito dispositivos alvo ou paralela (8 bits de } \\
\text { largura), aumentando a velocidade de programação de um único PLD. }\end{array}$ \\
\hline Compressão & $\begin{array}{l}\text { Podem armazenar 30 Mbits de dados em 16 Mbits de memória usando } \\
\text { compressão. }\end{array}$ \\
\hline
\end{tabular}

A tabela 5.2 relaciona os dispositivos de configuração disponíveis para utilização com os FPGAs APEX 20K. 
Tabela 5.2 - Dispositivos de Configuração Disponíveis para a Família APEX 20k

\begin{tabular}{|c|l|}
\hline $\begin{array}{c}\text { Dispositivo de } \\
\text { Configuração }\end{array}$ & \multicolumn{1}{c|}{ Descrição } \\
\hline EPC16 & $\begin{array}{l}\text { Capacidade de armazenamento de 16.777.216 bits. } \\
\text { Tensão de operação: 3,3 V. }\end{array}$ \\
\hline EPC2 & $\begin{array}{l}\text { Capacidade de armazenamento de 1.695.680 bits. } \\
\text { Tensão de operação: 3,3 V. }\end{array}$ \\
\hline EPC1 & $\begin{array}{l}\text { Capacidade de armazenamento de 1.046.496 bits. } \\
\text { Tensão de operação: 3,3 V. }\end{array}$ \\
\hline
\end{tabular}

O tamanho aproximado dos arquivos necessários para a configuração dos dispositivos APEX 20K é sumarizado na Tabela 5.3. Na configuração de múltiplos dispositivos, o espaço necessário para o armazenamento dos dados pode ser calculado simplesmente somando-se o tamanho do arquivo exigido para cada PLD associado.

Tabela 5.3 - Tamanho dos Arquivos de Configuração dos Dispositivos APEX 20K.

\begin{tabular}{|l|c|c|}
\hline Dispositiv & $\begin{array}{c}\text { Tamanho } \\
\text { (Bits) }\end{array}$ & $\begin{array}{c}\text { Tamanho } \\
\text { (KBytes) }\end{array}$ \\
\hline EP20K1500E & 12.011 .000 & 1.467 \\
\hline EP20K1000E & 8.938 .000 & 1.092 \\
\hline EP20K600E & 5.654 .000 & 691 \\
\hline EP20K400 & 3.878 .000 & 474 \\
\hline EP20K400E & 3.901 .000 & 477 \\
\hline EP20K300E & 2.733 .000 & 334 \\
\hline EP20K200 & $1.950,000$ & 239 \\
\hline EP20K200E & 1.964 .000 & 240 \\
\hline EP20K160E & 1.523 .000 & 186 \\
\hline EP20K100 & 985.000 & 121 \\
\hline EP20K100E & 1.009 .000 & 124 \\
\hline EP20K60E & 641.000 & 79 \\
\hline EP20K30E & 347.000 & 42 \\
\hline
\end{tabular}

Com o uso das Tabelas 5.2 e 5.3, é possível determinar-se o número de dispositivos de configuração necessários para a configuração de um único PLD ou para uma associação destes.

A seguir, serão descritas as características dos três dispositivos utilizados na configuração dos FPGAs APEX 20K. 


\subsection{Dispositivos de Configuração EPC1 e EPC2}

Os PLDs APEX 20K podem ser configurados através dos dispositivos de configuração EPC1 e EPC2, sem a necessidade de um controlador externo. Os sinais de controle $\mathrm{nCS}, \mathrm{OE}$, e DCLK, interagem diretamente com os sinais de controle do dispositivo alvo.

A Figura 5.1 apresenta o diagrama de blocos dos dispositivos de configuração EPC1 e EPC2. Os pinos OE e nCS controlam o buffer do pino de saída DATA. Quando OE é levado ao nível lógico baixo, o dispositivo de configuração reinicializa o contador de endereços (address counter) e desabilita o pino DATA. A saída do dispositivo é controlada pelo pino nCS. Se este permanecer no nível lógico alto depois que OE recebe um pulso de reset, o contador é desabilitado e o pino de saída DATA fica no estado de alta impedância. Quando nCS recebe nível baixo, o contador e o pino DATA são habilitados. Se OE for levado ao nível baixo novamente, o contador de endereços é reinicializado e o pino de saída DATA é desabilitado, independente do estado de nCS.

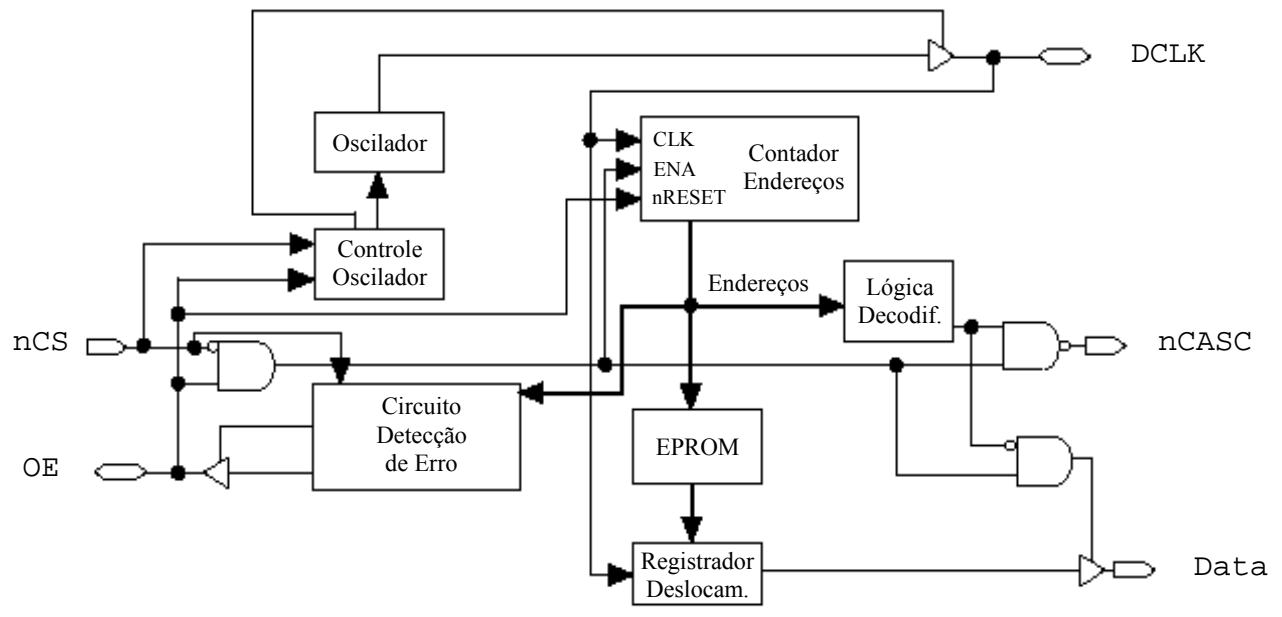

Figura 5.1 - Diagrama de Blocos dos Dispositivos de Configuração EPC1 e EPC2.

O dispositivo EPC2 permite ao usuário iniciar a configuração do FPGA através de um pino adicional, o nINIT_CONF, que deve ser conectado ao pino nCONFIG do dispositivo a ser configurado. Uma instrução JTAG faz com que o dispositivo EPC2 torne baixo o nível lógico de nINIT_CONF, levando consigo o nível do pino 
nCONFIG. Para iniciar a configuração, o EPC2 então leva o nível de nINIT_CONF para alto.

Os dispositivos EPC1 e EPC2 armazenam os dados de configuração numa EPROM interna. Estes dados são enviados para o dispositivo alvo de maneira serial, com o auxílio de um oscilador interno. A Figura 5.2 mostra um APEX 20K sendo configurado por um dispositivo EPC1 ou EPC2.

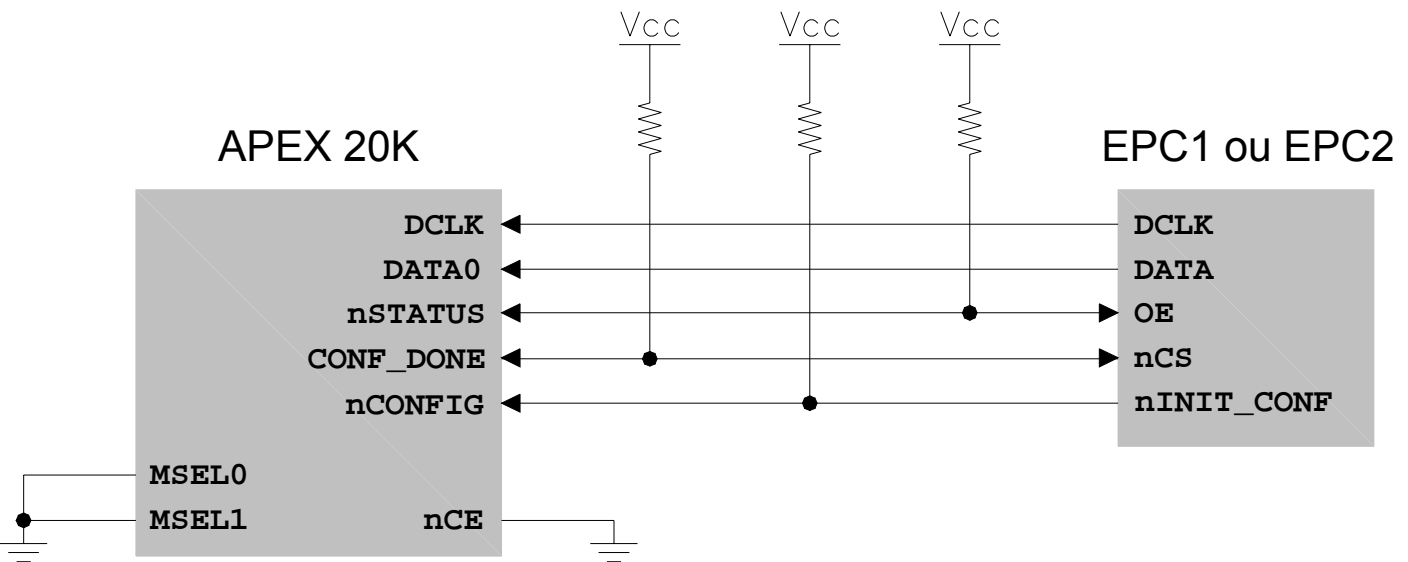

Figura 5.2 - FPGA APEX 20K Configurado com EPC1 ou EPC2.

\subsection{Dispositivos de Configuração EPC16}

O EPC16 é o mais eficiente dispositivo de configuração disponível para a família de PLDs APEX 20K. Internamente, ele pode ser dividido em dois blocos principais, a memória Flash e um controlador. A memória Flash é utilizada para a configuração de PLDs, mas posições de memória não utilizadas podem servir como espaço de armazenamento para os próprios PLDs ou processadores. A Figura 5.3 ilustra o diagrama de blocos do dispositivo de configuração EPC16, sua conexão com o PLD, e sua ligação com a interface JTAG/ISP. 


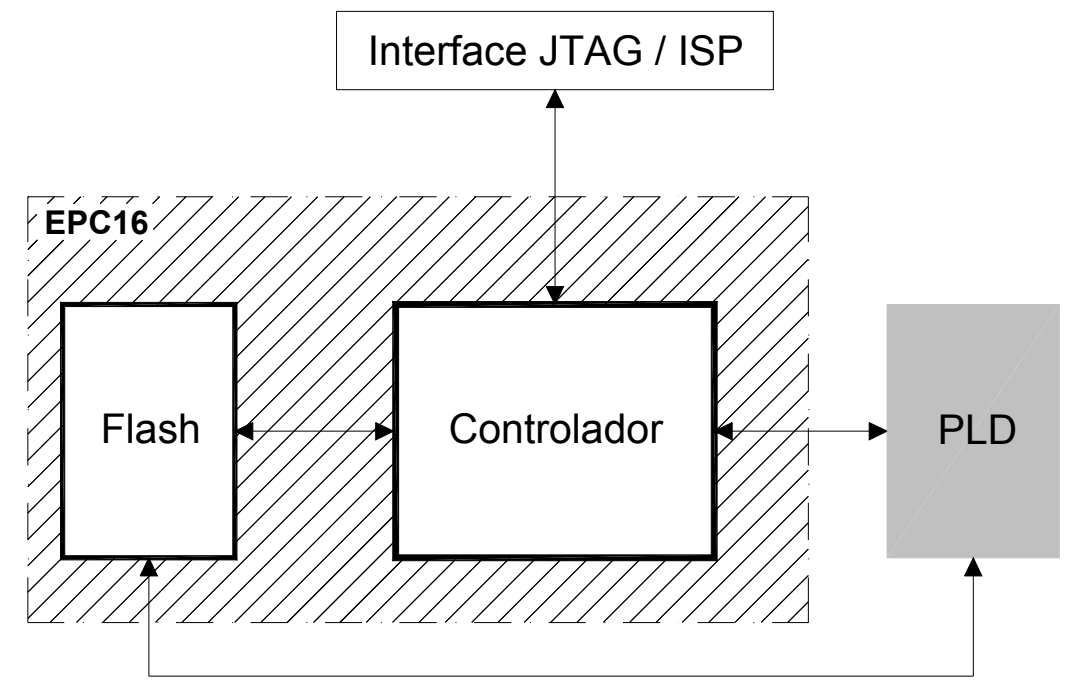

Figura 5.3 - Diagrama de Blocos do Dispositivo de Configuração EPC16.

\subsubsection{A Unidade de Controle do EPC16}

A unidade de controle do dispositivo de configuração EPC16 é um sistema síncrono que consiste das seguintes unidades:

- Unidade POR (power-on-reset);

- Oscilador interno (IOSC);

- $\quad$ Unidade de divisão de clock (CDU);

- Dispositivo de descompressão;

- Unidade de configuração do PLD (PCU);

- Unidade de interface JTAG (JIU).

A Figura 5.4 apresenta o diagrama de blocos da unidade de controle do dispositivo EPC16. 


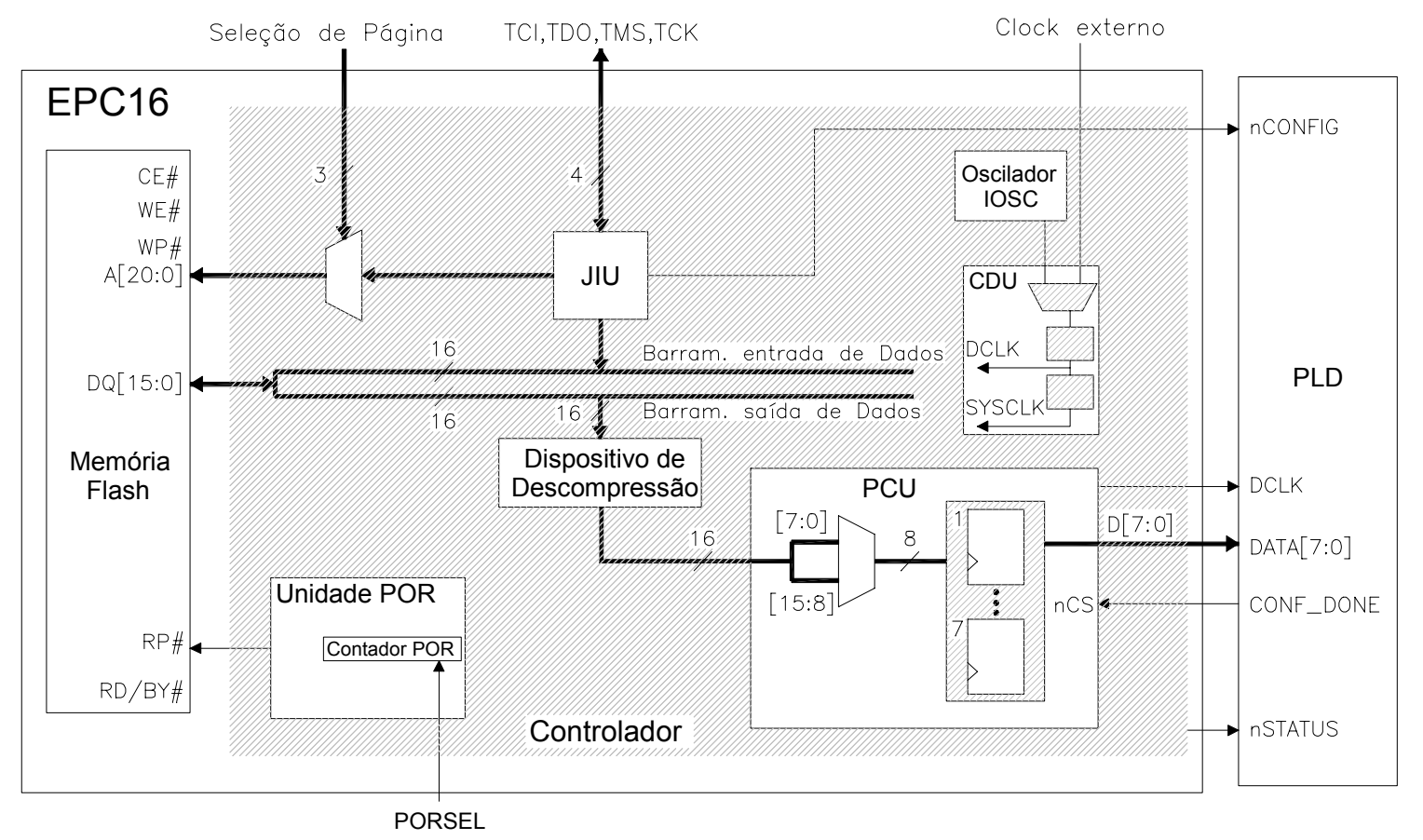

Figura 5.4 - Diagrama de Blocos da Unidade de Controle do Dispositivo EPC16.

\subsubsection{A Unidade Power-On Reset (POR)}

A unidade POR mantém o sistema em reset até que a fonte de tensão tenha se estabilizado. O dispositivo de configuração EPC16 permite ao usuário escolher, entre duas opções, o tempo em que o sistema permanecerá neste estado. Originalmente, o tempo de POR é de 100 ms, mas para aplicações que requerem uma rápida inicialização, este pode ser reduzido para $2 \mathrm{~ms}$. O pino PORSEL controla esta redução de tempo. Quando o tempo de POR expira, o pino OE é liberado e o EPC16 torna-se habilitado para o envio de dados ao dispositivo alvo. 


\subsubsection{Oscilador Interno (IOSC)}

O oscilador interno (IOSC) do dispositivo EPC16 permite o uso de quatro modos de freqüência interna de clock (ver Tabela 5.4). $\mathrm{O}$ usuário pode programar o oscilador através de software.

Tabela 5.4 - Freqüências do Oscilador Interno.

\begin{tabular}{|c|c|c|c|}
\hline Modo & $\begin{array}{c}\text { Mínimo } \\
(\mathbf{M ~ H z})\end{array}$ & $\begin{array}{c}\text { Típico } \\
(\mathbf{M ~ H z})\end{array}$ & $\begin{array}{c}\text { Máximo } \\
(\mathbf{M ~ H z})\end{array}$ \\
\hline A & 8 & 10,0 & 12,0 \\
\hline B & 29 & 40,0 & 50,0 \\
\hline C & 38 & 54,0 & 66,7 \\
\hline D & 48 & 66,7 & 88,0 \\
\hline
\end{tabular}

\subsubsection{Unidade de Divisão do Clock (CDU)}

A CDU gera os sinais de clock SYSCLK e DCLK para o controlador, através da divisão da freqüência de clock do oscilador interno (INTOSC) ou do clock externo (EXCLK). A arquitetura de divisão de clock da CDU tem duas partes (ver Figura 5.5). A primeira $(\mathrm{N})$ divide a freqüência de clock selecionada para gerar DCLK. O segundo divisor (M) divide DCLK gerando SYSCLK. Os divisores $\mathrm{M}$ e $\mathrm{N}$ podem dividir suas freqüências de entrada por um número inteiro, variando de 1 a 16.

A freqüência DCLK é limitada apenas pela freqüência DCLK do PLD, mas a freqüência de SYSCLK é limitada pelo máximo desempenho da memória Flash do EPC16. Desta forma, DCLK e SYSCLK podem assumir valores diferentes de freqüência. 


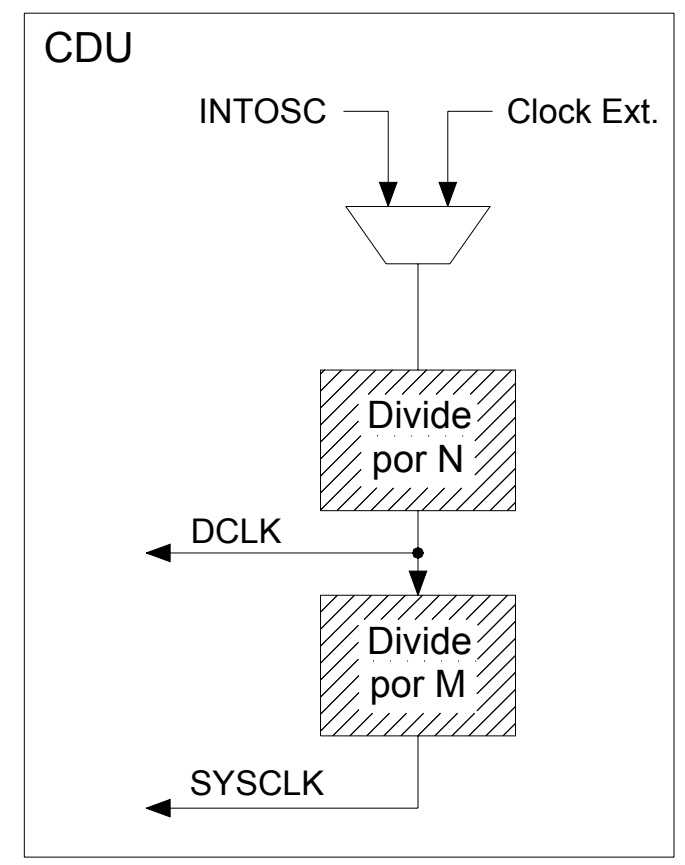

Figura 5.5 - A Unidade de Divisão de Clock.

\subsubsection{Dispositivo de Descompressão}

O dispositivo de configuração EPC16 possibilita descompressão. Os dados de configuração são comprimidos pelo software Quartus ${ }^{\mathrm{TM}}$ II e então, armazenados no EPC16. Durante a configuração, o dispositivo de descompressão do EPC16 comprime os dados, elevando a capacidade de armazenamento para 30 Mbits.

O tempo de configuração do PLD pode ser reduzido utilizando-se do barramento paralelo de dados suportado pelo dispositivo EPC16. Em alguns casos, a taxa de transferência de dados para o PLD é limitada pela velocidade da memória Flash. No modo de programação paralela do PLD, quando $\mathrm{N}=8$ e a freqüência DCLK é $66 \mathrm{MHz}$, a taxa de transferência de dados para o PLD é maior que a taxa de transferência entre a memória Flash e a unidade de configuração do PLD (PCU). Como o tempo de configuração depende da velocidade de leitura na memória e da largura de banda dos dados enviados ao dispositivo alvo, a compressão acelera o tempo de configuração. $\mathrm{O}$ dispositivo de descompressão descomprime os dados de configuração comprimidos, antes de enviá-los à PCU para configuração do PLD. 


\subsubsection{Unidade de Configuração do PLD (PCU)}

A função da PCU é transmitir dados descomprimidos para o PLD, dependendo do modo de programação. O dispositivo de configuração EPC16 admite quatro modos de configuração paralela, com $\mathrm{N}=1,2,4$, e 8 . Dependendo da largura dos dados, a PCU desloca os dados de forma a transmitir dados apropriados aos pinos do dispositivo alvo.

A PCU também gerencia a lógica de detecção de erro através de CONF_DONE. Um erro CONF_DONE ocorre quando nCS não assume nível lógico alto ao final de uma transmissão de dados para o PLD. Quando isto ocorre, a PCU envia um sinal à unidade POR, que por sua vez ajusta o nível lógico do pino $\mathrm{OE}$, habilitando a reconfiguração do PLD.

\subsubsection{Unidade de Interface JTAG (JIU)}

O padrão JTAG IEEE 1149.1 é implementado no dispositivo de configuração EPC16 para facilitar os testes de interconexões e de funcionalidade. O EPC16 também suporta o modo ISP. Além de programar, apagar e verificar sua memória Flash, o dispositivo EPC16 também admite a proteção de blocos e setores através de instruções complacentes ao padrão IEEE 1532.

A JIU comunica-se diretamente com a memória Flash (ver Figura 5.6). Antes da interface JTAG / ISP programar a memória Flash, uma instrução JTAG (PENDCFG) ajusta o nível do pino nCONFIG do PLD, encerrando qualquer acesso à Flash. Quando se inicia o modo ISP, a interface JTAG / ISP assume o barramento. Se ISP for iniciado durante a configuração do PLD, o ciclo é interrompido imediatamente. 


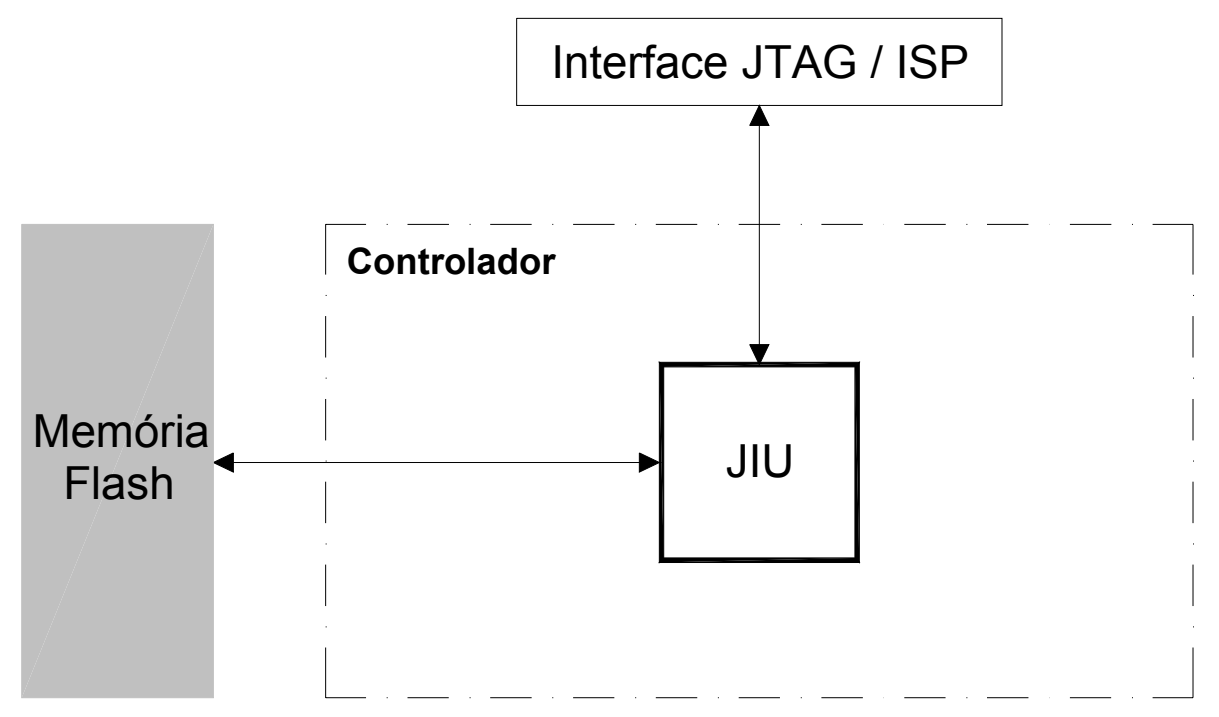

Figura 5.6 - Interface JTAG / ISP.

\subsubsection{Memória Flash}

A memória Flash é dividida em três blocos principais: bloco de boot, bloco de parâmetro, e bloco principal. Cada um destes blocos possui capacidade de proteção e podem ser apagados individualmente. O dispositivo EPC16 possibilita, através da interface JTAG, que lock bits sejam programados e apagados. Os lock bits protegem a Flash contra operações inadvertidas; um bloco pode ou não ser apagado, dependendo do estado de seu lock bit.

O bloco de boot permite a gravação de uma PROM de boot dedicada a um microprocessador (como encontrado no processador Excalibur ${ }^{\mathrm{TM}}$ ). $\mathrm{O}$ bloco de boot pode ainda, ser usado para outros sistemas de dados. Modificações neste bloco são controladas através de uma combinação entre os pinos RP\# e WP\# e o bloco lock bit.

O bloco de parâmetro é usado no armazenamento de dados e pequenos parâmetros freqüentemente regravados. Existem seis blocos de parâmetro de 4.000 palavras, armazenados em um bloco de memória Flash de 16 Mbit. A proteção do bloco de parâmetro é controlada por uma combinação entre o pino RP\# e o bloco lock bit.

O bloco principal preenche o restante da memória Flash. Em um bloco de 16 Mbits de memória, existem 31 blocos de 32.000 palavras. Da mesma forma que no 
bloco de parâmetro, a proteção do bloco principal é controlada com a combinação de RP\# e o bloco look bit. 


\section{Capítulo 6}

\section{O Kit de Desenvolvimento Excalibur}

\subsection{Introdução}

O kit de desenvolvimento Excalibur ${ }^{\mathrm{TM}}$ contém todas as ferramentas que os projetistas de hardware precisam para criar sistemas de alta performance em dispositivos lógicos programáveis. O kit provê o soft-core de um processador otimizado que pode ser imediatamente implementado, diminuindo o tempo de desenvolvimento de sistemas de hardware [26].

A ferramenta de desenvolvimento Excalibur contém os seguintes itens:

- Processador Nios RISC configurável;

- Compilador GNUPro® da Cygnus®, uma companhia Red Hat®;

- O Software de desenvolvimento Quartus ${ }^{\mathrm{TM}}$;

- $\quad$ Cabo ByteBlaster ${ }^{\mathrm{TM}}$;

- Placa de desenvolvimento equipada com o FPGA APEX ${ }^{\mathrm{TM}}$ EP20K200E.

\subsection{O Processador Nios}

O processador embutido Nios é um soft-core de um processador RISC configurável, desenvolvido especialmente para a arquitetura dos PLDs. Otimizado para uma área reduzida do PLD, este processador provê um desempenho de até 50MIPS. Inicialmente projetado para a família APEX, o Nios ocupa apenas $12 \%$ da área de um FPGA EP20K200E, permitindo ao projetista utilizar, de maneira conveniente, o restante da área disponível. O diagrama de blocos do processador Nios (configurado para 32 bits) é apresentado na Figura 6.1. 


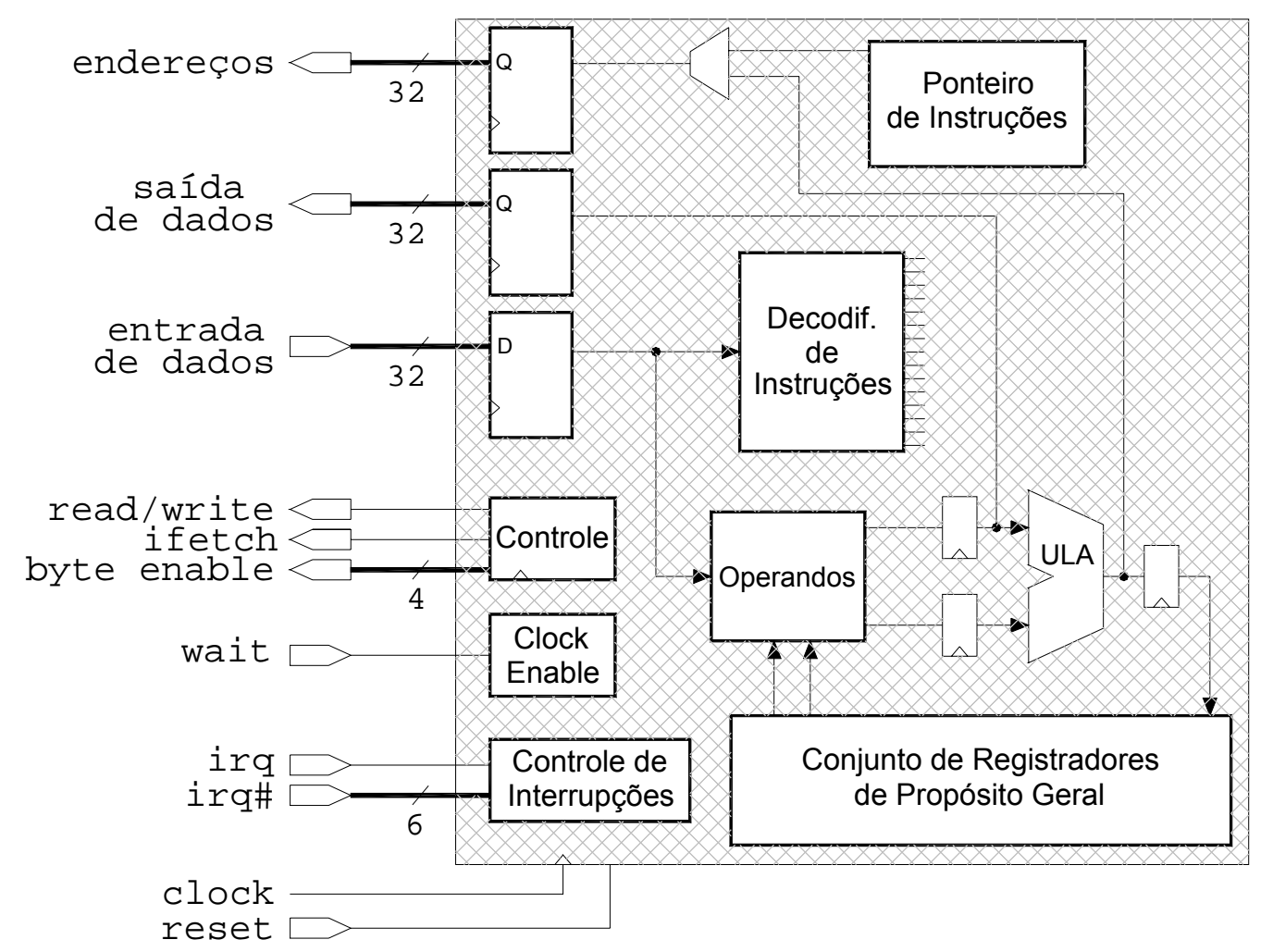

Figura 6.1 - Diagrama de Blocos do Processador Embutido Nios.

Características do processador embutido Nios:

- Conjunto de instruções de 16 bits;

- Barramento de dados de 16 ou 32 bits;

- Uma instrução por ciclo de clock;

- Suporte para memória on-chip ou of-chip;

- Desempenho de mais de 50 milhões de instruções por segundo (MIPS);

- Registrador para rápido manuseio de interrupções;

- Conjunto de 512 registradores de 32 bits;

- Registradores de acesso a periféricos.

Uma interface MegaWizard presente no ambiente de desenvolvimento Quartus, permite ao usuário especificar as conexões entre o processador Nios e o restante do sistema. Através desta interface, o usuário pode gerar um conjunto de periféricos e inseri-los ao soft-core final. 
Vários periféricos são disponíveis para utilização com o Nios. Dentre eles, pode-se citar:

- Receptor / transmissor assíncrono (UART);

- $\quad$ Entrada / saída paralela (PIO);

- Temporizador;

- Controlador de disco IDE;

- Interface para memórias SRAM e FLASH;

O esquema utilizado na comunicação entre o processador embutido Nios e os periféricos definidos pelo usuário é apresentado na figura 6.2.

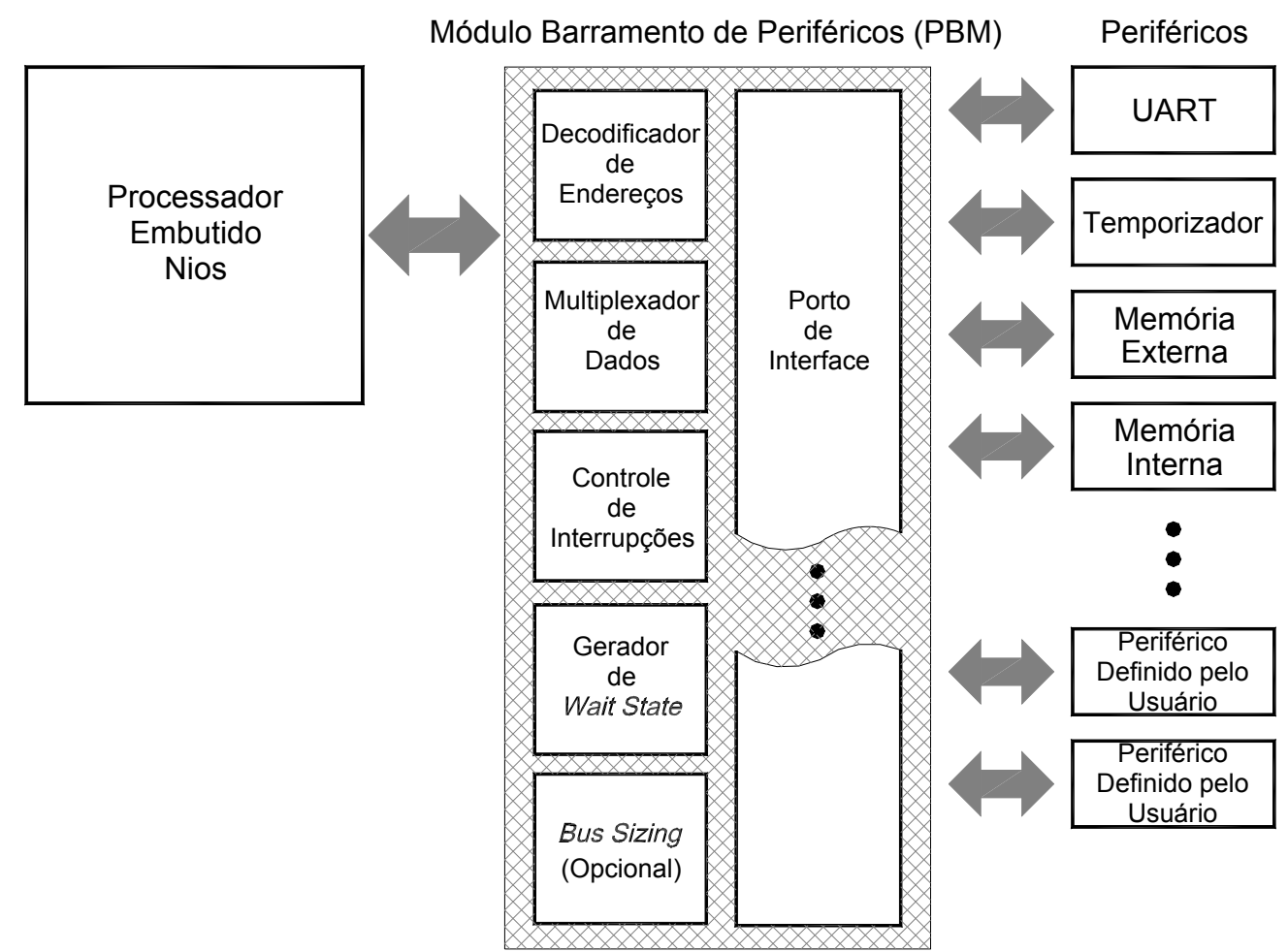

Figura 6.2 - Comunicação entre o Processador Nios e seus Periféricos.

A interface MegaWizard cria o Módulo de Barramento de Periféricos (PBM) de acordo com a configuração especificada. Características como endereço base, número de portos, largura de barramento de dados, wait-states e prioridade de IRQ são automaticamente customizadas. 
A eficiência da utilização do processador Nios permite que múltiplas instâncias do dispositivo possam ser implementadas num mesmo FPGA, satisfazendo assim às necessidades de aplicações que requerem desempenho intensivo. A figura 6.3 ilustra esta possibilidade.

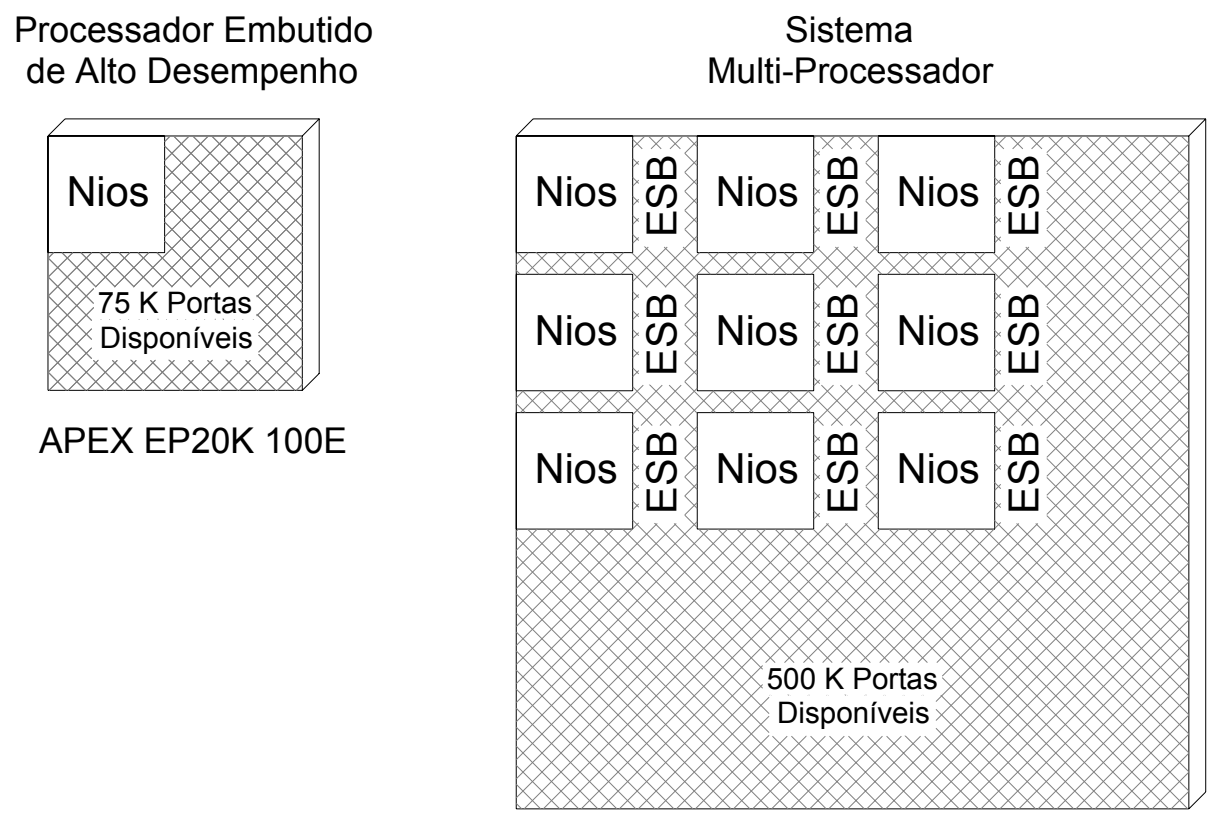

APEX EP20K 1000E

Figura 6.3 - Flexibilidade e Escalabilidade dos Processadores Embutidos Nios.

\subsection{Compilador GNUPro}

O compilador e debugger GNUPro da Cygnus, uma companhia da Red Hat, é uma ferramenta padrão, usada por fabricantes de software de todo o mundo. Ele é uma ferramenta de desenvolvimento $\mathrm{C} / \mathrm{C}++$. Otimizado para o processador embutido Nios, o GNUPro proporciona um ambiente de desenvolvimento familiar aos engenheiros e projetistas, incluindo:

- Compilador otimizado $\mathrm{C} / \mathrm{C}++$;

- Assembler GNU;

- Debugger interno;

- Utilitários binários. 


\subsection{A Ferramenta de Desenvolvimento Quartus}

O software de desenvolvimento Quartus permite aos projetistas, o processamento de milhões de portas lógicas. O software Quartus suporta soluções a nível de sistema com editoração de blocos, trabalho em grupo e um avançado suporte para megafunções. Além disso, um sistema de análise lógica embutido, permite aos usuários verificar a funcionalidade e a temporização do chip, observando os valores de sinais internos à velocidade de clock do sistema. O software Quartus é um ambiente ideal para o desenvolvimento de projetos SOPC (system-on-a-programmable-chip).

\subsection{Placa de Desenvolvimento}

O kit de desenvolvimento Excalibur inclui também uma placa de desenvolvimento onde os projetistas podem implementar seus sistemas sobre um chip programável [26]. O lay-out desta placa pode ser visualizado na Figura 6.4.

O chip reconfigurável que acompanha a placa de desenvolvimento, como pode ser visto na figura, é o APEX EP20K200E, com 526.000 portas lógicas e 106.496 bits de memória RAM. 


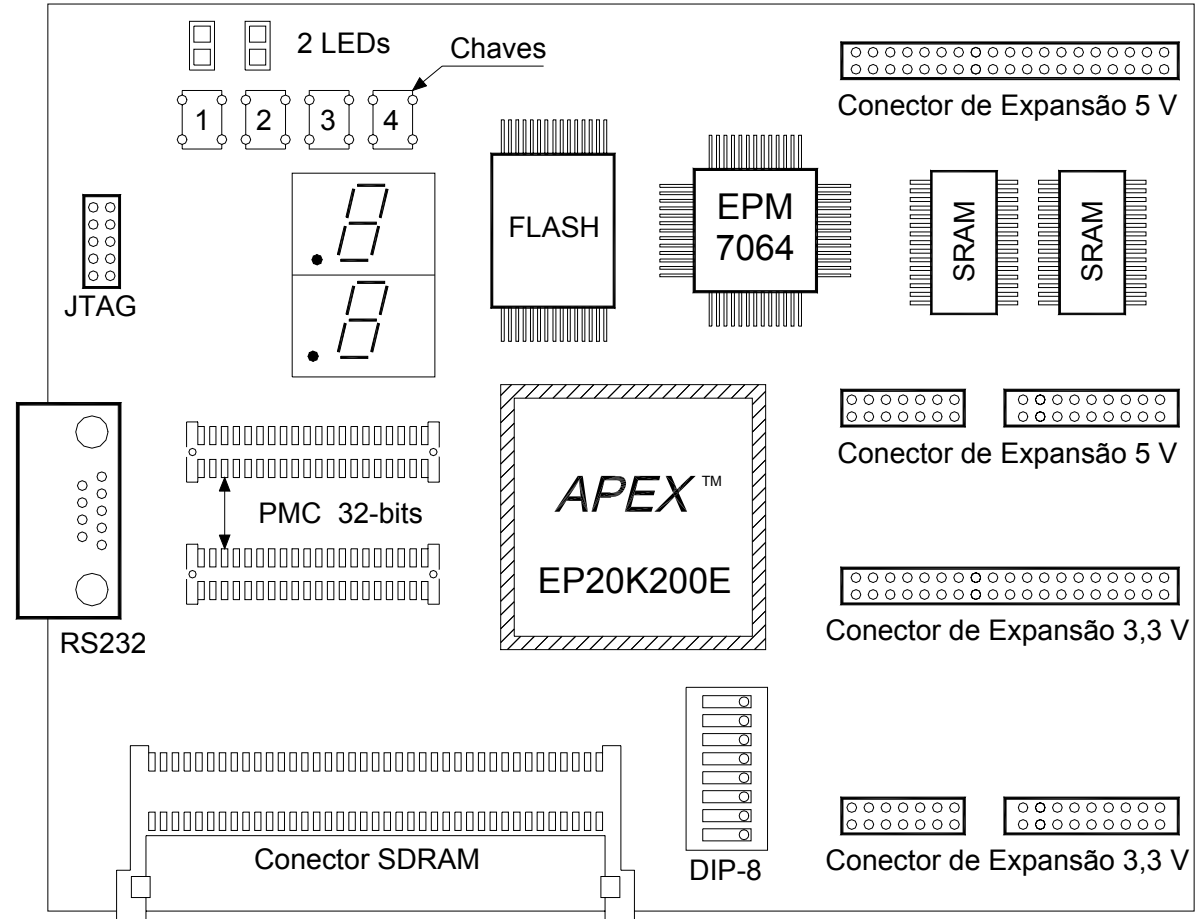

Figura 6.4 - Placa de Desenvolvimento Excalibur.

A Tabela 6.1 contém a listagem resumida dos componentes contidos na placa de desenvolvimento.

Tabela 6.1 - Componentes da Placa de Desenvolvimento Excalibur.

\begin{tabular}{|c|c|c|c|c|}
\hline COMPONENTE & QUANT. & ITEM-1 & ITEM-2 & ITEM-3 \\
\hline PLDS & 2 & $\begin{array}{c}\text { FPGA } \\
\text { EP20K200E }\end{array}$ & $\begin{array}{c}\text { CPLD } \\
\text { EPM 7064 }\end{array}$ & - \\
\hline MEMÓRIAS & 3 & $\begin{array}{c}\text { FLASH } \\
(1 \mathrm{MBytes})\end{array}$ & $\begin{array}{c}\text { SRAM } \\
(256 \mathrm{KBy} \text { tes })\end{array}$ & Conector SRAM \\
\hline $\begin{array}{c}\text { INTERFACES DE } \\
\text { COMUNICAÇÃO }\end{array}$ & 2 & RS 232 & JTAG & - \\
\hline $\begin{array}{c}\text { CONECTORES DE } \\
\text { EXPANSÃO }\end{array}$ & 3 & $5,0 \mathrm{~V}$ & $3,3 \mathrm{~V}$ & PMC - 32 bits \\
\hline LEDS & 2 & $\begin{array}{c}\text { Display 7 } \\
\text { Segmentos }\end{array}$ & Simples & - \\
\hline CHAVES & 2 & $\begin{array}{c}\text { DIP-Switch } \\
8 \text { contatos }\end{array}$ & $\begin{array}{c}\text { Contato } \\
\text { Momentâneo }\end{array}$ & - \\
\hline
\end{tabular}




\section{Capítulo 7}

\section{Considerações de Projeto}

\subsection{Caracterização da Linha de Pesquisa}

Os dispositivos de configuração disponíveis no mercado apenas configuram os FPGAs a eles conectados no momento da inicialização ou numa eventual reinicialização do sistema. Além disso, sistemas que se utilizam destes dispositivos comerciais, limitam-se a configurar os dispositivos alvo sempre com o mesmo arquivo de configuração. Caso haja a necessidade de se alterar a configuração dos FPGAs destes sistemas, um novo arquivo de configuração deve ser gravado na memória interna (EPROM ou FLASH) do dispositivo de configuração, sobrescrevendo desta forma o arquivo anteriormente armazenado.

O projeto ARMOSH exige que sua plataforma de hardware reconfigurável seja configurada não apenas no momento da sua inicialização, mas também quando o kernel do sistema operacional que controlará o robô, assim o determinar. Os FPGAs que irão compor a plataforma reconfigurável do robô serão configurados em tempo real e terão seus arquivos de configuração também determinados pelo kernel do sistema operacional. Uma biblioteca de arquivos de configuração, cada um dos quais especialmente projetado para implementação de um determinado algoritmo de navegação ou de reconhecimento de imagens, estará disponível em um dispositivo de armazenamento de dados. O kernel será inteligente o bastante para determinar qual dispositivo alvo deverá ser reconfigurado e com qual arquivo de configuração. Através de uma interface de comunicação (driver), tais informações serão passadas ao controlador de configuração do sistema e por intermédio deste, o processo de reconfiguração se completará. A Figura 7.1 elucida este arranjo.

As características do controlador de configuração a ser utilizado no projeto ARMOSH impedem a utilização de um dispositivo de configuração disponível 
comercialmente. Por esta razão, torna-se necessário a definição e o desenvolvimento de um hardware dedicado (controlador de configuração), bem como a construção de drivers a serem utilizados na reconfiguração dos FPGAs pertencentes à plataforma de hardware deste sistema.

A construção deste controlador de configuração e dos drivers pertinentes constituem o objetivo deste trabalho de mestrado.

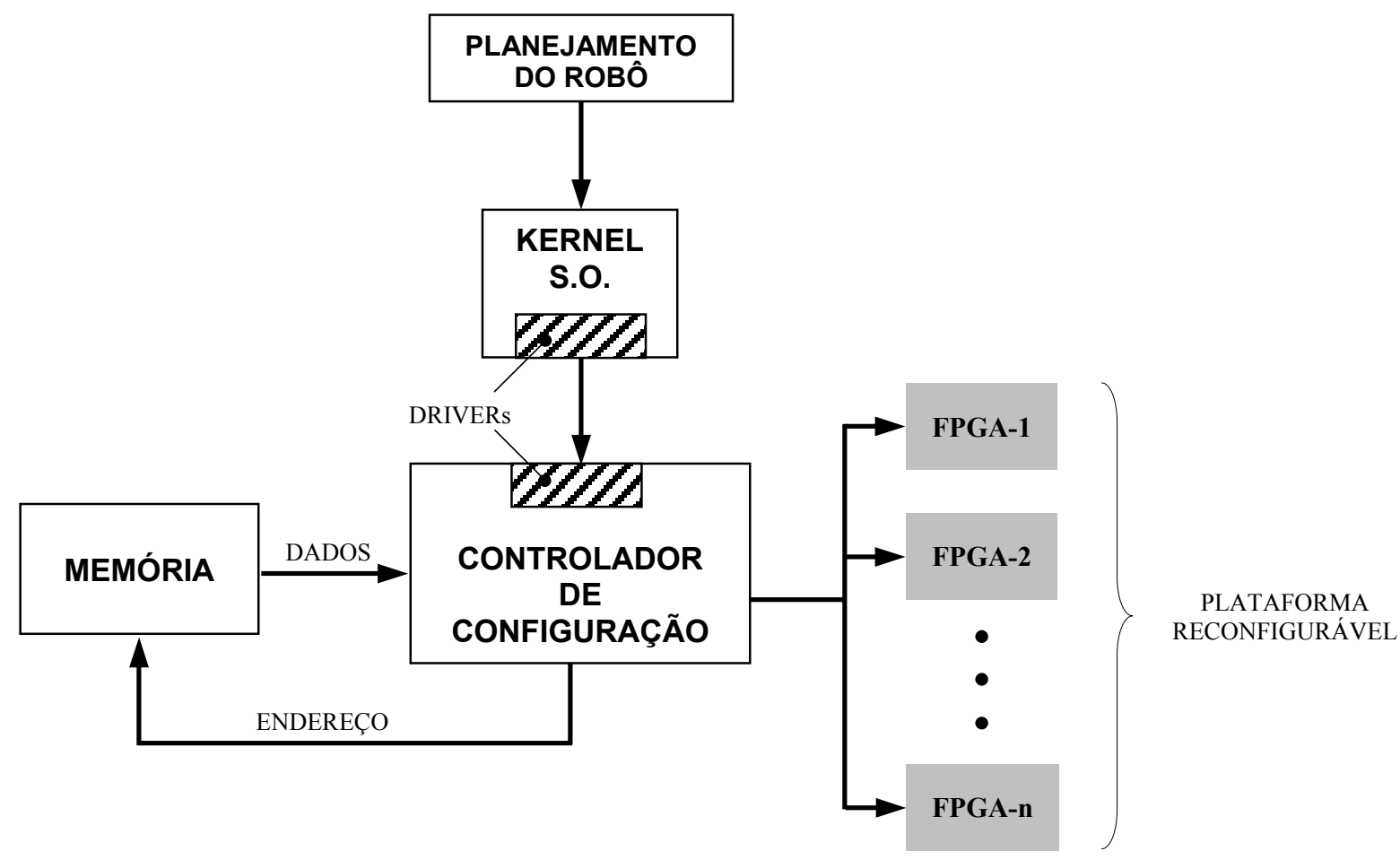

Figura 7.1 - Esquema de Configuração para o Projeto ARMOSH

\subsection{Desenvolvimento}

Como mencionado no capítulo 5, são três os dispositivos de configuração disponíveis para família de PLDs APEX 20K. Por se tratarem de propriedade intelectual, não se têm maiores informações sobre estes componentes além daquelas disponíveis nos catálogos do fabricante.

Um controlador de configuração, cujo código é aberto e disponível ao usuário, está presente no Kit de desenvolvimento Excalibur. Este controlador, implementado sobre um CPLD modelo EPM7064 da família MAX7000, cujos elementos de 
configuração são do tipo EEPROM, foi totalmente projetado em AHDL (Altera Hardware Description Language) e tem seu código disponível na documentação que acompanha o kit.

Por estar amplamente documentado e possuir várias características comuns às necessidades do projeto aqui desenvolvido, o controlador de configuração do Kit Excalibur é tomado como base para o desenvolvimento do hardware do controlador de configuração objetivo deste trabalho de mestrado.

Nas seções que se seguem, o projeto deste controlador de configuração será explorado em detalhes. O desenvolvimento do driver de comunicação do novo controlador de configuração também será aqui abordado. Maiores detalhes da implementação do controlador projetado serão apresentados no capítulo seguinte.

\subsubsection{O Esquema de Configuração do Kit de Desenvolvimento Excalibur}

O controlador de configuração EPM7064 da placa de desenvolvimento do Kit Excalibur conecta-se a um módulo de memória FLASH de 1 MBytes, dois módulos de memória SRAM de 128 Kbytes cada, e a um FPGA APEX 20K200E conforme ilustrado na Figura 7.2.

Quando o sistema é inicializado ou reinicializado, este controlador de configuração programa o FPGA através do esquema Passivo Paralelo Síncrono (PPS). Para tanto, o controlador utiliza-se de dados de configuração armazenados na memória FLASH conectada ao sistema. O controlador de configuração age como seqüenciador e gerador de endereços, fazendo com que dados corretos, no momento adequado, sejam enviados aos pinos de programação do dispositivo APEX. Depois de realizada sua função, este controlador remove-se do circuito colocando todos os seus pinos de saída em modo tri-state. 


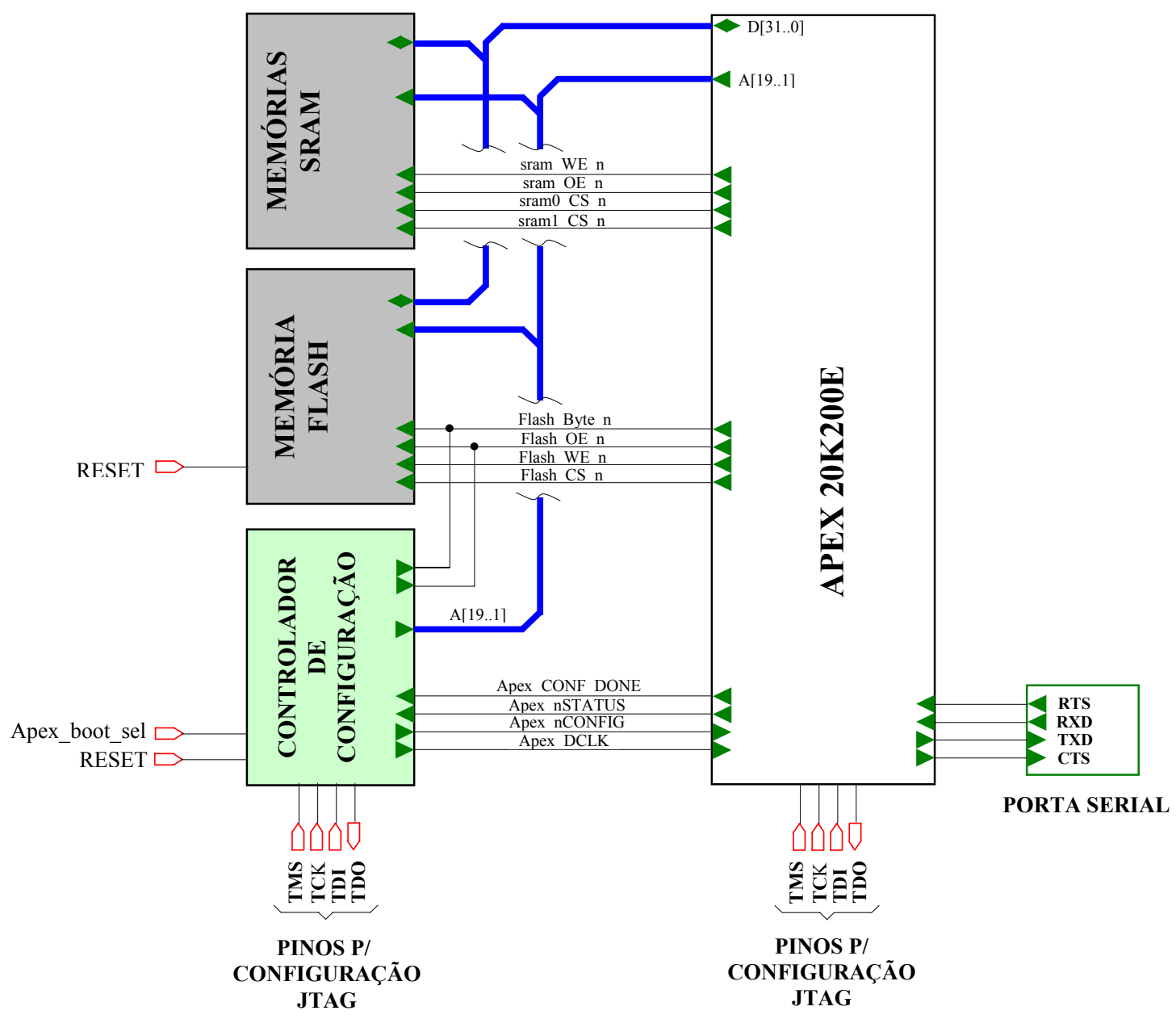

Figura 7.2 - Conexões do Controlador de Configuração aos Componentes da Placa de Desenvolvimento Excalibur.

Este controlador de configuração pode configurar o FPGA com dois arquivos distintos denominados "FACTORY" e "USER" [26]. O dispositivo possui uma lógica que vai, inicialmente, tentar carregar o FPGA com a configuração USER. Se esta tentativa não for bem sucedida (devido à presença de um arquivo inválido ou à ausência deste), o controlador procura então configurar o dispositivo alvo com o arquivo FACTORY.

O sistema pode ser forçado a configurar o dispositivo alvo com a configuração FACTORY sem a tentativa inicial de carregá-lo com o arquivo USER, bastando para isto, manter baixo o nível lógico do pino "Apex_boot_sel". 


\subsubsection{A Memória FLASH}

O controlador de configuração que acompanha o kit de desenvolvimento Excalibur assume que os arquivos de configuração FACTORY e USER estejam armazenados em posições fixas (offsets) da memória FLASH. Os segmentos desta memória formam o arranjo apresentado na Tabela 7.1.

Tabela 7.1 - Conteúdos Alocados à Memória FLASH.

\begin{tabular}{|c|c|l|}
\hline SEGMENTO & TAMANHO & \multicolumn{1}{|c|}{ CONTEÚDO } \\
\hline 00000 - 7FFFF & 512 KBytes & $\begin{array}{l}\text { Instruções do Processador Nios e espaço para dados } \\
\text { não voláteis. }\end{array}$ \\
\hline 80000 - BFFFF & 256 Kbytes & $\begin{array}{l}\text { Dados de configuração definidos pelo usuário para o } \\
\text { dispositivo APEX. }\end{array}$ \\
\hline C0000 - FFFFF & 256 Kbytes & $\begin{array}{l}\text { Dados de configuração definidos pelo fabricante para o } \\
\text { dispositivo APEX. }\end{array}$ \\
\hline
\end{tabular}

Um projeto de referência do processador Nios de 32 bits é pré-carregado na região de configuração definida pelo fabricante. A Altera recomenda que se evite sobrescrever esta região da memória.

O software Quartus II pode ,opcionalmente, gerar arquivos de configuração do tipo hexout para os projetos do usuário final do sistema. Estes arquivos podem ser diretamente carregados e armazenados na memória FLASH como dados de configuração definidos pelo usuário [27]. Um arquivo de configuração do tipo hexout para o dispositivo APEX 20K200E, que acompanha a placa de desenvolvimento do kit, é um pouco menor que 256 Kbytes e ,portanto, ocupa cerca de 1/4 do espaço útil da memória FLASH.

Novos arquivos hexout podem ser armazenados na memória FLASH através de um software rodando sobre o processador Nios. O projeto de referência deste processador inclui um programa monitor denominado "GERMS" que suporta a execução de download de tais arquivos a partir de um host. Além de arquivos de configuração, o GERMS executa também, download de softwares a serem armazenados na memória FLASH e posteriormente executados pelo processador Nios. 


\subsubsection{A Memória SRAM}

Os dois módulos de memória SRAM assíncronas possuem um barramento de dados de 16 bits e capacidade de endereçamento para $64 \mathrm{~K}$ posições. Conforme mostra a Figura 7.2, estes módulos estão conectados ao dispositivo APEX e, desta forma, podem ser utilizados como memória de propósito geral. Os dois módulos podem ser arranjados de forma a implementar uma única memória com barramento de dados de 32 bits. O projeto de referência do processador Nios identifica estes dois chips em seu espaço de endereçamento e os trata como memória principal de 256 Kbytes contínuos de 32 bits.

\subsection{O Controlador de Configuração do Kit de Desenvolvimento Excalibur}

Conforme já mencionado, o controlador de configuração da placa de desenvolvimento Excalibur configura o FPGA a ele conectado através do esquema Passivo Paralelo Síncrono (PPS). De acordo com o item 4.3.4 deste trabalho, e como o próprio nome sugere, neste esquema de configuração o dispositivo alvo é totalmente passivo e o dispositivo responsável pela configuração é quem controla o comportamento de todos os sinais envolvidos na execução do processo.

A Figura 7.3 apresenta o diagrama de blocos do controlador de configuração do kit Excalibur, suas conexões com o PLD e com a memória FLASH.

Como pode ser observado nesta figura, a partir dos endereços gerados pelo controlador de configuração, dados de configuração oriundos da memória FLASH são, de maneira paralela (8bits), diretamente enviados aos pinos de programação D [ 7 . . 0 ] do dispositivo APEX. 


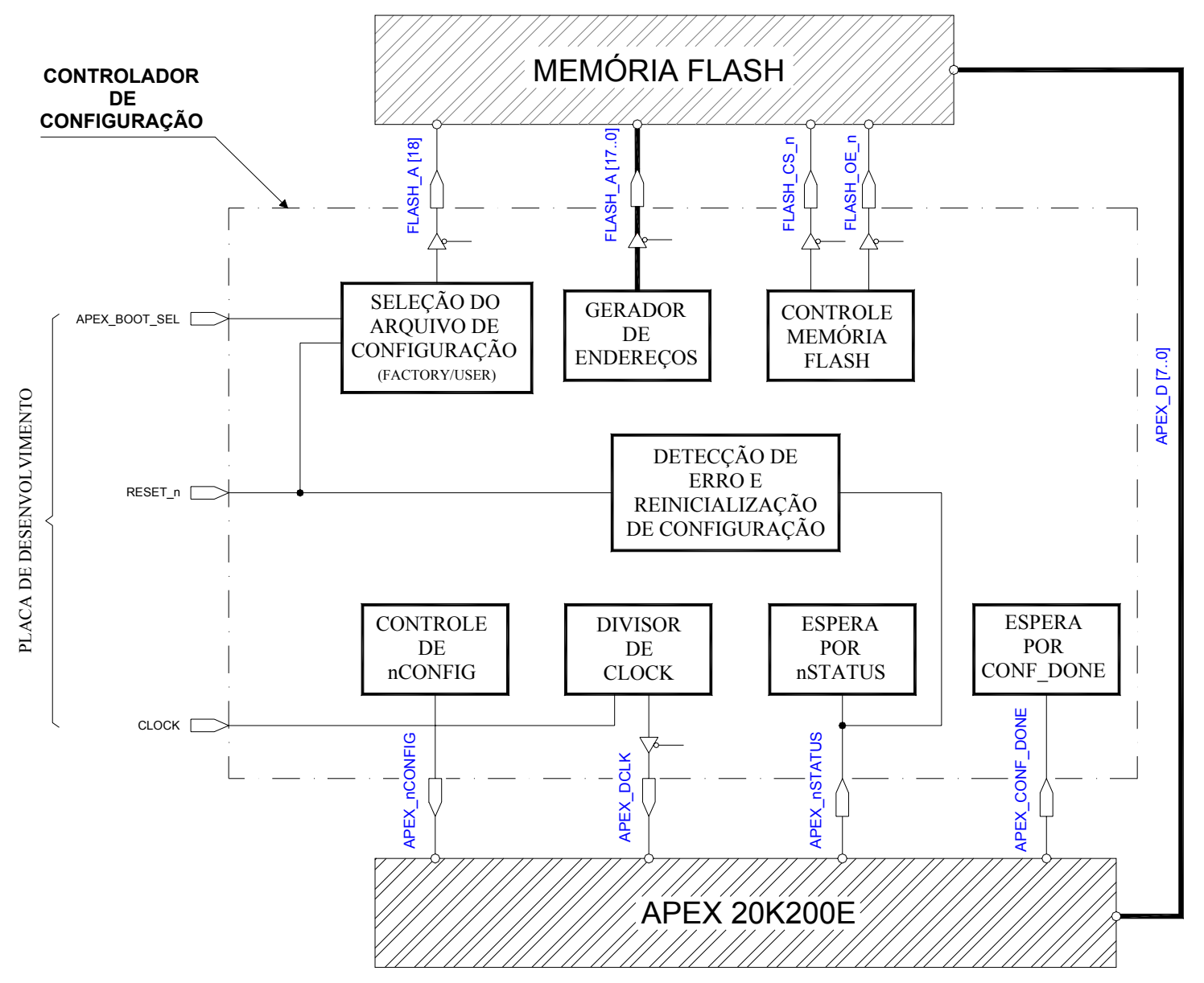

Figura 7.3 - Diagrama de Blocos do Controlador de Configuração do Kit de Desenvolvimento Excalibur.

Através do pino FLASH_A [18], o bloco funcional "Seleção do Arquivo de Configuração" determina o segmento de memória a ser utilizado (ver Tabela 7.1). O bloco "Gerador de Endereços" atua sobre os pinos FLASH_A [17..0], gerando assim o offset pertinente ao segmento selecionado.

Com o intuito de simplificar o esquema apresentado na Figura 7.3, as interligações entre os blocos funcionais do controlador foram omitidas. Estas porém, ficarão evidentes nas seções que seguem, onde a lógica utilizada na construção de cada bloco funcional será explanada. 


\subsubsection{Bloco Funcional de Seleção do Arquivo de Configuração}

Este bloco funcional é responsável pela determinação de qual arquivo será utilizado na configuração do FPGA (FACTORY ou USER). Quando o sistema é inicializado, o controlador Excalibur executa uma tentativa de configuração com o arquivo USER. Se esta configuração não for bem sucedida, o dispositivo alvo é então configurado com o arquivo FACTORY.

A lógica adotada na construção deste bloco pode ser observada na Figura 7.4.

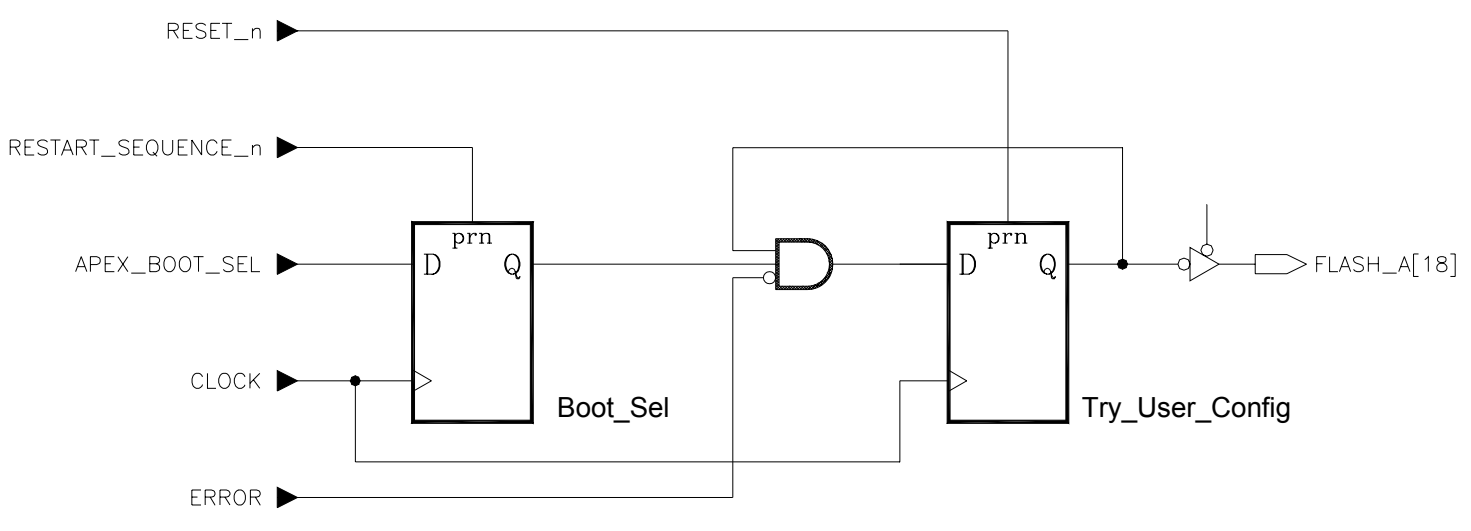

Figura 7.4 - Lógica do Bloco de Seleção do Arquivo de Configuração.

Os sinais RESTART_SEQUENCE_n e ERROR são gerados por blocos funcionais a serem discutidos posteriormente. A Figura 7.5 mostra a origem dos sinais RESET_ne APEX_BOOT_SEL.
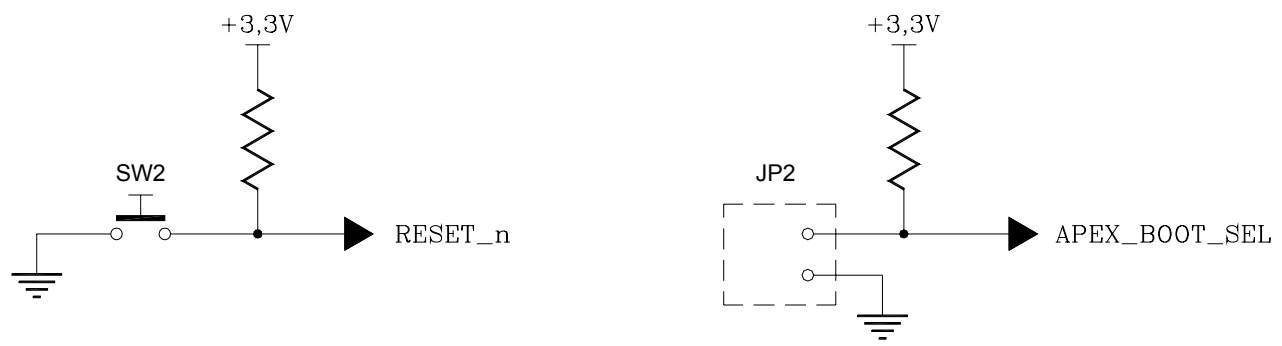

Figura 7.5 - Os Sinais APEX_BOOT_SEL e RESET_n. 
O flip-flop "Try-User-Config" inicialmente leva para baixo o nível de sua saída. Este nível é alterado em seguida através de RESET_n. Nesta situação, e dependendo dos níveis de APEX_BOOT_SEL e ERROR, FLASH_A[18] assume nível lógico baixo, impondo assim uma configuração a partir do arquivo USER. Se o jump JP2 for fechado ou se ocorrer um erro de configuração (conforme indicado pelo sinal ERROR), o nível de FLASH_A [18] será alterado e a configuração se dará através do arquivo FACTORY .

\subsubsection{Bloco Funcional de Deteç̧ão de Erro e Reinicialização de Configuração}

Conforme visto no Capítulo 4, os dispositivos APEX sinalizam um erro de configuração através do pino nSTATUS. Se o dispositivo estiver sendo configurado ou possuir esta fase já completada, supõe-se que este pino tenha nível lógico alto. Se durante o processo de configuração nSTATUS assumir nível baixo, um erro pode ter ocorrido e o processo deve ser reinicializado. A Figura 7.6 apresenta a lógica utilizada na construção deste bloco.

No caso da configuração USER, um erro pode ainda ocorrer ao surgir um carry-out no contador responsável pela geração dos endereços de acesso à memória, sem que antes o FPGA tenha sinalizado (através de CONF_DONE) o sucesso da configuração. De forma a tratar o sinal de carry-out, um flip-flop (denominado Counter_Wrapped) foi inserido neste bloco funcional (Figura 7.7). 


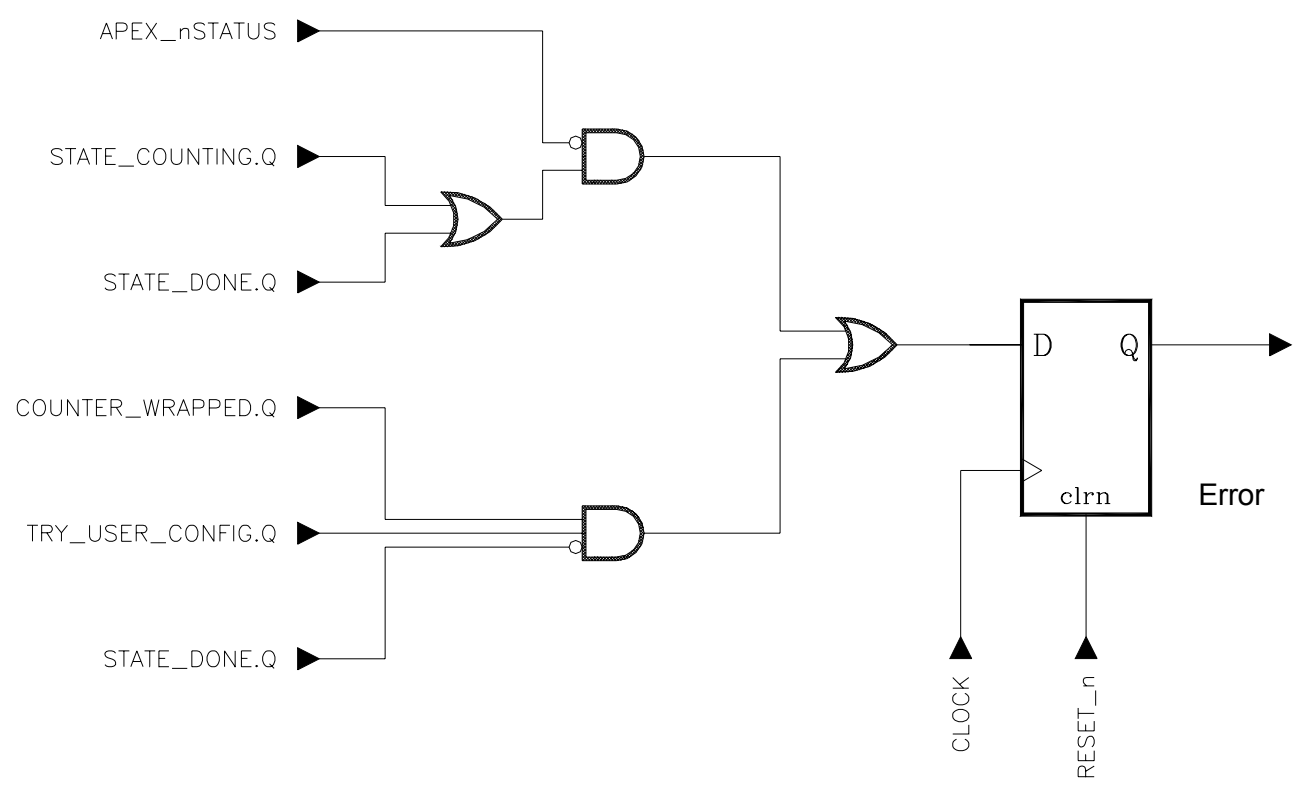

Figura 7.6 - A Geração do Sinal de Erro.

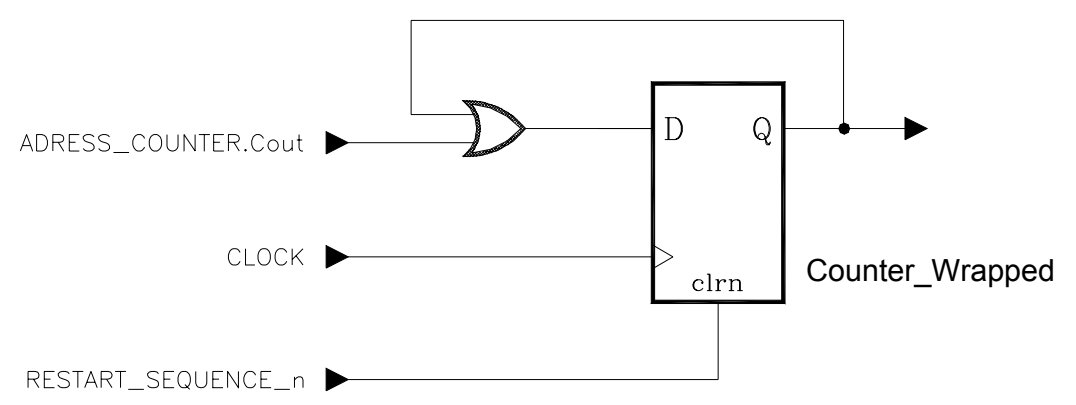

Figura 7.7 - O Flip-Flop "Counter_Wrapped".

Na ocorrência de um erro na configuração, conforme indicado pelo flip-flop de nome Error (Fig. 7.6), todos os blocos funcionais do controlador devem ser reinicializados. O sinal de reinicialização é gerado conforme mostra a Figura 7.8.

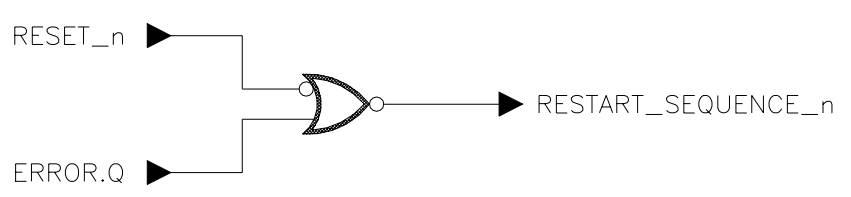

Figura 7.8 - O Sinal de Reinicialização do Sistema. 


\subsubsection{Bloco Funcional de Divisão de Clock}

Todo o sistema controlador de configuração opera sob um sinal de clock (DCLK_en) de aproximadamente $8 \mathrm{MHz}$, o que representa $1 / 4$ do sinal de clock principal ( $\mathrm{Clk}$ _CPLD) gerado na placa de desenvolvimento. DCLK_en poderia assumir freqüências mais elevadas, mas foi assim mantido devido ao estilo tradicional, onde flipflops e registradores são habilitados durante apenas 1/4 do tempo.

O sinal DCLK_en é gerado a partir do carry-out de um contador de 02 bits. $\mathrm{O}$ bit mais significativo deste contador é levado diretamente ao pino DCLK do dispositivo alvo. A Figura 7.9 mostra o arranjo adotado.

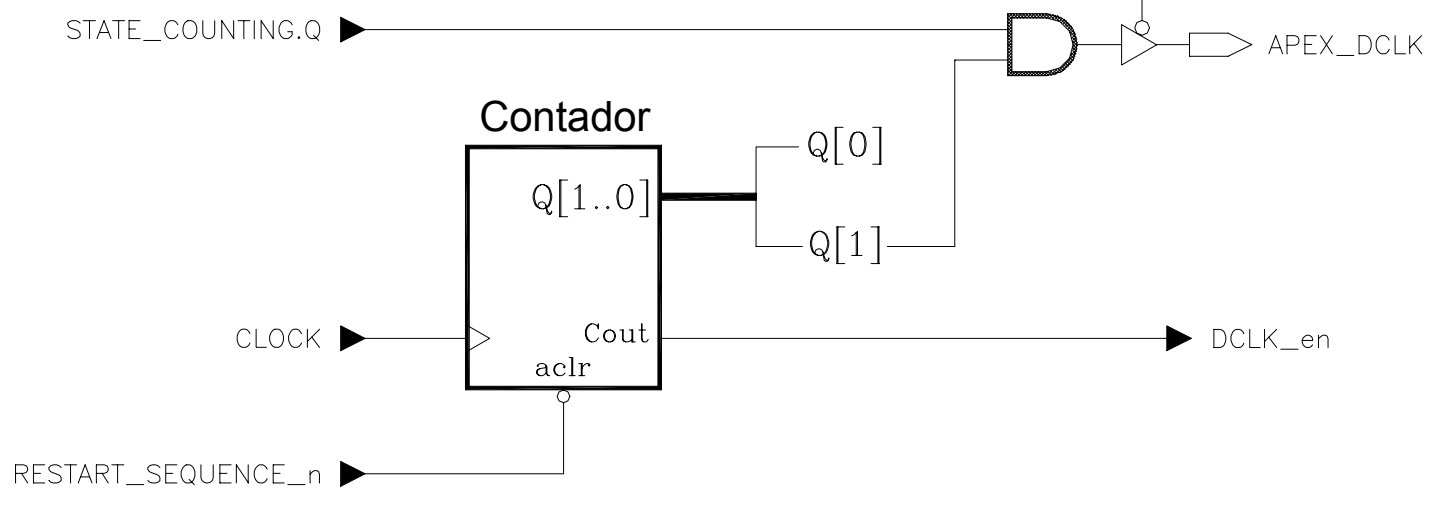

Figura 7.9 - O Divisor de Clock.

O sinal de clock APEX_DCLK deve ser mantido baixo a menos que o dispositivo esteja em modo de configuração. Esta condição é satisfeita através da utilização do sinal STATE_COUNTING.Q adquirido do bloco funcional "Gerador de Endereços". Este sinal tem nível lógico alto apenas enquanto o FPGA recebe dados de configuração (ver item 7.3.6 adiante).

\subsubsection{Bloco Funcional de Controle do Sinal "nCONF IG"}

Conforme visto no Capítulo 4, para se configurar ou reconfigurar um dispositivo APEX, um pulso alto-baixo deve ser imposto ao pino nCONFIG. Para se alcançar este comportamento, adotou-se o arranjo apresentado na Figura 7.10. A saída 
do flip-flop assumirá nível lógico baixo apenas no momento da reinicialização do sistema (conforme indicado pelo sinal RESTART_SEQUENCE_n).

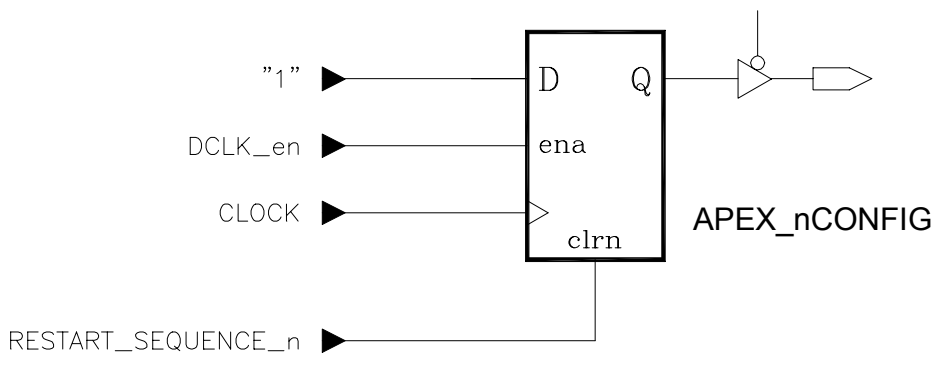

Figura 7.10 - A Geração do Sinal "nCONF IG".

Iniciado o processo de configuração, RESTART_SEQUENCE_n volta a valer "1", passando a este também o nível de APEX_nCONFIG.

\subsubsection{Bloco Funcional de Espera por "nStATUS"}

O controlador de configuração monitora o sinal nSTATUS fornecido pelo dispositivo alvo. Um nível alto neste pino indica que o dispositivo está pronto para receber os dados de configuração. Desta forma, depois de enviado o sinal nCONF IG, o controlador Excalibur entra num estado de espera pela transição baixo-alto no pino APEX_nSTATUS. Um sinal, denominado "Waiting_for_nSTATUS" representa este estado (ver Figura 7.11).

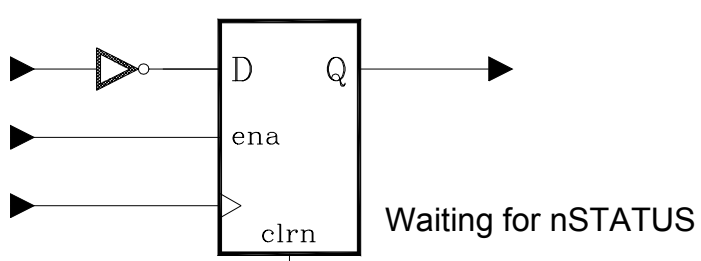

Figura 7.11 - Implementação do Estado de Espera por "nSTATUS". 


\subsubsection{Bloco Funcional Gerador de Endereços}

Os endereços de acesso à memória FLASH são gerados conforme mostra a Figura 7.12. O sinal USING_FLASH, interno ao controlador, habilita o funcionamento do contador de endereços. Quando o dispositivo alvo está apto a receber os dados de configuração (indicado através do sinal nSTATUS), USING_FLASH assume nível lógico alto. Neste bloco funcional, a disponibilidade do dispositivo alvo em receber os dados de configuração é representada pelo sinal WAITING_FOR_nSTATUS.Q.

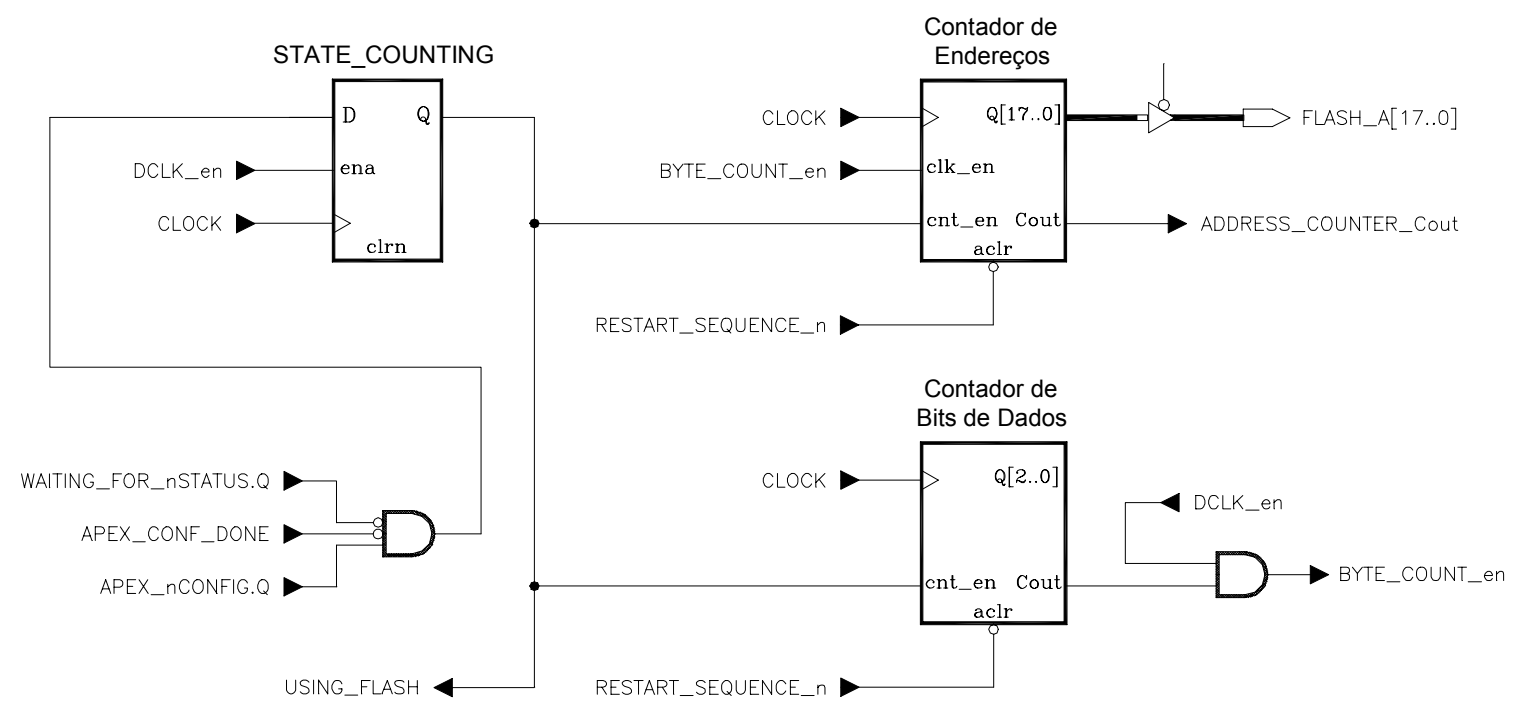

Figura 7.12 - A Lógica do Bloco Gerador de Endereços.

A contagem continua até que o FPGA sinalize o término de sua configuração, quando APEX_CONF_DONE é levado para o nível lógico alto. STATE_COUNTING.Q vai para zero, desabilitando o contador.

Os endereços gerados pelo bloco devem ser incrementados a cada 08 (oito) ciclos de APEX_DCLK. Isto permite a serialização dos dados de configuração no interior do dispositivo alvo. O sinal BYTE_COUNT_en impõe este comportamento ao contador de endereços. 


\subsubsection{Bloco Funcional de Espera por "CONF_DONE"}

A Figura 7.13 apresenta o arranjo utilizado na construção deste bloco. O flipflop STATE_DONE terá sua saída em nível lógico alto quando uma das seguintes condições for verdadeira:

- Sinalização de configuração bem sucedida através do pino APEX_CONF_DONE;

- Transição baixo-alto no sinal de carry-out do contador de endereços.

Quando configurado corretamente, o FPGA torna alto o nível de seu pino APEX_CONF_DONE, levando consigo o nível de STATE_DONE.Q.

Quando o contador de endereços chega ao final de sua contagem (conforme indicado por COUNTER_WRAPPED), STATE_DONE.Q tem seu nível lógico ajustado em alto e o contador tem seu funcionamento interrompido quer o dispositivo alvo tenha sido configurado ou não. O bloco de detecção de erro é quem se encarrega em determinar o sucesso de cada tentativa de configuração.

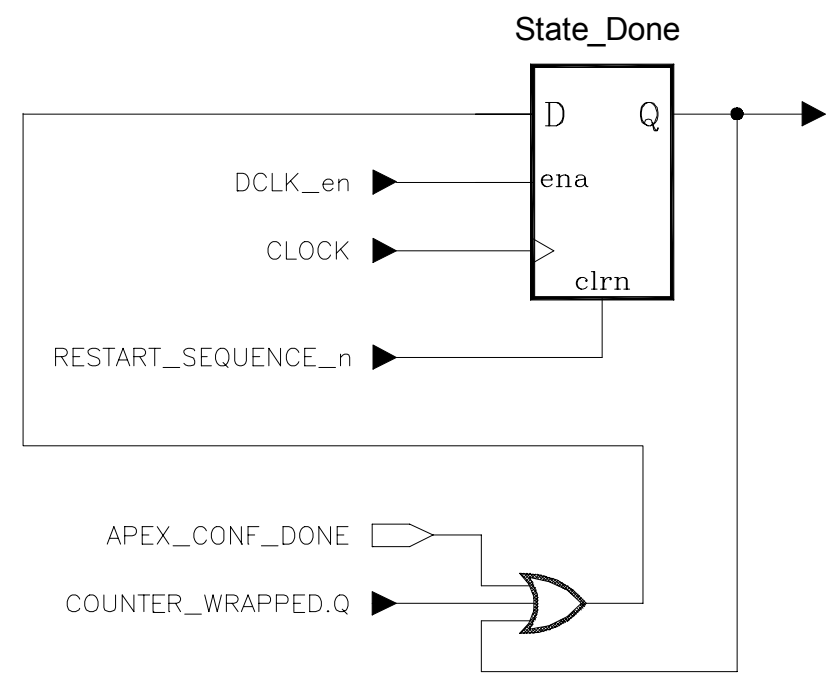

Figura 7.13 - A Lógica do Bloco de Espera por "CONF_DONE". 


\subsubsection{Controle das Saídas}

Terminado o processo de configuração, o controlador de configuração Excalibur coloca todas as suas saídas em modo "alta-impedância". Para isto, o sinal de output-enable dos buffers que conduzem estes sinais ao dispositivo alvo são conectados ao sinal STATE_DONE.Q invertido. Exceção a esta regra é o pino APEX_nCONFIG, por ser este do tipo "coletor-aberto".

\subsection{O Driver do Controlador de Configuração}

O Driver a ser desenvolvido, para a realização da comunicação entre o kernel do sistema operacional do robô e o hardware do Controlador de Configuração, será executado pelo soft-core do processador Nios ${ }^{\mathrm{TM}}$ configurável que acompanha o kit de desenvolvimento Excalibur. A implementação deste processador bem como o desenvolvimento do driver serão discutidos a seguir.

\subsubsection{O Projeto do Driver do Controlador de Configuração}

O driver (software escrito em linguagem "C") do controlador de configuração, objetivo deste trabalho de mestrado, terá como função transmitir ao hardware deste controlador informações provenientes do kernel do sistema operacional. O driver irá monitorar o kernel, aguardando pelas seguintes informações:

- Identificação do próximo FPGA a ser configurado;

- Arquivo de configuração a ser utilizado.

Os dados passados pelo kernel serão então enviados ao hardware do controlador que se encarregará de executar a configuração do dispositivo alvo especificado. Em seguida, o driver deverá aguardar uma sinalização, proveniente do hardware dedicado, de configuração realizada com sucesso. Após isto, o driver volta ao 
seu estado inicial, esperando por uma nova solicitação de configuração por parte do kernel do S. O.

\subsubsection{A Inserção do Processador Nios}

A existência do soft-core de um processador RISC configurável acelerou em muito o desenvolvimento do driver deste controlador de configuração. Utilizando-se do software Quartus ${ }^{\mathrm{TM}}$, pode-se criar instâncias parametrizadas do processador Nios, e dispositivos periféricos como PIO, UART, Timers e etc., podem ser a este conectados.

Depois de especificados o processador e seus periféricos através de um ambiente de desenvolvimento próprio, o projeto é sintetizado e um bloco é gerado. Os terminais deste bloco podem ser então conectados aos vários componentes encontrados na placa de desenvolvimento (LEDs, chaves, Displays e etc.), bem como aos terminais de um hardware dedicado projetado pelo usuário do sistema.

Para o sistema desenvolvido neste trabalho, o processador Nios possuirá interfaces paralelas para comunicação com o hardware dedicado (controlador de configuração) e com as memórias FLASH e SRAM contidas na placa de desenvolvimento Excalibur. Além destas, o processador deverá contar com uma interface serial (RS-232) para comunicação com um host. O hardware projetado e o processador Nios serão unidos em um único projeto e posteriormente implementados num FPGA (ver Figura 7.14). A junção destas duas instâncias da origem ao controlador de configuração objetivo deste trabalho de mestrado.

O processador Nios, inserido no controlador de configuração, se encarregará da execução do driver de comunicação entre o próprio controlador e o kernel do sistema operacional que controlará o robô. Inicialmente, e para a validação deste trabalho de mestrado, as informações a serem recebidas e geradas pelo driver do controlador, serão criadas e tratadas por um host. 


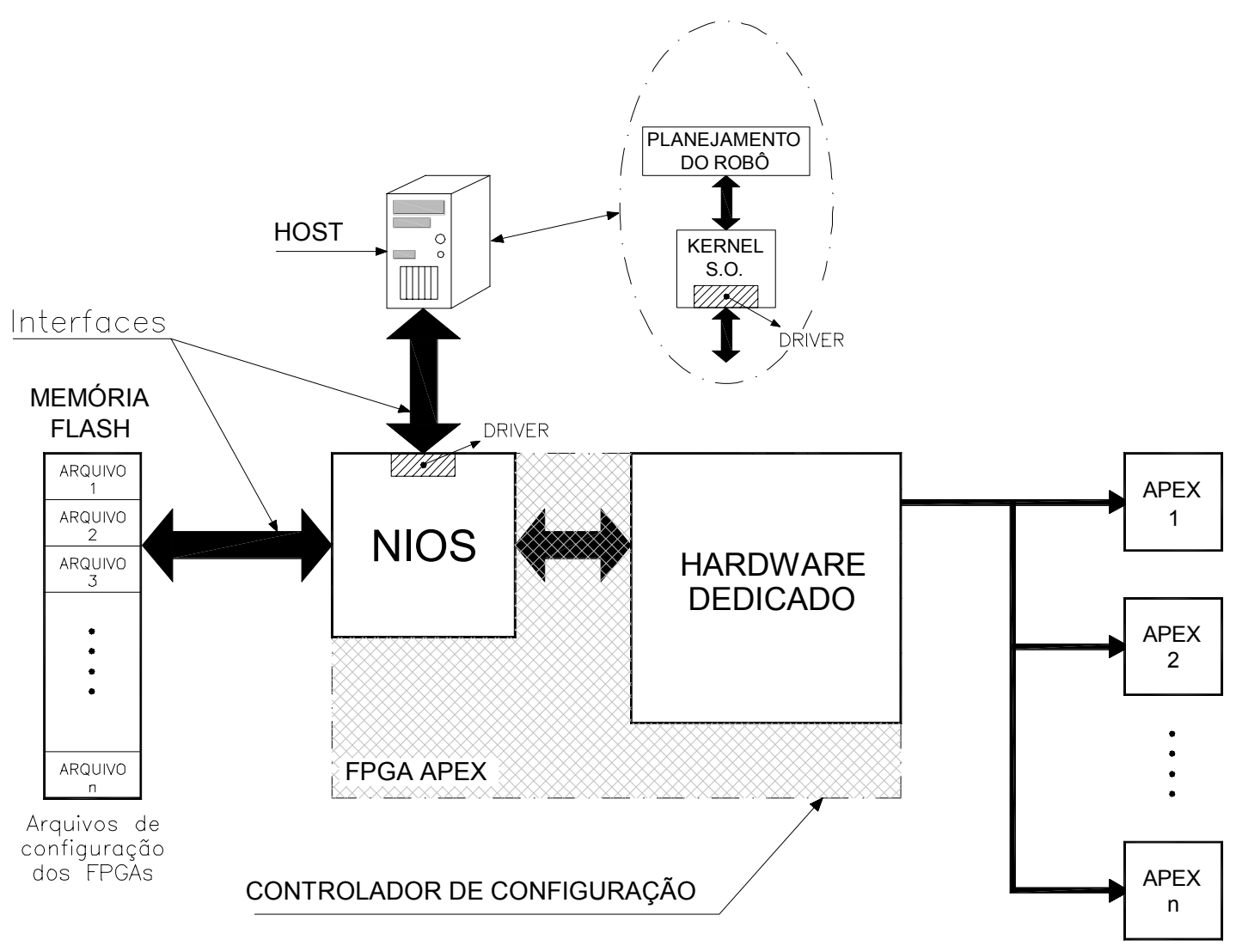

Figura 7.14 - O Processador Nios no Esquema de Configuração.

Posteriormente, num projeto futuro entre os laboratórios LCR e LABIC, o host será substituído pelo hardware do robô. A Figura 7.15 apresenta o esquema a ser futuramente implementado.

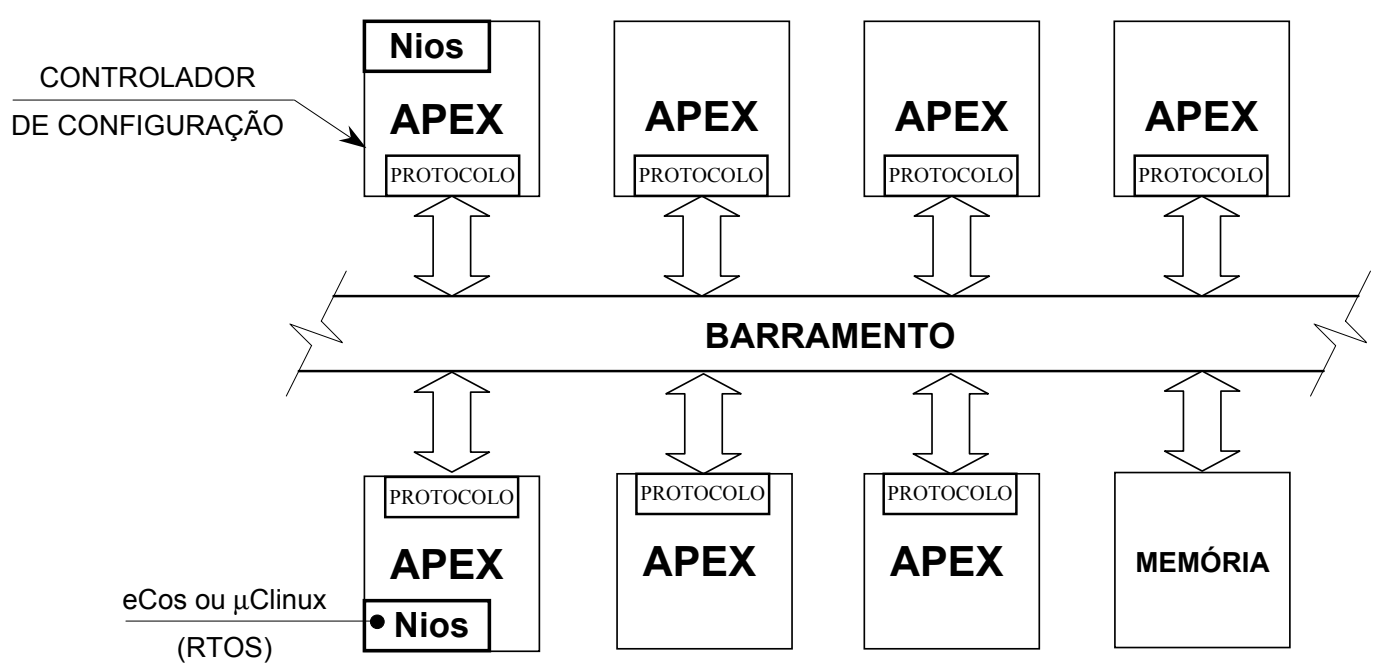

Figura 7.15 - O Hardware do Projeto ARMOSH. 
Neste esquema (Fig. 7.15), cada FPGA APEX estará engajado numa determinada tarefa do robô. A atribuição destas tarefas aos FPGAs será realizada por um aplicativo gerenciador de planejamento de tarefas rodando sobre um sistema operacional embutido.

Um sistema operacional de tempo real (RTOS) será adotado. Como opção, pode-se citar o eCos ${ }^{\mathrm{TM}}$ (Embedded Cygnus Operating Systems), um sistema operacional de código aberto e livre de royalties, desenvolvido de forma a prover portabilidade e customização por parte do usuário final [28]. Com estas características, esta poderosa infraestrutura fornece um ambiente ideal para o desenvolvimento de softwares embutidos. Outra opção seria o $\mu$ Clinux, um ambiente de desenvolvimento linux completo especificamente portado para o processador Nios [29]. 


\section{Capítulo 8}

\section{Detalhes de Implementação do Controlador de Configuração}

O controlador de configuração do kit de desenvolvimento Excalibur envia ao dispositivo alvo a ele conectado, um dentre dois arquivos de configuração. $\mathrm{O}$ mecanismo de seleção de arquivos deste dispositivo é muito simples e pode ser facilmente expandido para um arranjo onde vários arquivos de configuração estejam disponíveis. As principais diferenças entre o controlador acima citado e o controlador objeto deste trabalho de mestrado, residem na capacidade deste último em controlar a configuração de múltiplos FPGAs e na existência de um driver de comunicação entre o hardware deste novo controlador e o kernel de um sistema operacional.

A implementação do hardware dedicado e do driver de comunicação serão a partir de agora detalhados.

\subsection{O Hardware do Novo Controlador de Configuração}

A lógica adotada no desenvolvimento do controlador Excalibur foi, em grande parte, aproveitada no projeto do novo controlador de configuração. As alterações realizadas devem-se principalmente às novas interfaces impostas ao controlador aqui desenvolvido. Nesta seção, o projeto do novo controlador de configuração será apresentado através da análise da implementação destas novas interfaces. 


\subsubsection{A Interface Entre o Driver e o Hardware do Controlador de Configuração}

São cinco os sinais trocados entre o driver e o hardware do novo controlador de configuração. Informações tais como: qual FPGA deve ser configurado e o respectivo arquivo de configuração a ser utilizado, serão passadas através de barramentos. A transição baixo-alto do sinal $\mathrm{nCONFIG}$, necessário para o início do processo de configuração do dispositivo alvo, será gerado pelo driver e transmitido ao hardware dedicado. Além disso, o driver deverá aguardar por uma sinalização de sucesso ou de fracasso na configuração solicitada. A seguir, serão detalhados a geração e o tratamento destes cinco sinais.

\subsubsection{Seleção do Arquivo de Configuração}

Conforme mencionado no item 7.3.1, o controlador Excalibur tem parte do seu funcionamento controlado pelo jump JP2 e pela chave SW2 (Figura 7.5). De acordo com o estado destes dois componentes, define-se qual arquivo de configuração deve ser enviado ao dispositivo alvo.

Para o novo controlador de configuração, o arquivo a ser utilizado será definido pelo kernel do sistema operacional e esta informação será então enviada para o hardware dedicado através de um barramento de três bits denominado "F[2..0]". Com este arranjo, o novo controlador poderá configurar um FPGA a partir de oito arquivos diferentes. A largura deste barramento foi escolhida aleatoriamente e sistemas que necessitam de uma maior quantidade de arquivos de configuração podem ser facilmente atendidos, bastando-se para isto alterar-se a largura deste barramento. Não existem fatores limitantes para o aumento da largura deste barramento a não ser a capacidade do dispositivo de armazenamento em relação ao tamanho dos arquivos de configuração.

Os três bits que chegam pelo barramento $\mathrm{F}$ [ ] são diretamente enviados para a parte mais significativa do barramento de endereços de acesso à memória gerados pelo controlador de configuração. A Figura 8.1 ilustra esta idéia. 


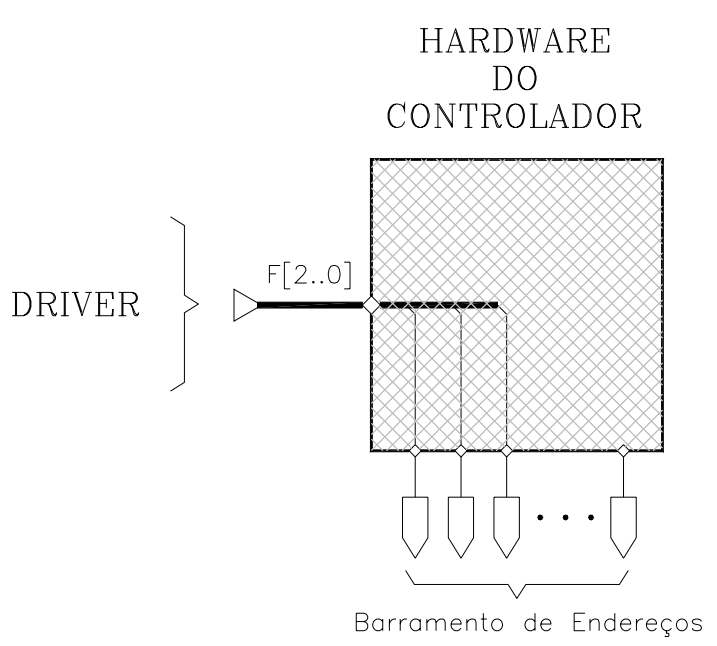

Figura 8.1 - Controle da Seleção de Arquivos de Configuração.

A geração dos sinais para os demais bits do barramento de endereços é realizada por um bloco funcional gerador de endereços idêntico ao utilizado pelo controlador Excalibur (ver item 7.3.6).

\subsubsection{Seleção do FPGA a ser Reconfigurado}

A identificação do FPGA a ser configurado, também gerada pelo kernel do S.O., será transmitida ao hardware através de outro barramento de três bits denominado "S[2..0]". Da mesma forma que no barramento de seleção de arquivo de configuração, a largura do barramento S [ ] foi escolhida aleatoriamente e pode ser alterada facilmente.

Os sinais envolvidos na configuração de um FPGA da família APEX, conforme visto no capítulo 4, são quatro (DCLK, nCONFIG, nSTATUS e CONF_DONE). Os dois primeiros serão gerados pelo hardware do controlador e enviados ao dispositivo alvo (determinado pelo kernel do S.O.) por intermédio de demultiplexadores. Os dois sinais restantes, gerados pelo FPGA selecionado, chegarão ao hardware dedicado através de multiplexadores.

Os dados que chegam pelo barramento $S$ [ ] são enviados ao barramento de seleção destes dispositivos combinacionais, fazendo com que apenas um dentre os 
FPGAs do sistema esteja apto a ser reconfigurado (ver Figura 8.2). Aqui, o fator limitante para o aumento na quantidade de FPGAs que compõem a plataforma reconfigurável, é a quantidade de pinos disponíveis no chip controlador de configuração. Quatro pinos são necessários para cada FPGA APEX inserido na arquitetura.

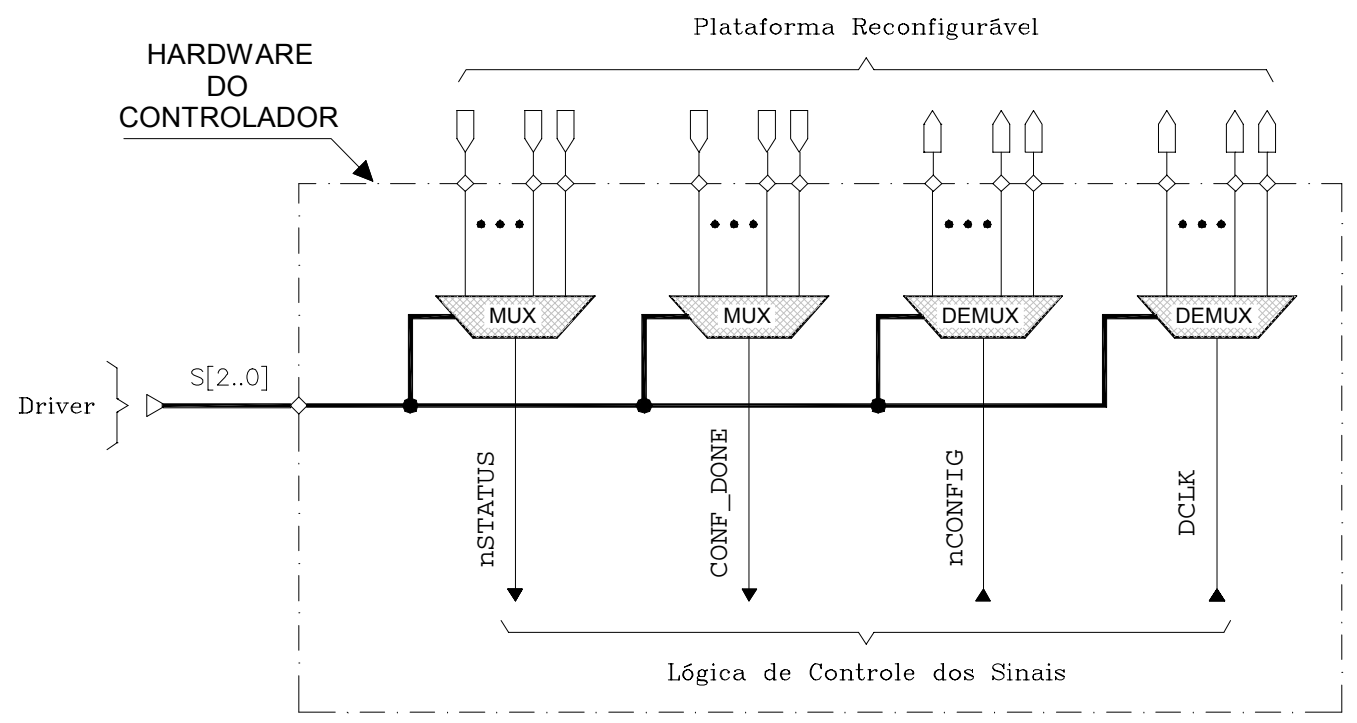

Figura 8.2 - Multiplexação e Demultiplexação dos Sinais.

\subsubsection{A Transição Baixo-alto do Sinal "nCONF IG"}

Conforme discutido no capítulo 7, no controlador de configuração Excalibur a transição baixo-alto no pino APEX_nCONFIG é gerada sob três condições diferentes. No momento da inicialização do sistema, um flip-flop gera a transição (Figura 7.10). Na ocorrência de um erro de configuração ou ao pressionar-se o botão de reset da placa de desenvolvimento, o sinal RESTART_SEQUENCE_n (ver Figura 7.8) assume nível lógico baixo, e por estar este conectado ao pino clear (clrn) do flip-flop acima citado, a transição também será gerada. 
A lógica adotada para a geração do sinal nCONFIG no controlador de configuração aqui desenvolvido é um pouco diferente. A transição do sinal nCONF IG será controlada pelo driver. Depois de determinado o dispositivo a ser reconfigurado e o arquivo de configuração a ser utilizado, um pulso (baixo-alto-baixo) será gerado pelo driver e então transmitido ao hardware do controlador. No interior deste, o sinal é distribuído para flip-flops e contadores conforme mostra a Figura 8.3.

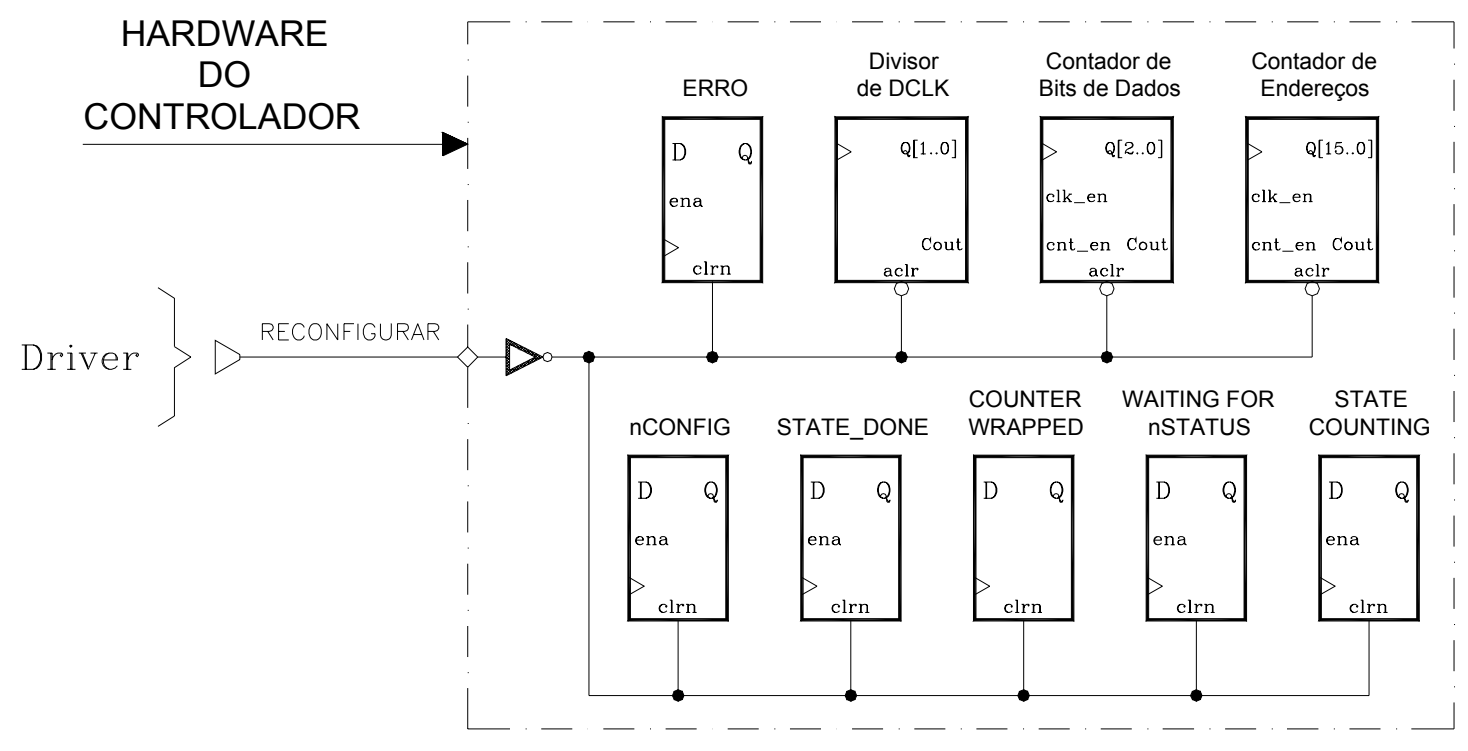

Figura 8.3 - O Sinal de Reinicialização do Novo Sistema.

Este sinal, denominado "RECONFIGURAR", é utilizado em substituição ao sinal RESTART_SEQUENCE_n gerado pelo controlador Excalibur.

Como pode ser observado na figura, um pulso para baixo no sinal RECONFIGURAR leva consigo o nível de nCONFIG.q. O pulso em nCONFIG.q dá início ao processo de configuração. Para o novo controlador, o comportamento do sinal RECONFIGURAR não está associado à ocorrência de um erro de configuração, diferentemente do comportamento do sinal RESTART_SEQUENCE_n do controlador Excalibur. 


\subsubsection{O Tratamento do Sinal de Sucesso e de Fracasso na Configuração}

O driver de comunicação entre o hardware do controlador e o kernel do S.O. deverá informar a este último sobre o sucesso ou o fracasso no processo de configuração solicitado. Para satisfazer a esta imposição, o sinal CONF_DONE, gerado pelo dispositivo alvo previamente selecionado, deve ser enviado ao hardware do controlador. O terminal do hardware dedicado que receberá este sinal conecta-se, através de um multiplexador, a um outro terminal, denominado "SUCESSO", que transmitirá a informação ao driver (Figura 8.4). Nível alto no terminal SUCESSO indica uma configuração bem sucedida.

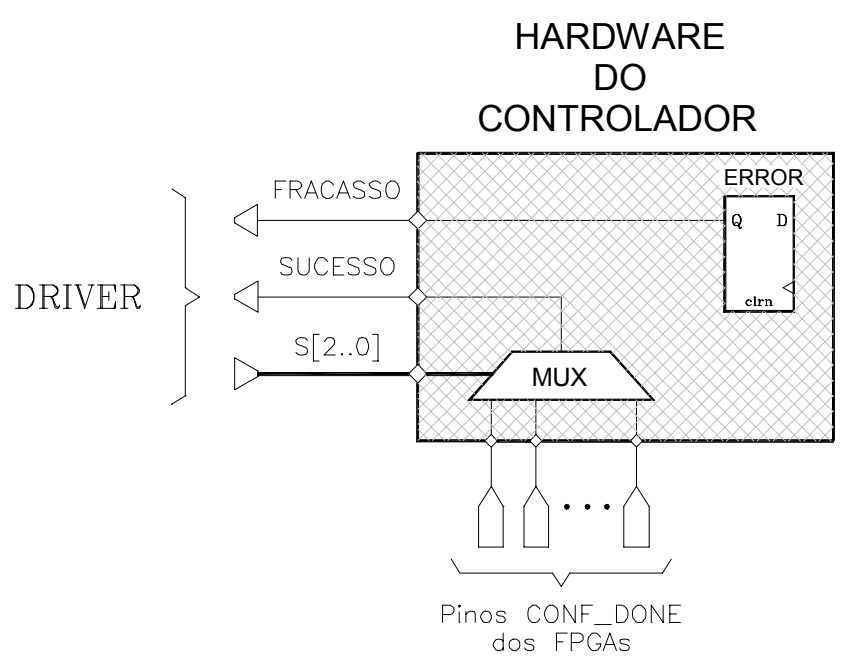

Figura 8.4 - A Transmissão dos Sinais de Sucesso e de Fracasso na Configuração.

Para o novo controlador, o sinal de fracasso será gerado por um bloco funcional de detecção de erro idêntico ao utilizado no controlador Excalibur (Figura 7.6). O sinal ERROR deste bloco está interligado ao pino FRACASSO, que se encarregará de levar a informação ao driver. 


\subsubsection{A Interface Entre o Controlador de Configuração e a Plataforma Reconfigurável}

Os sinais envolvidos na configuração dos dispositivos APEX 20K foram apresentados e discutidos no capítulo 4 desta monografia. Para facilitar o trabalho do leitor, estes sinais são reapresentados na Figura 8.5. O conjunto de sinais que formam a interface entre o controlador de configuração e um FPGA pertencente à plataforma reconfigurável, será denominado "Canal de Configuração".

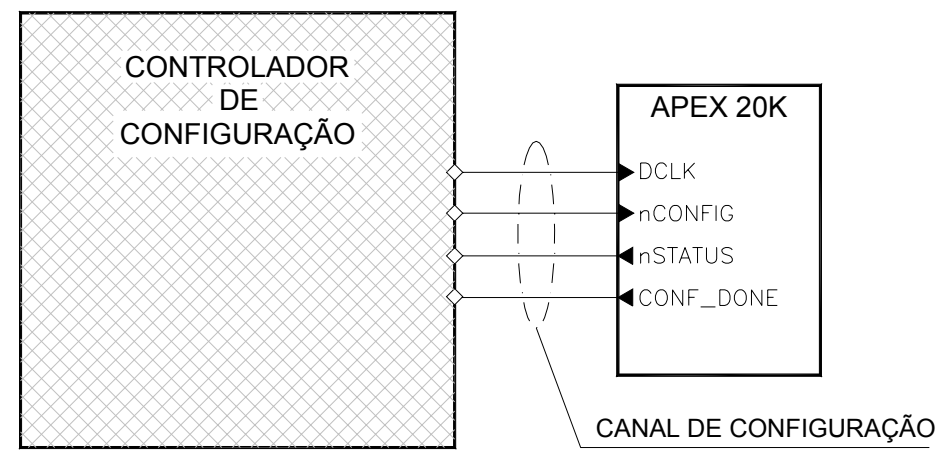

Figura 8.5 - Um Canal de Configuração.

Para o controlador de configuração aqui projetado, cada FPGA da plataforma reconfigurável terá seu próprio canal de configuração. Através do barramento S[2..0] do novo controlador, seleciona-se um canal de configuração dentre os oito possíveis e o FPGA a ele conectado pode então ser reconfigurado. A Figura 8.6 mostra o novo controlador e seus canais de configuração.

Conforme já mencionado, a quantidade de pinos do chip controlador de configuração é o único fator que limita o aumento do número de canais de configuração. Porém, com a quantidade de pinos dos FPGAs atualmente disponíveis (1.020 para o dispositivo APEX - EP20K1500E), as possibilidades são muito grandes. 


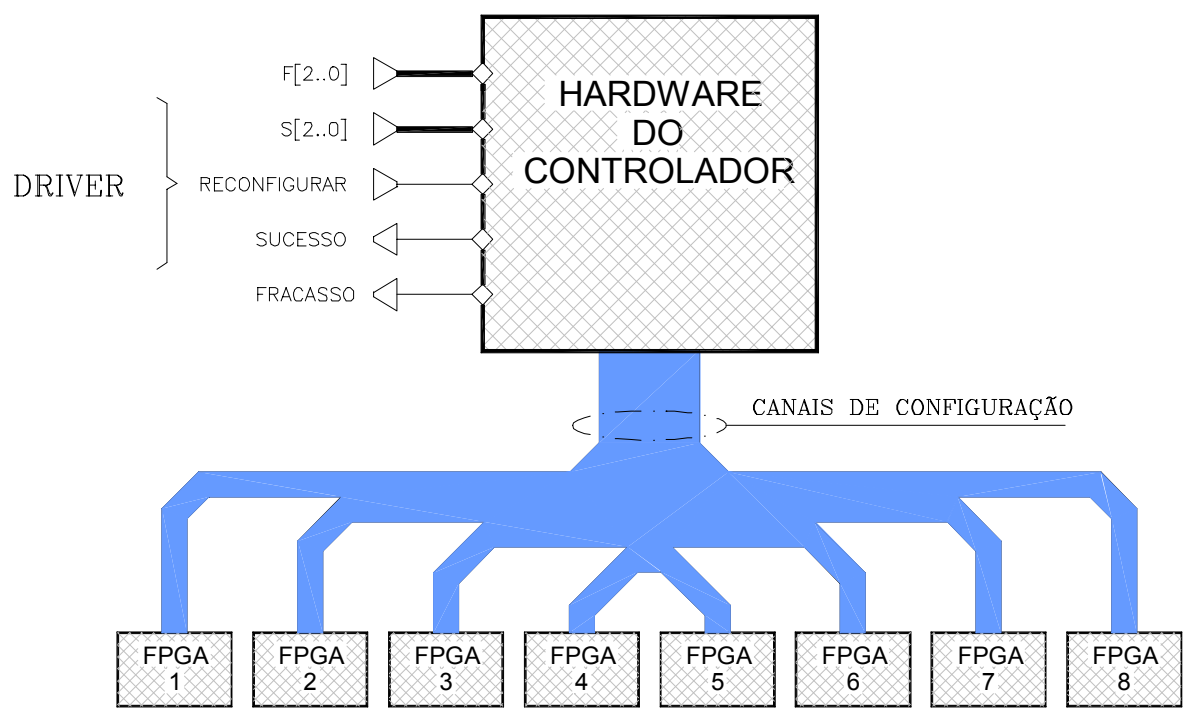

Figura 8.6 - Canais de Configuração para a Plataforma reconfigurável.

\subsubsection{A Interface Entre o Controlador de Configuração e o Dispositivo de Armazenamento de Dados}

Da mesma maneira que no controlador Excalibur, o novo controlador de configuração fornecerá, através de um bloco funcional gerador de endereços, as posições de memória a um dispositivo de armazenamento de dados onde os arquivos de configuração estarão gravados.

Os dados disponibilizados pelo dispositivo de armazenamento serão enviados ao FPGA selecionado através de um barramento denominado D [ 7 . 0 ], comum a toda plataforma reconfigurável. A Figura 8.7 apresenta o esquema adotado.

Os pinos DATA [7.0] dos dispositivos APEX 20K recebem os bytes de configuração. O pino DATA[0] é utilizado tanto na configuração PPS como na PS (Passiva Serial), e não pode ser utilizado como pino de I/O pelo usuário após o término do processo de configuração. No entanto, dispondo-se de um barramento de dados dedicado para um FPGA, os pinos DATA [7..1] não possuem esta restrição e podem, após configurado o dispositivo, ser utilizados pelo usuário como qualquer outro pino de I/O. 


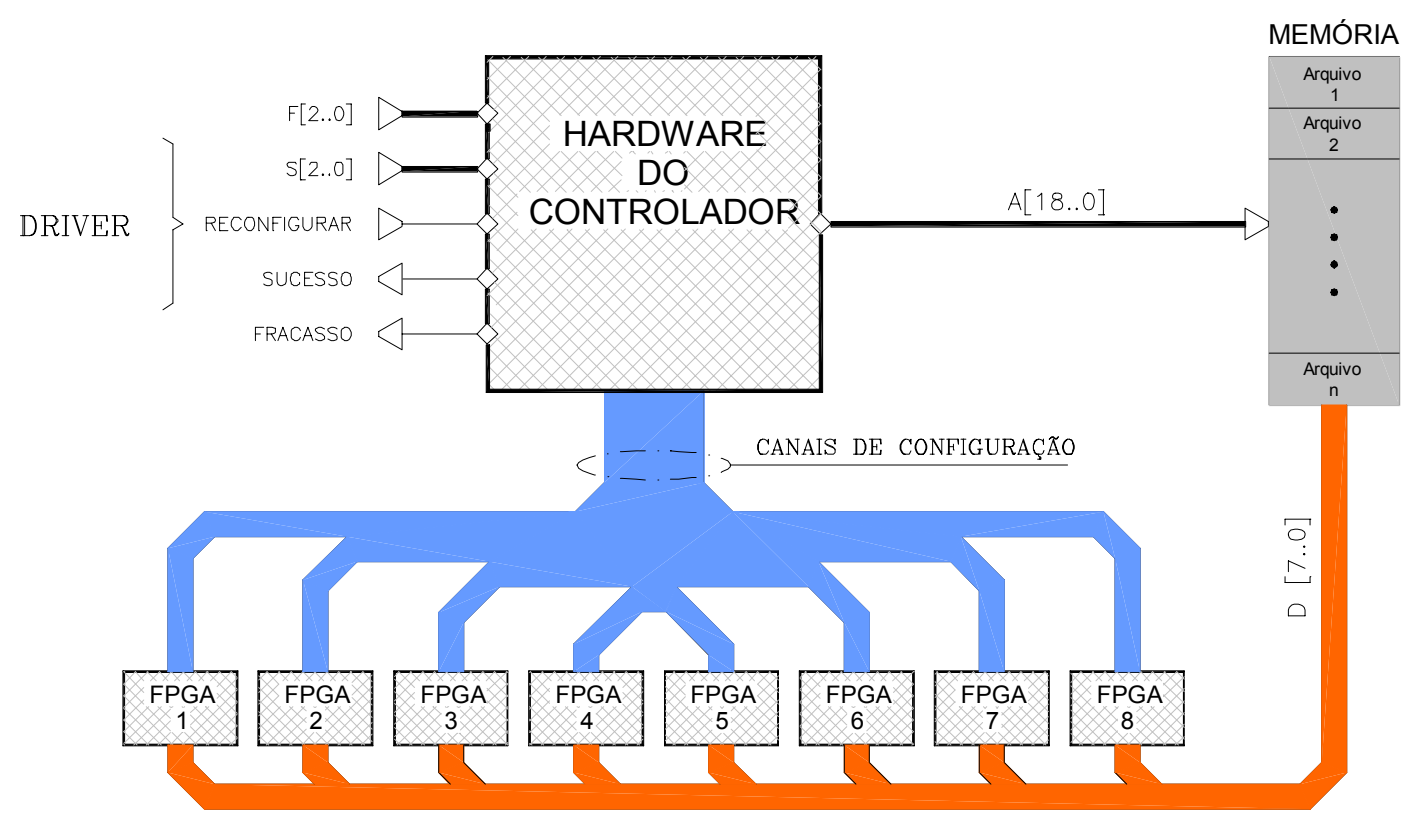

Figura 8.7 - O Hardware Dedicado e suas Interfaces.

Devido ao arranjo aqui adotado, nenhum FPGA da arquitetura poderá ter seus pinos DATA [ 7 . 1] utilizados como pinos de I/O. Os dados de configuração destinado a um determinado dispositivo pertencente à plataforma, chegam aos pinos DATA [7..1] de toda a arquitetura, gerando conflito se estes forem utilizados para outro fim.

\subsection{O Driver do Novo Controlador de Configuração}

O item 7.4 apresenta o funcionamento básico do driver do novo controlador de configuração. A inserção de uma instância do processador Nios também foi brevemente discutida. Nesta seção, serão detalhadas as implementações destes dois itens. 


\subsubsection{A Parametrização do Processador Nios ${ }^{\mathrm{TM}}$}

Um módulo completo do sistema Nios é composto pelo processador Nios embutido e por um sistema de periféricos a ele conectado. $\mathrm{O}$ ambiente de desenvolvimento Quartus ${ }^{\mathrm{TM}}$, através da sua interface MegaWizard Plug-In Manager ${ }^{\mathrm{TM}}$, propicia uma fácil especificação de parâmetros pertinentes à arquitetura do processador em construção, além da determinação dos periféricos opcionais a serem utilizados pelo módulo gerado.

Na primeira fase deste processo, o projetista usuário do sistema pode optar por um processador de 16 ou de 32 bits. Para o controlador de configuração aqui projetado, optou-se pela segunda opção. Devido à simplicidade do driver a ser executado pela instância do processador utilizado, uma opção pelo processador de 16 bits seria extremamente satisfatória. No entanto, sua limitada capacidade de endereçamento tornou inviável a sua utilização.

Além da largura do barramento de dados, definiu-se um barramento de endereços de 21 bits e também um conjunto de registradores com 256 unidades.

Definidas estas características, inicia-se a fase de determinação do conjunto de periféricos a serem conectados ao módulo processador.

\subsubsection{Definição do Conjunto de Periféricos}

O sistema de periféricos Nios permite ao processador embutido gerado, conectar-se e comunicar-se com uma lógica interna ao FPGA, onde este será implementado, ou com o hardware externo contido na placa de desenvolvimento Excalibur. Através do ambiente Quartus, pode-se especificar o nome, tipo, endereço (mapeado na memória), além de prioridades para as interrupções do sistema de periféricos definido.

O módulo processador Nios, utilizado no projeto do controlador de configuração aqui desenvolvido, contará com um conjunto de periféricos conforme 
indica a Figura 8.8. A função e as características adotadas para cada um deles serão explanadas nas próximas seções.

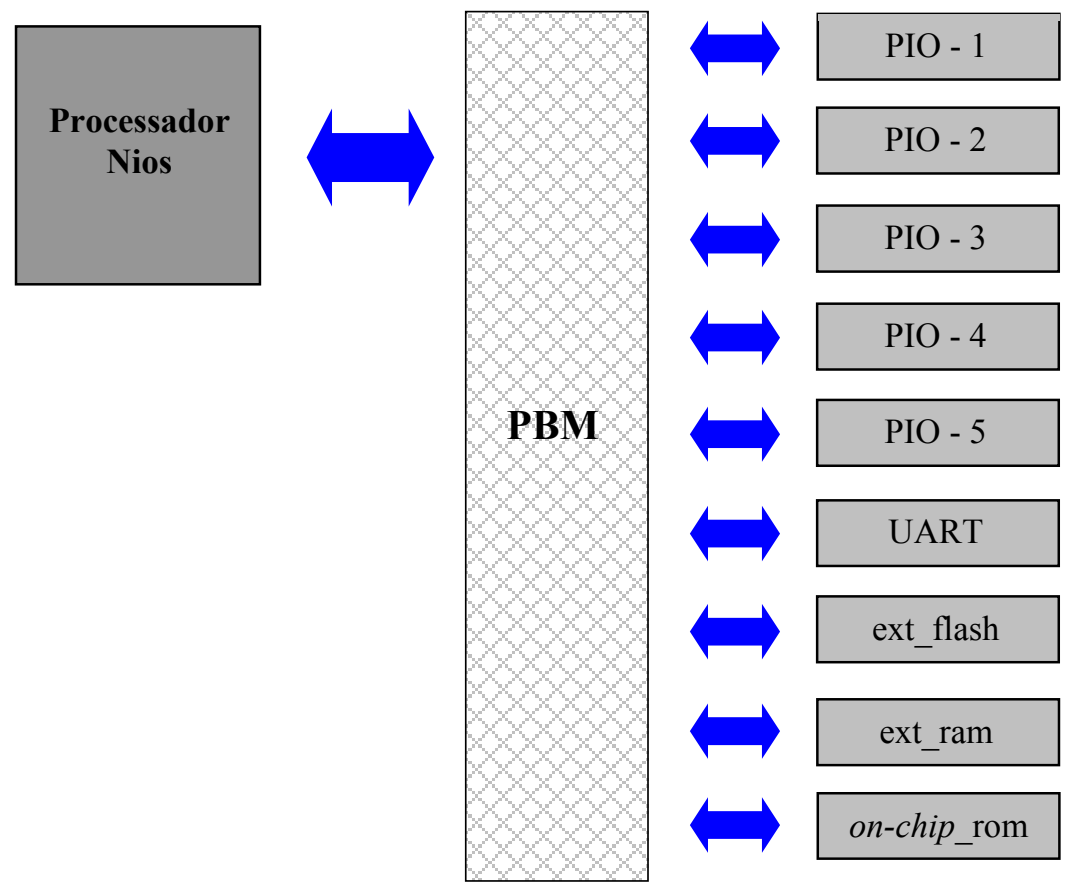

Figura 8.8 - O Processador Nios e o Conjunto de Periféricos Utilizado.

\subsubsection{Memória ROM para Arquivo de Boot do Processador Nios}

Para a inicialização do processador Nios, faz-se necessária a existência de uma memória ROM on-chip onde estará armazenado o arquivo de Boot do módulo processador. Esta memória, implementada através dos ESBs contidos nos dispositivos APEX, tem seu conteúdo também determinado pelo projetista do sistema.

Dentro das opções disponíveis, adotou-se uma memória ROM de 32 bits com capacidade de armazenamento de 1 KBytes. Para o conteúdo desta memória, definiu-se o programa monitor "GERMS". Este programa contém as instruções necessárias para a inicialização do sistema Nios, além de permitir a realização de downloads de arquivos para a memória FLASH da placa Excalibur, conforme citado no item 7.2.2. 


\subsubsection{Periféricos para Comunicação com Memórias FLASH e SRAM}

Os periféricos denominados ext_ram e ext_flash estão disponíveis para utilização por parte do usuário do sistema. Estes dois periféricos possibilitam a comunicação entre o processador embutido Nios e as memórias off-chip SRAM e FLASH contidas na placa de desenvolvimento do kit Excalibur.

A parametrização adotada para o periférico ext_ram faz com que o módulo do sistema Nios reconheça os dois chips de memória SRAM da placa, como um único bloco de 32 bits e capacidade de armazenamento de 256 KBytes.

Para o periférico ext_flash, a configuração adotada trata a memória FLASH contida na placa como um bloco de 8 bits e 1 MBytes.

\subsubsection{Periférico UART para Comunicação com o Host.}

A instância do processador Nios aqui utilizada possui uma interface de comunicação serial RS-232 para troca de dados com o Host. Para implementar esta interface, utilizou-se do periférico UART encontrado no conjunto de periféricos disponíveis. Para este periférico, a interface MegaWizard permite que sejam configuradas todas as características listadas na Tabela 8.1.

Tabela 8.1 - Parâmetros Ajustáveis para o Periférico UART.

\begin{tabular}{|c|l|}
\hline CARACTERÍSTICA & \multicolumn{1}{|c|}{ POSSIBILIDADES } \\
\hline Tamanho dos Frames & O usuário pode optar por frames de 7 ou 8 bits. \\
\hline Bit de Paridade & $\begin{array}{l}\text { Opcionalmente, o bit de paridade pode ser desconsiderado pelo } \\
\text { periférico em modo receptor. }\end{array}$ \\
\hline Taxa de Transmissão (Bauds) & $\begin{array}{l}\text { A taxa de transmissão pode ser ajustada dentro de uma faixa de } 300 \text { a } \\
115200 \text { Bauds. }\end{array}$ \\
\hline Stop Bits & Pode-se optar por 1 ou 2 stop bits. \\
\hline
\end{tabular}


Através do ambiente Quartus, definiu-se para este periférico uma taxa de transmissão de 115200 Bauds, frames com 8 bits de dados, 2 stop bits e ausência de bit de paridade.

\subsubsection{Periféricos PIO para Comunicação com o Hardware Dedicado.}

Para a comunicação com o hardware dedicado, a instância do processador Nios necessita de cinco periféricos PIO (Parallel Input/Output). Para este periférico, a interface MegaWizard permite que sejam configuradas todas as características listadas na Tabela 8.2.

Tabela 8.2 - Parâmetros Ajustáveis para o Periférico PIO.

\begin{tabular}{|c|l|}
\hline CARACTERÍSTICA & \multicolumn{1}{|c|}{ POSSIBILIDADES } \\
\hline Tamanho do Porto & $\begin{array}{l}\text { O tamanho do barramento de dados do periférico PIO pode ser } \\
\text { escolhido dentro de uma faixa que vai de } 1 \text { a } 32 \text { bits. }\end{array}$ \\
\hline Direção dos Dados & $\begin{array}{l}\text { O periférico pode ter seus terminais ajustados como pinos } \\
\text { unidirecionais (entrada ou saída de dados), ou como pinos } \\
\text { bidirecionais (tri-state) }\end{array}$ \\
\hline Tipo de Sincronismo & $\begin{array}{l}\text { Um registrador pode ser opcionalmente incluído ao periférico. Este } \\
\text { registrador pode ser ajustado para capturar dados na borda de subida, } \\
\text { de descida ou em qualquer transição do sinal de clock. }\end{array}$ \\
\hline Interrupção & $\begin{array}{l}\text { O periférico pode opcionalmente gerar um sinal de interrupção. A } \\
\text { prioridade atribuída ao sinal também é especificada. }\end{array}$ \\
\hline
\end{tabular}

Conforme discutido no item 8.1.1.2, o driver do controlador de configuração aqui desenvolvido deverá informar ao hardware dedicado qual FPGA será reconfigurado. O periférico PIO-1 responsável pela transmissão desta informação (Figura 8.8), foi configurado com um barramento unidirecional de saída de dados com 3 bits de largura. Através do ambiente de desenvolvimento Quartus, os 3 bits de dados deste periférico são, posteriormente, conectados ao barramento S[2..0] (Figura 8.2) do hardware dedicado do controlador em questão. 
Com o mesmo procedimento e adotando-se as mesmas características do periférico PIO-1, gerou-se o periférico PIO-2. Este periférico, responsável pela transmissão da informação de arquivo de configuração a ser utilizado, conectar-se-á ao barramento F[2..0] (Figura 8.1) do hardware dedicado.

A transição do sinal nCONFIG, gerada pelo driver e transmitida ao pino RECONFIGURAR do hardware dedicado, será enviada através do periférico PIO-3. Configurado com um barramento de dados de 1 bit, este periférico também recebeu a característica unidirecional de saída de dados.

Para o tratamento dos sinais de SUCESSO e FRACASSO, gerados pelo hardware dedicado, criou-se os periféricos PIO-4 e PIO-5. Possuindo características comuns, estes periféricos foram configurados com um barramento de dados unidirecional de entrada de dados de 1 bit.

Todos os periféricos PIO utilizados foram configurados de forma a não gerar sinais de interrupção. Além disso, todos funcionarão de maneira assíncrona.

Para programas em C, o mapeamento dos registradores, utilizados para troca de dados entre o processador Nios e os seus respectivos periféricos, é implementado na forma de estruturas de dados. A estrutura utilizada para os periféricos PIO pode ser visualizada na Figura 8.9.

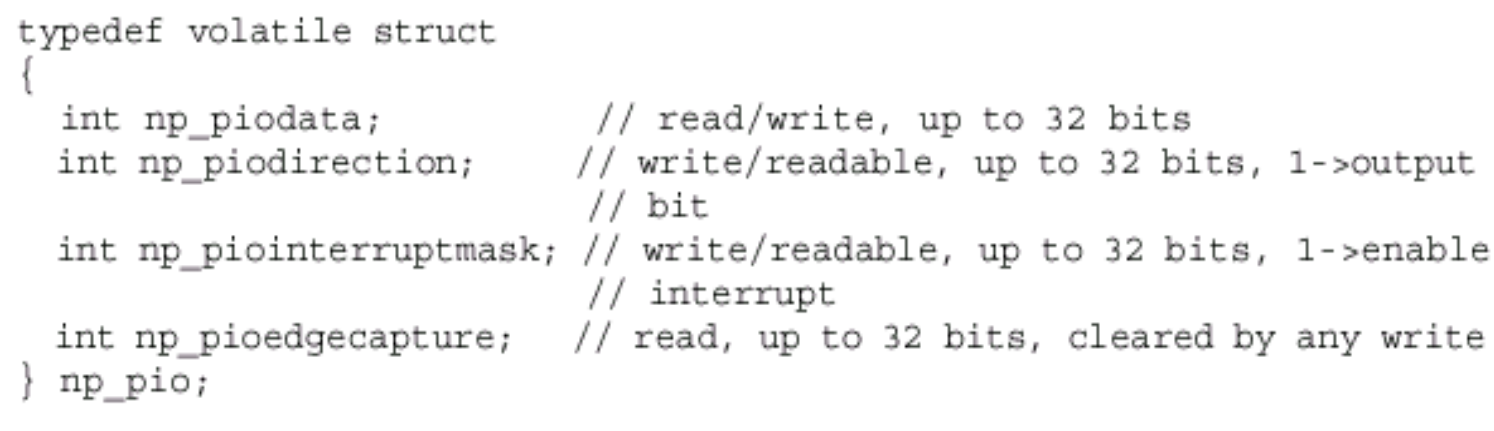

Figura 8.9 - Estrutura de Dados dos Periféricos PIO. 


\subsubsection{O Projeto do Driver do Novo Controlador}

O desenvolvimento de aplicativos para o processador Nios é ligeiramente diferente que a maneira tradicionalmente utilizada. Esta característica deve-se ao fato de o projetista ter a liberdade de configurar a arquitetura do processador e especificar o conjunto de periféricos conectados a este. Em outras palavras, o usuário do sistema Nios pode construir um microcontrolador de acordo com suas necessidades ao invés de escolher um dispositivo pré-fabricado com um conjunto fixo de periféricos, memória on-chip, e interfaces externas.

O driver responsável pela comunicação entre o kernel do sistema operacional do robô e o hardware dedicado do novo controlador de configuração foi construído em linguagem C. Nesta fase do projeto, o software gerado será controlado por um usuário que fornecerá as informações necessárias para o início do processo de configuração. Através do host conectado ao sistema, as informações de FPGA a ser reconfigurado e arquivo de configuração a ser utilizado serão solicitadas pelo driver e fornecidas a este pelo usuário.

O programa desenvolvido possui quatro variáveis do tipo inteiro. O nome e a função destas variáveis são apresentados na Tabela 8.3.

Tabela 8.3 - As Variáveis do Software.

\begin{tabular}{|c|l|}
\hline VARIÁVEL & \multicolumn{1}{c|}{ DADO ARMAZENADO } \\
\hline FPGA & Número do FPGA a ser reconfigurado. \\
\hline FILE & Identificação do arquivo a ser utilizado no processo solicitado. \\
\hline DONE & Nível lógico do sinal "SUCESSO" originado no hardware dedicado. \\
\hline eek & Nível lógico do sinal "FRACASSO" originado no hardware dedicado. \\
\hline
\end{tabular}

Através do display conectado ao host, o software solicita a identificação do FPGA a ser reconfigurado. O usuário deve digitar um número entre 0 e 7 . Esta informação fica armazenada na variável "FPGA". Em seguida, surge na tela uma solicitação de arquivo de configuração a ser utilizado. Digitada a opção, também entre 
0 e 7, a variável "FILE” é carregada. O fluxograma da Figura 8.10 apresenta este trecho do programa.

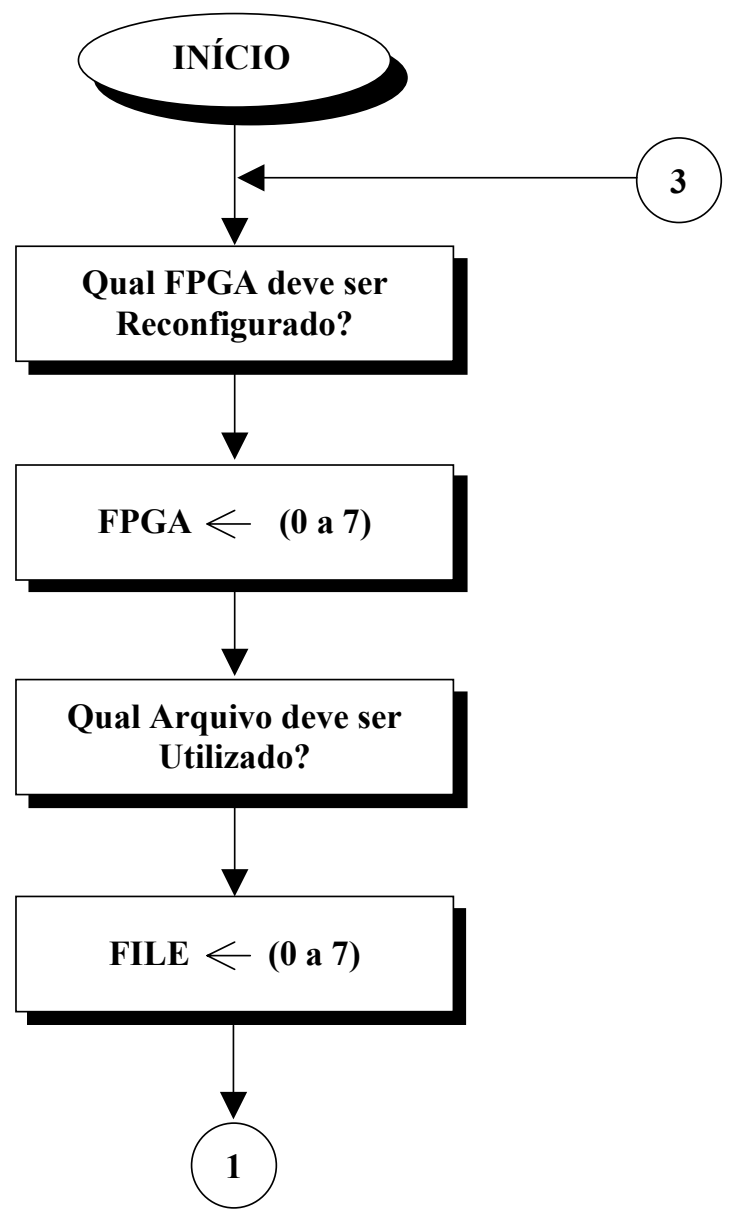

Figura 8.10 - Fluxograma do Trecho Inicial do Programa C.

Após a etapa de entrada de dados, o software projetado realiza uma chamada às funções denominadas "Seleção do Dispositivo" e "Seleção do Arquivo". Estas funções acionam os periféricos PIO-1 e PIO-2 que se encarregam de enviar as informações recém digitadas ao hardware dedicado.

Cada uma destas funções acessa seu respectivo periférico através do endereço determinado pela variável ponteiro "pio". O código das duas funções em questão pode ser observado na Figura 8.11. 


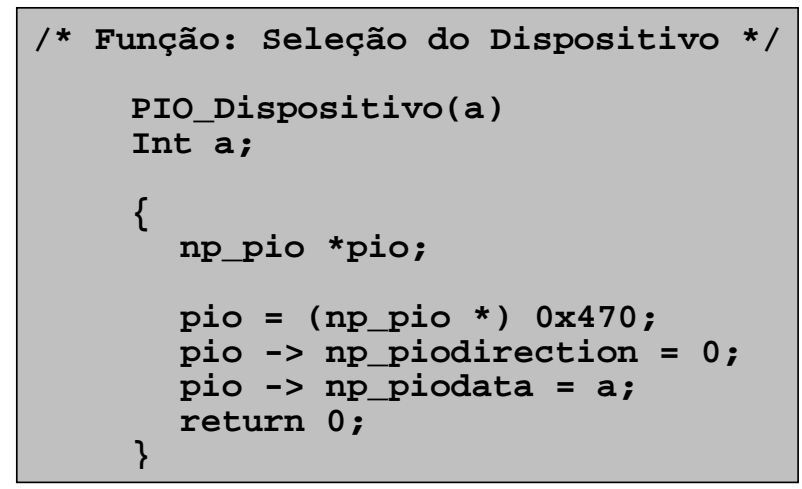

(a) Seleção do Dispositivo a ser Reconfigurado.

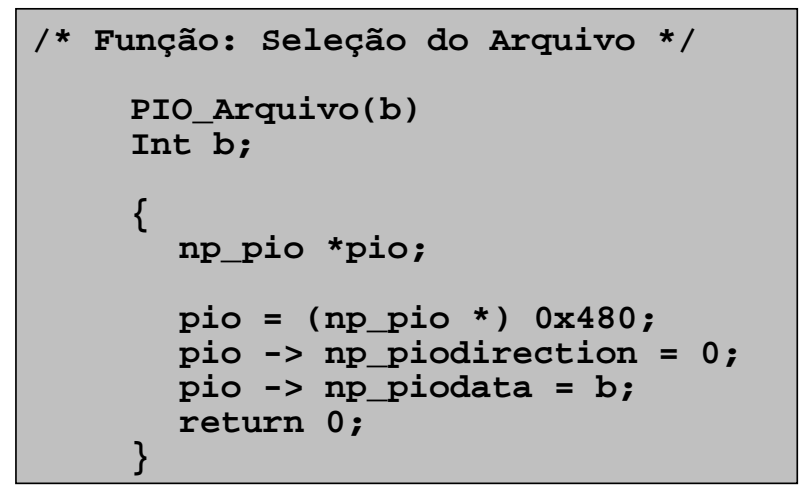

(b) Seleção do Arquivo a ser Utilizado.

Figura 8.11 - Código das Funções "Seleção do Dispositivo" e "Seleção do Arquivo".

Executadas estas duas funções, uma terceira função é chamada. Esta última, denominada "Pulso", tem como intuito gerar o pulso para o sinal "RECONF IGURAR" do hardware dedicado.

O pulso gerado por esta função é obtido através de um laço for. Enquanto fora deste laço, a função envia ao periférico por ela acionado (PIO-3) o valor binário 0 (zero). Quando a execução do programa entra no laço, o valor binário enviado passa a ser 1 (um) e então inicia-se uma contagem. Ao término desta, a expressão do laço tornase falsa e este é terminado. A instrução seguinte reajusta para 0 (zero) o valor binário enviado ao periférico. O código $\mathrm{C}$ desta função é apresentado na Figura 8.12. 


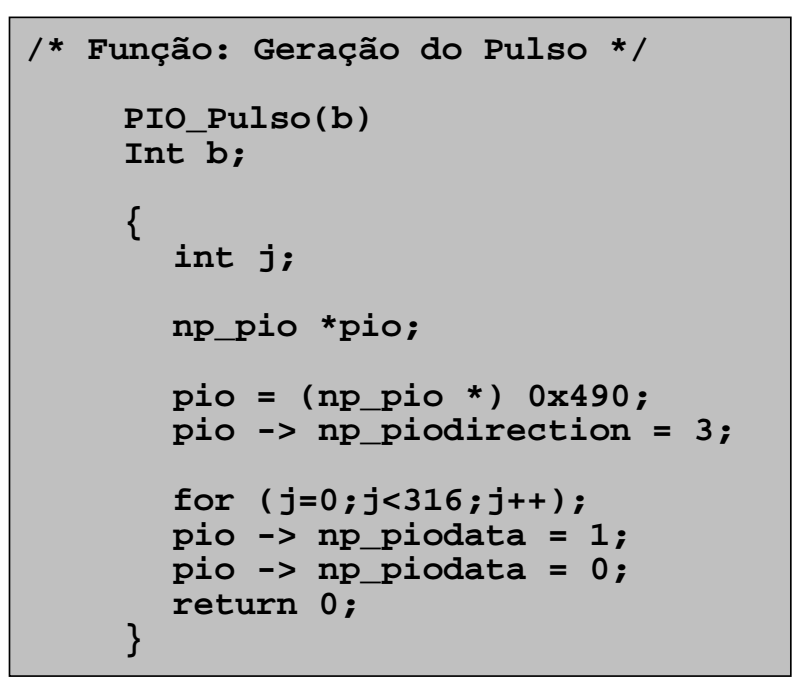

Figura 8.12 - Código da Função "Pulso".

A execução da função "Pulso" gera um pulso baixo-alto-baixo. Conectado ao pino adequado do hardware dedicado (Figura 8.3), este sinal dá inicio ao processo de configuração determinado pelo usuário. Esta segunda etapa do programa pode ser visualizada no fluxograma da Figura 8.13.

Depois de executadas as três funções anteriormente citadas, o driver permanece em estado de espera por uma sinalização, por parte do hardware dedicado, de sucesso ou fracasso do processo em andamento. Estas informações, geradas conforme descreve o item 8.1.1.4, chegam respectivamente através dos periféricos PIO4 e PIO-5. De acordo com o sinal recebido, uma mensagem é gerada. 


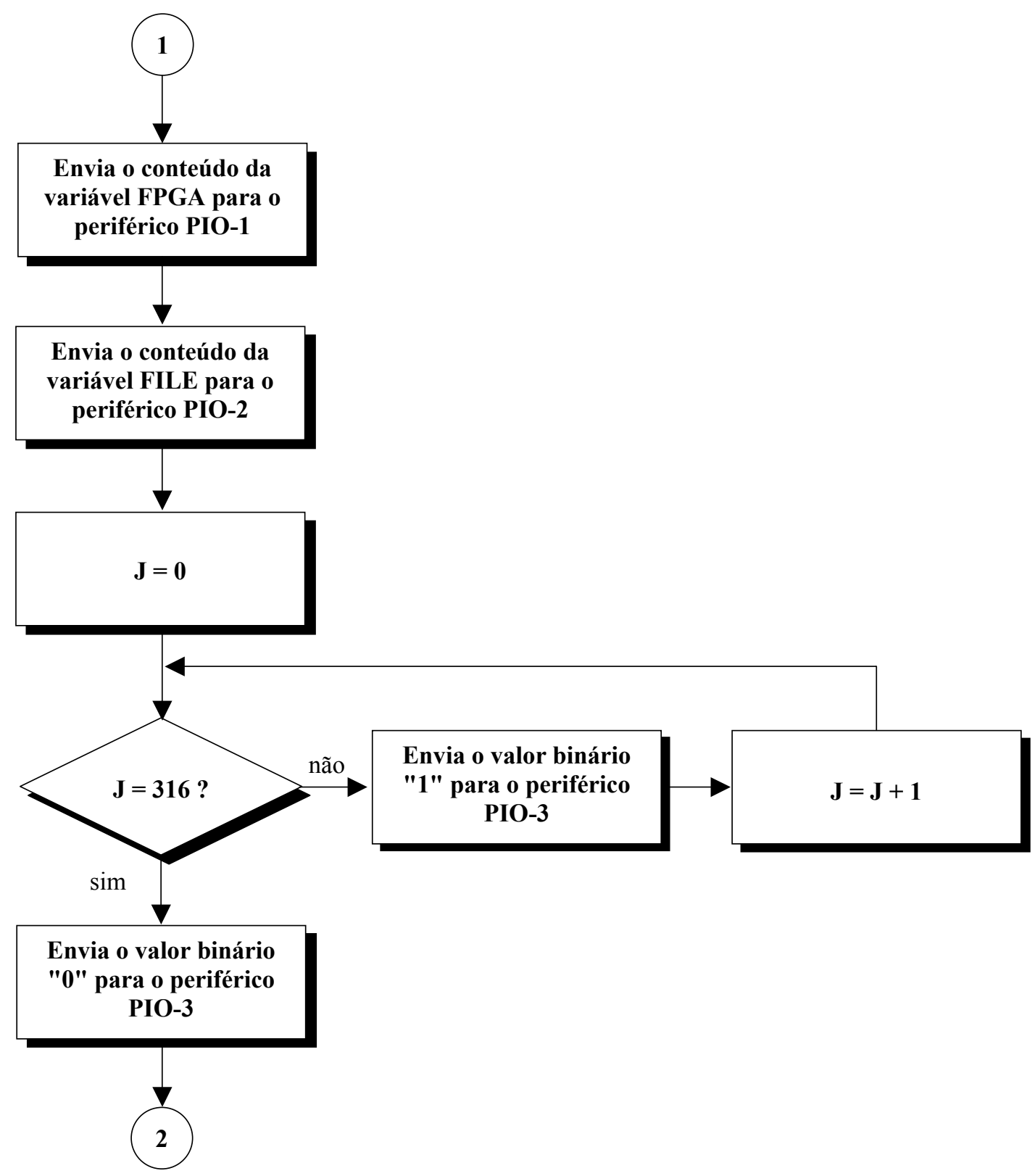

Figura 8.13 - O Envio das Informações ao Hardware Dedicado.

Este comportamento do driver é implementado através de um laço while. Neste laço, os periféricos PIO-4 e PIO-5 são constantemente checados e esta situação permanece inalterada enquanto o nível lógico dos sinais que chegam a estes for 0 (zero). Assim que um destes periféricos recebe uma transição baixo-alto, o laço é encerrado e uma mensagem apropriada é enviada pelo driver à tela do host. O fluxograma apresentado na Figura 8.14 ilustra esta etapa final do programa. 


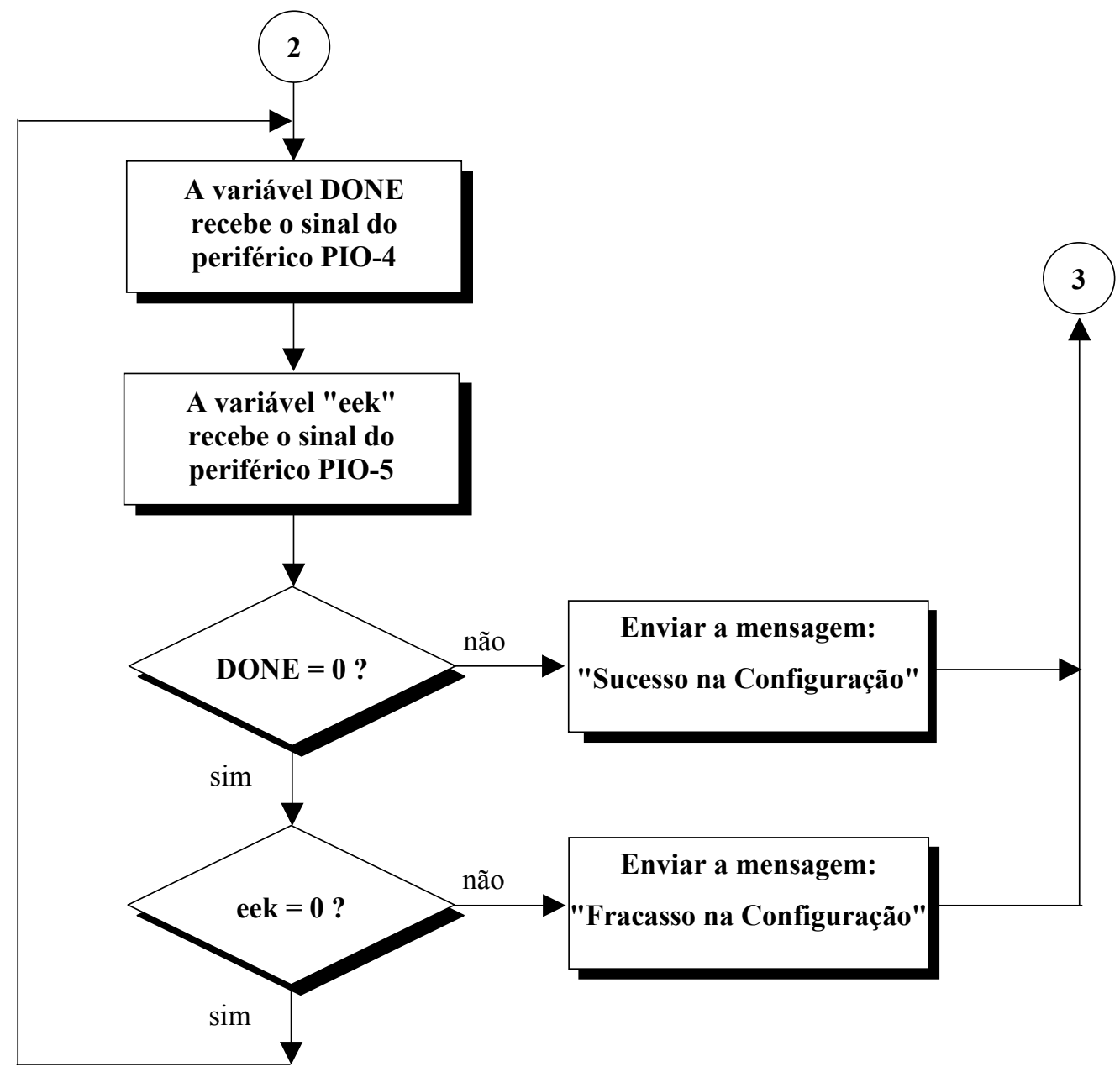

Figura 8.14 - O Tratamento dos Sinais de Sucesso e Fracasso do Processo de Configuração.

Após o envio da mensagem ao host, o software retorna ao seu estado inicial, solicitando a identificação de FPGA e arquivo de configuração a serem utilizados no próximo processo de configuração.

Numa outra etapa do projeto ARMOSH, conforme descrito no item 7.4.2, as informações aqui fornecidas pelo usuário e aquelas enviadas à tela do host, serão trocadas entre o driver e o kernel do sistema operacional do robô. 


\section{Capítulo 9}

\section{Validação e Resultados}

\subsection{Adoção do Método de Validação}

Para a validação deste trabalho de mestrado tinha-se como proposta inicial, a utilização do CPLD EPM7064 contido na placa de desenvolvimento do kit Excalibur. Conforme mencionado no item 7.2, é através deste dispositivo que se implementou o controlador de configuração do referido kit. A idéia inicial era reconfigurar o EPM7064, a partir de sua interface JTAG, com o projeto do novo controlador de configuração aqui desenvolvido. Através desta metodologia, a validação deste trabalho seria bastante direta. Poderia se montar um arranjo composto por duas (ou mais) placas de desenvolvimento Excalibur. Em uma delas o novo controlador seria implementado e o FPGA APEX da mesma poderia ser reconfigurado. As placas estariam interligadas e o controlador configuraria também os FPGAs pertencentes às outras placas interligadas ao sistema.

Numa análise mais aprofundada sobre as características do CPLD EPM7064 e também sobre o diagrama esquemático da placa, constatou-se que este método de validação não poderia ser adotado. O chip EPM7064 possui uma quantidade de pinos bastante limitada (36 pinos de I/O disponíveis), suficiente para um controlador simples como o encontrado na placa de desenvolvimento mas muito pequena para as necessidades do controlador aqui projetado. Além disso, com exceção dos pinos de configuração JTAG, nenhum outro pino do chip EPM7064 são acessíveis pelo usuário impossibilitando a implementação do arranjo inicialmente proposto. A adoção deste método de validação também foi inviabilizada pela pequena capacidade lógica do dispositivo. Com apenas 1250 portas lógicas utilizáveis, torna-se impossível a implementação de um processador como o Nios.

Frente a estas dificuldades, um outro método de validação deveria ser adotado. Optou-se então por implementar o novo controlador de configuração no próprio 
dispositivo APEX da placa excalibur. Após a implementação, os canais de configuração do controlador seriam interligados aos conectores de expansão da placa e o projeto poderia ser então testado. Entretanto, a idéia inicial de se configurar os FPGAs APEX de outras placas de desenvolvimento não foi bem sucedida. O FPGA do kit Excalibur tem seus pinos de configuração fisicamente interligados aos correspondentes terminais do EPM7064. A inacessibilidade destes torna o processo de configuração do dispositivo APEX destas placas, uma exclusividade do controlador implementado no CPLD do kit.

Para a validação do novo controlador passou-se então a pensar na compra de ao menos um FPGA da família APEX. Um FPGA APEX EP20K30E com 30.000 portas lógicas, 144 pinos e encapsulamento tipo TQFP (Thin Quad Flat Pack) foi cotado por aproximadamente U\$40,00. O custo relativamente baixo viabilizava a compra porém, dois fatores fizeram com que a idéia fosse também deixada de lado. O representante da Altera no Brasil levaria de dois a dois meses e meio para entregar o dispositivo, o que atrasaria em muito o desenvolvimento do projeto. Além disso, o componente ainda deveria ser soldado a uma placa de circuito impresso especialmente desenhada para este propósito. Pouquíssimas empresas no país possuem tecnologia para trabalhar com este tipo de encapsulamento e o custo para este desenvolvimento superaria em muito o custo do próprio chip.

A impossibilidade de utilização dos dispositivos APEX contidos nos kits de desenvolvimento Excalibur e a inviabilidade na aquisição dos mesmos através de representantes da Altera no Brasil, fizeram com que restassem duas possibilidades de validação. Numa delas, os sinais gerados pelo controlador projetado poderiam ser registrados por um analisador lógico e comparados com as especificações do fabricante. Uma outra forma seria a emulação de um APEX20K, ou seja, construiria-se um hardware dedicado que respondesse ao controlador de configuração projetado da mesma maneira que um FPGA APEX o faria.

As facilidades para o projeto e simulação de hardware, proporcionadas pelas ferramentas EDA disponíveis no laboratório LCR, tornaram esta última opção bastante atraente e foi então este o método adotado para a validação deste trabalho. 


\subsection{O Projeto de Emulação dos FPGAs da Família APEX}

O projeto do hardware de emulação dos dispositivos APEX foi totalmente desenvolvido em modo esquemático, através da ferramenta de desenvolvimento Quartus. O projeto prevê terminais para todos os sinais envolvidos no processo de configuração dos dispositivos reais, incluindo um barramento destinado à recepção dos dados de configuração. A Figura 9.1 apresenta todos os terminais do hardware de emulação projetado.

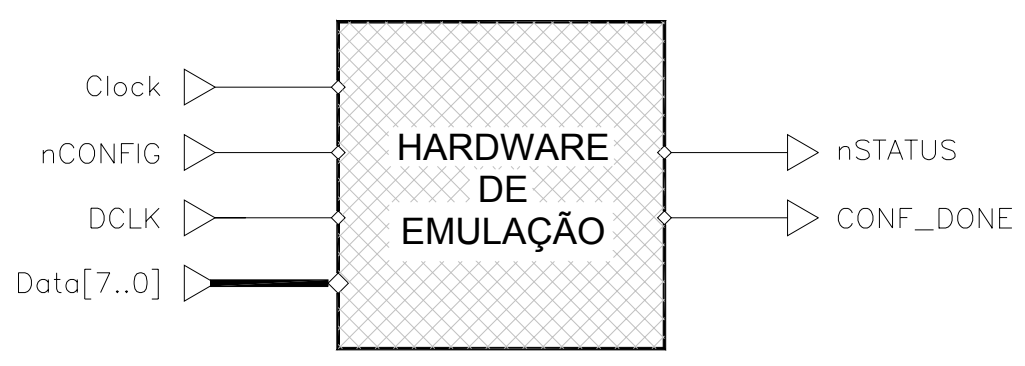

Figura 9.1 - Os Terminais do FPGA Emulado.

O funcionamento do APEX emulado tem início assim que um pulso (altobaixo-alto), gerado pelo controlador de configuração a ele conectado, é aplicado ao pino "nCONF IG". Recebido este pulso, o hardware de emulação gera uma transição no pino "nSTATUS" e em resposta, o controlador de configuração passa a enviar o sinal de clock "DCLK" utilizado na serialização dos dados de configuração recebidos através barramento "Data [ 7 . .0]".

A arquitetura dos FPGAs pertencentes à família APEX foi desenvolvida de forma a minimizar os efeitos de ruídos no sistema e assegurar que dados de configuração, corrompidos durante a fase de transmissão, não sejam utilizados no processo de configuração. Estes dispositivos são providos de circuitos com características particulares que promovem um alto nível de confiabilidade aos mesmos [17]. Os circuitos utilizados na detecção de frames corrompidos são baseados no algoritmo - Código de Redundância Cíclica (CRC) - brevemente descrito na próxima seção. Maiores detalhes sobre o algoritmo podem ser encontrados no Anexo-I.

Para uma perfeita emulação desta família de FPGAs, torna-se importante a incorporação destes circuitos ao hardware de emulação projetado. Nas seções que 
seguem, o projeto do hardware de emulação dos dispositivos APEX é apresentado em detalhes.

\subsubsection{O Algoritmo CRC e sua Inserção ao Hardware de Emulação}

O CRC é uma poderosa técnica, porém facilmente implementada, utilizada para se obter confiabilidade na transmissão de dados [30]. Utilizando-se desta técnica, o transmissor da informação anexa uma seqüência extra de bits, denominada Frame Check Sequence (FCS), a todos os frames por ele enviados. O FCS carrega consigo informações redundantes sobre o frame transmitido, que auxiliam ao receptor da mensagem na detecção de erros inseridos durante o processo de transmissão.

Um CRC implementado em hardware está presente nos FPGAs APEX e é utilizado na validação de cada frame de dados carregado no dispositivo alvo. Se o FCS gerado no FPGA não coincide com aquele anexado aos frames originalmente transmitidos, o processo de configuração é interrompido e o nível lógico do sinal nSTATUS é levado para "0", indicando uma condição de erro ao controlador de configuração do sistema. O circuito CRC garante um alto grau de imunidade a ruídos, diminuindo assim a probabilidade de uma configuração incorreta ou incompleta.

Contatada, a Altera negou-se a fornecer o algoritmo CRC utilizado para estes dispositivos, alegando ser este um software proprietário. Sendo assim, um CRC foi criado, testado e posteriormente acrescentado ao projeto de emulação desenvolvido.

\subsubsection{O CRC Utilizado no Hardware de Emulação}

O FCS anexado aos frames é obtido de acordo com a seguinte equação:

$$
\mathrm{FCS}=\text { resto de }\left[M(x) \times \frac{x^{n}}{G(x)}\right]
$$


Os bits que compõem o dado a ser transmitido são os coeficientes do polinômio $\mathrm{M}(\mathrm{x})$. Para se determinar o FCS de uma mensagem um outro polinômio, denominado polinômio gerador $\mathrm{G}(\mathrm{x})$, é adotado. O cálculo do FCS envolve a multiplicação de $\mathrm{M}(\mathrm{x})$ por $\mathrm{x}^{\mathrm{n}}$ (onde $\mathrm{n}$ representa o grau do polinômio $\mathrm{G}(\mathrm{x})$ ), o que resulta em um deslocamento à direita dos coeficientes de $\mathrm{M}(\mathrm{x})$. $\mathrm{O}$ resto, obtido da operação indicada pela equação 9.1, constitui o FCS a ser anexado à mensagem. Este código é baseado na aritmética polinomial (em módulo 2). No lado do receptor, a seqüência de bits recebida $(\mathrm{M}(\mathrm{x})+\mathrm{FCS})$ é utilizada numa outra divisão polinomial onde o divisor é o mesmo $\mathrm{G}(\mathrm{x})$ utilizado no lado transmissor. A não ocorrência de resto nesta última operação indica uma transmissão livre de erros.

Para o projeto do hardware de emulação dos FPGAs APEX, os frames a serem recebidos são compostos por 8 bits. Devido a esta característica, adotou-se um padrão onde o FCS a ser anexado às mensagens será composto por 3 bits, implicando num overhead de $37,5 \%$ sobre cada frame transmitido. O modelo adotado impõe a utilização de um polinômio $\mathrm{G}(\mathrm{x})$ de terceiro grau. Neste projeto, os coeficientes escolhidos para este polinômio foram "1101". Logo:

$$
G(x)=x^{3}+x^{2}+1
$$

O hardware de implementação para o CRC desenvolvido é apresentado na Figura 9.2. Esta implementação é específica para os parâmetros adotados. A quantidade e localização das portas XOR são determinadas de acordo com os coeficientes do polinômio $G(x)$, ou seja, a presença ou ausência de uma porta corresponde à presença ou ausência de um termo no polinômio $\mathrm{G}(\mathrm{x})$.

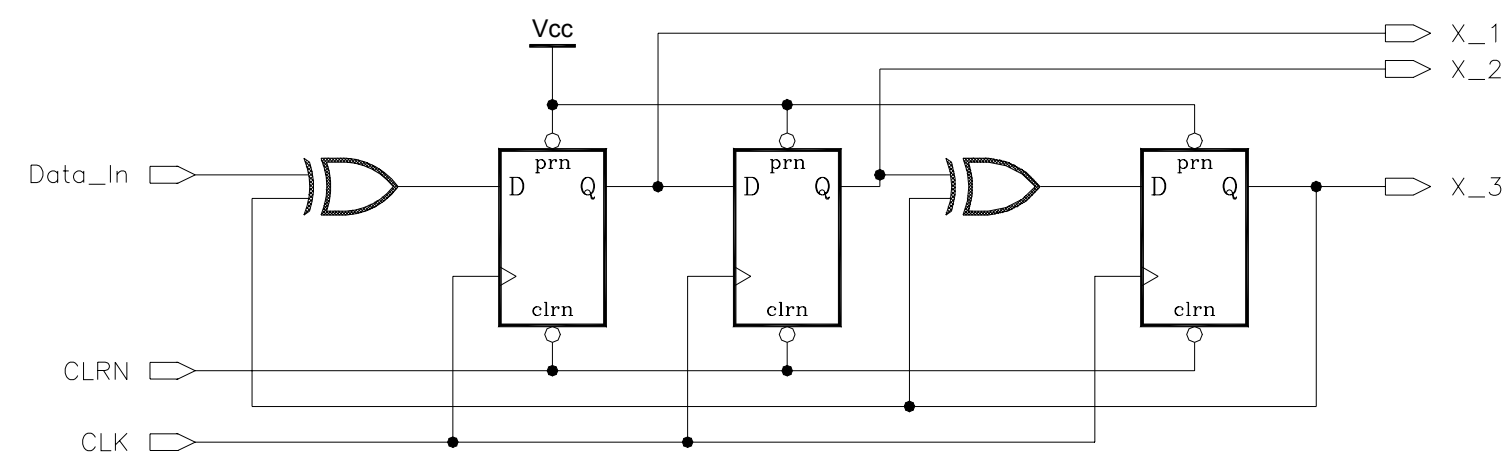

Figura 9.2 - O Hardware para o CRC Utilizado. 
Para o circuito CRC transmissor, depois de processados os 8 bits resultantes da multiplicação $\left(\mathrm{M}(\mathrm{x}) \cdot \mathrm{x}^{\mathrm{n}}\right)$, o FCS é obtido a partir das saídas $\mathrm{x} \_1, \mathrm{x} \_2$ e X_3.

Para que o algoritmo funcione corretamente, tanto o transmissor quanto o receptor da mensagem devem utilizar-se do mesmo circuito CRC. Ao receber a mensagem $(\mathrm{M}(\mathrm{x})+\mathrm{FCS})$, o conteúdo do registrador de deslocamento do CRC receptor deve ser zero. A ocorrência de um valor diferente deste indica a recepção de um frame corrompido.

Resultados empíricos mostram que o CRC projetado é bastante eficiente na detecção de frames contendo um ou dois bits corrompidos. Para uma maior incidência de erros, o projeto demonstra-se pouco confiável.

\subsubsection{Inserindo o CRC no Projeto de Emulação}

Para serem processados pelo $\mathrm{CRC}$, os dados de configuração que chegam ao FPGA emulado precisam ser serializados. Com este propósito, um registrador de deslocamento é inserido entre o pino Data [ 7 . o ] e o terminal de entrada de dados do CRC (Figura 9.3).

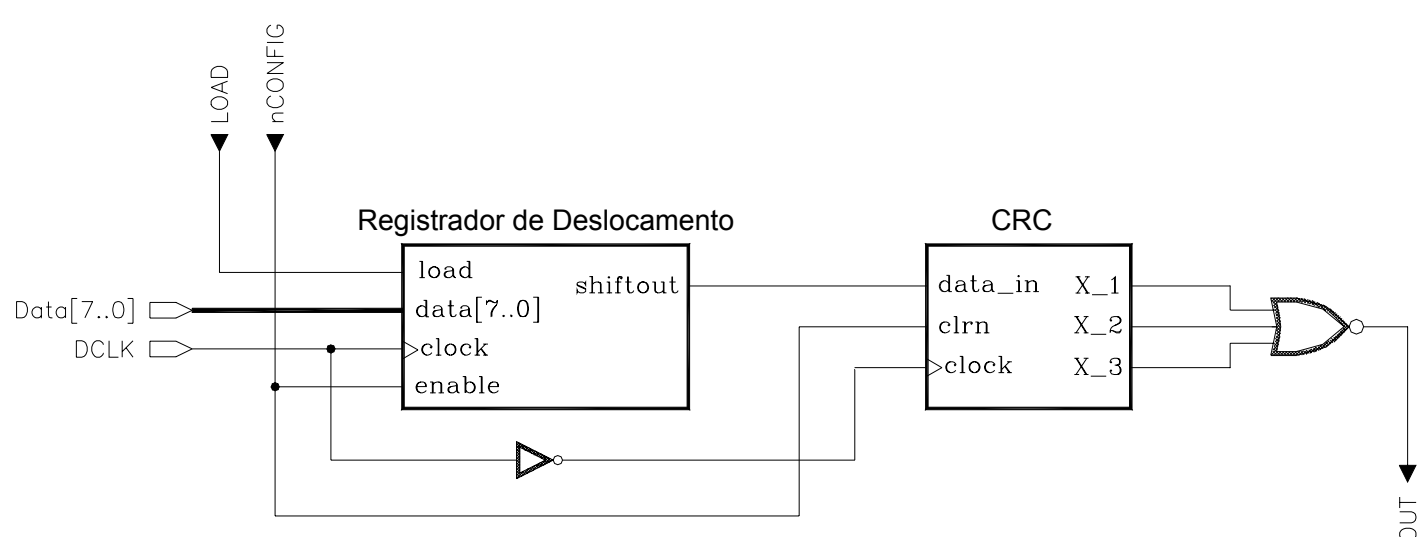

Figura 9.3 - O CRC Inserido ao Sistema. 
O sinal "LOAD", gerado de acordo com o esquema apresentado na Figura 9.4, se encarrega em sincronizar o carregamento do referido registrador. Este último deve ser carregado com o dado contido no barramento Data [7 . . 0] sempre que o sistema é inicializado e posteriormente, a cada oito ciclos de clock do sinal DCLK. Este procedimento faz com que o processo de serialização seja ininterrupto, visto que o controlador de configuração impõe a presença de um novo dado de configuração também a cada oito ciclos de DCLK.

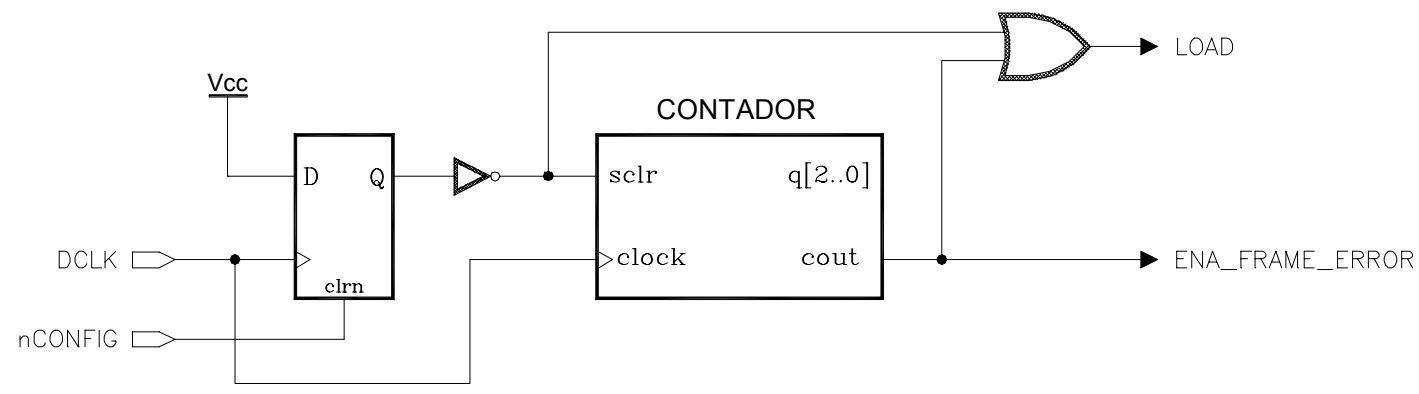

Figura 9.4 - A Geração dos Sinais "LOAD" e "ENA_FRAME_ERROR".

Como pode ser observado na Figura 9.4, sempre que um pulso for aplicado ao pino nCONFIG ou quando o contador de 3 bits atingir o limite de sua contagem, um pulso será enviado através do sinal $L O A D$, fazendo com que o registrador de deslocamento da Figura 9.3 seja carregado no momento adequado.

$\mathrm{O}$ algoritmo do CRC projetado garante que suas saídas $\mathrm{x} \_1, \mathrm{x} \_2$ e $\mathrm{x} \_3$ possuam nível lógico "0" somente depois de processados os 8 bits de um frame livre de erros. Durante a fase de processamento de cada frame, as saídas do CRC flutuam de acordo com o nível lógico dos bits recentemente inseridos. Esta característica faz com que o sinal CRC_OUT (Fig. 9.3) deva ser verificado somente depois de processado o último bit (LSB) de cada frame recebido. Para tanto, CRC_OUT deve estar associado a um flip-flop conforme mostra o esquema da Figura 9.5. 


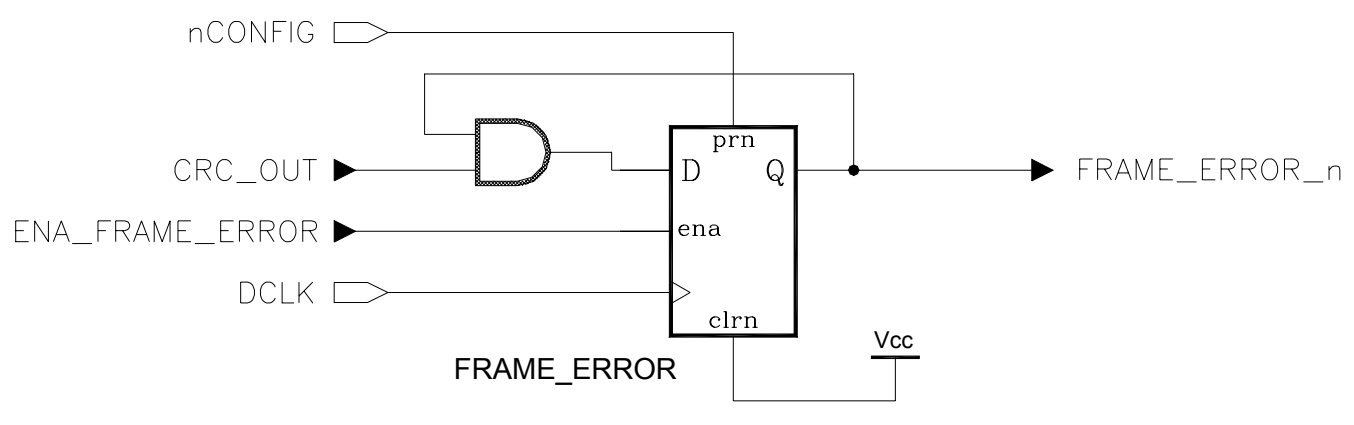

Figura 9.5 - A Geração do Sinal "FRAME_ERROR_n".

Com exceção do momento da inicialização do sistema, sempre que o sinal LOAD torna-se alto, habilitando o carregamento do registrador de deslocamento, o LSB do último frame já foi processado e portanto, é neste instante que CRC_OUT informa sobre a integridade do mesmo. Sendo assim, ao utilizar-se o sinal "ENA_ERAME_ERROR" (Fig. 9.4) como sinal de enable para o flip-flop "FRAME_ERROR" visto na Figura 9.5, o sinal CRC_OUT será armazenado e transferido para FRAME_ERROR_n de forma correta.

No momento da inicialização do sistema, FRAME_ERROR_n assume nível lógico alto. A cada oito ciclos de DCLK o flip-flop FRAME_ERROR é habilitado e o sinal CRC_OUT é amostrado. Se este possuir nível alto, o que indica a recepção de um frame livre de erros, a situação permanece inalterada. $\mathrm{O}$ recebimento de um frame corrompido tornará baixo o nível lógico de FRAME_ERROR_n.

\subsubsection{A Geração do Sinal "CONF_DONE"}

$\mathrm{Na}$ emulação dos dispositivos APEX, os dados de configuração a serem utilizados não serão aqueles produzidos pelo ambiente de desenvolvimento Quartus mas sim, dados cujo conteúdo foi escolhido de maneira casual.

Ao final do processo de configuração, se bem sucedido, os dispositivos APEX elevam o nível lógico do sinal CONF_DONE. Para se obter este mesmo comportamento, o sinal CONF_DONE do hardware de emulação é obtido conforme ilustra a Figura 9.6. 


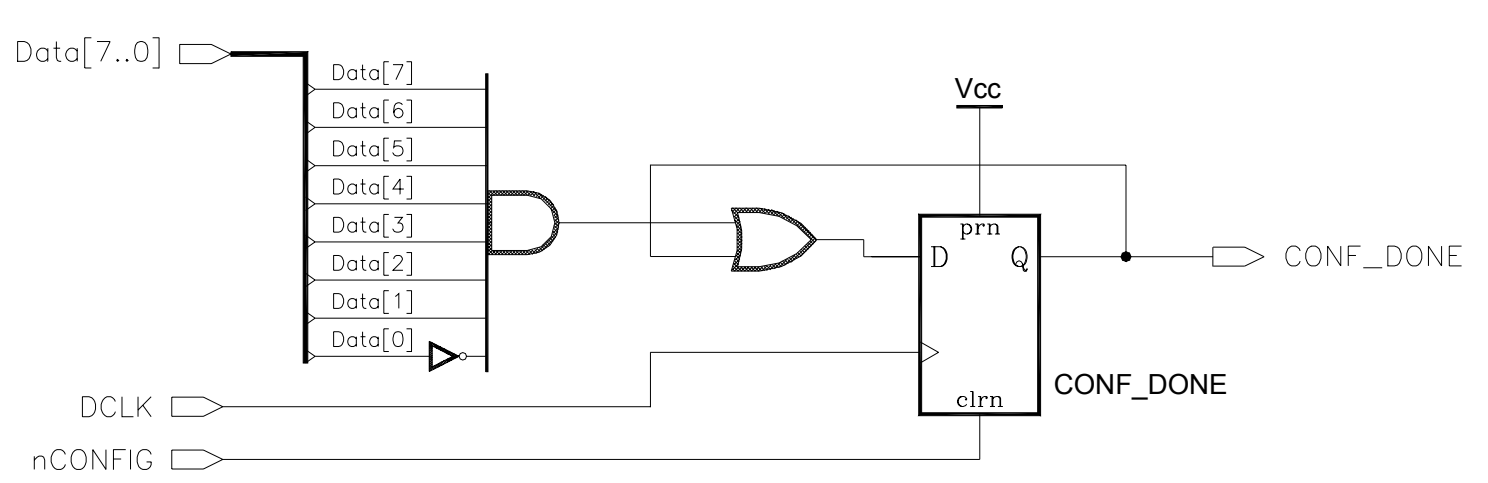

Figura 9.6 - A Geração do Sinal "CONF_DONE".

De acordo com a figura, um pulso em nCONF IG leva para "0" o nível do sinal CONF_DONE. Este por sua vez, permanece neste estado até que o barramento Data [7..0] receba uma palavra contendo o valor binário "11111110". Qualquer valor diferente deste, não interfere no estado de CONF_DONE. Uma palavra contendo este valor $\left(\mathrm{FE}_{(\mathrm{H})}\right)$ tornará alto o nível lógico de $\mathrm{CONF} \_\mathrm{DONE}$, indicando ao controlador de configuração o final bem sucedido de um processo de pseudo-configuração do APEX emulado.

\subsubsection{A Geração do Sinal "nStatus"}

Para a emulação do sinal nSTATUS utilizou-se de um contador e um flip-flop. O contador é acionado pelo sinal de clock de 33,3 $\mathrm{MHz}$ fornecido pela placa de desenvolvimento do kit Excalibur, onde o hardware de emulação será implementado. Sempre que este hardware dedicado receber um pulso no pino nCONFIG, o contador é reinicializado e o flip-flop tem sua saída ajustada em "0". A Figura 9.7 apresenta o esquema adotado. 


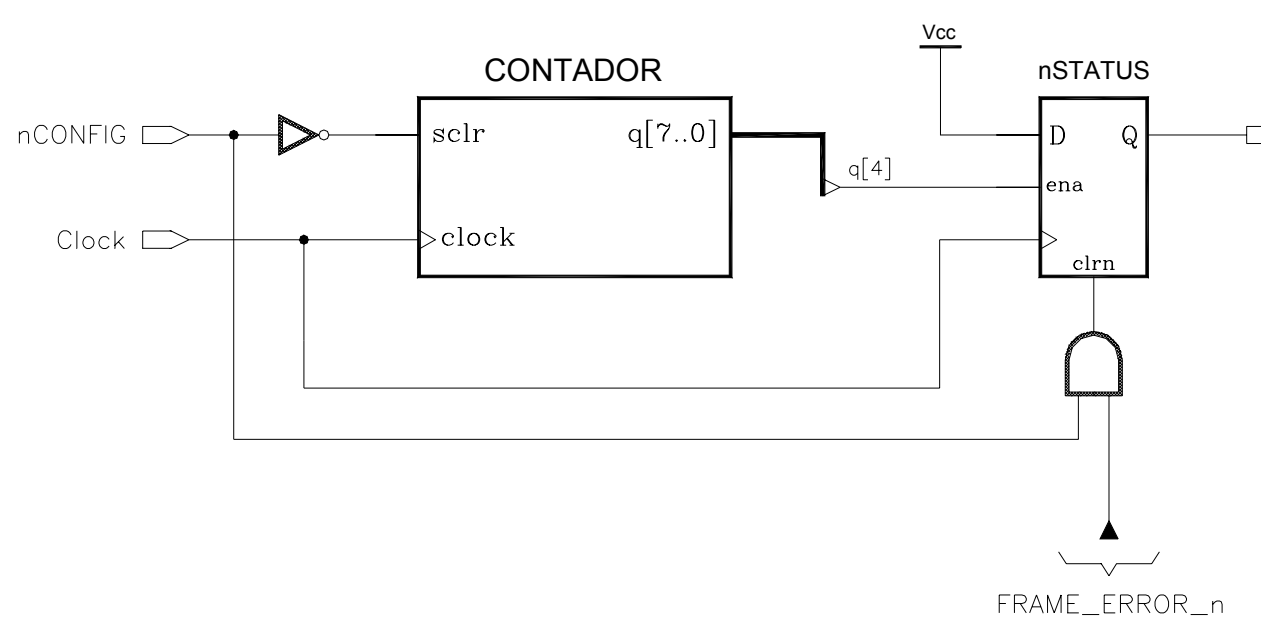

Figura 9.7 - A Geração do Sinal "nSTATUS".

Decorrido um determinado intervalo de tempo depois do pulso em nCONFIG, os dispositivos APEX reajustam para "1" o nível lógico do pino nSTATUS . De acordo com as especificações do fabricante, esta transição deve ocorrer em no máximo 1,0 $\mu$ s. Para se obter este mesmo comportamento no hardware de emulação, o flip-flop responsável pelo controle do sinal nSTATUS tem o nível lógico de sua entrada " $D$ " constantemente ajustado em "1". Conectando-se ao terminal enable deste flip-flop, um sinal ou um conjunto de sinais adequados do barramento $q[7 \ldots 0]$ do contador, podese obter a resposta desejada em nSTATUS num intervalo de tempo ajustável. Dispondo-se de um barramento de 8 bits, o tempo de resposta do sinal nSTATUS pode variar entre $60 \eta \mathrm{s}$ a $7,7 \mu$ s (2 a 256 ciclos de $c l o c k)$.

Quando os dispositivos APEX recebem frames de configuração incorretos, o nível lógico do sinal nSTATUS volta a "0" ocasionando a interrupção do processo de configuração. No hardware de emulação, a recepção de um frame corrompido é indicada através do sinal FRAME_ERROR_n (Fig. 9.5). Quando FRAME_ERROR_n estiver ativo (nível lógico baixo), o flip-flop "nSTATUS" (Fig. 9.7) terá sua saída "Q" reajustada em zero, fazendo com que o comportamento do sinal nSTATUS do hardware de emulação projetado, torne-se exatamente o mesmo que o correspondente sinal dos dispositivos APEX reais. 


\subsection{O Esquema de Validação}

Devido às circunstâncias descritas no item 9.1, adotou-se para a validação deste trabalho, um arranjo onde o controlador de configuração projetado é implementado no próprio FPGA APEX contido na placa de desenvolvimento Excalibur. Quando carregado, este conjunto composto pelo processador Nios e pelo hardware dedicado ocupa cerca de $22 \%$ dos elementos lógicos (LE's) daquele dispositivo. Esta taxa de ocupação permite ainda que outros componentes de hardware sejam adicionados ao esquema de validação.

Conforme descreve o capítulo 8, o novo controlador foi projetado de forma a gerenciar a configuração de oito FPGAs a partir de oito arquivos de configuração distintos. Dispondo-se ainda de 78\% dos LE's do FPGA do kit Excalibur, o esquema de validação pode ser expandido de maneira a incluir também, mais oito instâncias do projeto de emulação dos dispositivos APEX. A Figura 9.8 mostra o esquema proposto.

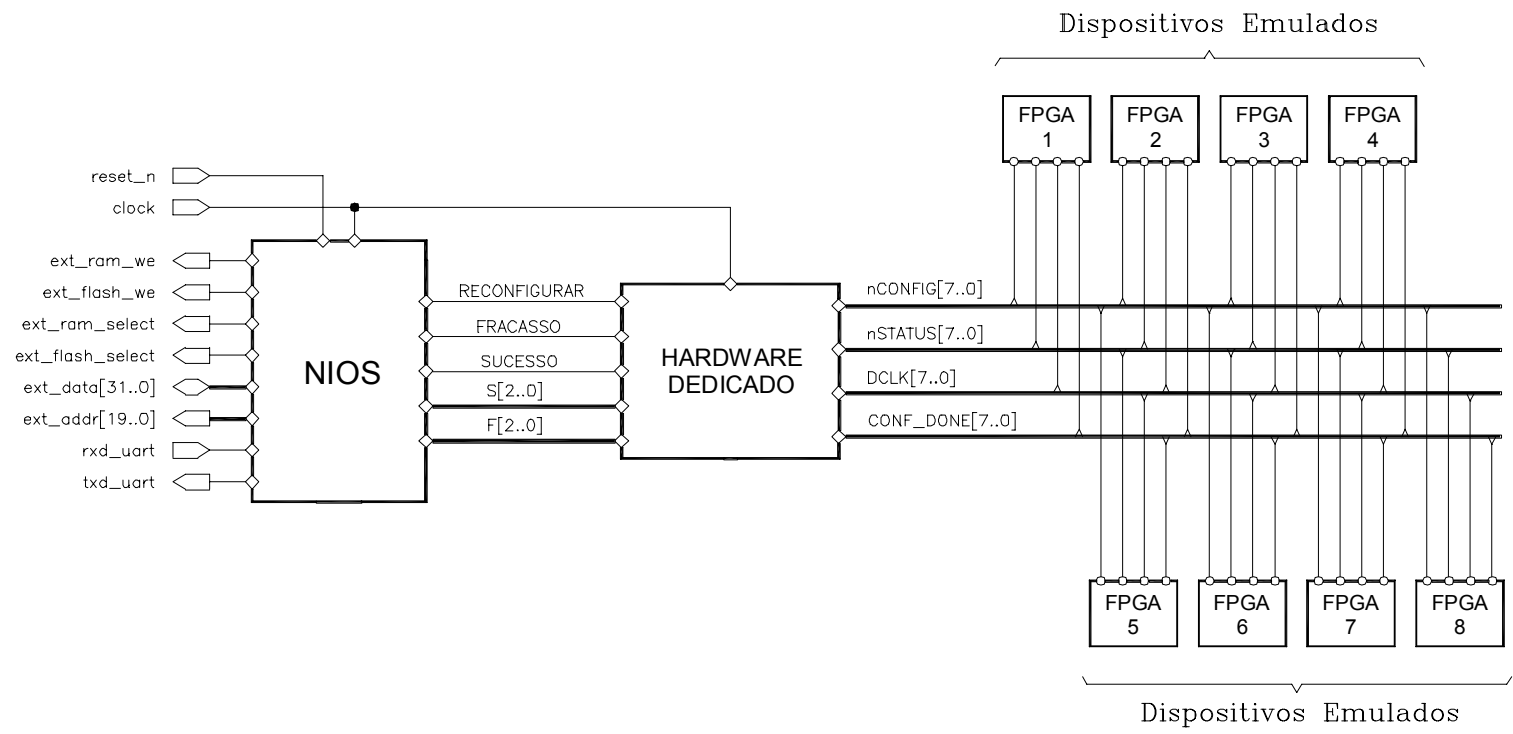

Figura 9.8 - O Controlador de Configuração Interligado aos FPGAs Emulados.

Para se chegar ao esquema de validação final, faz-se ainda necessário a inclusão de um módulo de memória capaz de armazenar os oito arquivos de configuração a serem utilizados na pseudo-configuração dos FPGAs emulados. A interface Megawizard do ambiente Quartus provê uma Megafunction (1pm_ram_io) que implementa módulos de memória $R A M$ parametrizáveis. Depois de compiladas, 
estas Megafunctions são implementadas nas estruturas ESBs presentes na arquitetura MultiCore $^{\mathrm{TM}}$ dos FPGAs da família APEX. A utilização dos ESBs não implica na diminuição da capacidade lógica do dispositivo alvo. Selecionada esta Megafunction, a interface Megawizard permite que se determine a capacidade de armazenamento dos módulos gerados e também o conteúdo a estes inserido.

De acordo com as características do projeto a ser validado, utilizou-se de oito instâncias da Megafunction lpm_ram_io. Cada módulo instanciado foi parametrizado de forma a armazenar 256 palavras de 8 bits. A Tabela 9.1 apresenta o conteúdo inserido em cada módulo de memória $R A M$ utilizado no esquema de validação.

Tabela 9.1 - Conteúdo dos Módulos de Memória e seus efeitos sobre o Hardware de Emulação.

\begin{tabular}{|c|c|c|c|c|}
\hline \multirow{2}{*}{$\begin{array}{l}\text { Módulo de } \\
\text { Memória }\end{array}$} & \multicolumn{2}{|c|}{$\begin{array}{c}\text { Conteúdo das Posições de } \\
\text { Memória }\end{array}$} & \multirow{2}{*}{ Configuração } & \multirow{2}{*}{ Motivo } \\
\hline & $\begin{array}{l}\text { Posições I } \\
\text { Conteúdo }\end{array}$ & $\begin{array}{l}\text { Posições I } \\
\text { Conteúdo }\end{array}$ & & \\
\hline RAM - 1 & $\begin{array}{l}\text { De } 0 \text { até } 255: \\
\mathrm{CA}_{(\mathrm{H})}\end{array}$ & & Fracasso & $\begin{array}{l}\text { Counter } \\
\text { Wrapped }\end{array}$ \\
\hline RAM - 2 & $\begin{array}{l}\text { De } 0 \text { até } 254: \\
\qquad \mathrm{AF}_{(\mathrm{H})}\end{array}$ & $\begin{array}{l}\text { Pos. 255: } \\
\operatorname{FE}_{(\mathrm{H})}\end{array}$ & Sucesso & $\begin{array}{l}\text { Dado FE }_{(\mathrm{H})} \\
\text { "11111110 }\end{array}$ \\
\hline RAM - 3 & $\begin{array}{l}\text { De } 0 \text { até } 255: \\
\qquad \mathrm{AA}_{(\mathrm{H})}\end{array}$ & & Fracasso & $\begin{array}{c}\text { Dado } \\
\text { Corrompido }\end{array}$ \\
\hline RAM - 4 & $\begin{array}{l}\text { De } 0 \text { até } 170: \\
\qquad \mathrm{BB}_{(\mathrm{H})}\end{array}$ & $\begin{array}{l}\text { De } 171 \text { a } 255: \\
00_{(\mathrm{H})}\end{array}$ & Fracasso & $\begin{array}{c}\text { Dado } \\
\text { Corrompido }\end{array}$ \\
\hline RAM - 5 & $\begin{array}{l}\text { De } 0 \text { até 136: } \\
\qquad \mathrm{AA}_{(\mathrm{H})}\end{array}$ & $\begin{array}{l}\text { De } 137 \text { a } 255: \\
55_{(\mathrm{H})}\end{array}$ & Fracasso & $\begin{array}{c}\text { Dado } \\
\text { Corrompido }\end{array}$ \\
\hline RAM - 6 & $\begin{array}{l}\text { De } 0 \text { até } 136: \\
\qquad \mathrm{AA}_{(\mathrm{H})}\end{array}$ & $\begin{array}{l}\text { De } 137 \text { a } 255: \\
55_{(\mathrm{H})}\end{array}$ & Fracasso & $\begin{array}{c}\text { Dado } \\
\text { Corrompido }\end{array}$ \\
\hline RAM - 7 & $\begin{array}{l}\text { De } 0 \text { até } 136: \\
\qquad \mathrm{AA}_{(\mathrm{H})}\end{array}$ & $\begin{array}{l}\text { De } 137 \text { a } 255: \\
\quad \mathrm{FF}_{(\mathrm{H})}\end{array}$ & Fracasso & $\begin{array}{c}\text { Dado } \\
\text { Corrompido }\end{array}$ \\
\hline RAM - 8 & $\begin{array}{l}\text { De } 0 \text { até } 136: \\
\qquad \mathrm{AA}_{(\mathrm{H})}\end{array}$ & $\begin{array}{l}\text { De } 137 \text { a } 255: \\
00_{(\mathrm{H})}\end{array}$ & Fracasso & $\begin{array}{c}\text { Dado } \\
\text { Corrompido }\end{array}$ \\
\hline
\end{tabular}

Nota: As posições de memória estão expressas na base decimal.

Os arquivos inseridos nos módulos de memória foram determinados em função do algoritmo CRC projetado (item 9.2.1.1). O valor $\mathrm{CA}_{(\mathrm{H})}$, armazenado em todas a posições do módulo RAM-1, constitui-se num frame que não gera erro por parte do CRC 
contido nos FPGAs emulados. Entretanto, a atribuição deste arquivo a um dos FPGAs pertencentes ao arranjo de validação leva o correspondente processo de pseudoconfiguração ao fracasso. A ausência do valor $\mathrm{FE}_{(16)}$ neste arquivo impede que o hardware de emulação selecionado sinalize uma configuração bem sucedida. Neste caso, o conteúdo do módulo $R A M-1$ é continuamente enviado ao dispositivo alvo até que o bloco gerador de endereços do controlador de configuração atinja o limite de sua contagem (Fig. 7.12). Como descreve o item 7.3.2, este fato gera um sinal de erro interno ao controlador que então interrompe o processo em andamento.

$\mathrm{O}$ arquivo armazenado no módulo $R A M-2$ é parcialmente preenchido com o valor $\mathrm{AF}_{(16)}$ também correspondente a um frame livre de erros. Frames com este valor são serializados pelo dispositivo de emulação selecionado, mas não geram nenhuma resposta (sucesso ou fracasso) por parte deste. Quando o valor $\mathrm{FE}_{(16)}$ da última posição de memória deste módulo é enviado ao dispositivo alvo selecionado, o correspondente sinal CONF_DONE torna-se alto sinalizando o sucesso do processo.

A composição dos arquivos de todos os outros módulos de memória (RAM-3 a $R A M-8)$ possui dados correspondentes a frames corrompidos, fazendo com que, quando atribuídos a um dos dispositivos de emulação, levem a uma sinalização de fracasso de configuração.

A Figura 9.9 apresenta o esquema final adotado para a validação deste trabalho. Na figura, além do controlador de configuração e dos dispositivos de emulação dos FPGAs APEX, pode-se visualizar também os módulos de memória inseridos ao esquema. A seleção do módulo de memória pertinente a um processo de pesudo-configuração é realizada através de um decodificador. Conforme descreve o item 8.1.1.1, a identificação do arquivo de configuração chega ao hardware dedicado do controlador através do barramento $F[2 \ldots 0]$. Esta informação é diretamente enviada aos três bits mais significativos do barramento de endereços $A[18 \ldots 0]$ de acesso à memória. Conectando-se estes três bits ao barramento de entrada data [2..0] do decodificador visualizado na Figura 9.9, obtém-se a habilitação do módulo de memória desejado. Como os módulos utilizados possuem 256 posições, a utilização dos oito bits menos significativos do barramento de endereços A [], obtido conforme descrito no item 8.1.3, é suficiente para a geração dos endereços de acesso aos módulos de memória do esquema. 


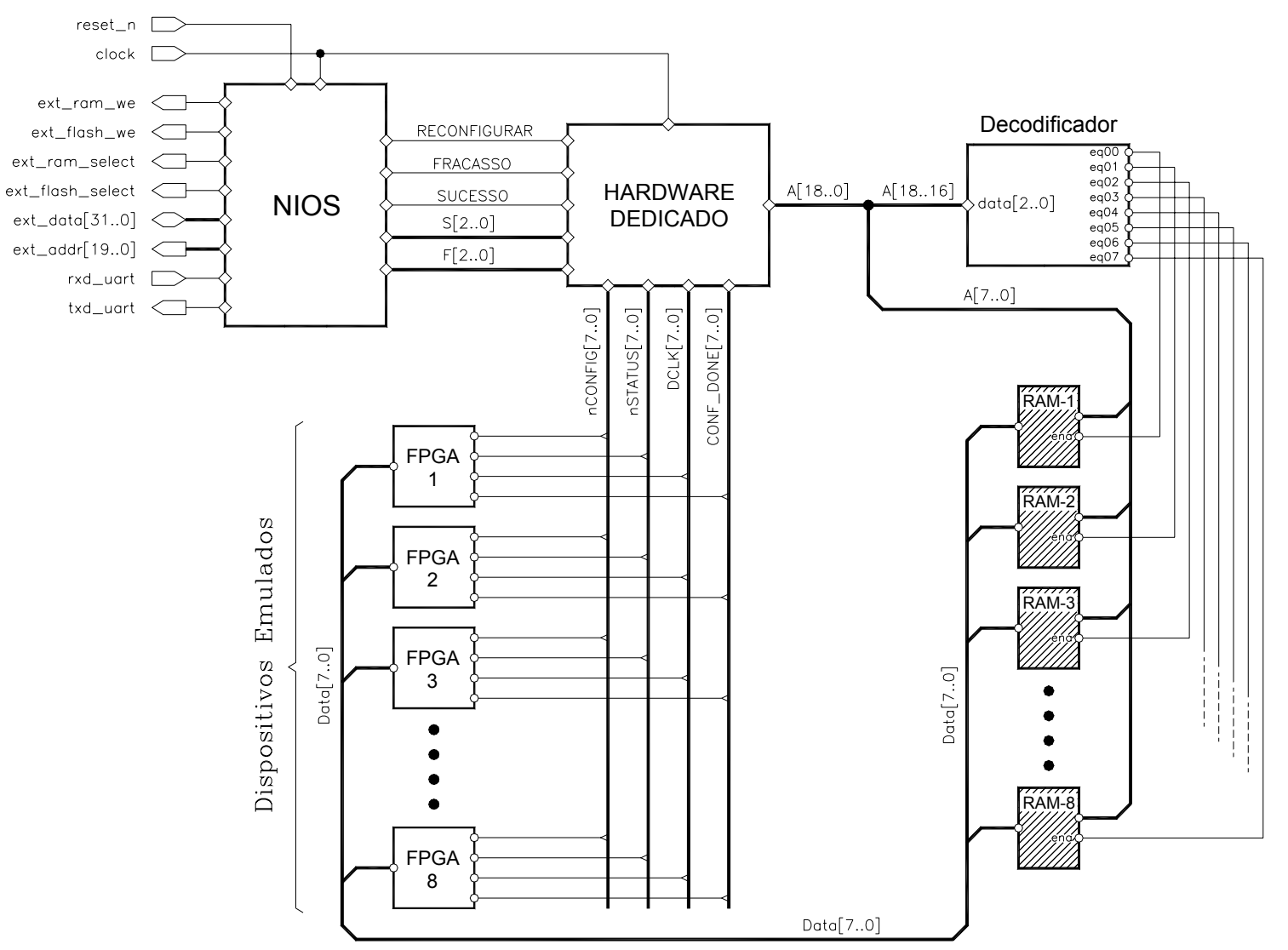

Figura 9.9 - O Esquema Final de Validação.

O esquema de validação apresentado na Figura 9.9 torna possível a validação do controlador de configuração projetado. A seção seguinte apresenta os resultados obtidos.

\subsection{Resultados}

Para a validação do controlador de configuração desenvolvido, vários parâmetros de temporização devem ser checados. A Figura 9.10 apresenta as formas de onda e a correspondente temporização para todos os sinais envolvidos na configuração PPS dos dispositivos APEX 20K. Os símbolos observados nesta figura constituem-se nos parâmetros que, se em conformidade com as especificações da Altera, validam o presente trabalho. 


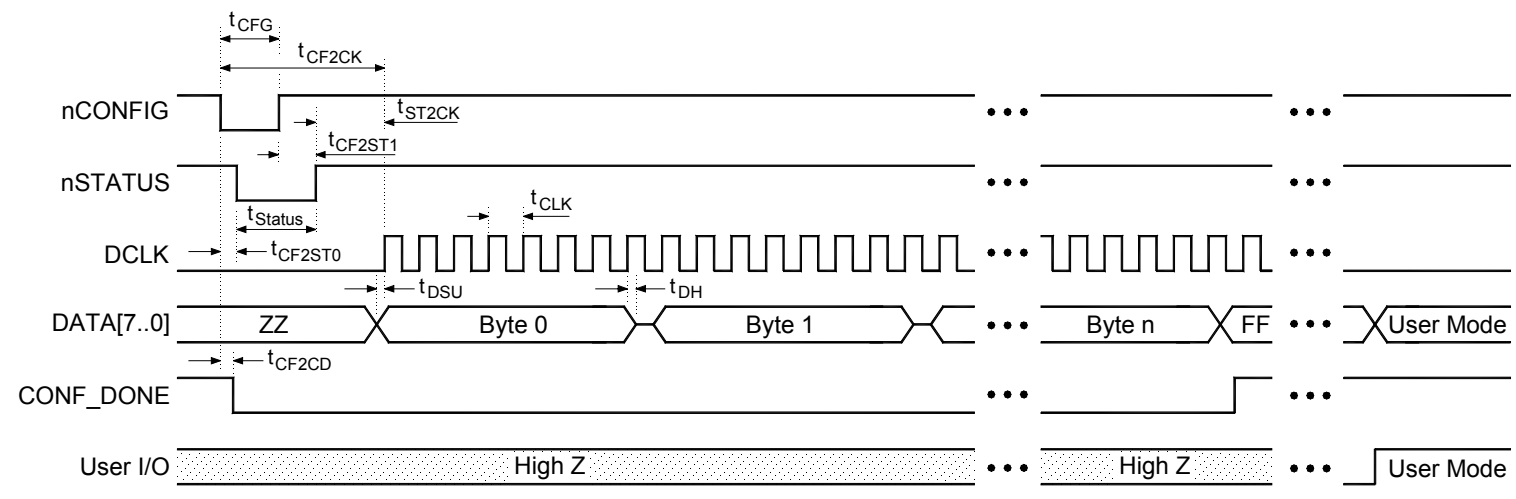

Figura 9.10 - Diagrama de Tempo para os Sinais Envolvidos na Configuração PPS dos FPGAs APEX.

A Tabela 9.2 mostra os valores admissíveis para os parâmetros apresentados na Figura 9.10.

Tabela 9.2 - Parâmetros de Temporização para Dispositivos APEX 20K no Modo PPS.

\begin{tabular}{|c|c|c|c|c|}
\hline Símbolo & Parâmetro & Min. & Máx & Unid. \\
\hline$t_{\text {CF2CK }}$ & $\begin{array}{l}\text { nCONF IG baixo até primeira rampa de } \\
\text { subida de DCLK }\end{array}$ & 40 & & $\mu \mathrm{s}$ \\
\hline$t_{\text {DSU }}$ & $\begin{array}{l}\text { Tempo de setup dos dados antes da rampa } \\
\text { de subida de DCLK }\end{array}$ & 10 & & ns \\
\hline$t_{D H}$ & $\begin{array}{l}\text { Tempo de permanência dos dados depois da } \\
\text { rampa de subida de DCLK }\end{array}$ & 0 & & ns \\
\hline $\mathbf{t}_{\mathrm{CFG}}$ & Largura do pulso $\mathrm{p}$ / baixo em nCONF IG & 8 & & $\mu \mathrm{s}$ \\
\hline$t_{\text {CLK }}$ & Período de DCLK & 60 & & ns \\
\hline$f_{\text {MAX }}$ & Freqüência de DCLK & & 16,7 & $\mathrm{MHz}$ \\
\hline$t_{\text {CF2CD }}$ & nCONFIG baixo até CONF_DONE baixo & & 200 & $\mathrm{~ns}$ \\
\hline$t_{\text {CF2ST0 }}$ & nCONF IG baixo até nSTATUS baixo & & 200 & ns \\
\hline$t_{\text {CF2ST1 }}$ & nCONFIG alto até nSTATUS alto & & 1 & $\mu \mathrm{s}$ \\
\hline $\mathbf{t}_{\text {Status }}$ & Largura do pulso p/ baixo de nSTATUS & 10 & 40 & $\mu \mathrm{s}$ \\
\hline$t_{\text {ST2CK }}$ & $\begin{array}{l}\text { nSTATUS alto até primeira rampa de subida } \\
\text { de DCLK }\end{array}$ & 1 & & $\mu \mathrm{s}$ \\
\hline
\end{tabular}

Fonte: Tabela 14 - PPS Timing Waveform for APEX 20K Devices [17]. 
Alguns dos parâmetros encontrados na Tabela 9.2 são pertinentes ao FPGA a ser configurado. Os parâmetros que não pertencem a esta categoria, são comandados pelo controlador de configuração. As próximas seções apresentam os valores alcançados para os parâmetros relativos ao hardware de emulação dos FPGAs APEX e também os pertinentes ao controlador de configuração projetado.

\subsubsection{Validação do Hardware de Emulação dos FPGAs APEX}

A Tabela 9.3 apresenta os parâmetros relativos ao hardware de emulação projetado.

Tabela 9.3 - Parâmetros Relativos ao Hardware de Emulação.

\begin{tabular}{|c|l|}
\hline Símbolo & \multicolumn{1}{|c|}{ Parâmetro } \\
\hline $\mathbf{t}_{\text {CF2CD }}$ & $\begin{array}{l}\text { nCONFIG baixo até CONF_DONE } \\
\text { baixo }\end{array}$ \\
\hline $\mathbf{t}_{\text {CF2ST0 }}$ & nCONFIG baixo até nSTATUS baixo \\
\hline $\mathbf{t}_{\text {CF2ST1 }}$ & nCONFIG alto até nSTATUS alto \\
\hline $\mathbf{t}_{\text {Status }}$ & $\begin{array}{l}\text { Largura do pulso } \mathrm{p} / \text { baixo de } \\
\text { nSTATUS }\end{array}$ \\
\hline
\end{tabular}

Através do ambiente de desenvolvimento Quartus, pôde-se simular o hardware de emulação dos dispositivos APEX e conferir os valores alcançados para todos estes parâmetros.

Nas figuras que seguem, obtidas a partir da tela de simulação do Quartus, pode-se identificar os sinais envolvidos na simulação observando-se a coluna à esquerda. Os nomes encontrados nesta coluna correspondem às linhas e barramentos apresentados na Figura 9.9. A única exceção é o sinal clk_CPLD. Este sinal, presente em todas as simulações, corresponde ao sinal de clock da Figura 9.9. Nas telas de simulação apresentadas a seguir, observam-se dois marcadores representados por um pequeno quadrado cinza. $\mathrm{O}$ marcador mais à esquerda indica a origem do intervalo medido. O marcador à direita sinaliza o término do mesmo. Sobre este último pode-se observar o valor do intervalo medido. 


\subsubsection{O Parâmetro t ${ }_{\text {CF2CD }}$}

Para o parâmetro $\mathrm{t}_{\mathrm{CF} 2 \mathrm{CD}}$, é assegurado um valor máximo de 200ns (Tabela 9.2). A Figura 9.11 apresenta o valor $t_{\mathrm{CF} 2 \mathrm{CD}}$ alcançado pelo hardware de emulação.

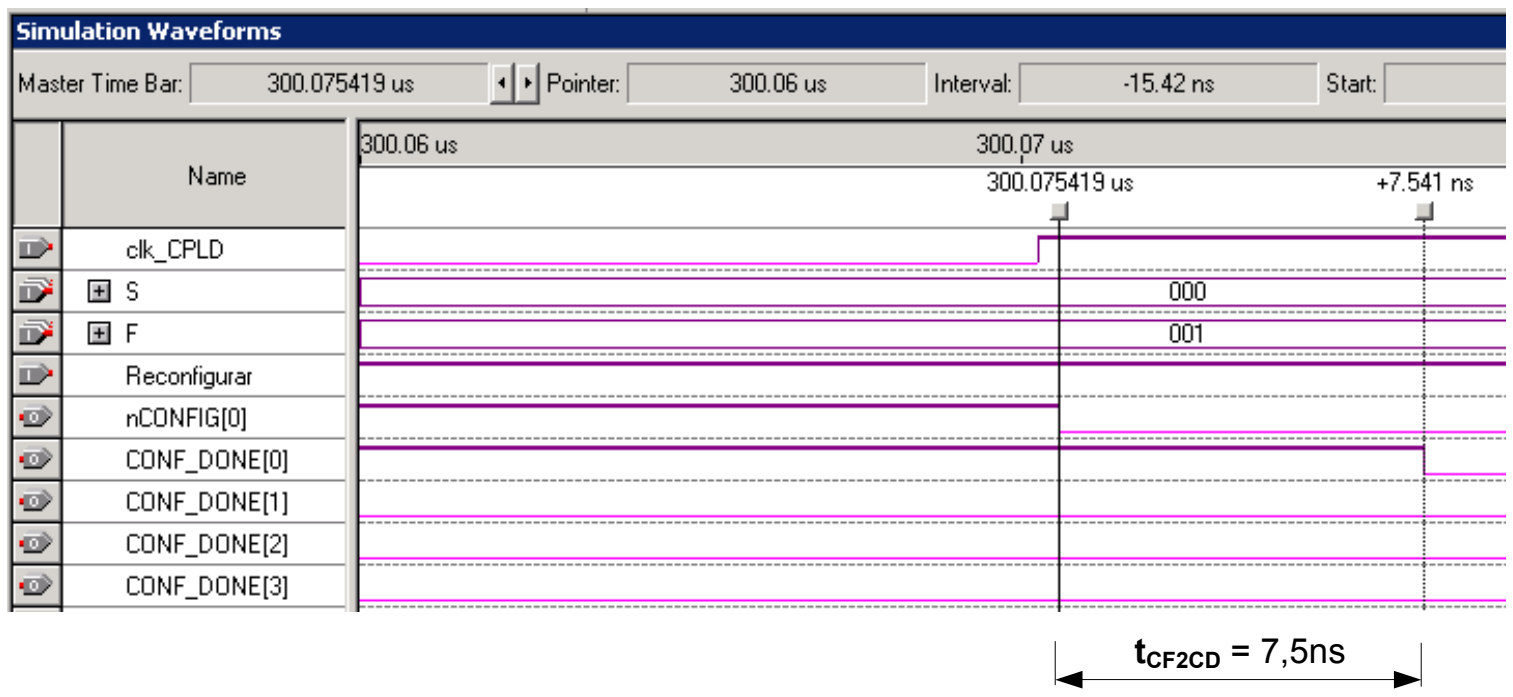

Figura 9.11 - Parâmetro $\mathrm{t}_{\mathrm{CF} 2 \mathrm{CD}}$ do Hardware de Emulação.

De maneira análoga, obtém-se os valores para todos os outros parâmetros a serem validados.

\subsubsection{O Parâmetro t ${ }_{\text {CF2ST0 }}$}

Também com um valor máximo de 200ns, a simulação para o parâmetro $\mathrm{t}_{\mathrm{CF} 2 \mathrm{ST0}}$ do FPGA emulado é apresentado na Figura 9.12.

Estando dentro da faixa estabelecida pela Altera (Tab. 9.2), considerou-se validado o parâmetro em questão. 


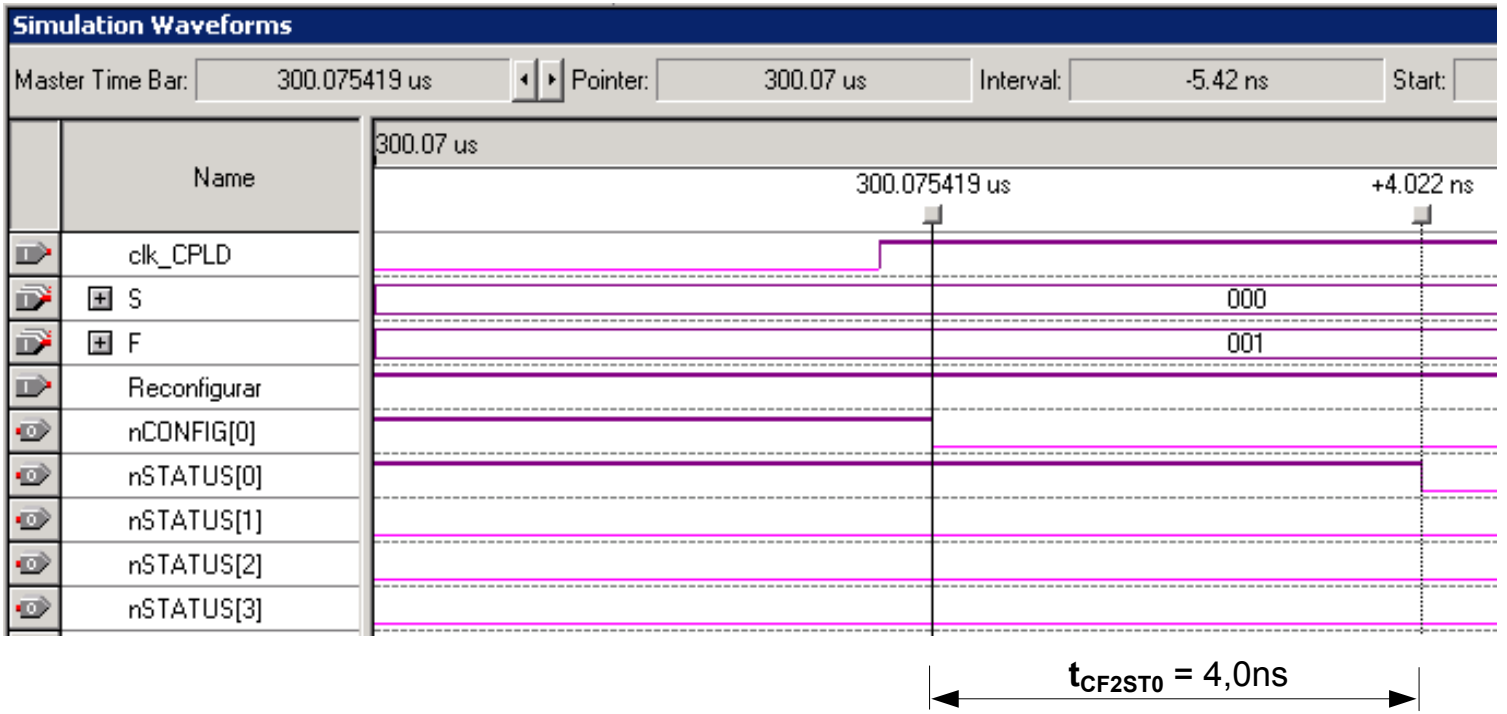

Figura 9.12 - Parâmetro $\mathrm{t}_{\mathrm{CF} 2 \mathrm{ST} \text { 0 }}$ do Hardware de Emulação.

\subsubsection{O Parâmetro ${ }_{\text {CF2ST1 }}$}

Conforme descreve o item 9.2.3, o hardware de emulação tem seu parâmetro $\mathrm{t}_{\mathrm{CF} 2 \mathrm{ST} 1}$ ajustável. Podendo chegar a no máximo $1 \mu$ s (Tabela 9.2), optou-se em ajustá-lo para algo em torno de 500ns. O valor alcançado pode ser observado na Figura 9.13.

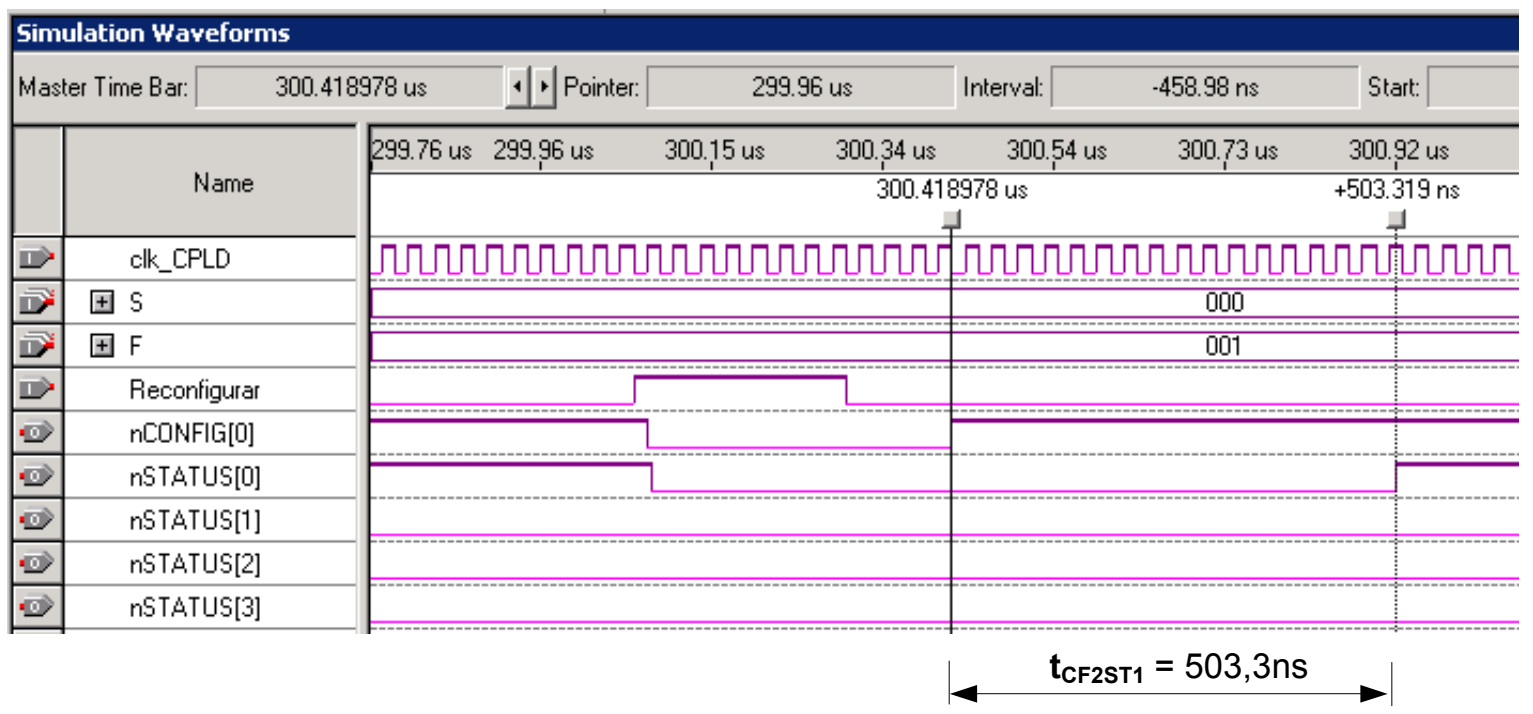

Figura 9.13 - Parâmetro $\mathrm{t}_{\mathrm{CF} 2 \mathrm{ST} 1}$ do Hardware de Emulação. 


\subsubsection{O Parâmetro t $t_{\text {Status }}$}

$\mathrm{O}$ parâmetro $\mathrm{t}_{\text {Status }}$ é função da largura do pulso nCONFIG gerado pelo controlador de configuração. Conforme observado na Figura 9.10, este parâmetro pode ser obtido através da seguinte equação:

$$
\mathrm{t}_{\text {Status }}=\mathrm{t}_{\mathrm{CFG}}+\mathrm{t}_{\mathrm{CF} 2 \mathrm{ST} 1}-\mathrm{t}_{\mathrm{CF} 2 \mathrm{ST} 0}
$$

De acordo com a equação 9.3, nota-se que a validação do parâmetro t $_{\text {Status }}$ está associada a validação dos três parâmetros dos quais este é função. Os parâmetros $\mathrm{t}_{\mathrm{CF} 2 \mathrm{ST} 0}$ e $\mathrm{t}_{\mathrm{CF} 2 \mathrm{ST} 1}$ já estão validados (Fig. 9.11 e Fig 9.12). Sob controle do controlador de configuração, o parâmetro ${ }_{\mathrm{CFG}}$ será validado na próxima seção. Desta forma, podese considerar validado o parâmetro em questão.

Estando de acordo com as especificações contidas na Tabela 9.2, os valores alcançados para os parâmetros $\mathrm{t}_{\mathrm{CF} 2 \mathrm{CD}},{ }^{\mathrm{t}} \mathrm{CF} 2 \mathrm{ST} 0,{ }_{\mathrm{CF}} \mathrm{ST} 1$ e ${ }^{\mathrm{t}_{\text {Status }}}$ do hardware de emulação validam o relativo projeto.

\subsubsection{Validação do Controlador de Configuração}

Os parâmetros pertinentes ao controlador de configuração projetado são apresentados na Tabela 9.4.

Tabela 9.4 - Parâmetros Relativos ao Controlador de Configuração.

\begin{tabular}{|c|l|}
\hline Símbolo & \multicolumn{1}{|c|}{ Parâmetro } \\
\hline $\mathbf{t}_{\text {CF2CK }}$ & $\begin{array}{l}\text { nCONF IG baixo até primeira rampa } \\
\text { de subida de DCLK }\end{array}$ \\
\hline $\mathbf{t}_{\text {DSU }}$ & $\begin{array}{l}\text { Tempo de setup dos dados antes da } \\
\text { rampa de subida de DCLK }\end{array}$ \\
\hline $\mathbf{t}_{\mathbf{D H}}$ & $\begin{array}{l}\text { Tempo de permanência dos dados } \\
\text { depois da rampa de subida de DCLK }\end{array}$ \\
\hline $\mathbf{t}_{\mathbf{C F G}}$ & $\begin{array}{l}\text { Largura do pulso p/ baixo em } \\
\text { nCONF IG }\end{array}$ \\
\hline $\mathbf{t}_{\mathbf{C L K}}$ & Período de DCLK \\
\hline $\mathbf{f}_{\mathbf{M A X}}$ & Freqüência de DCLK \\
\hline $\mathbf{t}_{\mathbf{S T 2 C K}}$ & $\begin{array}{l}\text { nSTATUS alto até primeira rampa de } \\
\text { subida de DCLK }\end{array}$ \\
\hline
\end{tabular}




\subsubsection{O Parâmetro $t_{\mathrm{CFG}}$}

Dentre os parâmetros presentes na Tabela 9.4, apenas $\mathrm{t}_{\mathrm{CFG}}$ não pode ser validado através do ambiente de simulação do Quartus. Este parâmetro é controlado pelo driver do controlador, diferentemente dos outros parâmetros que são controlados pelo hardware dedicado. Esta característica de $t_{\mathrm{CFG}}$ impede que este seja simulado como os outros parâmetros.

Conforme ilustram as Figuras 8.12 e 8.13 , a largura do pulso em nCONF IG (parâmetro $\mathrm{t}_{\mathrm{CFG}}$ ) varia em função do valor atribuído à variável "J". Resultados empíricos mostram que cada ciclo do laço for (Fig. 8.12) é executado em 123,61ns, ou seja, se à variável "J" for atribuído o valor 100, obtém-se um pulso de $12,36 \mu$ s em nCONFIG. Para que a condição imposta ao parâmetro $t_{\mathrm{CF} 2 \mathrm{CK}}$ (discutida na seqüência) seja satisfeita, atribuiu-se à variável "J" o valor 316. Assim, $\mathrm{t}_{\mathrm{CFG}}$ foi ajustado para $39,06 \mu$ s, satisfazendo à condição imposta pelo fabricante.

\subsubsection{Os Parâmetros t ${ }_{\text {CLK }}$ e $\mathbf{f}_{\text {MAX }}$}

Os parâmetros $t_{\mathrm{CLK}}$ e $\mathrm{f}_{\mathrm{MAX}}$ dependem apenas da freqüência do sinal de clock aplicado ao sistema. Obtidos conforme descreve o item 7.3.3, estes parâmetros impedem que a freqüência do sinal de aplicado seja maior que 66,6 MHz. Como $\mathrm{f}_{\mathrm{MAX}}$ equivale a $1 / 4$ da freqüência deste sinal, um clock de $66,6 \mathrm{MHz}$ leva DCLK ao seu valor máximo (16,7 MHz) estabelecido pela Altera. Ao esquema de validação da Figura 9.9 foi aplicado um sinal de clock de 33,3 MHz fazendo com que DCLK assumisse um valor de 8,33 MHz. Para esta freqüência de DCLK tem-se um período $t_{\text {CLK }}$ de aproximadamente 120,0 ns, maior que o valor mínimo imposto. 


\subsubsection{Os Parâmetros $t_{D S U}$ e $t_{D H}$}

Os dados de configuração enviados aos FPGAs devem ser disponibilizados de acordo com a restrição imposta ao parâmetro $\mathrm{t}_{\mathrm{DSU}}$. Este parâmetro está relacionado com o intervalo de tempo mínimo entre a apresentação de um frame de configuração e a rampa de subida de DCLK. Conforme mostra a Tabela 9.2, este intervalo deve ser de no mínimo 10,0 ns. A Figura 9.14 apresenta o valor correspondente obtido pelo controlador de configuração projetado.

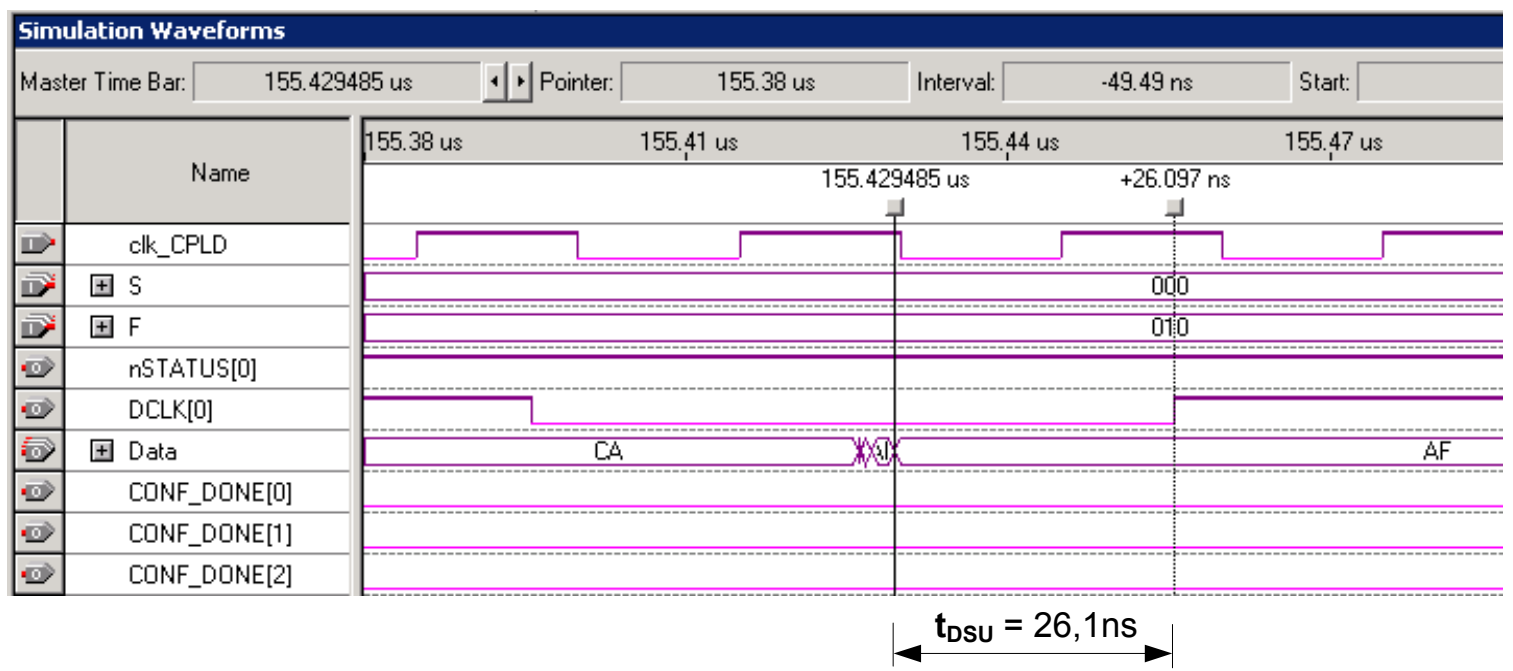

Figura 9.14 - Parâmetro ${ }_{\text {DSU }}$ do Controlador de Configuração.

$\mathrm{O}$ parâmetro $\mathrm{t}_{\mathrm{DH}}$ refere-se ao tempo de permanência de um frame no barramento Data $[7 \ldots 0]$ após a rampa de subida de DCLK. A Figura 9.15 apresenta o valor alcançado na simulação do novo controlador. 


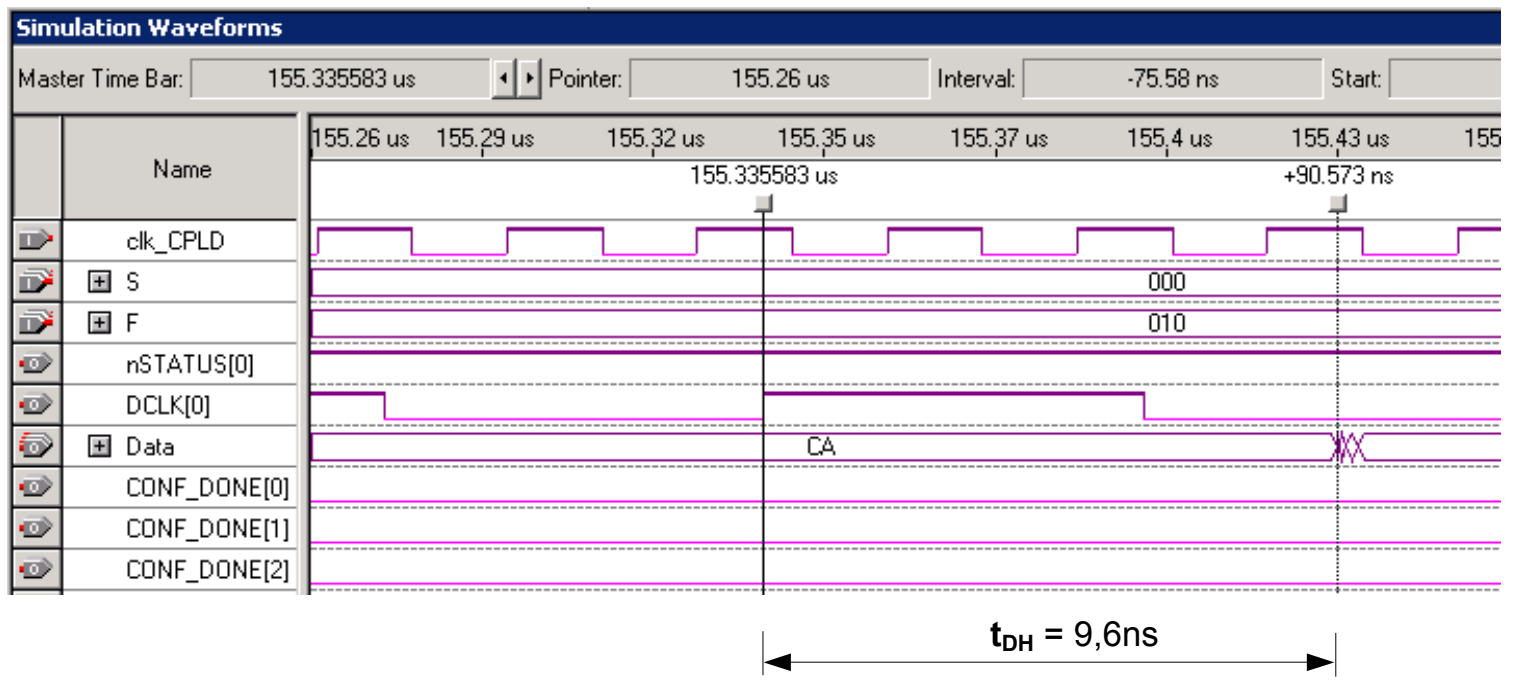

Figura 9.15 - Parâmetro $\mathrm{t}_{\mathrm{DH}}$ do Controlador de Configuração.

\subsubsection{O Parâmetro $\mathbf{t}_{\mathrm{ST} 2 \mathrm{CK}}$}

$\mathrm{O}$ parâmetro $\mathrm{t}_{\mathrm{ST} 2 \mathrm{CK}}$ representa o intervalo de tempo entre a recepção da transição baixo-alto de nSTATUS e o instante em que se inicia o envio do sinal DCLK, utilizado na serialização dos dados de configuração por parte do dispositivo alvo. Este parâmetro não é constante e varia em função do exato momento em que a rampa de subida de nSTATUS chega ao hardware dedicado. Analisando-se as Figuras 7.11 e 7.12, verifica-se que o controlador de configuração leva de 6 a 9 ciclos de clock (clk_CPLD) para responder à transição de nSTATUS e dar inicio ao envio de DCLK. Com uma freqüência de $33,3 \mathrm{MHz}$, o sinal de clock aplicado ao sistema impõe um $\mathrm{t}_{\mathrm{ST} 2 \mathrm{CK}}$ variando entre aproximadamente 180,0 e 270,0 ns. A Figura 9.16 mostra o valor máximo obtido nas simulações deste parâmetro. 


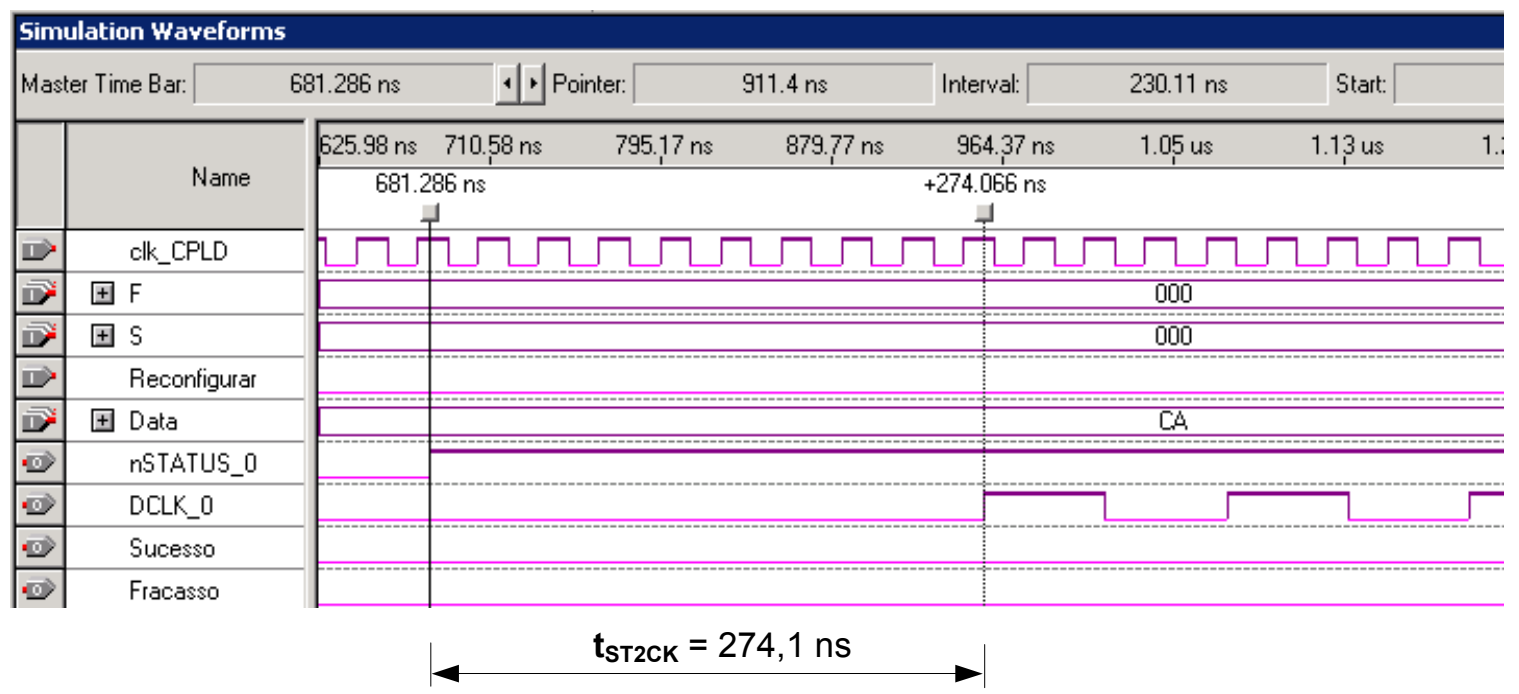

Figura 9.16 - Parâmetro $\mathrm{t}_{\mathrm{ST} 2 \mathrm{CK}}$ Originalmente Obtido pelo Controlador de Configuração.

Os valores obtidos para $\mathrm{t}_{\mathrm{ST} 2 \mathrm{CK}}$ não coincidem com aquele verificado na Tabela 9.2. No entanto, a forma com que é gerado o sinal DCLK no hardware dedicado do novo controlador é exatamente a mesma que a encontrada no projeto do controlador de configuração disponível no kit Excalibur. As simulações dos dois projetos levaram aos mesmos resultados.

A não conformidade entre o valor imposto e o alcançado fez com que fosse mantido contato com o departamento de suporte da Altera. Um funcionários do setor de aplicações informou ser possível um $\mathrm{t}_{\mathrm{ST} 2 \mathrm{CK}}$ menor que $1 \mu \mathrm{s}$, podendo chegar a valores entre 700 a $800 \mathrm{~ns}$.

Tentou-se discutir o projeto ao nível de lógica digital alegando ser coerente o valor encontrado. O funcionário então recusou-se a continuar a discussão e solicitou que o parâmetro fosse medido a partir da placa de desenvolvimento e não através de simulações do projeto. Para que a solicitação deste funcionário fosse efetivada, seria necessária a utilização de um analisador lógico. A utilização deste equipamento não é trivial e tomaria algum tempo até que se conseguisse dominá-lo e então realizar a medição desejada.

Uma solução simples, e que contorna o problema verificado, foi então adotada. Supondo-se que os FPGAs APEX realmente necessitem de um $\mathrm{t}_{\mathrm{ST} 2 \mathrm{CK}}$ maior que $1 \mu \mathrm{s}$, basta que se atrase a chegada de nSTATUS aos componentes do hardware dedicado 
responsáveis pelo tratamento do sinal. $\mathrm{O}$ acréscimo de um contador associado a um flipflop pode produzir o atraso desejado. A Figura 9.17 detalha o esquema proposto e posteriormente implementado.

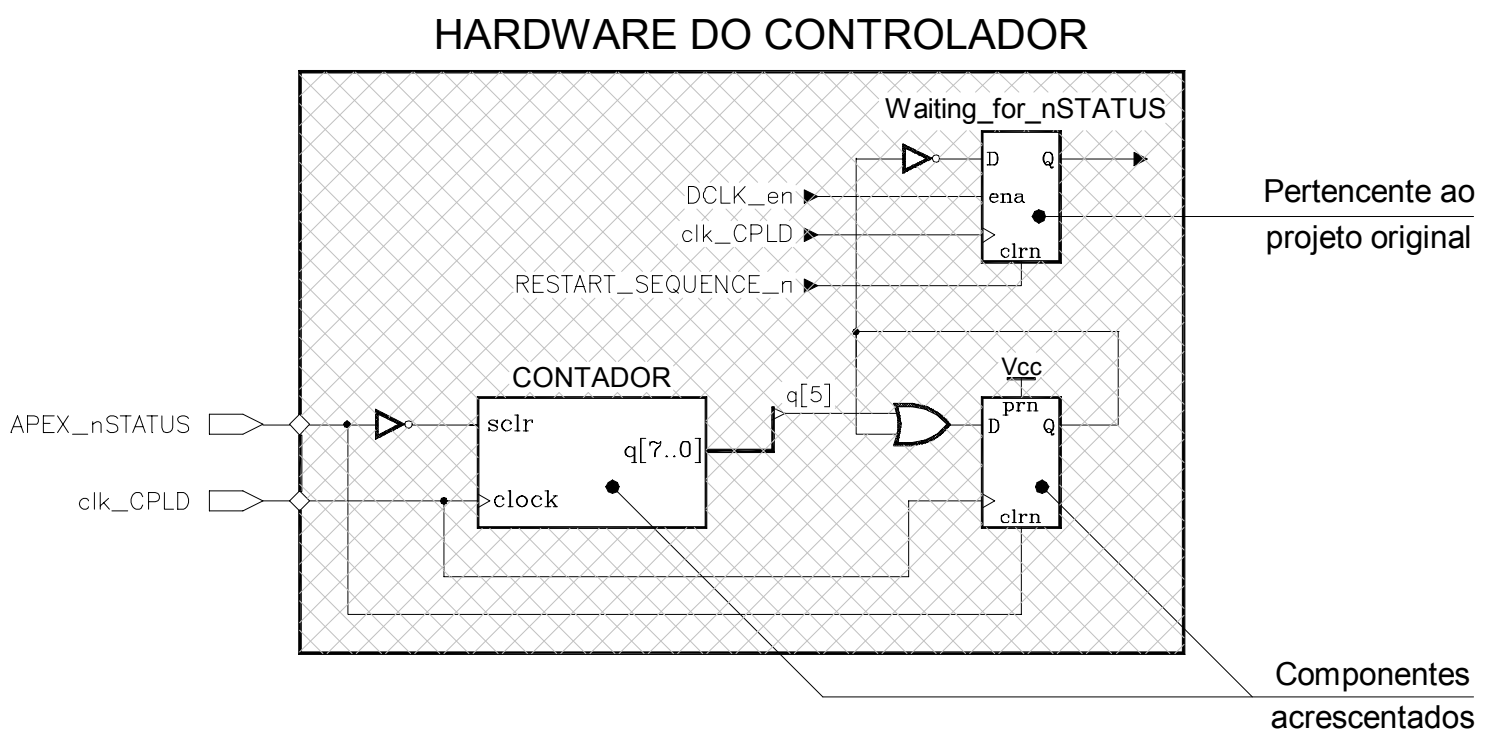

Figura 9.17 - Obtenção do Atraso no Sinal nSTATUS.

$\mathrm{Na}$ figura, pode-se observar o componente originalmente responsável pela recepção de nSTATUS e também os novos componentes inseridos, encarregados de gerar o atraso desejado. A simulação do hardware dedicado revisado leva aos resultados apresentados na Figura 9.18.

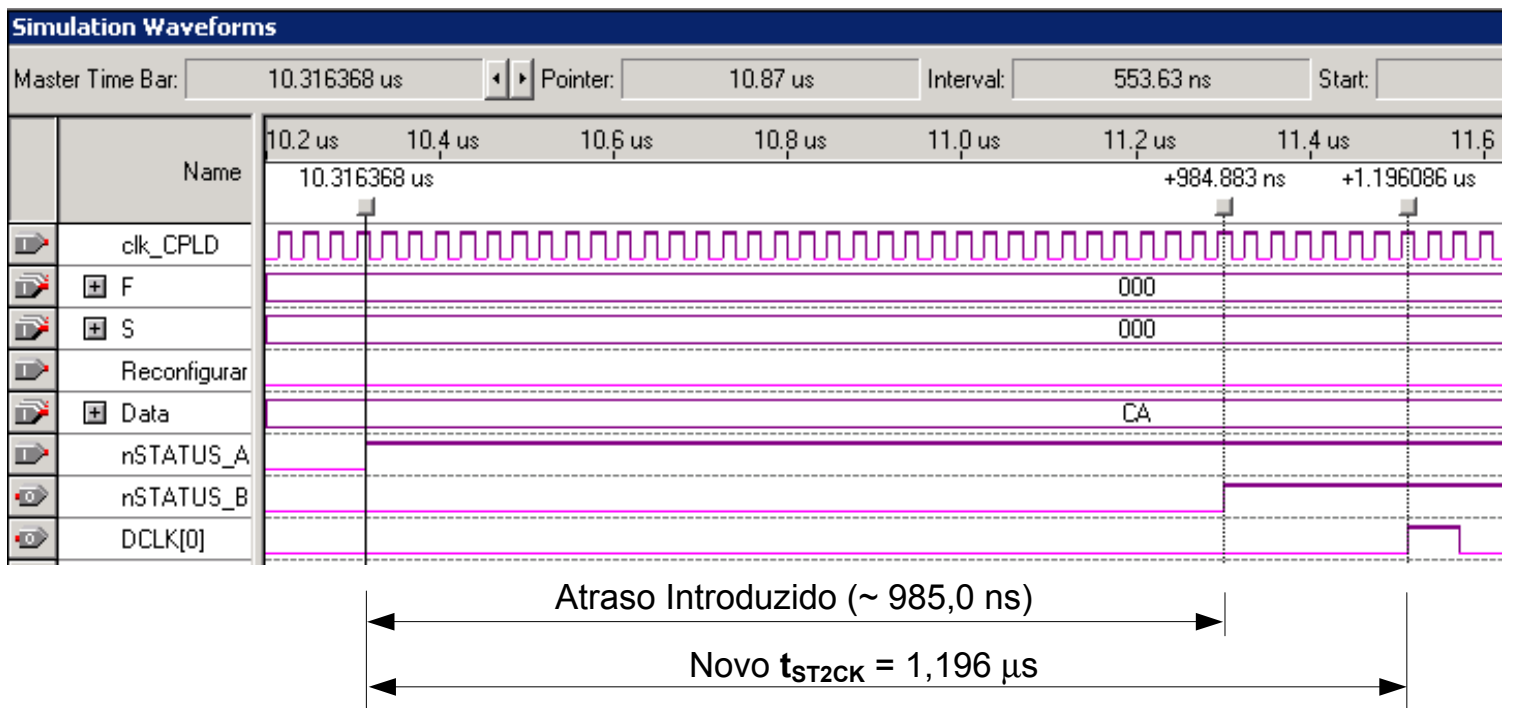

Figura 9.18 - Parâmetro $\mathrm{t}_{\mathrm{ST} 2 \mathrm{CK}}$ após Alterações no Hardware Dedicado do Controlador de Configuração. 
$\mathrm{O}$ valor de $\mathrm{t}_{\mathrm{ST} 2 \mathrm{CK}}$ continua dependendo do exato momento em que nSTATUS chega ao hardware do controlador. $\mathrm{O}_{\mathrm{ST} 2 \mathrm{CK}}$ apresentado na Figura 9.18 corresponde ao valor mínimo obtido. Com os novos valores alcançados torna-se validado o referido parâmetro.

\subsubsection{O Parâmetro t ${ }_{\text {CF2CK }}$}

A validação do parâmetro $\mathrm{t}_{\mathrm{CF} 2 \mathrm{CK}}$ pode ser obtida através de uma análise dos valores já obtidos e validados. Observando-se a Figura 9.10, nota-se que ${ }_{\mathrm{CF} 2 \mathrm{CK}}$ pode ser obtido conforme a seguinte equação:

$$
\mathrm{t}_{\mathrm{CF} 2 \mathrm{CK}}=\mathrm{t}_{\mathrm{CFG}}+\mathrm{t}_{\mathrm{CF} 2 \mathrm{ST} 1}+\mathrm{t}_{\mathrm{ST} 2 \mathrm{CK}}
$$

De acordo com a equação 9.4 e considerando os resultados já apresentados para os parâmetros dos quais $\mathrm{t}_{\mathrm{CF} 2 \mathrm{CK}}$ é função, chega-se a um valor de 40,76 $\mu \mathrm{s}$, validando assim o parâmetro em questão. De qualquer forma, simulou-se o hardware do controlador e o resultado obtido para ${ }_{\mathrm{CF} 2 \mathrm{CK}}$ é apresentado na Figura 9.19.

\begin{tabular}{|c|c|c|c|c|c|c|c|c|}
\hline \multicolumn{9}{|c|}{ Simulation Waveforms } \\
\hline \multicolumn{2}{|c|}{ Master Time Bar: } & 1.695884 us & 1.|Pointer: & $22.22 \mathrm{us}$ & Interval: & 20.52 us & Start: & \\
\hline & \multirow[b]{2}{*}{ Name } & \multirow{2}{*}{$500.0 \mathrm{~ns}$} & 6.65 us & 18.95 us & 25.1 us & 31.25 us & 37.4 us & 43.55 us \\
\hline & & & & & & & & $\begin{array}{c}+40.773535 \mathrm{us} \\
!\end{array}$ \\
\hline I) & clk_CPLD & \begin{tabular}{|l|l|} 
& \\
\end{tabular} & & & & & & \\
\hline$\overline{1}$ & $\boxplus F$ & \begin{tabular}{|l|l|} 
& \\
\end{tabular} & & & & 000 & & \\
\hline$\overline{1}$ & Ð & \begin{tabular}{|l|l|}
$-\cdots$ & \\
\end{tabular} & & & & 000 & & \\
\hline I) & Reconfigurar & 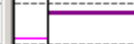 & & & & & & \\
\hline$\Rightarrow$ & nCONFIG & 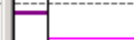 & & & & & & \\
\hline 이 & DCLK & + & & & & & & \\
\hline 미) & nSTATUS & 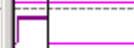 & & & & & & \\
\hline
\end{tabular}

Figura 9.19 - Parâmetro $\mathrm{t}_{\mathrm{CF} 2 \mathrm{CK}}$ do Controlador de Configuração. 
Com a validação de $\mathrm{t}_{\mathrm{CF} 2 \mathrm{CK}}$ conclui-se a validação de todos os parâmetros relativos ao controlador de configuração. Desta forma considera-se validado o projeto a que se propunha este trabalho de mestrado.

\subsection{Trabalhos Futuros}

Depois dos FPGAs APEX 20K, novas famílias de PLDs foram lançadas pela Altera. Com o objetivo de atender às necessidades crescentes de componentes de melhor desempenho e maior largura de banda, impostas por aplicações relacionadas à transmissão de dados, várias características como desempenho em operações de I/O e suporte para SOPC (System-On-a-Programmable-Chip) tem sido melhoradas. Um notável aumento de densidade e expansão da capacidade de implementação de blocos de memória embutidos tem sido também observados.

A família de PLDs APEX II supera o seu antecessor APEX 20K em praticamente todos os pontos. Mais recentemente (março de 2002), foi lançada uma nova família denominada Stratix ${ }^{\mathrm{TM}}$. A Tabela 9.5 apresenta uma comparação entre algumas características destas famílias de FPGAs.

Tabela 9.5 - Comparativo entre as famílias de FPGAs mais recentes (Altera).

\begin{tabular}{|c|c|c|c|}
\hline Família & APEX 20K & APEX II & STRATIX \\
\hline Dispositivo & EP20K1500E & EP2A70 & EP1S120 \\
\hline $\begin{array}{c}\text { Elementos Lógicos } \\
\text { (LEs) }\end{array}$ & 51.840 & 67.200 & 114.140 \\
\hline ESBs & 216 & 280 & 1.650 \\
\hline $\begin{array}{c}\text { Memória RAM } \\
\text { (bits) }\end{array}$ & 442.368 & 1.146 .880 & 10.118 .016 \\
\hline $\begin{array}{c}\text { Pinos de I/O disponíveis } \\
\text { p/ o usuário }\end{array}$ & 808 & 1.060 & 1.310 \\
\hline
\end{tabular}


Além da melhoria em diversas características, cada uma das novas famílias apresenta algumas novidades.

Os dispositivos APEX II são equipados com circuitos especiais de multiplicação e divisão de freqüência de clock, minimizando o número de fontes externas de clock, necessárias em algumas aplicações [31]. Além deste avanço, esta família de PLDs apresenta circuitos dedicados que oferecem aos projetistas a flexibilidade de sincronização de até 36 canais de dados independentes de alta velocidade.

A família Stratix utiliza uma nova estrutura de memória composta por três tipos de blocos ESBs de tamanhos diferentes. Estes blocos de memória embutidos foram especialmente desenvolvidos para diferentes classes de aplicação [32]. Os dispositivos Stratrix incluem ainda 28 blocos de processamento digital de sinais (DSP) que promovem melhor desempenho para aplicações aritméticas.

Quanto à configuração destes novos dispositivos, algumas mudanças também são observadas. Os sinais envolvidos na configuração permanecem os mesmos. Alterações são observadas no que diz respeito à velocidade de carregamento dos dados de configuração por parte do dispositivo alvo. Os FPGAs APEX II foram projetados de forma a receber um byte de configuração por ciclo de clock (no modo passivo síncrono), diferente de seu antecessor APEX 20K que recebia um byte de configuração a cada oito ciclos de clock. Este avanço permite que estes dispositivos sejam configurados em menos de $100 \mathrm{~ms}$ e a uma freqüência de $66 \mathrm{MHz}$ para o sinal DCLK. Dispondo desta mesma característica, a família Stratix permite ainda que DCLK chega a $100 \mathrm{MHz}$.

Estas novas características de configuração impedem que o controlador de configuração aqui projetado, seja encarregado de configurar os PLDs pertencentes às famílias APEX II e Stratix. Como trabalho futuro, propõe-se que o projeto deste controlador de configuração seja alterado de forma a capacitá-lo também à configuração destes novos FPGAs. O controlador poderia ter sob seu comando, uma plataforma reconfigurável mista, composta por FPGAs das três famílias citadas.

Para que este arranjo seja passível de implementação, o driver do controlador de configuração deverá passar ao hardware dedicado não só a identificação de dispositivo e arquivo de configuração a serem utilizados num determinado processo, mas também a família a que o dispositivo alvo pertence. Esta informação permitiria que 
o hardware dedicado fosse ajustado de acordo com as características de configuração de cada FPGA pertencente à plataforma mista. $\mathrm{O}$ controlador poderia ainda ser capaz de gerar uma freqüência de clock de configuração (DCLK) variável, ajustada em conformidade com os limites máximos permitidos para cada família de PLDs contida no arranjo, minimizando assim o tempo de configuração e reconfiguração destes dispositivos.

\subsection{Considerações Finais}

Os objetivos inicialmente propostos para este trabalho de mestrado foram alcançados. O controlador de configuração, bem como o driver pertinente, foram construídos e validados. As características do controlador desenvolvido enquadram-se perfeitamente às necessidades impostas pelo projeto ARMOSH.

O desenvolvimento deste projeto exigiu consideráveis esforços. Grande tempo de pesquisa foi despendido até que fossem dominadas as ferramentas de desenvolvimento SOPC e a linguagem de descrição de hardware AHDL.

Frustrante foi a impossibilidade de aquisição de ao menos um FPGA APEX $20 \mathrm{~K}$ para que fosse testado em campo o controlador de configuração desenvolvido. Este fator tomou muito tempo de pesquisa, até que se conseguisse uma implementação bem sucedida do dispositivo APEX emulado. A maior dificuldade enfrentada neste projeto de emulação foi a construção de um circuito CRC que operasse similarmente ao circuito CRC embutido em todo dispositivo APEX.

Finalmente, espera-se que num futuro próximo o laboratório LCR possa adquirir os chips necessários para a implementação da primeira versão do "cérebro" do robô do ARMOSH, que terá todo processo de reconfiguração de sua plataforma de hardware, gerenciado pelo controlador de configuração aqui desenvolvido. 


\section{ANEXO I}

\section{CÓDIGO DE REDUNDÂNCIA CÍCLICA - CRC}

\section{Introdução}

Em sistemas de comunicação de dados, um importante papel da camada de enlace de dados é converter a conexão física entre duas máquinas, numa ligação segura e livre de erros. Isto é conseguido através da introdução de informação redundante nos frames transmitidos. O código de redundância cíclica (CRC) é um esquema de detecção de erros largamente utilizado em transmissão serial de dados [30].

O CRC é baseado na aritmética polinomial. Os bits de dados a serem transmitidos constituem os coeficientes do polinômio. Como um exemplo, considere a seqüência de bits (bit-stream) "1101011011" composta por 10-bits, representando um polinômio de grau nove:

$$
\begin{aligned}
& M_{(x)}=1 \cdot x^{9}+1 \cdot x^{8}+0 \cdot x^{7}+1 \cdot x^{6}+0 \cdot x^{5}+1 \cdot x^{4}+1 \cdot x^{3}+0 \cdot x^{2}+1 \cdot x^{1}+1 \cdot x^{0} \\
& M_{(x)}=x^{9}+x^{8}+x^{6}+x^{4}+x^{3}+x^{1}+1
\end{aligned}
$$

Para calcular o CRC de uma mensagem, um outro polinômio, denominado polinômio gerador $\mathrm{G}_{(\mathrm{x})}$, deve ser escolhido. Como regra, $\mathrm{G}_{(\mathrm{x})}$ deve ser de grau maior que zero e menor que o grau do polinômio $M_{(x)}$. Outra imposição para $G_{(x)}$ é o coeficiente do termo $\mathrm{x}^{0}$, que deve ser sempre igual a um. Estas características levam a várias opções possíveis para o polinômio gerador, e por essa razão surge a necessidade de uma padronização.

$$
\begin{aligned}
& \text { O padrão CRC - } 16 \text { usa o seguinte polinômio gerador: } \\
& \mathrm{G}_{(\mathrm{x})}=\mathrm{x}^{16}+\mathrm{x}^{15}+\mathrm{x}^{2}+1
\end{aligned}
$$


O CRC - 16 detecta todos os erros simples e duplos e todos os erros com um número ímpar de bits.

O polinômio $G_{(x)}$ a seguir é o padrão utilizado para as transmissões com frames de 32 bits.

$$
G_{(x)}=x^{32}+x^{26}+x^{23}+x^{22}+x^{16}+x^{12}+x^{11}+x^{10}+x^{8}+x^{7}+x^{5}+x^{4}+x^{2}+x+1
$$

Em geral, um CRC de n-bits é obtido representando-se a bit-stream como o polinômio $\mathrm{M}_{(\mathrm{x})}$, multiplicando-se $\mathrm{M}_{(\mathrm{x})}$ por $\mathrm{x}^{\mathrm{n}}$ (onde $\mathrm{n}$ é o grau do polinômio $\mathrm{G}_{(\mathrm{x})}$ ), e dividindo-se o resultado pelo polinômio gerador $\mathrm{G}_{(\mathrm{x})}$. $\mathrm{O}$ resto, resultante desta operação, é anexado ao polinômio $\mathrm{M}_{(\mathrm{x})}$ e transmitido. No lado receptor da mensagem, o polinômio completo transmitido é então dividido pelo mesmo polinômio gerador. Se o resultado desta divisão não possuir resto, não existem erros na transmissão. Matematicamente, a obtenção do CRC pode ser representada pela seguinte equação:

$$
C R C=\text { resto de }\left[M(x) \times \frac{x^{n}}{G(x)}\right]
$$

\section{O Código de Redundância Cíclica (CRC)}

O cálculo do CRC envolve a manipulação dos polinômios $M_{(x)}$ e $G_{(x)}$ usando a aritmética "módulo 2". A aritmética em módulo leva aos mesmos resultados para operações de soma e subtração. Desta forma, torna-se necessário considerar apenas três operações envolvendo os polinômios, ou seja, adição, multiplicação e divisão.

A adição dos polinômios $\mathrm{x}^{8}+\mathrm{x}^{7}+\mathrm{x}^{5}+\mathrm{x}^{4}+\mathrm{x}^{2}+\mathrm{x}+1$ e $\mathrm{x}^{5}+\mathrm{x}^{4}+\mathrm{x}^{3}+\mathrm{x}^{2}$ resulta em $x^{8}+x^{7}+x^{3}+x+1$.

$$
\begin{aligned}
& x^{8}+x^{7}+x^{5}+x^{4}+0+x^{2}+x+1=110110111 \\
& 0+0+x^{5}+x^{4}+x^{3}+x^{2}+0+0=000111100 \\
& x^{8}+x^{7}+0+0+x^{3}+0+x+1=110001011
\end{aligned}
$$


A multiplicação entre os polinômios $x^{7}+x^{6}+x^{5}+x^{2}+1$ e $x+1$ resulta em $x^{8}+x^{5}+x^{3}+x^{2}+x+1$.

$$
\begin{aligned}
& \left(x^{7}+x^{6}+x^{5}+x^{2}+1\right)(x+1)=(11100101) x(11) \\
& x^{8}+x^{7}+x^{6}+0+0+x^{3}+0+x+0=111001010 \\
& 0+x^{7}+x^{6}+x^{5}+0+0+x^{2}+0+1=011100101 \\
& x^{8}+0+0+x^{5}+0+x^{3}+x^{2}+x+1=110001011
\end{aligned}
$$

A multiplicação de um polinômio por $\mathrm{x}^{\mathrm{m}}$ resulta em um deslocamento de seus coeficientes à direita, com a inserção de "m" zeros nas posições menos significativas. Veja o exemplo a seguir:

$$
x^{5}\left(x^{11}+x^{10}+x^{8}+x^{4}+x^{3}+x+1\right)=x^{16}+x^{15}+x^{13}+x^{9}+x^{8}+x^{6}+x^{5}
$$

A divisão do polinômio $\mathrm{x}^{13}+\mathrm{x}^{11}+\mathrm{x}^{10}+\mathrm{x}^{7}+\mathrm{x}^{4}+\mathrm{x}^{3}+\mathrm{x}+1$ por $\mathrm{x}^{6}+\mathrm{x}^{5}+$ $x^{4}+x^{3}+1$ resulta no quociente $x^{7}+x^{6}+x^{5}+x^{2}+x+1$ com um resto de $x^{4}+x^{2}$, conforme representado a seguir:

$$
\begin{aligned}
x^{13}+x^{11}+x^{10}+x^{7}+x^{4}+x^{3}+x+1 & =10110010011011 \\
x^{6}+x^{5}+x^{4}+x^{3}+1=1111001 & \\
\frac{11100111}{1111001} & \\
\frac{1111001}{1110010} & \frac{1111001}{1011110} \\
\frac{1111001}{1001111} & \text { Resultado: } \\
\frac{1111001}{1101101} & Q_{(x)}=11100111=x^{7}+x^{6}+x^{5}+x^{2}+x+1 \\
\frac{1111001}{10100} & R_{(x)}=10100=x^{4}+x^{2} \\
&
\end{aligned}
$$




\section{Implementação do Algoritmo CRC em Hardware}

A implementação do hardware do CRC é apresentada na Figura A.1.

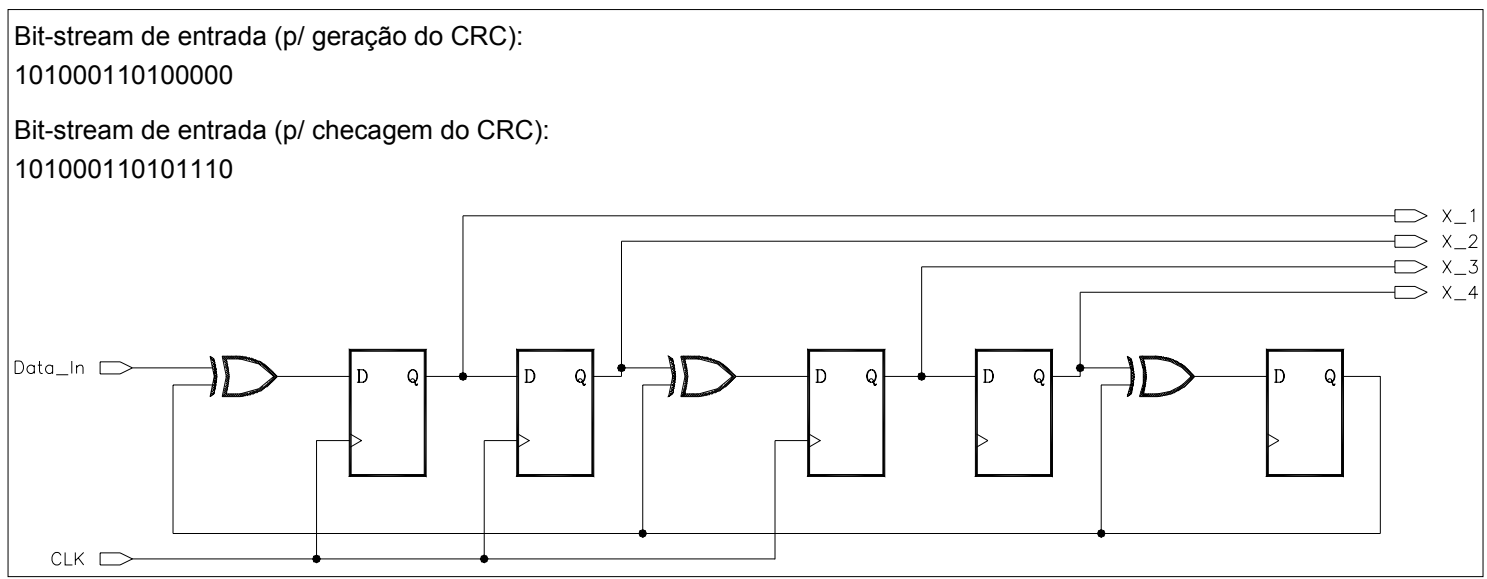

Figura A.1 - Hardware para CRC.

A implementação apresentada é específica para o seguinte conjunto de parâmetros:

$$
\begin{aligned}
& M_{(x)}=1010001101 \\
& G_{(x)}=110101 \\
& C R C=1110 \text { (a ser calculado) }
\end{aligned}
$$

O circuito é implementado da seguinte maneira:

- O registrador contém "n" bits, onde n é igual ao tamanho do CRC.

- Existem no máximo n portas XOR.

- A presença ou ausência de uma porta XOR corresponde a presença ou ausência de um termo no polinômio divisor $\mathrm{G}_{(\mathrm{x})}$.

O mesmo circuito é usado em ambos os extremos de uma transmissão. No momento da geração do CRC, o circuito aceita os bits pertencentes ao polinômio $\mathrm{M}_{(\mathrm{x})} \mathrm{e}$ depois uma seqüência de zeros. O tamanho desta seqüência é o mesmo que o tamanho do CRC. O conteúdo do registrador de deslocamento será o $\mathrm{CRC}$ a ser anexado a $\mathrm{M}_{(\mathrm{x})}$. No lado receptor da mensagem, o circuito aceita a bit-stream $\left(\mathrm{M}_{(\mathrm{x})}+\mathrm{CRC}\right)$ emitida 
pelo transmissor. O conteúdo do registrador de deslocamento deve ser zero caso contrário, um frame, corrompido durante o processo de transmissão, foi recebido. 


\section{Referências Bibliográficas}

[1] Brown, S.; Rose, J.; Francis, R.; Vranesic, Z., Field Programmable Gate Arrays, Kluwer Academic Publisher, 1997.

[2] Harding, B., HDLs: a high-powered way to look at complex design, Computer Design, p. 74-84, March 1990.

[3] Atwell, J., A Multiplexed Memory Port for Run Time Reconfigurable Applications, Virginia Polytechnic Institute and State University, Master Thesis, December 1999.

[4] Dehon, A., Reconfigurable Architectures for General-Purpose Computing, Massachussetts Institute of Technology, Ph.D. Thesis, October 1996.

[5] Dehon, A.; Wawrzynek, J., Reconfigurable Computing: What, Why, and Design Automation Requirements? , in Proceedings of the 1999 Design Automation Conference, pp. 610-615, June 1999.

[6] Sanchez, E. et al., Static and Dynamic Configurable Systems, IEEE Transactions on Computers. Vol. 48, no. 6, pp. 556-564, June 1999.

[7] Romero, R. A, Aprendizado em Robôs Móveis Via Software e HardwareARMOSH - Projeto de Pesquisa do ICMC-USP, Março de 2000.

[8] Aragão, A.; Romero, R.; Marques, E., Computação Reconfigurável Aplicada à Robótica, in Computação Reconfigurável - Experiências e Perspectivas, pp.184-188, CORE-2000, Marília-SP, Agosto 2000.

[9] Aragão, A. C. O. S.; Uma Arquitetura Sistólica para Soluções de Sistemas Lineares Implementada com Circuitos FPGAs; ICMC - USP; Dezembro de 1998;

[10] Chan P. K.; Mourad S. Digital Design Using Field Programmable Gate Arrays, Prentice Hall, 1994.

[11] Brown S., Rode J. Architecture of FPGAs and CPLDs: A Tutorial, IEEE Design and Teste of Computers, vol. 13 No. 2, pp. 42-57, Junho, 1996. 
[12] Brown S., Vranesic Z. Fundamentals of Digital Logic with VHDL Design, McGraw-Hill Series in Computer Enginnering, 2000.

[13] Brown S. Routing Algorithms and Architectures for Field-Programmable Gate Arrays, Department of Electrical Engineering - University of Toronto, CANADA. Doctor of Philosophi thesis, Janeiro, 1992.

[14] Actel, Corp.; FPGA Data Book and Design Guide; 1995.

[15] Rose, J.; Gamal, A. E.; A. Sangiovanni-Vincentelli; Architecture of FieldProgrammable Gate Arrays; In Proceedings of the IEEE; vol. 81, no. 7, pp. 1013-1029; Julho de 1993.

[16] Altera Corp.; APEX 20K Programmable Logic Device Family; January 2001; in http://www.altera.com/literature/ds/apex.pdf;

[17] Altera Corp.; Configuring APEX 20K, FLEX 10K \& FLEX 6000 Devices; December 1999; Aplication Note 116; in http://www.altera.com/literature/lit.apx.pdf;

[18] Altera Corp.; EPC16 Configuration Device; March 2001; Data sheet; in http://www.altera.com/literature/ds/dsepc16.pdf;

[19] Altera Corp.; Configuration Devices for APEX \& FLEX Devices; November 1999; Data Sheet; in http://www.altera.com/literature/ds/dsconf.pdf;

[20] Altera Corp.; Quartus - Programmable Logic Development System \& Software; May 1999; Data Sheet; in http://www.altera.com/literature/ds/quartus.pdf;

[21] Altera Corp.; Configuring APEX 20K, FLEX 10K \& FLEX 6000 Devices; May 2000; Aplication Notes - AN 116; in http://www.altera.com/literature/ds/an/an116.pdf;

[22] Xilinx Inc.; Configuration and Readback of Virtex FPGAs Using (JTAG) Boundary-Scan; February 2000; Application Notes - Virtex Series; in http://www.xilinx.com/xapp/xapp139.pdf;

[23] Xilinx Inc.; Using the XC9500 JTAG Boundary-Scan Interface; Application Notes; in http://www.xilinx.com/xapp/xapp069.pdf;

[24] Altera Digital Library - CD-ROM; March 2000.

[25] Altera Corp.; IEEE 1149.1 (JTAG) Boundary-Scan Testing in Altera Devices; March 2000; Application Notes; in http://www.altera.com/literature/ds/an/an39.pdf; 
[26] Altera Corp.; Nios Embedded Processor Development Board; April 2002; Data Sheet, ver. 2.1; in http://www.altera.com/literature/ds/ds_nios_devboard.pdf;

[27] Altera Corp.; Nios Embedded Processor Hardware Tutorial; April 2002; ver. 1.1; in http://www.altera.com/literature/lit-nio.html;

[28] Red Hat eCos; Embedded Linux and Technologies; May 2002; in http://www.redhat.com/embedded/technologies/ecos;

[29] Microtronix; Embedded Hardware and Software Designs; June 2002; Press Releases; http://www.microtronix.com/port to nios.html;

[30] Xilinx Inc.; IEEE 802.3 Cyclic Redundancy Check; March 2001; Application Notes; in http://www.xilinx.com/xapp/xapp209.pdf;

[31] Altera Corp.; APEX II - Programmable Logic Device Family; May 2002; ver. 2.0; in http://www.altera.com/literature/lit-ap2.html;

[32] Altera Corp.; STRATIX - Programmable Logic Device Family; April 2002; ver. 2.0; in http://www.altera.com/literature/ds/ds stx.pdf; 